\title{
Bone imaging and strength in chronic obstructive pulmonary disease
}

Citation for published version (APA):

Romme, E. A. P. M. (2014). Bone imaging and strength in chronic obstructive pulmonary disease.

[Doctoral Thesis, Maastricht University]. Maastricht University. https://doi.org/10.26481/dis.20140220er

Document status and date:

Published: 01/01/2014

DOI:

10.26481/dis.20140220er

Document Version:

Publisher's PDF, also known as Version of record

\section{Please check the document version of this publication:}

- A submitted manuscript is the version of the article upon submission and before peer-review. There can be important differences between the submitted version and the official published version of record.

People interested in the research are advised to contact the author for the final version of the publication, or visit the DOI to the publisher's website.

- The final author version and the galley proof are versions of the publication after peer review.

- The final published version features the final layout of the paper including the volume, issue and page numbers.

Link to publication

\footnotetext{
General rights rights.

- You may freely distribute the URL identifying the publication in the public portal. please follow below link for the End User Agreement:

www.umlib.nl/taverne-license

Take down policy

If you believe that this document breaches copyright please contact us at:

repository@maastrichtuniversity.nl

providing details and we will investigate your claim.
}

Copyright and moral rights for the publications made accessible in the public portal are retained by the authors and/or other copyright owners and it is a condition of accessing publications that users recognise and abide by the legal requirements associated with these

- Users may download and print one copy of any publication from the public portal for the purpose of private study or research.

- You may not further distribute the material or use it for any profit-making activity or commercial gain

If the publication is distributed under the terms of Article $25 \mathrm{fa}$ of the Dutch Copyright Act, indicated by the "Taverne" license above, 
Bone imaging and strength in chronic obstructive pulmonary disease

Elisabeth APM Romme 


\section{COLOFON}

(C) Elisabeth Anna Petronella Maria Romme, Eindhoven 2014

ISBN:

978-94-6259-030-4

Cover and lay-out: Marlies van Hoof, www.madebymarlies.nl

Production:

Ipskamp Drukkers B.V.

Research of this thesis was conducted at the department of Respiratory Medicine of the Catharina hospital, Centre of expertise for chronic organ failure $\left(\mathrm{CIRO}^{+}\right)$and the University of Edinburgh (Scotland).

Research of this thesis was financially supported by the private Foundation Pulmonology Research Education and Development, a research grant of the European Respiratory Society and an unrestricted grant of GlaxoSmithKline (the Netherlands). Publication of this thesis was financially supported by those mentioned above and Centre of expertise for chronic organ failure $\left(\mathrm{CIRO}^{+}\right)$. 


\title{
Bone imaging and strength in chronic obstructive pulmonary disease
}

\author{
PROEFSCHRIFT
}

ter verkrijging van de graad van doctor aan de Universiteit Maastricht, op gezag van de Rector Magnificus, prof. dr. L.L.G. Soete volgens het besluit van het College van Decanen, in het openbaar te verdedigen op donderdag 20 februari 2014 om 12.00 uur

door

Elisabeth Anna Petronella Maria Romme 


\section{Promotores}

Prof. dr. E.F.M. Wouters

Prof. dr. F.W.J.M. Smeenk (Catharina ziekenhuis Eindhoven)

\section{Copromotor}

Dr. E.P.A. Rutten (CIRO+ Horn)

\section{Beoordelingscommissie}

Prof. dr. L. van Rhijn (voorzitter)

Prof. dr. A. Boonen

Prof. dr. W. Janssens (Katholieke Universiteit Leuven, België)

Prof. dr. C. Vogelmeier (Universitätsklinikum Standort Marburg, Duitsland)

Prof. dr. J. Wildberger 


\section{TABLE OF CONTENTS}

Chapter $1 \quad$ General introduction and outline of this thesis

Chapter 2 Osteoporosis in chronic obstructive pulmonary disease 20 (COPD)

Chapter 3 Vitamin D status is associated with bone mineral density 40 and functional exercise capacity in patients with COPD

$\begin{array}{lll}\text { Chapter } 4 & \text { Bone attenuation on routine chest CT correlates with } & 56\end{array}$ bone mineral density on DXA in patients with COPD

$\begin{array}{lll}\text { Chapter } 5 & \text { CT-measured bone attenuation in patients with COPD: } \quad 72\end{array}$ relation to clinical features and outcomes

$\begin{array}{lll}\text { Chapter } 6 & \text { Associations between COPD-related manifestations: } & 92\end{array}$ arterial calcification and stiffness, bone density, emphysema and all-cause mortality

$\begin{array}{lll}\text { Chapter } 7 & \text { Bone stiffness and failure load are related with clinical } & 108\end{array}$ parameters in men with COPD

$\begin{array}{lll}\text { Chapter } 8 & \text { General discussion and future perspectives }\end{array}$

Chapter 9 Summary of this thesis / Samenvatting van dit proefschrift 138

$\begin{array}{ll}\text { List of publications } & 144\end{array}$

$\begin{array}{ll}\text { Dankwoord } & 148\end{array}$

$\begin{array}{lr}\text { Curriculum Vitae } & 154\end{array}$ 



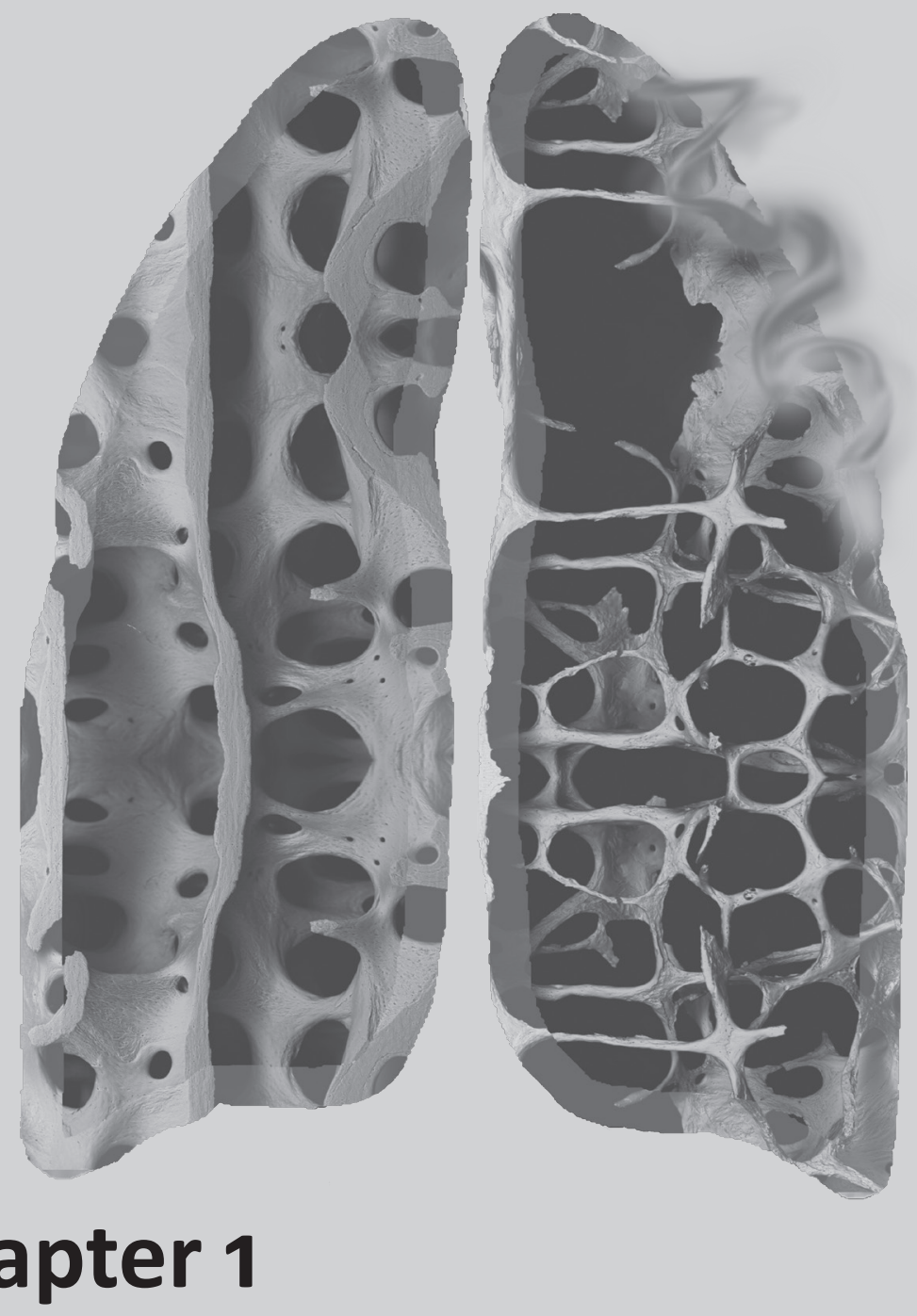

General introduction and outline of this thesis 


\section{GENERAL INTRODUCTION}

\section{Definition of COPD}

Chronic obstructive pulmonary disease (COPD) is defined as "A common preventable and treatable disease which is characterised by persistent airflow limitation that is usually progressive and associated with an enhanced chronic inflammatory response in the airways and the lung to noxious particles or gases. Exacerbations and comorbidities contribute to the overall severity in individual patients." ${ }^{1,2}$

COPD should be considered in any patient who has dyspnoea, chronic cough or sputum production and a history of exposure to COPD risk factors. ${ }^{3}$ Diagnosis of COPD is confirmed when the ratio between post-bronchodilator forced expiratory volume in 1 second $\left(\mathrm{FEV}_{1}\right)$ and forced vital capacity (FVC) is below $0.70 .^{1,2}$

\section{Prevalence of COPD}

Data on the prevalence of COPD have shown remarkable variation due to differences in survey methods, diagnostic criteria and analytic approaches. The World Health Organisation showed that moderate to severe COPD was found in 65 million people worldwide. ${ }^{4} \mathrm{~A}$ systematic review and meta-analysis demonstrated that the prevalence of physiologically defined COPD was approximately 9 to $10 \%$ in adults aged 40 or older. ${ }^{5}$

COPD is more common in smokers and ex-smokers than in non-smokers and in subjects aged 40 or older than in subjects under age $40 .{ }^{5}$ In the past, COPD was more common in men than women, ${ }^{5}$ but the disease now affects men and women almost equally because of increased tobacco use among women in high-income countries and higher risk of exposure to indoor air pollution in low-income countries. ${ }^{4}$

\section{Burden of COPD}

COPD is an important cause of morbidity and mortality worldwide and results in an economic and social burden that is both substantial and increasing. More than 3 million people died of COPD in $2005 .{ }^{4}$ COPD was the fifth leading cause of death in the world in 2002, and is projected to be the third leading cause of death by $2030 .{ }^{4}$ The total direct costs of respiratory diseases are estimated to be about $6 \%$ of the total health care budget in the European Union, with COPD accounting for $56 \%$ (38.6 billion Euros) of the total costs of respiratory diseases. ${ }^{1}$ The social burden of a disease can be estimated in Disability-Adjusted Life Years (DALYS). This is the sum of years lost due to premature mortality and years of life lived with disability, adjusted for the severity of disability. COPD was the twelfth leading cause of DALYs lost in the world in 1990, and is projected to be the seventh leading cause of DALYs lost worldwide by $2030 .^{6}$

\section{Global Strategy for the Diagnosis, Management and Prevention of COPD}

In order to increase the awareness of COPD and to help the millions of people who suffer from it, a committed group of scientists formed the Global Strategy for the Diagnosis, 
Management and Prevention of COPD (GOLD) in 1998. A consensus report was released in 2001 and revised in 2006, 2011 and 2013.

In the latest report, some major revisions were made. ${ }^{1}$ At the time of the first report, it was believed that the majority of COPD patients followed a path of disease progression in which the severity of the disease tracked the severity of airflow limitation. However, the severity of airflow limitation has been shown to be an unreliable marker of the severity of breathlessness, exercise limitation and health status impairment of the individual patient. Therefore, the staging system for classifying COPD severity has been replaced by a grading system, and additionally, a new assessment approach has been introduced to better reflect the complexity of COPD (Figure 1). This assessment approach uses a combination of spirometry, symptomatic assessment and exacerbation rate to classify patients to either category A, B, C or D.

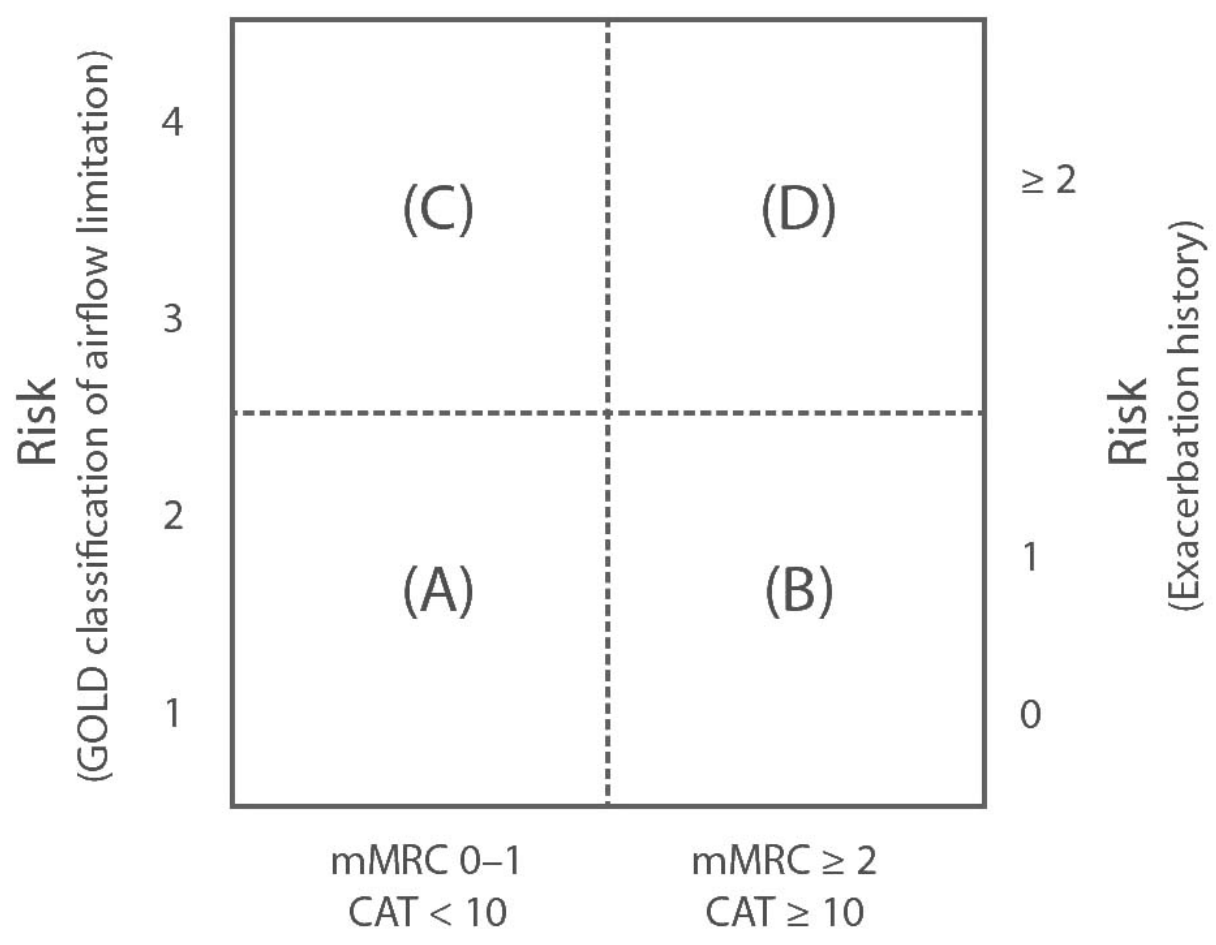

\section{Symptoms}

Figure 1. The combined COPD assessment approach

mMRC=modified Medical Research Council Dyspnoea Scale, CAT=COPD assessment test Source: Global Initiative for Chronic Obstructive Lung Disease: Global strategy for the Diagnosis, Management and Prevention of Chronic Obstructive Pulmonary Disease ${ }^{1,2}$ 


\section{Multi-component involvement in COPD}

In addition to persistent airflow limitation, COPD is characterised by several pulmonary (e.g. emphysema, lung cancer) and extrapulmonary comorbidities (Table 1). COPD-related comorbidities are highly variable between patients and only weakly related to the severity of airflow limitation. ${ }^{7}$ They may influence the course of the disease. ${ }^{8-10}$ Comorbidities have been shown to increase the number of hospitalisations, ${ }^{11}$ influence outcomes of exacerbations ${ }^{12}$ and contribute to the economic burden of COPD. ${ }^{3}$ In addition, COPD patients are more likely to die from a comorbidity than from COPD itself. ${ }^{14,15}$ Therefore, COPD is nowadays being considered as a complex heterogeneous disease with clinically significant pulmonary and extrapulmonary comorbidities. ${ }^{16}$

Table 1. Extrapulmonary comorbidities of COPD

\begin{tabular}{lc}
\hline Comorbidity & Prevalence in COPD (\%) \\
\hline Osteoporosis/osteopenia & $50-70$ \\
Hypertension & $40-60$ \\
Gastro-oesophageal reflux disease & $30-60$ \\
Skeletal muscle dysfunction & 32 \\
Depression & 25 \\
Ischemic heart disease & $10-23$ \\
Previous myocardial infarction & $4-23$ \\
Anaemia & 17 \\
Diabetes & $12-13$ \\
Previous stroke & $10-14$ \\
Arrhythmia & $6-14$ \\
Chronic renal failure & $6-11$ \\
Congestive heart failure & $5-7$ \\
Obstructive sleep apnoea & $1-4$ \\
\hline
\end{tabular}

Source: Extrapulmonary comorbidities in chronic obstructive pulmonary disease: state of the $\operatorname{art}^{17}$

\section{Noncommunicable diseases and phenotyping}

COPD is considered to be one of the major noncommunicable diseases. Other major noncommunicable diseases are cardiovascular diseases (e.g. heart attacks and stroke), cancers and diabetes. Noncommunicable diseases are the leading causes of death globally, killing more people each year than all other causes combined. Of the 57 million deaths that occurred globally in 2008, 36 million were due to major noncommunicable diseases. ${ }^{18}$

Noncommunicable diseases are associated with complex gene-environment interactions. Figure 2 shows the interactions between genes, lifestyle, socio-economic determinants, age and gender. The products of these interactions might lead to the biological expression of noncommunicable diseases, and hence, to their clinical expression and complex phenotypes. ${ }^{19}$ 
A phenotype traditionally reflects the observable structural and functional characteristics of an organism determined by its genotype and modulated by its environment, i.e. the interactions between "nature" and "nurture". ${ }^{20}$ Since this definition of a phenotype is not necessarily clinically relevant, the term "clinical phenotype" has been introduced. ${ }^{21}$ A "clinical phenotype" is defined as "A single or combination of disease attributes that describes differences between individuals as they relate to clinically meaningful outcomes (e.g. symptoms, exacerbations, response to therapy, rate of disease progression or death)."21

Since individuals with a unique COPD phenotype exhibit similar clinical outcomes, they might share a similar underlying mechanism and therapeutic response profile. Previous studies have shown that a specific therapy can be more effective in individuals sharing a specific phenotype. ${ }^{22}$ For instance, the National Emphysema Treatment Trial showed that lung volume reduction surgery improved prognosis in a subgroup of patients with upper lobepredominant emphysema and low exercise capacity after rehabilitation. ${ }^{23}$ Thus, identification of COPD phenotypes might be helpful to gain insight into pathophysiologic mechanisms and improve management of COPD.

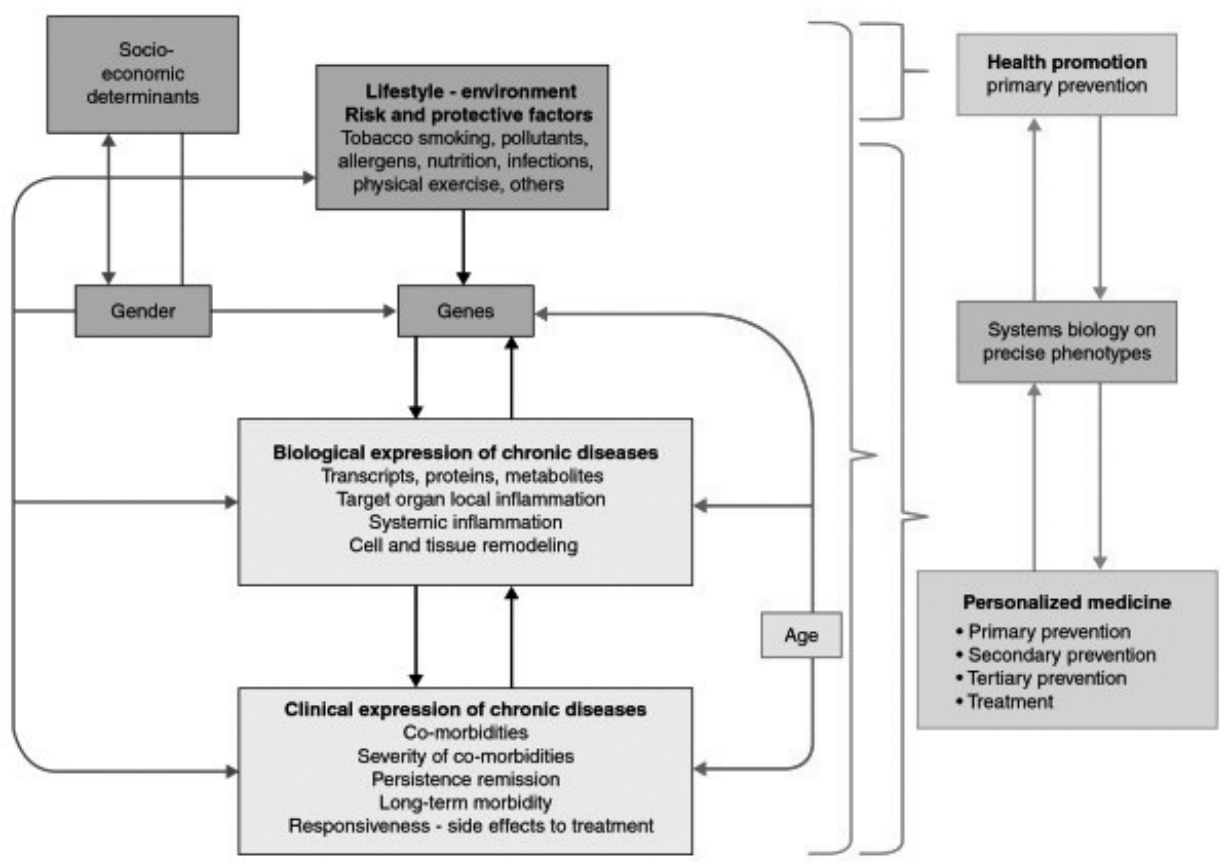

Figure 2. Noncommunicable diseases are associated with complex gene-environment interactions modulated by socio-economic determinants, psychological factors, age and gender

Source: Systems medicine and integrated care to combat chronic noncommunicable diseases ${ }^{19}$ Reproduced with permission from the editor. 


\section{Current understanding of the pathogenesis of multi-component involvement}

Previous research has identified several factors linking COPD with comorbidities, including shared risk factors, physical inactivity, side effects of treatments given for COPD and systemic inflammation (Table 2). Tobacco smoking and older age have been shown to be important risk factors for both COPD and multimorbidity. ${ }^{24-26}$ In addition, COPD patients are less physically active than smoking controls, ${ }^{27-29}$ and physical inactivity has been related with coronary heart disease, type 2 diabetes, breast cancer and colon cancer. ${ }^{30}$ Moreover, corticosteroids that are widely used for the prevention and treatment of COPD exacerbations may induce pneumonia, ${ }^{31}$ osteoporosis ${ }^{32-37}$ and myopathy. ${ }^{38}$ Furthermore, parameters of systemic inflammation have been shown to be increased in COPD patients and to be related with lower health related quality of life, more frequent COPD exacerbations, worse exercise tolerance, obesity and cardiovascular disease. ${ }^{39,40}$ Although several factors have been related with COPD and its comorbidities, their underlying pathophysiologic mechanisms are still not fully understood.

\section{Osteoporosis in COPD}

This thesis is focussed on a well-recognised comorbidity of COPD, osteoporosis. Osteoporosis is characterised by low bone mass or microarchitectural deterioration of bone tissue, leading to enhanced bone fragility and, consequently, an increased risk of fracture. ${ }^{41}$ The gold standard for diagnosing osteoporosis is dual energy X-ray absorptiometry (DXA). The World Health Organisation ${ }^{41}$ and the International Society for Clinical Densitometry ${ }^{42}$ recommend a diagnosis of osteoporosis based on the lowest T-score of the hip or the lumbar spine assessed on DXA (Table 3). The T-score is defined as the number of standard deviations by which the bone mineral density differs from the average bone mineral density of a young adult at peak bone density. In this thesis, we will give a clear overview of the current literature on the pathophysiology, prevalence, risk factors and management of osteoporosis in COPD patients (chapter 2).

In the general population, vitamin D deficiency is a well-established risk factor of osteoporosis. ${ }^{43}$ In addition to its role in bone health, vitamin $\mathrm{D}$ deficiency has been related with several other diseases, including infectious and autoimmune diseases, diabetes mellitus, cardiovascular disease, cancer, muscle weakness, poor exercise capacity and respiratory diseases. ${ }^{44,45}$ In this thesis, we will study associations between vitamin $D$, bone mineral density, muscle strength and functional exercise capacity in patients with moderate to very severe COPD (chapter 3).

Although DXA has a low radiation dose and is easy to use, previous studies have reported underdiagnosis of osteoporosis. ${ }^{46}$ In order to diagnose osteoporosis in an early stage, current research is focussed on screening for osteoporosis using Computed Tomography (CT) scans that were performed for other purposes. Abdominal and coronary CT have already been shown to be useful for assessing bone mineral density and osteoporosis screening. ${ }^{47-49}$ Since chest CT scans are frequently made in COPD patients, we will study whether chest CT can provide useful information on bone health in COPD patients. In this thesis, we will describe an 
algorithm for assessing bone attenuation of the thoracic vertebrae on chest CT and validate this technique against the gold standard, DXA (chapter 4).

Table 2. Potential mechanisms of multi-component involvement in COPD

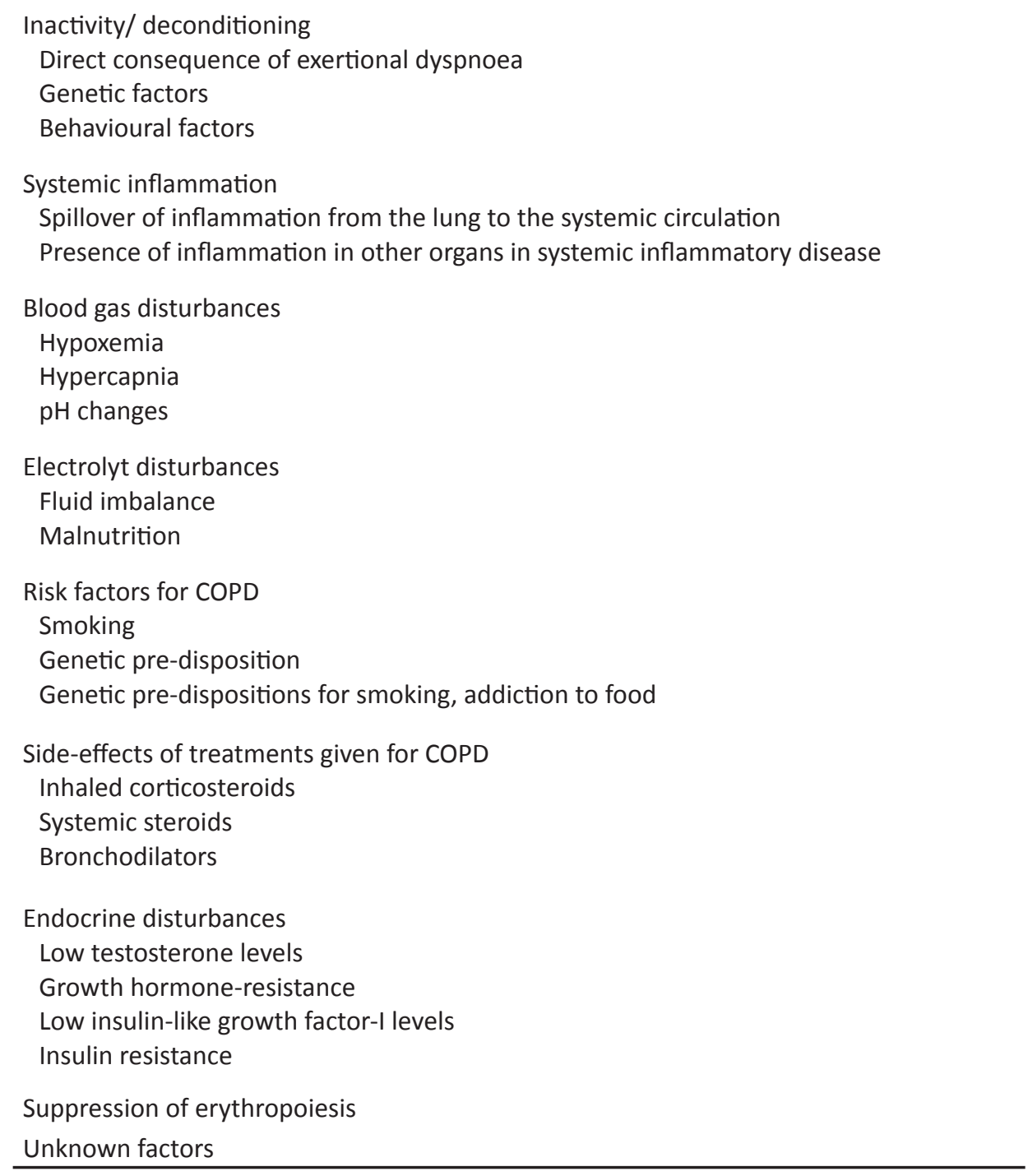

Source: COPD as a lung disease with systemic consequences - clinical impact, mechanisms, and potential for early intervention ${ }^{8}$ 
Chest CT might be helpful to better characterise COPD patients and separate various COPD phenotypes. ${ }^{50}$ Previous studies have shown that chest CT is useful for lung cancer screening, quantifying emphysema and assessing vascular calcification. The National Lung Screening Trial showed that lung cancer screening using chest $\mathrm{CT}$ reduced lung cancer-specific mortality by more than $20 \%$ and all-cause mortality by $7 \% .^{51}$ In addition, more severe emphysema has been related with increased all-cause mortality in COPD patients ${ }^{52,53}$ and coronary artery calcification has been shown to be a predictor of cardiovascular events and mortality in smokers..$^{54-57}$ In this thesis, we will assess extent of emphysema, markers of cardiovascular disease (coronary artery calcium and thoracic aortic calcium) and bone attenuation of the thoracic vertebrae on routine chest CT. Subsequently, we will study associations between CT-measured bone attenuation of the thoracic vertebrae and clinical features of COPD in two large cohorts (chapters 5 and 6).

In addition to bone mineral density, bone strength is influenced by material and structural properties of bone..$^{8}$ One of the most promising developments over the past 10 years has been the introduction of High Resolution peripheral Quantitative Computed Tomography (HR-pQCT). ${ }^{59} \mathrm{HR}-\mathrm{pQCT}$ can be used to assess structural parameters of trabecular and cortical bone, such as trabecular thickness, trabecular number and cortical thickness. In addition, HRpQCT images can be used to assess mechanical parameters of bone, such as bone stiffness and failure load, based on micro-finite element models. ${ }^{59-61}$ Structural and mechanical parameters of bone are related with fragility fractures ${ }^{59,62}$ and might even be superior to bone mineral density in discriminating men with and without vertebral fractures. ${ }^{63}$ In this thesis, we will study structural and mechanical parameters of bone using HR-pQCT and micro-finite element analysis ( $\mu \mathrm{FEA}$ ) in men with and without COPD (chapter 7).

Table 3. Diagnosis of osteoporosis

\begin{tabular}{lc}
\hline & T-score \\
\hline Normal bone mass & $\geq-1.0$ \\
Osteopenia & -1.0 to -2.5 \\
Osteoporosis & $\leq-2.5$ \\
\hline
\end{tabular}




\section{OUTLINE OF THIS THESIS}

Main objectives of this thesis were 1) to give an overview of the current literature on osteoporosis in COPD; 2 ) to develop a new algorithm for measuring bone density on routine chest $\mathrm{CT}$; 3) to study associations between $\mathrm{CT}$-measured bone attenuation and clinical features of COPD; and 4) to study structural and mechanical parameters of bone in subjects with and without COPD.

Chapter 2 gives an overview of the current literature on the pathophysiology, prevalence, risk factors and management of osteoporosis in COPD patients.

Vitamin D deficiency is a well-established risk factor of osteoporosis in healthy elderly, and additionally, vitamin $\mathrm{D}$ deficiency might play a role in respiratory diseases and skeletal muscle function. Chapter $\mathbf{3}$ describes the prevalence of vitamin D deficiency and its associations with bone mineral density, quadriceps muscle strength and functional exercise capacity in patients with moderate to very severe COPD.

Chapter 4 describes an algorithm for measuring bone attenuation of the thoracic vertebrae on routine chest CT and its validation against DXA, which is the gold standard for diagnosing osteoporosis. Subsequently, this algorithm is applied to two large cohort studies. Chapter $\mathbf{5}$ describes comparisons in CT-measured bone attenuation between COPD subjects and smoker and non-smoker controls, and associations between CT-measured bone attenuation and clinical features of COPD in the ECLIPSE cohort. Chapter 6 describes associations between CT-measured bone attenuation, arterial calcification and stiffness, emphysema and all-cause mortality in a Scottish cohort of COPD patients.

Although studies on structural and mechanical parameters of bone have shown interesting findings, studies on these bone parameters in COPD patients are limited. Chapter 7 describes comparisons in structural and mechanical parameters of bone between men with and without COPD and associations between parameters of bone and clinical features of COPD.

Finally, chapter 8 discusses the previous chapters and future perspectives and chapter 9 summarises the main findings of this thesis. 


\section{REFERENCES}

1. Global Strategy for the Diagnosis, Management and Prevention of COPD. Global Initiative for Chronic Obstructive Lung Disease (GOLD) 2013 [updated 2013 February, cited 2013 August]. Available from: http://www.goldcopd.org.

2. Vestbo J, Hurd SS, Agusti AG et al. Global Strategy for the Diagnosis, Management and Prevention of Chronic Obstructive Pulmonary Disease, GOLD Executive Summary. Am J Respir Crit Care Med 2013; 187: 347-65.

3. van Schayck CP, Loozen JM, Wagena E, Akkermans RP, Wesseling GJ. Detecting patients at a high risk of developing chronic obstructive pulmonary disease in general practice: cross sectional case finding study. BMJ 2002; 324: 1370 .

4. World Health Organization. Chronic respiratory diseases [cited 2013 August]. Available from: http:// www.who.int/respiratory/copd/burden/en/index.html.

5. Halbert RJ, Natoli JL, Gano A, Badamgarav E, Buist AS, Mannino DM. Global burden of COPD: systematic review and meta-analysis. Eur Respir J 2006; 28: 523-32.

6. Mathers CD, Loncar D. Projections of global mortality and burden of disease from 2002 to 2030. PLoS Med 2006; 3: e442.

7. Agusti A, Calverley PM, Celli B et al. Characterisation of COPD heterogeneity in the ECLIPSE cohort. Respir Res 2010; 11: 122.

8. Decramer M, Rennard S, Troosters T et al. COPD as a lung disease with systemic consequences--clinical impact, mechanisms, and potential for early intervention. COPD 2008; 5: 235-56.

9. Divo M, Cote C, de Torres JP et al. Comorbidities and Risk of Mortality in Patients with Chronic Obstructive Pulmonary Disease. Am J Respir Crit Care Med 2012; 186: 155-61.

10. Sin DD, Anthonisen NR, Soriano JB, Agusti AG. Mortality in COPD: Role of comorbidities. Eur Respir J 2006; 28: 1245-57.

11. Anthonisen NR, Connett JE, Enright PL, Manfreda J. Hospitalizations and mortality in the Lung Health Study. Am J Respir Crit Care Med 2002; 166: 333-9.

12. Roberts CM, Stone RA, Lowe D, Pursey NA, Buckingham RJ. Co-morbidities and 9o-day outcomes in hospitalized COPD exacerbations. COPD 2011; 8: 354-61.

13. Lin PJ, Shaya FT, Scharf SM. Economic implications of comorbid conditions among Medicaid beneficiaries with COPD. Respir Med 2010; 104: 697-704.

14. McGarvey LP, Magder S, Burkhart D, Kesten S, Liu D, Manuel RC, Niewoehner DE. Cause-specific mortality adjudication in the UPLIFT(R) COPD trial: findings and recommendations. Respir Med 2012; 106: 515-21.

15. McGarvey LP, John M, Anderson JA, Zvarich M, Wise RA. Ascertainment of cause-specific mortality in COPD: operations of the TORCH Clinical Endpoint Committee. Thorax 2007; 62: 411-5.

16. Agusti AG. COPD, a multicomponent disease: implications for management. Respir Med 2005; 99 670-82.

17. Patel AR, Hurst JR. Extrapulmonary comorbidities in chronic obstructive pulmonary disease: state of the art. Expert Rev Respir Med 2011; 5: 647-62.

18. World Health Organization. Global status report on noncommunicable diseases 2010 [updated 2011, cited 2013 August]. Available from: http://whqlibdoc.who.int/publications/2011/9789240686458_eng. pdf.

19. Bousquet J, Anto JM, Sterk PJ et al. Systems medicine and integrated care to combat chronic noncommunicable diseases. Genome Med 2011; 3: 43.

20. Rice JP, Saccone NL, Rasmussen E. Definition of the phenotype. Adv Genet 2001; 42: 69-76.

21. Han MK, Agusti A, Calverley PM et al. Chronic obstructive pulmonary disease phenotypes: the future of COPD. Am J Respir Crit Care Med 2010; 182: 598-604. 
22. Agusti A, Sobradillo P, Celli B. Addressing the complexity of chronic obstructive pulmonary disease: from phenotypes and biomarkers to scale-free networks, systems biology, and P4 medicine. Am J Respir Crit Care Med 2011; 183: 1129-37.

23. Fishman A, Martinez F, Naunheim K et al. A randomized trial comparing lung-volume-reduction surgery with medical therapy for severe emphysema. N Engl J Med 2003; 348: 2059-73.

24. Vanfleteren LE, Franssen FM, Wesseling G, Wouters EF. The prevalence of chronic obstructive pulmonary disease in Maastricht, the Netherlands. Respir Med 2012; 106: 871-4.

25. Barnett K, Mercer SW, Norbury M, Watt G, Wyke S, Guthrie B. Epidemiology of multimorbidity and implications for health care, research, and medical education: a cross-sectional study. Lancet 2012; 380: $37-43$.

26. National Center for Chronic Disease Prevention and Health Promotion (US) Office on Smoking and Health. Preventing Tobacco Use Among Youth and Young Adults: A Report of the Surgeon General. Atlanta (GA): Centers for Disease Control and Prevention (US); 2012. Available from: http://www.ncbi. nlm.nih.gov/books/NBK99237/.

27. Troosters T, Sciurba F, Battaglia S et al. Physical inactivity in patients with COPD, a controlled multi-center pilot-study. Respir Med 2010; 104: 1005-11.

28. Van Remoortel H, Hornikx M, Demeyer $\mathrm{H}$ et al. Daily physical activity in subjects with newly diagnosed COPD. Thorax 2013; doi: 10.1136/thoraxjnl-2013-203534 [Epub ahead of print].

29. Watz H, Waschki B, Meyer T, Magnussen H. Physical activity in patients with COPD. Eur Respir J 2009; 33: $262-72$.

30. Lee IM, Shiroma EJ, Lobelo F, Puska P, Blair SN, Katzmarzyk PT. Effect of physical inactivity on major non-communicable diseases worldwide: an analysis of burden of disease and life expectancy. Lancet 2012; 380: 219-29.

31. Yang IA, Clarke MS, Sim EH, Fong KM. Inhaled corticosteroids for stable chronic obstructive pulmonary disease. Cochrane Database Syst Rev 2012; 7: CDoo2991.

32. Weinstein RS. Clinical practice. Glucocorticoid-induced bone disease. N Engl J Med 2011; 365: 62-70.

33. van Staa TP, Leufkens HG, Cooper C. The epidemiology of corticosteroid-induced osteoporosis: a metaanalysis. Osteoporos Int 2002; 13: 777-87.

34. Kanis JA, Johansson $\mathrm{H}$, Oden A et al. A meta-analysis of prior corticosteroid use and fracture risk. J Bone Miner Res 2004; 19: 893-9.

35. McEvoy CE, Ensrud KE, Bender E, Genant HK, Yu W, Griffith JM, Niewoehner DE. Association between corticosteroid use and vertebral fractures in older men with chronic obstructive pulmonary disease. Am J Respir Crit Care Med 1998; 157: 704-9.

36. Walsh LJ, Wong CA, Oborne $\mathrm{J}$ et al. Adverse effects of oral corticosteroids in relation to dose in patients with lung disease. Thorax 2001; 56: 279-84.

37. Loke YK, Cavallazzi R, Singh S. Risk of fractures with inhaled corticosteroids in COPD: systematic review and meta-analysis of randomised controlled trials and observational studies. Thorax 2011; 66: 699-708.

38. Schakman O, Kalista S, Barbe C, Loumaye A, Thissen JP. Glucocorticoid-induced skeletal muscle atrophy. Int J Biochem Cell Biol 2013; doi: 10.1016/j.biocel.2013.05.036 [Epub ahead of print].

39. Garcia-Rio F, Miravitlles M, Soriano JB et al. Systemic inflammation in chronic obstructive pulmonary disease: a population-based study. Respir Res 2010; 11: 63.

40. Agusti A, Edwards LD, Rennard SI et al. Persistent systemic inflammation is associated with poor clinical outcomes in COPD: a novel phenotype. PLoS One 2012; 7: e37483.

41. World Health Organization. Prevention and Management of Osteoporosis; report of a WHO scientific group [updated 2003; cited 2013 August]. Available from: http://whqlibdoc.who.int/trs/WHO_ TRS_921.pdf.

42. Lewiecki EM, Gordon CM, Baim S et al. International Society for Clinical Densitometry 2007 Adult and Pediatric Official Positions. Bone 2008; 43: 1115-21.

43. Holick MF. Vitamin D deficiency. N Engl J Med 2007; 357: 266-81. 
44. Pludowski P, Holick MF, Pilz $S$ et al. Vitamin D effects on musculoskeletal health, immunity, autoimmunity, cardiovascular disease, cancer, fertility, pregnancy, dementia and mortality-A review of recent evidence. Autoimmun Rev 2013; 12: 976-89.

45. Herr C, Greulich T, Koczulla RA et al. The role of vitamin D in pulmonary disease: COPD, asthma, infection, and cancer. Respir Res 2011; 12: 31.

46. Lewiecki EM, Laster AJ, Miller PD, Bilezikian JP. More bone density testing is needed, not less. J Bone Miner Res 2012; 27: 739-42.

47. Pickhardt PJ, Lee $\sqcup$, Munoz Del RA et al. Simultaneous screening for osteoporosis at CT colonography: Bone mineral density assessment using MDCT attenuation techniques compared with the DXA reference standard. J Bone Miner Res 2011; 26: 2194-203.

48. Miyabara Y, Holmes D, Camp J, Miller VM, Kearns AE. Comparison of calibrated and uncalibrated bone mineral density by CT to DEXA in menopausal women. Climacteric 2012; 15: 374-81.

49. Pickhardt PJ, Pooler BD, Lauder T, del Rio AM, Bruce RJ, Binkley N. Opportunistic screening for osteoporosis using abdominal computed tomography scans obtained for other indications. Ann Intern Med 2013; 158: 588-95.

50. Mets OM, de Jong PA, Prokop M. Computed tomographic screening for lung cancer: an opportunity to evaluate other diseases. JAMA 2012; 308: 1433-4

51. Aberle DR, Adams AM, Berg CD et al. Reduced lung-cancer mortality with low-dose computed tomographic screening. N Engl J Med 2011; 365: 395-409.

52. Haruna A, Muro S, Nakano Y et al. CT scan findings of emphysema predict mortality in COPD. Chest 2010; 138: 635-40.

53. Celli BR, Locantore N, Yates J et al. Inflammatory biomarkers improve clinical prediction of mortality in chronic obstructive pulmonary disease. Am J Respir Crit Care Med 2012; 185: 1065-72.

54. Jacobs PC, Prokop M, van der Graaf $Y$ et al. Comparing coronary artery calcium and thoracic aorta calcium for prediction of all-cause mortality and cardiovascular events on low-dose non-gated computed tomography in a high-risk population of heavy smokers. Atherosclerosis 2010; 209: 455-62.

55. Shemesh J, Henschke $\mathrm{Cl}$, Shaham D et al. Ordinal scoring of coronary artery calcifications on low-dose CT scans of the chest is predictive of death from cardiovascular disease. Radiology 2010; 257: 541-8.

56. Sverzellati N, Cademartiri F, Bravi F et al. Relationship and prognostic value of modified coronary artery calcium score, FEV1, and emphysema in lung cancer screening population: the MILD trial. Radiology 2012; 262: 460-7.

57. Shaw L, Raggi P, Callister TQ, Berman DS. Prognostic value of coronary artery calcium screening in asymptomatic smokers and non-smokers. Eur Heart J 2006; 27: 968-75.

58. Seeman E, Delmas PD. Bone quality--the material and structural basis of bone strength and fragility. N Engl J Med 2006; 354: 2250-61.

59. Link TM. Osteoporosis imaging: state of the art and advanced imaging. Radiology 2012; 263: 3-17.

60. Macneil JA, Boyd SK. Bone strength at the distal radius can be estimated from high-resolution peripheral quantitative computed tomography and the finite element method. Bone 2008; 42: 1203-13.

61. Pistoia W, van RB, Lochmuller EM, Lill CA, Eckstein F, Ruegsegger P. Estimation of distal radius failure load with micro-finite element analysis models based on three-dimensional peripheral quantitative computed tomography images. Bone 2002; 30: 842-8.

62. Vilayphiou N, Boutroy S, Sornay-Rendu E, van RB, Munoz F, Delmas PD, Chapurlat R. Finite element analysis performed on radius and tibia HR-pQCT images and fragility fractures at all sites in postmenopausal women. Bone 2010; 46: 1030-7.

63. Graeff $\mathrm{C}$, Marin F, Petto $\mathrm{H}$ et al. High resolution quantitative computed tomography-based assessment of trabecular microstructure and strength estimates by finite-element analysis of the spine, but not DXA, reflects vertebral fracture status in men with glucocorticoid-induced osteoporosis. Bone 2012; 52: 568-77. 




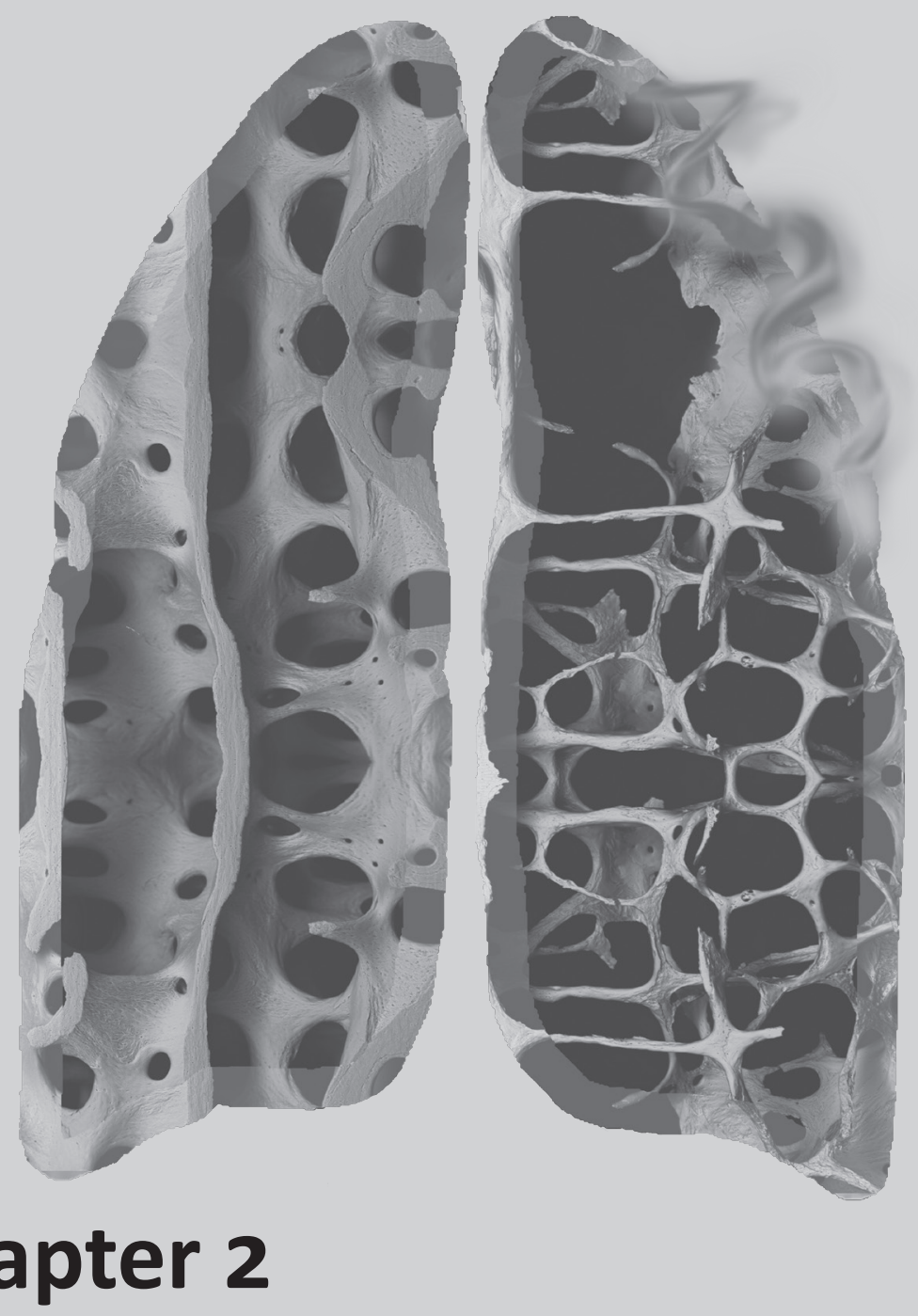

Osteoporosis in chronic obstructive pulmonary disease

Elisabeth A.P.M. Romme

Frank W.J.M. Smeenk

Emiel F.M. Wouters

Erica P.A. Rutten

European Respiratory Monograph 2013; number 59: COPD and comorbidity 


\section{SUMMARY}

Chronic obstructive pulmonary disease (COPD) is, in addition to progressive airflow obstruction, characterised by extrapulmonary manifestations that contribute to the disease severity in individual patients. Osteoporosis is recognised as one such extrapulmonary manifestation, since the prevalence of osteoporosis is higher in COPD patients than in control subjects matched for age and sex. Osteoporosis is a skeletal disease characterised by low bone mineral density or micro-architectural deterioration, resulting in increased risk of fracture. The high prevalence of osteoporosis in COPD is likely to be due to common risk factors such as advanced age and smoking, and to COPD-specific risk factors such as systemic inflammation and the use of corticosteroids. Interventions against common risk factors, like smoking cessation, exercise and healthy diet, might reduce the risk of fracture in patients with osteoporosis. In addition to these lifestyle guidelines, pharmacological treatment with calcium and vitamin D supplementation and antiresorptive treatment (e.g. bisphosphonates) have been indicated to prevent fractures in patients with osteoporosis. 


\section{INTRODUCTION}

Chronic obstructive pulmonary disease (COPD) originates from an abnormal inflammatory response of the lung to noxious particles and gasses. It is characterised by airflow limitation that is not fully reversible and by significant extrapulmonary manifestations that contribute to the disease severity in individual patients. ${ }^{1}$ COPD is a major health problem with a significant financial and medical impact, and its prevalence is estimated to be about $10 \%$ in adults aged 40 and older. ${ }^{2,3}$

Nowadays, COPD is considered a complex and heterogeneous disease. ${ }^{4}$ This was illustrated, for instance, by the baseline data of the study Evaluation of COPD Longitudinally to Identify Predictive Surrogate Endpoints (ECLIPSE), which showed that the clinical manifestations of COPD were highly variable between patients and only weakly related to the severity of airflow limitation. ${ }^{5}$ Both the pulmonary and extrapulmonary manifestations of COPD contribute to morbidity and mortality in COPD. The extrapulmonary manifestations might even be more important than the pulmonary manifestations. Indeed, cardiovascular diseases were a more frequent cause of hospitalisation or death than COPD itself. ${ }^{6}$ In addition, the BODE index (an index compiled of body mass index, airflow obstruction, dyspnoea and exercise capacity) was a better predictor of risk of death from any cause or from respiratory causes than the severity of airflow limitation alone. ${ }^{7}$ Recently, the COPD comorbidity (COTE) index, which is based on 12 comorbidities, appeared to be correlated with risk of death from any cause, independent of the BODE index. ${ }^{8}$

Since the prevalence of osteoporosis is higher in COPD patients than in control subjects matched for age and sex, ${ }^{5,9}$ osteoporosis is recognised as an extrapulmonary manifestation of COPD that might contribute to morbidity and mortality in COPD. ${ }^{10}$ In this chapter, we will give an overview of the prevalence, risk factors and treatment of osteoporosis in patients with COPD.

\section{OSTEOPOROSIS}

Osteoporosis is a systemic skeletal disease that is characterised by low bone mineral density or micro-architectural deterioration resulting in bone fragility and hence increased risk of fracture. ${ }^{11}$ Osteoporosis-related fractures may cause significant morbidity and mortality, particularly in patients with COPD, in whom vertebral compression fractures may reduce already compromised pulmonary function. ${ }^{10,12}$ Moreover, COPD results in a higher operation risk for hip surgery after osteoporosis related fractures. ${ }^{13}$

At present, the gold standard to diagnose osteoporosis is dual energy X-ray absorptiometry (DXA). The World Health Organisation (WHO) ${ }^{11}$ and the International Society for Clinical Densitometry ${ }^{14}$ recommend a diagnosis of osteoporosis based on the lowest T-score of the hip or the lumbar spine measured on DXA (Table 1). The T-score is defined as the number of standard deviations by which the bone mineral density differs from the average bone mineral density of a young adult at peak bone density. 
Table 1. Diagnosis of osteoporosis

\begin{tabular}{ll}
\hline & T-score \\
\hline Normal bone mass & $\geq-1.0$ \\
Osteopenia & -1.0 to -2.5 \\
Osteoporosis & $\leq-2.5$ \\
\hline
\end{tabular}

In addition to DXA scanning, vertebral fracture assessment on X-rays of the spine has been recommended in patients with moderate to very severe COPD, ${ }^{14}$ since vertebral fractures are highly prevalent in COPD ${ }^{15}$ and related to a high annual number of incidental vertebral fractures ${ }^{16}$ The clinical technique of choice for diagnosing vertebral fracture is the Genant visual semi-quantitative method. ${ }^{17}$ With this method, vertebral deformities are classified into wedge, biconcave or crush and into grade 1 ( 20 to $25 \%$ reduction in height and 10 to $20 \%$ reduction of the projected vertebral area), grade 2 ( 25 to $40 \%$ reduction in height and 20 to $40 \%$ reduction of the projected vertebral area) and grade 3 (more than $40 \%$ reduction in height and area).

\section{PATHOPHYSIOLOGY OF OSTEOPOROSIS}

Bone is generally classified into two types: cortical bone, which is dense and strong and primarily present in the shafts of long bones, and trabecular bone, which is weak and porous and present at the ends of long bones or at the interior of vertebrae and flat bones. Bone tissue is continuously renewed throughout life. It is estimated that about $25 \%$ of trabecular bone and about $3 \%$ of cortical bone are replaced in adults every year.

Osteoporosis can occur because of failure to achieve peak bone mass, or it can be due to excessive bone resorption and decreased bone formation during bone remodelling. Bone remodelling is a complex interplay between osteoblasts, osteoclasts and osteocytes. These cells remove an area of bone and then replace the lost bone with new matrix which subsequently mineralises. Excessive bone resorption due to an imbalance in the amount of bone removed relative to the amount of bone replaced will lead to a decline in the total amount of bone and will increase the risk of fracture.

Bone remodelling is controlled by several mechanisms such as the osteoprotegerin (OPG)/ receptor activator of nuclear factor $\mathrm{KB}$ (RANK)/ RANK ligand (RANKL) system and the Wingless tail (Wnt)/ $\beta$ catenin signalling pathway (Figure 1). RANKL is expressed on the surface of osteoblasts, and its expression increases in response to a variety of pro-resorptive signals, such as parathyroid hormone (PTH) and inflammatory cytokines. RANKL binds to the RANK receptor, which is expressed on osteoclasts and their precursors, thereby stimulating the differentiation and activation of osteoclasts and hence promoting bone resorption. OPG is a decoy receptor for RANKL that is secreted by osteoblasts and other stromal-derived cells and acts to reduce bone resorption. Imbalance between RANKL and OPG results in excessive 
activity of osteoclasts and is considered a major cause of osteoporosis. The Wnt/ $\beta$-catenin signalling pathway is less well understood, but it is known that it has an important role in bone formation by activating osteoblasts. Wnt inhibitors such as inflammatory cytokines negatively regulate this pathway resulting in bone loss. ${ }^{10,18}$

\section{PREVALENCE OF OSTEOPOROSIS IN COPD}

The prevalence of osteoporosis is high in patients with COPD. In the study TOwards a Revolution in COPD Health (TORCH), which included 658 COPD patients, $23 \%$ had osteoporosis and $43 \%$ had osteopenia at the hip or the lumbar spine on DXA according to the WHO guidelines. ${ }^{19}$ This is in line with another study on 255 COPD patients admitted for pulmonary rehabilitation, $24 \%$ of whom had osteoporosis and $46 \%$ had osteopenia. ${ }^{20}$ When taking the vertebral fractures into account, the prevalence of osteoporosis even increased to $51 \%{ }^{20}$

Smaller studies have demonstrated that the prevalence of osteoporosis is higher in patients with COPD than in healthy control subjects. In a group of 81 COPD patients and 38 sex matched controls, $30 \%$ of the COPD patients and $13 \%$ of the controls had osteoporosis. ${ }^{21}$

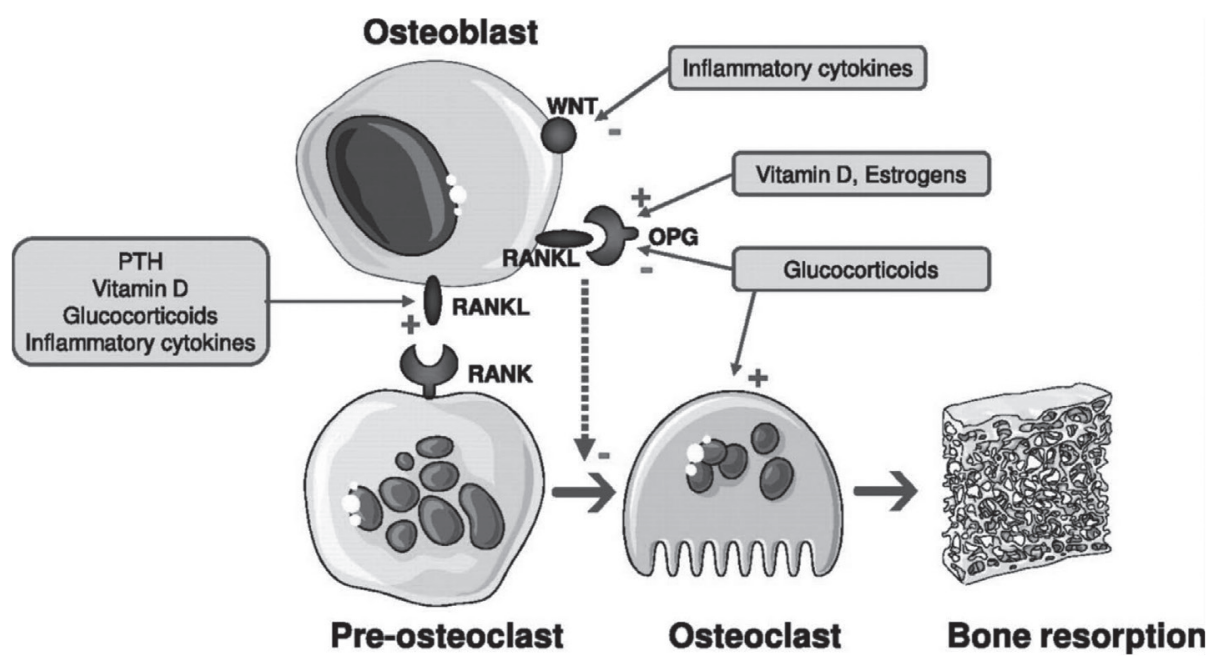

Figure 1. Key mechanisms in the pathogenesis of osteoporosis in COPD

Figure legend. Key mechanisms in the pathogenesis of osteoporosis in COPD. Osteoblasts direct osteoclast precursors into mature activated osteoclasts through RANK/RANKL, an interaction that is blocked by OPG.

OPG = osteoprotegerin; PTH = parathyroid hormone; RANK = receptor activator of nuclear factor-kB; RANKL = receptor activator of nuclear factor- $\mathrm{kB}$ ligand; $\mathrm{WNT}=\mathrm{Wnt}$ signaling pathway. Source: COPD, bone metabolism and osteoporosis ${ }^{10}$ 
However, in this study the controls were younger than the COPD patients. Nevertheless, in a more recent study the prevalence of osteoporosis was $24 \%$ in COPD patients and $5 \%$ in controls matched for age and sex. ${ }^{22}$ Although large case-control studies are not yet available, the available data suggest a higher prevalence of osteoporosis among patients with COPD than in subjects without coexisting COPD.

\section{RISK FACTORS OF OSTEOPOROSIS IN COPD}

In healthy men and women, the main risk factors for osteoporosis are advanced age, smoking, low body weight, physical inactivity, prevalent fractures after the age of 50 and postmenopausal status. ${ }^{23,24} \mathrm{~A}$ collection of these risk factors is summarised in the fracture risk assessment (FRAX) tool, which predicts the 10 year probability of fracture. ${ }^{25}$ Since some of these risk factors like advanced age, smoking and low body weight coincide in patients with COPD, it is not surprising that osteoporosis and COPD are strongly related. However, there is evidence that various COPD-specific factors such as systemic inflammation, vitamin $D$ deficiency, use of corticosteroids and lung function impairment themselves might contribute to the increased risk of osteoporosis in patients with COPD. In the following paragraphs, we will discuss the most important risk factors of osteoporosis in patients with COPD.

\section{Airflow obstruction and emphysema}

Osteoporosis has been related to severity of airflow obstruction. The Third National Health and Nutrition Examination Survey, which included 9502 participants, showed that the prevalence of osteopenia and osteoporosis increased with more severe airflow obstruction. ${ }^{26}$ In line, in 4830 women recruited from general practice registers, forced expiratory volume in one second $\left(\mathrm{FEV}_{1}\right)$ was positively correlated with bone mineral density after adjustment for confounders, including e.g. corticosteroid use. ${ }^{27}$ More recently, a cross-sectional study with 95 COPD patients demonstrated that the patients with osteoporosis had lower FEV than the patients with normal bone mass. ${ }^{28}$ In line, a review stated that osteoporosis was associated with more severe airflow obstruction in patients with COPD. ${ }^{9}$ In contrast, some studies on patients with COPD did not find a relationship between bone mineral density and severity of airflow obstruction after correction for confounders..$^{29,30}$

In addition to its association with severity of airflow obstruction, bone density has been related to the extent of emphysema. ${ }^{31}$ Already in 1999, a study on about 100 patients with severe COPD who had been admitted for pulmonary rehabilitation showed that total body bone mineral density was lower in the patients with emphysema, based on visual scores on high resolution computed tomography (HRCT) scans, than in those without emphysema. ${ }^{32}$ Bon and colleagues ${ }^{33}$ recently confirmed these data in a tobacco-exposed cohort of which only a subset of subjects had obstructive lung disease. They showed that radiographic emphysema was an independent predictor of low bone mineral density. However, they did not correct for body mass index, even though body mass index is related to both emphysema and bone mineral density. Still, in another study on 65 male patients with COPD radiographic emphysema was correlated with CT-measured bone mineral density of the thoracic vertebrae even after adjustment for body mass index. ${ }^{34}$ 
Since bone mineral density was shown to be correlated independently with both the severity of airflow obstruction and the extent of emphysema, recent research has been focused on common links between the skeletal and pulmonary systems. ${ }^{31}$ Both direct and indirect pathways have been suggested.

Regarding the indirect pathways, COPD is associated with increased plasma markers of systemic inflammation that might stimulate osteoclastogenesis and generate RANKL, resulting in decreased bone mass. In a clinical study with 80 subjects, plasma markers of systemic inflammation, interleukin- 6 (IL-6) and tumour necrosis factor- $\alpha$ (TNF- $\alpha$ ) were higher in the COPD patients than in the control subjects and higher in the COPD patients with low bone density than in the COPD patients with normal bone density. ${ }^{35}$ In addition, the RANKL concentration and the RANKL/OPG ratio were higher in the COPD patients with low bone density than in the COPD patients with normal bone density. Therefore, it seems likely that systemic inflammation in COPD results in a disturbance of the RANK/RANKL/OPG pathway and, hence, in osteoporosis. A review stated indeed that systemic inflammation might result in disturbance of the RANK/RANKL/OPG pathway in patients with inflammatory diseases. ${ }^{18}$

Regarding the direct pathways, the Wnt/ $\beta$-catenin signalling is involved in bone remodeling and repair of micro fractures, but it has also been associated with lung epithelial injury and repair processes. In a small study with 12 COPD and 12 transplant donor lung samples, Wnt/ $\beta$ catenin activation by lithium chloride attenuated experimental emphysema as assessed by decreased airspace enlargement, improved lung function, reduced collagen content and elevated expression of alveolar epithelial cell markers. ${ }^{36}$ Therefore, it might be the case that impairment of $\mathrm{Wnt} / \beta$-catenin signalling results in both osteoporosis and emphysema. However, only indirect and experimental evidence supporting this interaction is available so far.

\section{Aging}

Advanced age is a well-established risk factor for osteoporosis ${ }^{11,25}$ and has been related to the presence of COPD in a large population-based cohort study. ${ }^{37}$ COPD has even been suggested to be a syndrome of abnormal lung aging. ${ }^{38}$ Since patients with COPD show evidence of increased oxidative stress ${ }^{39}$ and shorter telomeres compared with controls matched for age and sex,,$^{40}$ there seems to be evidence that COPD is also associated with systemic abnormal aging. ${ }^{41}$

The underlying patho-physiologic mechanism of the relationship between advanced age and bone loss has been studied widely. ${ }^{42}$ In a healthy young skeleton the rate of bone formation and matrix mineralisation equals the rate of bone resorption and matrix degradation. However, during the process of aging significant amounts of bone are lost due to enhanced bone resorption coupled with decreased bone formation. In addition to bone loss, advanced age is associated with increased fall risk due to muscle weakness and balance disorders resulting in increased risk of fracture. ${ }^{43,44}$ 


\section{Body composition}

Body mass/fat free mass

Low body mass and low fat free mass are well-known risk factors for osteoporosis in the general population. ${ }^{11,25}$ Moreover, low body mass and low fat free mass are both commonly present and have been investigated extensively in patients with COPD as they are associated with decreased exercise tolerance, ${ }^{45}$ disease-related quality of life ${ }^{46}$ and increased mortality risk. ${ }^{47}$ In addition, accumulating evidence shows a relationship between low body and muscle mass and osteoporosis in patients with COPD even after adjustment for confounders such as age and the use of corticosteroids. . $, 21,29,30,48^{2}$

Low body mass, low fat free mass and the poor exercise capacity related to $\mathrm{it}^{45}$ might induce bone loss due to decreased mechanical loading. Indeed, astronauts lose bone mass in the proximal femur during space flights, ${ }^{49}$ and long term bed rest leads to loss of bone mass..$^{50}$ Although 'disuse' osteoporosis has been investigated widely, ${ }^{51}$ its underlying mechanism has not been fully understood yet. In addition to decreased mechanical loading, poor exercise capacity might cause sarcopenia and lower-limb muscle weakness which has been related to increased fall risk and hence increased risk of fracture. However, more research concerning the underlying patho-physiological mechanism of the relationship between low body mass and fat free mass and osteoporosis is warranted in patients with COPD.

\section{Fat mass}

Overweight and obesity are, in addition to underweight, common in patients with COPD. Indeed, 28 to $64 \%$ of male COPD patients and 33 to $50 \%$ of female COPD patients were overweight (body mass index $>25 \mathrm{~kg} / \mathrm{m}^{2}$ ). ${ }^{47}$ Notably, an overweight or obese body mass index is protective of osteoporosis. ${ }^{52}$ This might be due to an interaction between fat and bone tissue such as the effects of fat mass on the secretion of bone active hormones from the pancreatic beta cells (e.g. insulin and amylin) and the secretion of bone active hormones from adipocytes (e.g. leptin)..$^{22}$

Several studies have investigated the effects of leptin, an adipokine which is related to the amount of body fat. ${ }^{22,53}$ Leptin acts both via the central nervous system and via the circulation, resulting in different effects on bone metabolism (Figure 2). Circulating leptin increases the proliferation and differentiation of osteoblasts and promotes bone nodule formation. It also regulates osteoclast development, at least partly, through the RANK/ RANKL/OPG pathway, which results in net bone formation. Via the central nervous system, leptin has the opposite effect by influencing satiety and insulin secretion. It is believed that the local effects of leptin from adipose tissue are dominant over the central effects, resulting in a stronger skeleton, which is needed to support a greater soft tissue mass..$^{52}$

In patients with COPD, an overweight or obese body mass index was shown to be protective against osteoporosis..$^{30}$ More recently, adipose tissue leptin and OPG expressions correlated positively with bone density variables and serum $\beta$-crosslaps concentrations in 19 COPD patients with osteoporosis and 21 COPD patients with normal bone mass. ${ }^{54}$ These findings might suggest that leptin and OPG act as mediators between fat mass and bone density in 
patients with COPD. However, more research on the interaction between fat and bone is warranted in patients with COPD.

\section{Corticosteroids}

Oral and inhaled corticosteroids are widely used in patients with COPD despite their adverse effects, such as oropharyngeal candidiasis, hoarseness and pneumonia. ${ }^{55}$ In addition, the use of oral corticosteroids has been associated with decreased bone mass and increased risk of fracture. Indeed, the total cumulative dose of oral corticosteroids was inversely correlated with bone mineral density, ${ }^{56}$ and prior or current exposure to oral corticosteroids was associated with increased risk of fracture. ${ }^{57}$ With respect to COPD patients, patients receiving oral corticosteroids were more likely to have one or more vertebral fractures..$^{58,59}$

The effects of inhaled corticosteroids on bone health are less clear. A randomised controlled trial in 658 patients with moderate to severe COPD demonstrated that inhaled corticosteroids had no effect on bone mineral density at the hip and lumbar spine over 3 years. ${ }^{19}$ However, a case-control study including 1708 cases with non-vertebral fractures and 6817 matched controls showed that the use of high-dose corticosteroids ( $\geq 700$ microgram per day) was associated with increased risk of fracture compared with patients who did not use inhaled corticosteroids. ${ }^{60}$ More recently, a systematic review concluded that long-term use of inhaled fluticasone or budesonide was associated with a dose-dependent increased risk of fracture. ${ }^{61}$

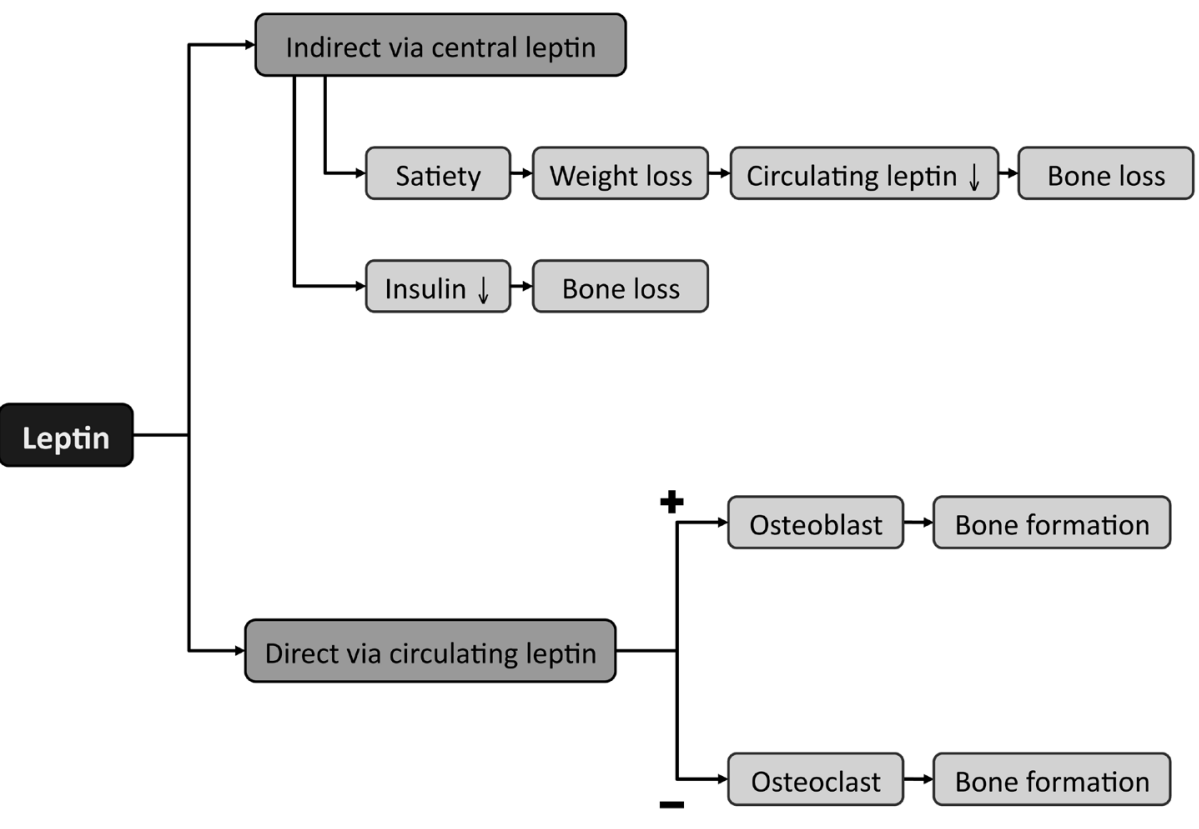

Figure 2. The effects of leptin on bone metabolism 
Although accumulating evidence shows that the use of inhaled corticosteroids is correlated with increased risk of fracture, there is need for more prospective studies that correct for confounders such as COPD severity.

Corticosteroids cause bone loss due to disruption of bone remodelling. Several mechanisms have been associated with corticosteroid-induced osteoporosis including impaired calcium intestinal absorption, decreased formation of osteoblasts, increased osteocytes apoptosis and altered sex hormone status in both men and women (Table 2). ${ }^{18,62}$ In addition, corticosteroids might also cause muscle dysfunction resulting in increased risk of falls.

Since oral and inhaled corticosteroids have been correlated with increased risk of fracture, clinicians should carefully consider the risk of fracture associated with the use of oral and inhaled corticosteroids for treating and preventing exacerbations.

\section{Vitamin D deficiency}

Vitamin D deficiency is related to osteoporosis and is highly prevalent in patients with COPD. The prevalence of vitamin $D$ deficiency, defined as plasma 25 -hydroxyvitamin $D$ concentrations below $50 \mathrm{nmol} / \mathrm{L}$, was $58 \%$ in a cross-sectional study with 151 COPD patients entering pulmonary rehabilitation during summer. ${ }^{63}$ The prevalence of vitamin $D$ deficiency seems to be higher in patients with COPD than in subjects without coexisting COPD, and it seems to be related to the severity of COPD. In the Bergen COPD cohort study, the

Table 2. Metabolic effects of corticosteroids leading to bone loss

\section{Effects on calcium metabolism}

Decrease intestinal absorption of calcium and phosphate

Increase urinary calcium excretion

Factors listed above promote the development of secondary hyperparathyroidism, which can increase bone resorption

\section{Effects on sex hormones}

Direct and indirect effects on adrenal androgen and gonadal hormone release leading to the loss of anabolic effects of these hormones on bone formation and resorption

\section{Direct bone effects}

Inhibition of osteoclast proliferation

Inhibition of osteoclast attachment to bone matrix

Inhibition of type I collagen and other proteins produced by osteoblasts

\section{Other effects}

Steroid myopathy may slow or prevent exercise-induced benefits in bone formation as well as reduce normal physical forces of muscle tension on bone

Source: Chronic glucocorticoid therapy-induced osteoporosis in patients with obstructive lung disease $^{95}$ 
prevalence of vitamin D deficiency was higher in the COPD patients than in the control subjects independent of season, age, smoking, comorbidities and body mass index. ${ }^{64}$ In addition, the prevalence of vitamin D deficiency was 39\% in GOLD stage I, $47 \%$ in GOLD stage II, $60 \%$ in GOLD stage III, and $77 \%$ in GOLD stage IV COPD patients. ${ }^{65}$ There are several potential explanations for the increased risk of vitamin $D$ deficiency in patients with COPD including poor diet, less exposure to sunlight due to poor physical activity, accelerated skin aging due to smoking, renal dysfunction and treatment with corticosteroids.

The uptake of vitamin D and its role in bone homeostasis is well established. Humans get vitamin $D$ by exposure to sunlight, from their diet (e.g. fat fish, butter, eggs) and from dietary supplements. In the liver, vitamin $D_{3}$ is metabolised to 25 -hydroxyvitamin $D$, which is the major circulating metabolite of vitamin D. 25-hydroxyvitamin $D$ is metabolised further to its active form, 1,25-dihydroxyvitamin $D$, in the kidneys by the enzyme 1- $\alpha$-hydroxylase. The renal production of 1,25-dihydroxyvitamin D is tightly regulated by plasma PTH levels and serum calcium and phosphorus levels. The efficiency of intestinal calcium and phosphorus absorption is increased through the interaction of 1,25-dihydroxyvitamin $D$ with the vitamin $D$ receptor. In case of vitamin D deficiency, decreased calcium absorption causes a compensatory increase in PTH. PTH enhances the tubular reabsorption of calcium and stimulates the kidneys to produce 1,25-dihydroxyvitamin D. PTH also activates osteoblasts, which stimulate the transformation of preosteoclasts into mature osteoclasts. Osteoclasts dissolve the mineralised collagen matrix in bone, causing osteopenia and osteoporosis. ${ }^{66}$ In addition, low 25 -hydroxyvitamin D concentrations might also cause muscle dysfunction and hence increase the risk of falls, resulting in increased risk of fracture. ${ }^{67}$

Although the role of vitamin $\mathrm{D}$ in bone health is well established in non-COPD populations, research in patients with COPD is limited. In underweight patients with end-stage pulmonary diseases waiting for lung transplantation, vitamin $D$ deficiency was associated with reduced femur neck T-scores, ${ }^{68}$ and in COPD patients admitted for pulmonary rehabilitation vitamin $D$ concentration was positively correlated with the lowest T-score of the hip and lumbar spine. ${ }^{63}$

\section{Physical inactivity}

COPD patients are less physically active compared with control subjects. ${ }^{69}$ In addition, reduced physical activity is associated with bone loss and osteoporosis-related fractures, ${ }^{70,71}$ whereas, on the other hand, exercise interventions may increase bone mineral density ${ }^{72}$ and reduce the risk of falls and fractures. ${ }^{73}$ In COPD patients, research on a relationship between physical activity and bone health is limited. Silva and colleagues ${ }^{28}$ showed that the International Physical Activity Questionnaire total activity score was related to the T-score of the femoral neck in 95 COPD patients, and Nishimura and colleagues ${ }^{74}$ demonstrated that the twelve minute walk test was related to changes in bone mineral content in 22 COPD patients.

\section{Smoking and alcohol use}

Smoking is a risk factor for both osteoporosis and COPD. ${ }^{11,37}$ Smoking has been found to induce parenchymal destruction by inflammation. This parenchymal destruction occurs in an early 
stage of COPD and increases with more pack-years of smoking. In addition to parenchymal destruction, smoking has been associated with osteoporosis. Indeed, smokers had a 2-4 fold increased odds ratio for osteoporotic fractures compared with non-smokers. The effect of smoking on bone loss has been suggested to be dose-dependent and related to several mechanisms. ${ }^{75}$ Firstly, smoking may increase bone loss through its effect on body weight. Smokers weigh less than non-smokers and smoking cessation has been associated with increased weight within three months after cessation. Secondly, smoking might influence bone health through an earlier menopause, because on average, smoking women begin natural menopause 1 to 2 years earlier than non-smokers, and age at menopause is a strong predictor of osteoporosis. Thirdly, cigarette smoke negatively affects hormones and enzymes engaged in the regulation of bone metabolism such as PTH and alkaline phosphatase.

COPD has been associated with high alcohol consumption in Japan, ${ }^{76}$ but not yet in the Caucasian population. Since alcohol consumption is recognised as a risk factor for osteoporosis, ${ }^{77,78}$ it might be that increased alcohol consumption contributes to osteoporosis in patients with COPD. The mechanisms of the action of ethanol on bone are not completely understood, but these are suggested to be both indirect and direct. Indirectly, high alcohol consumption might interact with bone tissue via poor nutritional intake and caloric restriction, which results in a reduced body and fat mass. In addition, alcohol consumption might also interact directly with bone remodeling by changes on the number and activity of osteoblasts and osteoclasts, increased osteocytes apoptosis, increased oxidative stress and increased fat accumulation in the bone marrow. ${ }^{78}$

Taken together, both COPD and osteoporosis will particularly occur later in life and are dependent on common shared risk factors such as nutritional and lifestyle factors. However, more research is warranted to discover whether COPD in itself is an independent risk factor due to shared underlying mechanisms such as systemic inflammation and the use of corticosteroids.

\section{NON-PHARMACOLOGICAL AND PHARMACOLOGICAL TREATMENT}

Since several lifestyle factors such as smoking, alcohol use and physical inactivity have been associated with fractures due to osteoporosis, intervention against these factors might improve bone density and reduce risk of fracture. A systematic review stated that exercise had a positive effect on bone mass in postmenopausal women, ${ }^{72}$ and smoking cessation was associated with improvement in bone density. ${ }^{79}$ Although multidisciplinary rehabilitation in patients with COPD has shown to have positive short-term and long-term functional effects, research on the effects of multidisciplinary rehabilitation on bone density and fracture risk is still lacking.

\section{Calcium and vitamin $D$ supplementation}

Nowadays, calcium and vitamin D supplementation are recommended in the treatment of osteoporosis since they have positive effects on bone health and muscle function, resulting in reduced risk of fracture. A meta-analysis stated that calcium supplementation alone or 
in combination with vitamin D was effective in the preventive treatment of osteoporosisrelated fracture.$^{80}$ In addition, another meta-analysis stated that vitamin D supplementation with doses of 700 to 800 IU per day reduced the relative risk of hip fracture by $26 \%$ and of any non-vertebral fracture by $23 \%$ compared with calcium supplementation or placebo in individuals 60 years or older. ${ }^{81}$ In contrast, a Cochrane review stated that vitamin D without calcium supplementation appeared unlikely to be effective in preventing hip fracture, vertebral fracture or any new fracture. ${ }^{82}$ These data suggest that both calcium and vitamin $\mathrm{D}$ are important in the prevention of osteoporosis-related fracture. In addition to its effect on fracture risk, vitamin $D$ supplementation had beneficial effects on fall prevention among ambulatory or institutionalised older individuals with stable health. ${ }^{83}$ Vitamin $D$ supplementation with doses of 700 to $1000 \mathrm{IU}$ per day reduced falls by 19 to $26 \%$, whereas vitamin D doses below $700 \mathrm{IU}$ did not prevent falls. ${ }^{84}$

Based on evidence from randomised controlled trials and meta-analyses, it has been suggested that adequate vitamin D supplementation with doses of at least $700 \mathrm{IU}$ per day is required for improving physical function and prevention of falls and fractures in the elderly. ${ }^{85}$ Additional calcium supplementation may be considered when dietary calcium intake is below $700 \mathrm{mg}$ per day, using a supplementation dose that leads to a maximum total daily calcium intake of 1000 to $1200 \mathrm{mg} .{ }^{85}$ However, dietary advice to attain an adequate calcium intake is preferred to calcium supplementation, since calcium supplementation has been associated with increased risk of myocardial infarction. ${ }^{86}$

\section{Antiresorptive therapy}

The role of bisphosphonates in the prevention and treatment of osteoporosis is well established. Bisphosphonates are chemically stable derivatives of inorganic pyrophosphate and inhibit calcification by binding to hydroxyapatite crystals. In addition, bisphosphonates inhibit hydroxyapatite breakdown, thereby effectively suppressing bone resorption. It has been suggested that bisphosphonates also function to limit both osteoblast and osteocytes apoptosis. In postmenopausal women with osteoporosis, alendronate was associated with significant and clinically important reductions in the incidence of hip fracture. ${ }^{87}$ In patients treated with corticosteroids, bisphosphonates were shown to increase bone mineral density and prevent the development of new fractures. ${ }^{88}$ In patients with airway disorders (asthma or chronic obstructive airway disease) daily intake of alendronate for 12 months was shown to significantly improve bone mineral density at the lumbar spine. ${ }^{89}$

In addition to bisphosphonates, teriparatide and denosumab have been shown to be effective in reducing the risk of fragility fractures..$^{90}$ In patients with corticosteroid-induced osteoporosis, patients treated with teriparatide had an even greater increase in lumbar spine bone mineral density and less incidental vertebral fractures than patients treated daily with alendronate..$^{91}$ Denosumab, a human monoclonal antibody to RANKL, is a relatively new drug that prevents the interaction of RANKL to RANK, thereby blocking the formation, function and survival of osteoclasts and resulting in decreased bone resorption. In postmenopausal 
women with osteoporosis, denosumab was associated with a significant reduction in the risk of vertebral as well as hip and other non-vertebral fractures. ${ }^{92}$

\section{COPD-SPECIFIC RECOMMENDATIONS}

Currently, osteoporosis is generally recognised as one of the systemic manifestations of COPD which contribute to worsening of the disease progression. Patients at risk of developing osteopenia or osteoporosis particularly include patients with advanced age, low body mass, frequent use of oral corticosteroids and vitamin D deficiency. These patients, but preferably all patients, should be screened for osteoporosis by DXA scan and vertebral fracture assessment, and, if necessary, treatment should be initiated. As no COPD-specific treatment has been developed yet, standard treatment for osteopenia and osteoporosis should be prescribed. However, COPD patients who use corticosteroids should be treated according to the guidelines for management of corticosteroid-induced osteoporosis. ${ }^{93}$ The American College of Rheumatology recommends a daily calcium intake of 1200 to $1500 \mathrm{mg}$ per day and vitamin D supplementation to achieve 'therapeutic' vitamin D concentrations or vitamin D dosages of 800 to 1000 units per day, in all patients who use corticosteroids. ${ }^{94}$ In addition, they recommend bisphosphonates in patients at low-risk of fractures who use $\geq 7.5 \mathrm{mg}$ prednisone equivalents per day, and in patients at medium or high-risk of fractures who use any dose of corticosteroids.

\section{CONCLUSION}

Since osteoporosis is highly prevalent in patients with COPD and might contribute to the morbidity and mortality, chest physicians should screen all COPD patients at risk for osteoporosis. Diagnosis of osteoporosis should be based on bone mineral density assessed on DXA and vertebral fracture assessment on X-rays of the spine. Main risk factors of osteoporosis in COPD include advanced age, low body and muscle mass, smoking and alcohol use and vitamin D deficiency. In addition to these main risk factors, COPD-specific factors such as the use of corticosteroids and systemic inflammation might contribute to the development of osteoporosis in patients with COPD. Treatment of osteoporosis is primarily focused on reducing the risk of fracture and include intervention of risk factors by nutritional and lifestyle guidelines, calcium and vitamin D supplementation and antiresorptive therapy (e.g. bisphosphonates). In order to prevent and optimise treatment of osteoporosis in COPD, more research on its underlying pathophysiologic mechanisms is warranted. 


\section{REFERENCES}

1. Rabe KF, Hurd S, Anzueto A et al. Global strategy for the diagnosis, management, and prevention of chronic obstructive pulmonary disease: GOLD executive summary. Am J Respir Crit Care Med 2007; 176: 532-55.

2. Lopez AD, Mathers CD, Ezzati M, Jamison DT, Murray CJ. Global and regional burden of disease and risk factors, 2001: systematic analysis of population health data. Lancet 2006; 367: 1747-57.

3. Halbert RJ, Natoli JL, Gano A, Badamgarav E, Buist AS, Mannino DM. Global burden of COPD: systematic review and meta-analysis. Eur Respir J 2006; 28: 523-32.

4. Agusti AG. COPD, a multicomponent disease: implications for management. Respir Med 2005; 99 : 670-82.

5. Agusti A, Calverley PM, Celli B et al. Characterisation of COPD heterogeneity in the ECLIPSE cohort. Respir Res 2010; 11: 122.

6. Huiart L, Ernst P, Suissa S. Cardiovascular morbidity and mortality in COPD. Chest 2005; 128: 2640-6.

7. Celli BR, Cote CG, Marin JM et al. The body-mass index, airflow obstruction, dyspnea, and exercise capacity index in chronic obstructive pulmonary disease. N Engl J Med 2004; 350: 1005-12.

8. Divo M, Cote C, de Torres JP et al. Comorbidities and Risk of Mortality in Patients with Chronic Obstructive Pulmonary Disease. Am J Respir Crit Care Med 2012; 186: 155-61.

9. Graat-Verboom L, Wouters EF, Smeenk FW, van den Borne BE, Lunde R, Spruit MA. Current status of research on osteoporosis in COPD: a systematic review. Eur Respir J 2009; 34: 209-18.

10. Lehouck A, Boonen S, Decramer M, Janssens W. COPD, Bone Metabolism, and Osteoporosis. Chest 2011; 139: 648-57.

11. World Health Organization. Prevention and Management of Osteoporosis; report of a WHO scientific group [updated 2003; cited 2013 August]. Available from: http://whqlibdoc.who.int/trs/WHO_ TRS_921.pdf.

12. Lyles KW, Gold DT, Shipp KM, Pieper CF, Martinez S, Mulhausen PL. Association of osteoporotic vertebral compression fractures with impaired functional status. Am J Med 1993; 94: 595-601.

13. Myers AH, Robinson EG, Van Natta ML, Michelson JD, Collins K, Baker SP. Hip fractures among the elderly: factors associated with in-hospital mortality. Am J Epidemiol 1991; 134: 1128-37.

14. Lewiecki EM, Gordon CM, Baim S et al. International Society for Clinical Densitometry 2007 Adult and Pediatric Official Positions. Bone 2008; 43: 1115-21.

15. Papaioannou A, Parkinson W, Ferko N et al. Prevalence of vertebral fractures among patients with chronic obstructive pulmonary disease in Canada. Osteoporos Int 2003; 14: 913-7.

16. Lindsay R, Silverman SL, Cooper $C$ et al. Risk of new vertebral fracture in the year following a fracture. JAMA 2001; 285: 320-3.

17. Genant $\mathrm{HK}, \mathrm{Wu} \mathrm{CY}$, van $\mathrm{KC}$, Nevitt MC. Vertebral fracture assessment using a semiquantitative technique. J Bone Miner Res 1993; 8: 1137-48.

18. Hardy R, Cooper MS. Bone loss in inflammatory disorders. J Endocrinol 2009; 201: 309-20.

19. Ferguson GT, Calverley PM, Anderson JA et al. Prevalence and progression of osteoporosis in patients with COPD: results from the TOwards a Revolution in COPD Health study. Chest 2009; 136: 1456-65.

20. Graat-Verboom L, van den Borne BE, Smeenk FW, Spruit MA, Wouters EF. Osteoporosis in COPD outpatients based on bone mineral density and vertebral fractures. J Bone Miner Res 2011; 26: 561-8.

21. Bolton $\mathrm{CE}$, lonescu $\mathrm{AA}$, Shiels $\mathrm{KM}$ et al. Associated loss of fat-free mass and bone mineral density in chronic obstructive pulmonary disease. Am J Respir Crit Care Med 2004; 170: 1286-93.

22. Sabit R, Bolton $\mathrm{CE}$, Edwards $\mathrm{PH}$ et al. Arterial stiffness and osteoporosis in chronic obstructive pulmonary disease. Am J Respir Crit Care Med 2007; 175: 1259-65.

23. Papaioannou A, Kennedy CC, Cranney A et al. Risk factors for low BMD in healthy men age 50 years or older: a systematic review. Osteoporos Int 2009; 20: 507-18. 
24. Waugh EJ, Lam MA, Hawker GA et al. Risk factors for low bone mass in healthy 40-60 year old women: a systematic review of the literature. Osteoporos Int 2009; 20: 1-21.

25. Kanis JA, Johnell O, Oden A, Johansson H, McCloskey E. FRAX and the assessment of fracture probability in men and women from the UK. Osteoporos Int 2008; 19: 385-97.

26. Sin DD, Man JP, Man SF. The risk of osteoporosis in Caucasian men and women with obstructive airways disease. Am J Med 2003; 114: 10-4.

27. Lekamwasam S, Trivedi DP, Khaw KT. An association between respiratory function and bone mineral density in women from the general community: a cross sectional study. Osteoporos Int 2002; 13: 710-5.

28. Silva DR, Coelho AC, Dumke A et al. Osteoporosis prevalence and associated factors in patients with COPD: a cross-sectional study. Respir Care 2011; 56: 961-8.

29. Coin A, Sergi G, Marin S et al. Predictors of low bone mineral density in elderly males with chronic obstructive pulmonary disease: the role of body mass index. Aging Male 2010; 13: 142-7.

30. Graat-Verboom L, Spruit MA, van den Borne BE, Smeenk FW, Martens EJ, Lunde R, Wouters EF. Correlates of osteoporosis in chronic obstructive pulmonary disease: An underestimated systemic component. Respir Med 2009; 103: 1143-51.

31. Bon J. Does radiographic emphysema correlate with low bone mineral density? Curr Opin Pulm Med 2012; 18: 125-30.

32. Engelen MP, Schols AM, Lamers RJ, Wouters EF. Different patterns of chronic tissue wasting among patients with chronic obstructive pulmonary disease. Clin Nutr 1999; 18: 275-80.

33. Bon J, Fuhrman CR, Weissfeld JL et al. Radiographic emphysema predicts low bone mineral density in a tobacco-exposed cohort. Am J Respir Crit Care Med 2011; 183: 885-90.

34. Ohara T, Hirai T, Muro S et al. Relationship between pulmonary emphysema and osteoporosis assessed by CT in patients with COPD. Chest 2008; 134: 1244-9.

35. Bai $P$, Sun $Y$, Jin J, Hou J, Li R, Zhang Q, Wang Y. Disturbance of the OPG/RANK/RANKL pathway and systemic inflammation in COPD patients with emphysema and osteoporosis. Respir Res 2011; 12: 157.

36. Kneidinger N, Yildirim AO, Callegari J et al. Activation of the WNT/beta-catenin pathway attenuates experimental emphysema. Am J Respir Crit Care Med 2011; 183: 723-33.

37. Afonso AS, Verhamme KM, Sturkenboom MC, Brusselle GG. COPD in the general population: prevalence, incidence and survival. Respir Med 2011; 105: 1872-84.

38. Faner R, Rojas M, MacNee W, Agusti A. Abnormal lung aging in chronic obstructive pulmonary disease and idiopathic pulmonary fibrosis. Am J Respir Crit Care Med 2012; 186: 306-13.

39. Nadeem A, Raj HG, Chhabra SK. Increased oxidative stress and altered levels of antioxidants in chronic obstructive pulmonary disease. Inflammation 2005; 29: 23-32.

40. Savale L, Chaouat A, Bastuji-Garin S et al. Shortened telomeres in circulating leukocytes of patients with chronic obstructive pulmonary disease. Am J Respir Crit Care Med 2009; 179: 566-71.

41. Lee J, Sandford A, Man P, Sin DD. Is the aging process accelerated in chronic obstructive pulmonary disease? Curr Opin Pulm Med 2011; 17: 90-7.

42. Syed FA, Ng AC. The pathophysiology of the aging skeleton. Curr Osteoporos Rep 2010; 8: 235-40.

43. Sturnieks DL, St GR, Lord SR. Balance disorders in the elderly. Neurophysiol Clin 2008; 38: 467-78.

44. Nguyen ND, Pongchaiyakul C, Center JR, Eisman JA, Nguyen TV. Identification of high-risk individuals for hip fracture: a 14-year prospective study. J Bone Miner Res 2005; 20: 1921-8.

45. Schols AM, Mostert R, Soeters PB, Wouters EF. Body composition and exercise performance in patients with chronic obstructive pulmonary disease. Thorax 1991; 46: 695-9.

46. Mostert R, Goris A, Weling-Scheepers C, Wouters EF, Schols AM. Tissue depletion and health related quality of life in patients with chronic obstructive pulmonary disease. Respir Med 2000; 94: 859-67.

47. Vestbo J, Prescott E, Almdal T et al. Body mass, fat-free body mass, and prognosis in patients with chronic obstructive pulmonary disease from a random population sample: findings from the Copenhagen City Heart Study. Am J Respir Crit Care Med 2006; 173: 79-83. 
48. Bolton CE, Cannings-John R, Edwards PH et al. What community measurements can be used to predict bone disease in patients with COPD? Respir Med 2008; 102: 651-7.

49. Cavanagh PR, Licata AA, Rice AJ. Exercise and pharmacological countermeasures for bone loss during long-duration space flight. Gravit Space Biol Bull 2005; 18: 39-58.

50. LeBlanc AD, Schneider VS, Evans HJ, Engelbretson DA, Krebs JM. Bone mineral loss and recovery after 17 weeks of bed rest. J Bone Miner Res 1990; 5: 843-50.

51. Takata S, Yasui N. Disuse osteoporosis. J Med Invest 2001; 48: 147-56.

52. Reid IR. Fat and bone. Arch Biochem Biophys 2010; 503: 20-7.

53. Kawai M, de Paula FJ, Rosen CJ. New insights into osteoporosis: the bone-fat connection. J Intern Med 2012; 272: 317-29.

54. Pobeha P, Ukropec J, Skyba P et al. Relationship between osteoporosis and adipose tissue leptin and osteoprotegerin in patients with chronic obstructive pulmonary disease. Bone 2011; 48: 1008-14.

55. Yang IA, Clarke MS, Sim EH, Fong KM. Inhaled corticosteroids for stable chronic obstructive pulmonary disease. Cochrane Database Syst Rev 2012; 7: CD002991.

56. van Staa TP, Leufkens HG, Cooper C. The epidemiology of corticosteroid-induced osteoporosis: a metaanalysis. Osteoporos Int 2002; 13: 777-87.

57. Kanis $\mathrm{JA}$, Johansson $\mathrm{H}$, Oden $\mathrm{A}$ et al. A meta-analysis of prior corticosteroid use and fracture risk. J Bone Miner Res 2004; 19: 893-9.

58. McEvoy CE, Ensrud KE, Bender E, Genant HK, Yu W, Griffith JM, Niewoehner DE. Association between corticosteroid use and vertebral fractures in older men with chronic obstructive pulmonary disease. Am J Respir Crit Care Med 1998; 157: 704-9.

59. Walsh LJ, Wong CA, Oborne J et al. Adverse effects of oral corticosteroids in relation to dose in patients with lung disease. Thorax 2001; 56: 279-84.

60. Lee TA, Weiss KB. Fracture risk associated with inhaled corticosteroid use in chronic obstructive pulmonary disease. Am J Respir Crit Care Med 2004; 169: 855-9.

61. Loke YK, Cavallazzi R, Singh S. Risk of fractures with inhaled corticosteroids in COPD: systematic review and meta-analysis of randomised controlled trials and observational studies. Thorax 2011; 66: 699-708.

62. Lafage-Proust MH, Boudignon B, Thomas T. Glucocorticoid-induced osteoporosis: pathophysiological data and recent treatments. Joint Bone Spine 2003; 70: 109-18.

63. Romme EA, Rutten EP, Smeenk FW, Spruit MA, Menheere PP, Wouters EF. Vitamin D status is associated with bone mineral density and functional exercise capacity in patients with chronic obstructive pulmonary disease. Ann Med 2013; 45: 91-6.

64. Persson LJ, Aanerud M, Hiemstra PS, Hardie JA, Bakke PS, Eagan TM. Chronic obstructive pulmonary disease is associated with low levels of vitamin d. PLoS One 2012; 7: e38934.

65. Janssens W, Bouillon R, Claes B et al. Vitamin D deficiency is highly prevalent in COPD and correlates with variants in the vitamin D-binding gene. Thorax 2010; 65: 215-20.

66. Holick MF. Vitamin D deficiency. N Engl J Med 2007; 357: 266-81.

67. Dirks-Naylor AJ, Lennon-Edwards S. The effects of vitamin D on skeletal muscle function and cellular signaling. J Steroid Biochem Mol Biol 2011; 125: 159-68.

68. Forli L, Halse J, Haug E, Bjortuft O, Vatn M, Kofstad J, Boe J. Vitamin D deficiency, bone mineral density and weight in patients with advanced pulmonary disease. J Intern Med 2004; 256: 56-62.

69. Vorrink SN, Kort HS, Troosters T, Lammers JW. Level of daily physical activity in individuals with COPD compared with healthy controls. Respir Res 2011; 12: 33.

70. Marie PJ, Kassem M. Extrinsic mechanisms involved in age-related defective bone formation. J Clin Endocrinol Metab 2011; 96: 600-9.

71. Pluijm SM, Koes B, De LC et al. A simple risk score for the assessment of absolute fracture risk in general practice based on two longitudinal studies. J Bone Miner Res 2009; 24: 768-74.

72. Howe TE, Shea B, Dawson $\mathrm{L}$ et al. Exercise for preventing and treating osteoporosis in postmenopausal women. Cochrane Database Syst Rev 2011; CD000333. 
73. De KD, Smulders E, Weerdesteyn V, Smits-Engelsman BC. Exercise interventions to reduce fall-related fractures and their risk factors in individuals with low bone density: a systematic review of randomized controlled trials. Osteoporos Int 2009; 20: 2111-25.

74. Nishimura $Y$, Nakata H, Tsutsumi M, Maeda H, Yokoyama M. Relationship between changes of bone mineral content and twelve-minute walking distance in men with chronic obstructive pulmonary disease: a longitudinal study. Intern Med 1997; 36: 450-3.

75. Ward KD, Klesges RC. A meta-analysis of the effects of cigarette smoking on bone mineral density. Calcif Tissue Int 2001; 68: 259-70.

76. Hirayama F, Lee AH, Binns CW, Oga T, Nishimura K. Alcohol consumption in patients with chronic obstructive pulmonary disease in Japan. Asia Pac J Public Health 2008; 20 Suppl: 87-94.

77. Fini M, Salamanna F, Veronesi F et al. Role of obesity, alcohol and smoking on bone health. Front Biosci (Elite Ed) 2012; 4: 2686-706.

78. Maurel DB, Boisseau N, Benhamou CL, Jaffre C. Alcohol and bone: review of dose effects and mechanisms. Osteoporos Int 2012; 23: 1-16.

79. Yoon V, Maalouf NM, Sakhaee K. The effects of smoking on bone metabolism. Osteoporos Int 2012; 23: 2081-92.

80. Tang BM, Eslick GD, Nowson C, Smith C, Bensoussan A. Use of calcium or calcium in combination with vitamin $D$ supplementation to prevent fractures and bone loss in people aged 50 years and older: a meta-analysis. Lancet 2007; 370: 657-66.

81. Bischoff-Ferrari HA, Willett WC, Wong JB, Giovannucci E, Dietrich T, Dawson-Hughes B. Fracture prevention with vitamin $D$ supplementation: a meta-analysis of randomized controlled trials. JAMA 2005; 293: 2257-64.

82. Avenell A, Gillespie WJ, Gillespie LD, O’Connell DL. Vitamin D and vitamin D analogues for preventing fractures associated with involutional and post-menopausal osteoporosis. Cochrane Database Syst Rev 2005; CD000227.

83. Bischoff-Ferrari HA, Dawson-Hughes B, Willett WC, Staehelin HB, Bazemore MG, Zee RY, Wong JB. Effect of Vitamin D on falls: a meta-analysis. JAMA 2004; 291: 1999-2006.

84. Bischoff-Ferrari HA, Dawson-Hughes B, Staehelin HB et al. Fall prevention with supplemental and active forms of vitamin D: a meta-analysis of randomised controlled trials. BMJ 2009; 339: b3692.

85. van den Bergh JP, Bours SP, van Geel TA, Geusens PP. Optimal use of vitamin D when treating osteoporosis. Curr Osteoporos Rep 2011; 9: 36-42.

86. Reid IR, Bolland MJ, Sambrook PN, Grey A. Calcium supplementation: balancing the cardiovascular risks. Maturitas 2011; 69: 289-95.

87. Papapoulos SE, Quandt SA, Liberman UA, Hochberg MC, Thompson DE. Meta-analysis of the efficacy of alendronate for the prevention of hip fractures in postmenopausal women. Osteoporos Int 2005; 16: 468-74.

88. Miller PD. Bisphosphonates for the prevention and treatment of corticosteroid-induced osteoporosis. Osteoporos Int 2001; 12 Suppl 3: S3-10.

89. Smith BJ, Laslett LL, Pile KD et al. Randomized controlled trial of alendronate in airways disease and low bone mineral density. Chron Respir Dis 2004; 1: 131-7.

90. Murad MH, Drake MT, Mullan RJ et al. Clinical review. Comparative effectiveness of drug treatments to prevent fragility fractures: a systematic review and network meta-analysis. J Clin Endocrinol Metab 2012; 97: 1871-80.

91. Saag KG, Shane E, Boonen S et al. Teriparatide or alendronate in glucocorticoid-induced osteoporosis. N Engl J Med 2007; 357: 2028-39.

92. Cummings SR, San MJ, McClung MR et al. Denosumab for prevention of fractures in postmenopausal women with osteoporosis. N Engl J Med 2009; 361: 756-65.

93. Weinstein RS. Clinical practice. Glucocorticoid-induced bone disease. N Engl J Med 2011; 365: 62-70.

94. Grossman JM, Gordon R, Ranganath VK et al. American College of Rheumatology 2010 recommendations for the prevention and treatment of glucocorticoid-induced osteoporosis. Arthritis Care Res (Hoboken) 2010; 62: 1515-26. 
95. Goldstein MF, Fallon JJ, Jr., Harning R. Chronic glucocorticoid therapy-induced osteoporosis in patients with obstructive lung disease. Chest 1999; 116: 1733-49. 



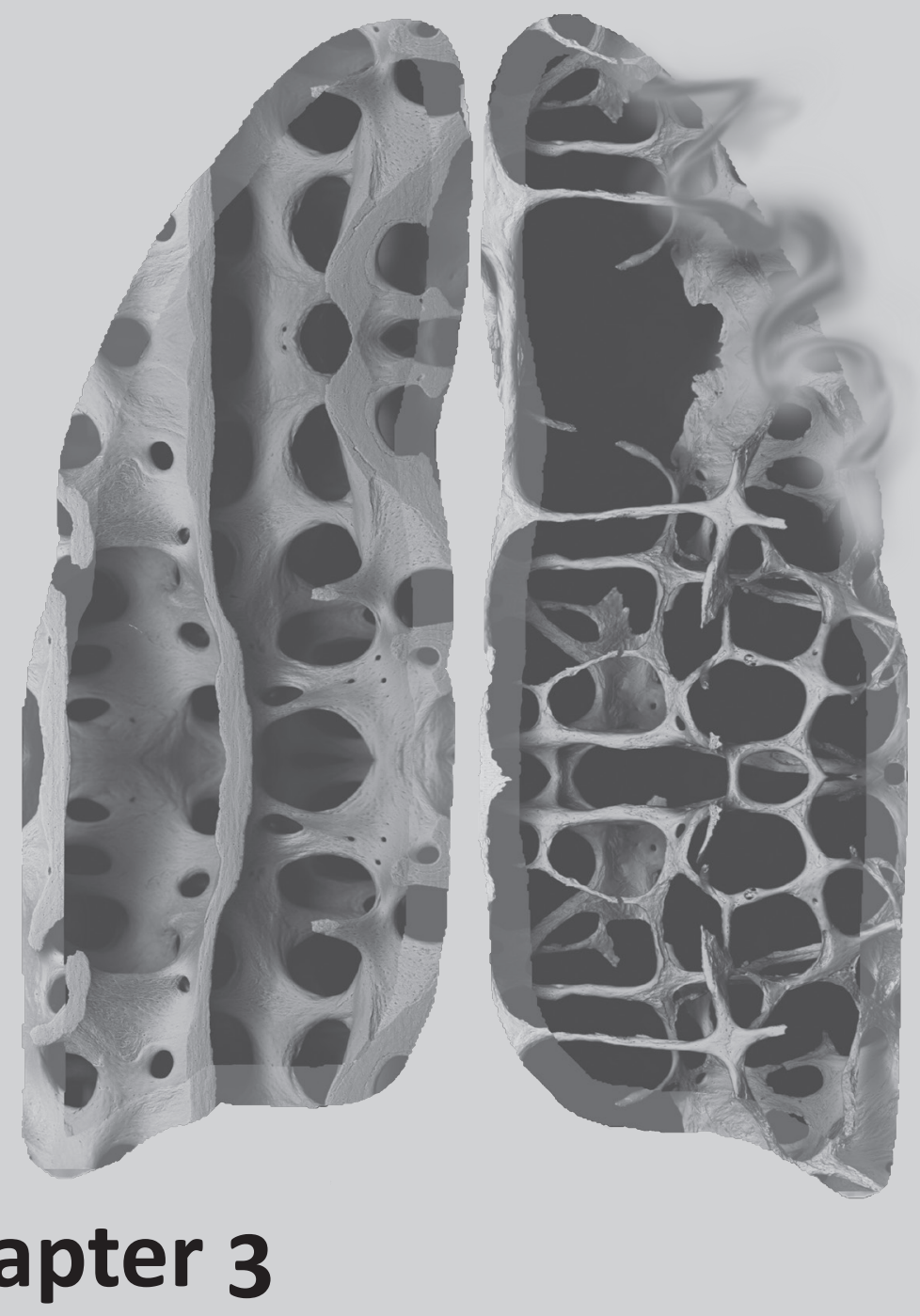

Vitamin D status is associated with bone mineral density and functional exercise capacity in patients with chronic obstructive pulmonary disease

Elisabeth A.P.M. Romme

Erica P.A. Rutten

Frank W.J.M. Smeenk

Paul P.C.A. Menheere

Emiel F.M. Wouters

Annals of Medicine 2013; 45: 91-6 


\section{ABSTRACT}

\section{Background}

Chronic obstructive pulmonary disease (COPD) is associated with several extrapulmonary effects that contribute to the severity of the disease. Vitamin $D$ is suggested to play a role in COPD and its related extrapulmonary effects.

\section{Aims}

To determine the prevalence of vitamin D deficiency and its relation with bone density, muscle strength and exercise capacity in patients with COPD.

\section{Methods}

Our cross-sectional study included patients with moderate to very severe COPD. We collected data on lung function, body composition, bone density, quadriceps muscle strength, 6-minute walking distance and plasma 25 -hydroxyvitamin $\mathrm{D}(25(\mathrm{OH}) \mathrm{D})$ concentration. Vitamin $\mathrm{D}$ deficiency was defined as plasma $25(\mathrm{OH}) \mathrm{D}$ concentration below $50 \mathrm{nmol} / \mathrm{L}$.

\section{Results}

In total, 151 COPD patients were included. Eighty-seven patients (58\%) had vitamin D deficiency. Plasma 25(OH)D concentration was positively associated with bone density $(p=0.005)$ and 6 -minute walking distance ( $p<0.001$ ) after adjustment for potential confounders. Plasma $25(\mathrm{OH})$ D concentration was not associated with quadriceps muscle strength.

\section{Conclusions}

The majority of COPD patients had vitamin D deficiency. Plasma 25(OH)D concentration was positively associated with bone density and exercise capacity. Intervention studies are necessary to determine whether vitamin $D$ supplementation is of benefit in the prevention or treatment of osteoporosis and poor exercise capacity in patients with COPD. 


\section{INTRODUCTION}

Chronic obstructive pulmonary disease (COPD) is primarily characterised by the presence of airflow limitation that is not fully reversible. ${ }^{1}$ However, COPD is also characterised by extrapulmonary effects that may contribute to the severity of the disease. ${ }^{2}$ Osteoporosis, impaired skeletal muscle strength and poor exercise capacity can be considered as extrapulmonary effects of COPD, as these are more frequently observed in patients with COPD than in age-matched controls..$^{3-5}$

Osteoporosis is characterised by low bone mineral density or micro-architectural changes resulting in impaired bone strength and hence increased fracture risk. ${ }^{6}$ Bone strength is influenced by the rate of bone remodelling and the balance between bone formation and resorption. Several factors, like systemic inflammation, use of oral and inhaled corticosteroids and vitamin $\mathrm{D}$ deficiency, have been suggested to interact with pathways of bone remodelling in patients with COPD. ${ }^{7}$

In healthy individuals the role of vitamin $D$ in bone health is well established. ${ }^{8}$ Vitamin $D$ is important in maintaining calcium homeostasis and subsequently mineralisation of bone. Indeed, in a randomised controlled trial with subjects aged $65-85$ years oral vitamin D supplementation reduced the number of fractures. ${ }^{9}$

Another COPD-related systemic effect is skeletal muscle dysfunction. ${ }^{4}$ Skeletal muscle dysfunction is an independent predictor of mortality in patients with COPD. ${ }^{\circ} \mathrm{It}$ is characterised by two related phenomena: net loss of muscle mass and malfunctioning of the muscle. ${ }^{11}$ Indeed, in patients with COPD reduced skeletal muscle mass has been related with impaired skeletal muscle strength. However, many more patho-physiological findings, such as physical inactivity, use of corticosteroids, abnormal protein turnover, systemic inflammation, vitamin $D$ deficiency and angiotensin converting enzyme and vitamin D receptor genotypes, have been related with skeletal muscle dysfunction.

Vitamin D is suggested to affect muscle strength and function by several processes, including calcium homeostasis, cell proliferation, cell differentiation, fibre size, prevention of fatty degeneration, protection against insulin resistance and arachidonic acid mobilisation. ${ }^{12}$ Indeed, vitamin D receptors were identified in human skeletal muscle tissue ${ }^{13}$ and a metaanalysis demonstrated that vitamin $\mathrm{D}$ supplementation reduced the risk of falling among older individuals. ${ }^{14}$

Nowadays, it is suggested that vitamin D plays an important role in COPD and its related systemic effects. ${ }^{15}$ Recent data showed that the prevalence of vitamin D deficiency was higher in patients with COPD than in smoking controls. ${ }^{16}$ Additionally, in patients with advanced pulmonary diseases waiting for lung transplantation vitamin $D$ deficiency was associated with reduced femur neck T-scores and a lower 6-minute walking distance. ${ }^{17,18}$ Moreover, in patients with COPD Fokl and Bsml polymorphisms of the vitamin D receptor gene were associated with quadriceps muscle strength. ${ }^{19}$ 
Based on these findings we hypothesised that vitamin D might play a role in COPD-related osteoporosis and skeletal muscle dysfunction. The aims of our cross-sectional study were to examine the prevalence of vitamin $D$ deficiency and its relation with bone mineral density, quadriceps muscle strength and functional exercise capacity in patients with COPD.

\section{SUBJECTS AND METHODS}

\section{Subjects}

Data were extracted from the records of 168 clinically stable patients with COPD who were evaluated at $\mathrm{CIRO}^{+}$, centre of expertise for chronic organ failure, in Horn (the Netherlands) between June and September 2009. The inclusion criteria were: Caucasian race, aged 40 years or older and moderate to very severe COPD according to the Global Initiative for Chronic Obstructive Lung Disease (GOLD) guidelines. ${ }^{1}$ In total, 151 patients fulfilled the inclusion criteria. Seventeen patients were excluded due to the following reasons: 1 patient was 37 years old; 4 patients had an $\mathrm{FEV}_{1} / \mathrm{FVC}$ ratio above $0.70 ; 7$ patients had mild COPD and in 5 patients no blood samples were collected. Because of the use of de-identified and pre-existing data, our retrospective study is institutional review board exempt.

\section{Measurements}

Before entering pulmonary rehabilitation, all patients were screened for disease related physiological problems. Medical Research Council (MRC) dyspnoea scale was used to assess dyspnoea perception. Daily vitamin D intake was assessed using a validated cross-check dietary history method and calculated using the Dutch Food Composition Database.

Pulmonary function measurements were performed with standardised equipment (Masterlab ${ }^{\circledR}$, Jaeger, Germany) according to the American Thoracic Society (ATS)/European Respiratory Society (ERS) guidelines. Forced expiratory volume in 1 second $\left(F E V_{1}\right)$ and forced vital capacity (FVC) were measured. The diffusing capacity of the lung $\left(D_{L} C O\right)$ was determined by the single breath carbon monoxide gas transfer method and expressed as percentage predicted of reference values.

Total body weight and height were measured to calculate body mass index (BMI). Fat free mass (FFM) was measured by using dual-energy X-ray absorptiometry (Lunar Prodigy system, GE Healthcare, Madison, USA). Furthermore, FFM index (FFMI) was calculated as FFM divided by height ${ }^{2}$.

Bone mineral density was measured at the hip and the lumbar spine (L1-L4) by using dualenergy X-ray absorptiometry. Diagnosis of osteoporosis was based on the lowest T-score of these locations and defined according to the World Health Organisation (osteoporosis: T-score $\leq-2.5$; osteopenia: T-score between -1.0 and -2.5; and normal bone tissue: T-score $\geq-1.0){ }^{6}$

Isometric quadriceps maximum voluntary contraction strength ( $Q M V C$ ) was measured using a Biodex dynamometer (Biodex Medical Corporation, Shirley, NY). The best of three efforts 
was used. The 6-minute walking distance (6MWD), including a practice walk, was determined to assess functional exercise capacity.

Plasma 25-hydroxyvitamin $\mathrm{D}(25 \mathrm{OH}) \mathrm{D})$ concentration was assayed by radioimmunoassay (Immunodiagnosticsystems, Boldon, UK) at the department of Clinical Chemistry of Maastricht University Medical Centre+, the Netherlands. The serum was extracted with acetonitrile in alkaline conditions to precipitate serum proteins. Next, the radioimmunoassay was performed using sheep anti-25(OH)D and $125 \mathrm{I} 25(\mathrm{OH}) \mathrm{D}$. Precipitation of the formed antigen-antibody complex was obtained by adding anti-sheep IgG coupled to cellulose.

Data on the optimal plasma 25(OH)D concentration for bone and muscle health are conflicting. A Dutch population-based study determined the threshold plasma 25(OH)D concentration with regard to parathyroid hormone, bone turnover markers, bone mineral density and physical performance in a subpopulation of the Longitudinal Aging Study Amsterdam. ${ }^{20}$ They showed a threshold of about $40 \mathrm{nmol} / \mathrm{L}$ for osteocalcin and deoxypyridinoline/creatinine, $50 \mathrm{nmol} / \mathrm{L}$ for bone mineral density and $60 \mathrm{nmol} / \mathrm{L}$ for physical performance. In our study plasma $25(\mathrm{OH}) \mathrm{D}$ concentrations below $50 \mathrm{nmol} / \mathrm{L}(20 \mathrm{ng} / \mathrm{mL})$ were classified as deficient. ${ }^{16,21,22}$

\section{Statistical analysis}

All statistical analyses were performed using Statistical Package for Social Sciences version 17.0 (SPSS Inc., Chicago, IL, USA). Two-sided p-values <0.05 were considered statistically significant. All data were first assessed for normal distribution.

Discrete variables were compared by the chi-square test and presented as percentages. Moreover, continuous variables were presented as mean \pm standard deviation (SD) and were compared by the standardised Student t-test.

Determinants of bone mineral density, quadriceps muscle strength and functional exercise capacity were assessed by standard multiple regression analyses (enter procedure). Covariates were based on the literature. Covariates used to assess determinants of the lowest T-score were gender, age, BMI, FEV $, 25(\mathrm{OH}) \mathrm{D}, 6 \mathrm{MWD}$ and corticosteroid use. . $^{3,6,7,23}$ Additionally, covariates used to assess determinants of quadriceps muscle strength and functional exercise capacity were gender, age, height, FFMI, FEV $, 25(\mathrm{OH}) \mathrm{D}, \mathrm{MRC}$ and $6 \mathrm{MWD}$ or QMVC. ${ }^{4,24}$ These covariates were included into the final multivariate regression analyses when significant at $p<0.10$ in the univariate regression analyses. Multicollinearity was assessed by Pearson Correlation, Tolerance and Variance Inflation Factor (VIF). We found no multicollinearity between variables (Pearson correlation $<0.70$, Tolerance $>0.2$ and VIF $<10$ ). 


\section{RESULTS}

\section{Characteristics and vitamin D status}

In total, 151 patients with moderate to very severe COPD entering pulmonary rehabilitation met the inclusion criteria. All data were collected before the patients started pulmonary rehabilitation. Thirty-four (22.5\%) patients had had rehabilitation previously.

Table 1 shows the patients' characteristics. Vitamin D deficiency was found in 87 patients (58\%). No differences were found in gender, age, vitamin D intake, use of oral or inhaled corticosteroids, arterial blood gases, BMI, FFMI, QMVC and bone mineral density between patients with and without vitamin D deficiency. Vitamin D deficient patients had a significantly lower FEV and FVC and performed worse on the 6MWD compared to patients with normal plasma $25(\mathrm{OH})$ D concentrations.

The prevalence of vitamin D deficiency was significantly different between the GOLD stages ( $p=0.001$ ). Vitamin D deficiency was found in $43 \%$ of GOLD stage II patients, $50 \%$ of GOLD stage III patients and $76 \%$ of GOLD stage IV patients. Figure 1 shows the plasma $25(\mathrm{OH}) \mathrm{D}$ concentrations among the GOLD stages.

\section{Determinants of bone mineral density and skeletal muscle function}

Table 2 and Table 3 show the univariate and multivariate analyses for bone mineral density. Gender, 6MWD and the use of corticosteroids were not associated with bone mineral density. In the multivariate analysis, age remained negatively associated with the lowest T-score and $\mathrm{BMI}$ and $25(\mathrm{OH}) \mathrm{D}$ remained positively associated with the lowest T-score. This model explained $22 \%$ of the variability of bone mineral density.

Table 4 and Table 5 show the univariate and multivariate regression analyses for quadriceps muscle strength and functional exercise capacity. In the multivariate analysis for muscle strength, age remained negatively associated with QMVC and height, FFMI and 6MWD remained positively associated with QMVC. This model explained $58 \%$ of the variability of muscle strength. In addition, in the multivariate analysis for functional exercise capacity, 25(OH)D and QMVC remained positively associated with 6MWD. This model explained $37 \%$ of the variability of functional exercise capacity.

Table 1. Patients' characteristics

\begin{tabular}{lcccc}
\hline & Total group & $\begin{array}{c}\text { Normal } \\
\text { vitamin } D \\
(\mathbf{n}=64)\end{array}$ & $\begin{array}{c}\text { Vitamin } \mathrm{C} \\
\text { deficiency } \\
(\mathbf{n}=\mathbf{8 7})\end{array}$ & p-value \\
\hline $25(\mathrm{OH}) \mathrm{D}, \mathrm{nmol} / \mathrm{L}$ & $49.0 \pm 16.1$ & $64.4 \pm 10.7$ & $37.7 \pm 7.9$ & $<0.001$ \\
Men, $\mathrm{n}(\%)$ & $88(58)$ & $39(61)$ & $48(55)$ & 0.479 \\
Age, years & $64.8 \pm 8.8$ & $64.2 \pm 9.1$ & $65.3 \pm 8.6$ & 0.479
\end{tabular}

Table 1 continues on next page 
Continuation of table 1

\begin{tabular}{|c|c|c|c|c|}
\hline $\mathrm{BMI}, \mathrm{kg} / \mathrm{m}^{2}$ & $25.1 \pm 5.4$ & $24.5 \pm 3.6$ & $25.6 \pm 6.4$ & 0.179 \\
\hline $\mathrm{FEV}_{1}, \%$ predicted & $45.8 \pm 16.6$ & $49.2 \pm 15.7$ & $43.3 \pm 16.8$ & 0.032 \\
\hline FVC, \% predicted & $94.7 \pm 20.6$ & $100.5 \pm 20.9$ & $90.5 \pm 19.4$ & 0.003 \\
\hline \multicolumn{5}{|l|}{ GOLD stage } \\
\hline II, \% & 28 & 38 & 21 & \multirow{3}{*}{0.001} \\
\hline III, \% & 36 & 42 & 31 & \\
\hline $\mathrm{IV}, \%$ & 36 & 20 & 48 & \\
\hline $\mathrm{D}_{\mathrm{L}} \mathrm{CO}, \%$ predicted & $53.2 \pm 19.7$ & $55.6 \pm 22.0$ & $51.4 \pm 17.7$ & 0.157 \\
\hline $\mathrm{PaO} 2, \mathrm{kPa}$ & $9.6 \pm 1.3$ & $9.7 \pm 1.4$ & $9.6 \pm 1.2$ & 0.415 \\
\hline $\mathrm{PaCO} 2, \mathrm{kPa}$ & $5.3 \pm 0.6$ & $5.2 \pm 0.6$ & $5.4 \pm 0.6$ & 0.099 \\
\hline MRC score & $3.5 \pm 1.1$ & $3.6 \pm 1.0$ & $3.5 \pm 1.1$ & 0.789 \\
\hline \multicolumn{5}{|l|}{ BMD } \\
\hline Lumbar spine, $\mathrm{g} / \mathrm{cm}^{2}$ & $1.08 \pm 0.20$ & $1.11 \pm 0.21$ & $1.06 \pm 0.19$ & \multirow{4}{*}{$\begin{array}{l}0.073 \\
0.168 \\
0.059\end{array}$} \\
\hline $\mathrm{Hip}, \mathrm{g} / \mathrm{cm}^{2}$ & $0.82 \pm 0.14$ & $0.84 \pm 0.15$ & $0.80 \pm 0.14$ & \\
\hline Total, $\mathrm{g} / \mathrm{cm}^{2}$ & $1.08 \pm 0.12$ & $1.10 \pm 0.11$ & $1.07 \pm 0.12$ & \\
\hline Lowest T-score & $-1.98 \pm 1.12$ & $-1.78 \pm 1.12$ & $-2.13 \pm 1.11$ & \\
\hline \multicolumn{5}{|l|}{ Bone classification } \\
\hline Normal bone, \% & 21 & 26 & 16 & \multirow{3}{*}{0.038} \\
\hline Osteopenia, \% & 41 & 44 & 39 & \\
\hline Osteoporosis, \% & 38 & 30 & 45 & \\
\hline \multicolumn{5}{|c|}{ Muscle mass and strength } \\
\hline FFMI, $\mathrm{kg} / \mathrm{m}^{2}$ & $17.2 \pm 2.3$ & $17.2 \pm 2.2$ & $17.2 \pm 2.3$ & 0.947 \\
\hline QMVC, kg & $28.6 \pm 9.8$ & $29.9 \pm 9.6$ & $27.4 \pm 9.9$ & 0.207 \\
\hline QMVC/FFM & $0.59 \pm 0.16$ & $0.62 \pm 0.15$ & $0.57 \pm 0.17$ & 0.159 \\
\hline $6 \mathrm{MWD}$, meters & $425.7 \pm 122.0$ & $477.7 \pm 124.2$ & $387.0 \pm 105.3$ & $<0.001$ \\
\hline Vitamin D intake, $\mu \mathrm{g}$ & $5.5 \pm 3.1$ & $5.6 \pm 3.4$ & $5.5 \pm 2.9$ & 0.843 \\
\hline \multicolumn{5}{|c|}{ Use of corticosteroids (\%) } \\
\hline Oral & 13.9 & 6.3 & 19.5 & 0.059 \\
\hline Inhaled & 88.1 & 87.5 & 88.5 & 0.897 \\
\hline
\end{tabular}

Results are presented as mean \pm standard deviation unless otherwise indicated. The $p$-values represent the differences between normal vitamin $\mathrm{D}$ and vitamin $\mathrm{D}$ deficiency.

$25(\mathrm{OH}) \mathrm{D}=25$-hydroxyvitamin $\mathrm{D} ; \mathrm{BMI}=$ body mass index; $\mathrm{FEV}_{1}=$ forced expiratory volume in the first second; $F V C=$ forced vital capacity; $D_{L} C O$ = diffusing capacity for carbon monoxide; $\mathrm{PaO} 2=$ partial pressure of oxygen in arterial blood; $\mathrm{PaCO} 2=$ partial pressure of carbon dioxide in arterial blood; $\mathrm{MRC}=$ medical research council dyspnoea scale, $\mathrm{BMD}=$ bone mineral density; $\mathrm{FFMI}$ = fat free mass index; $\mathrm{QMVC}=$ quadriceps maximum voluntary contraction strength; FFM = fat free mass; $6 \mathrm{MWD}=6$-minute walking distance. 


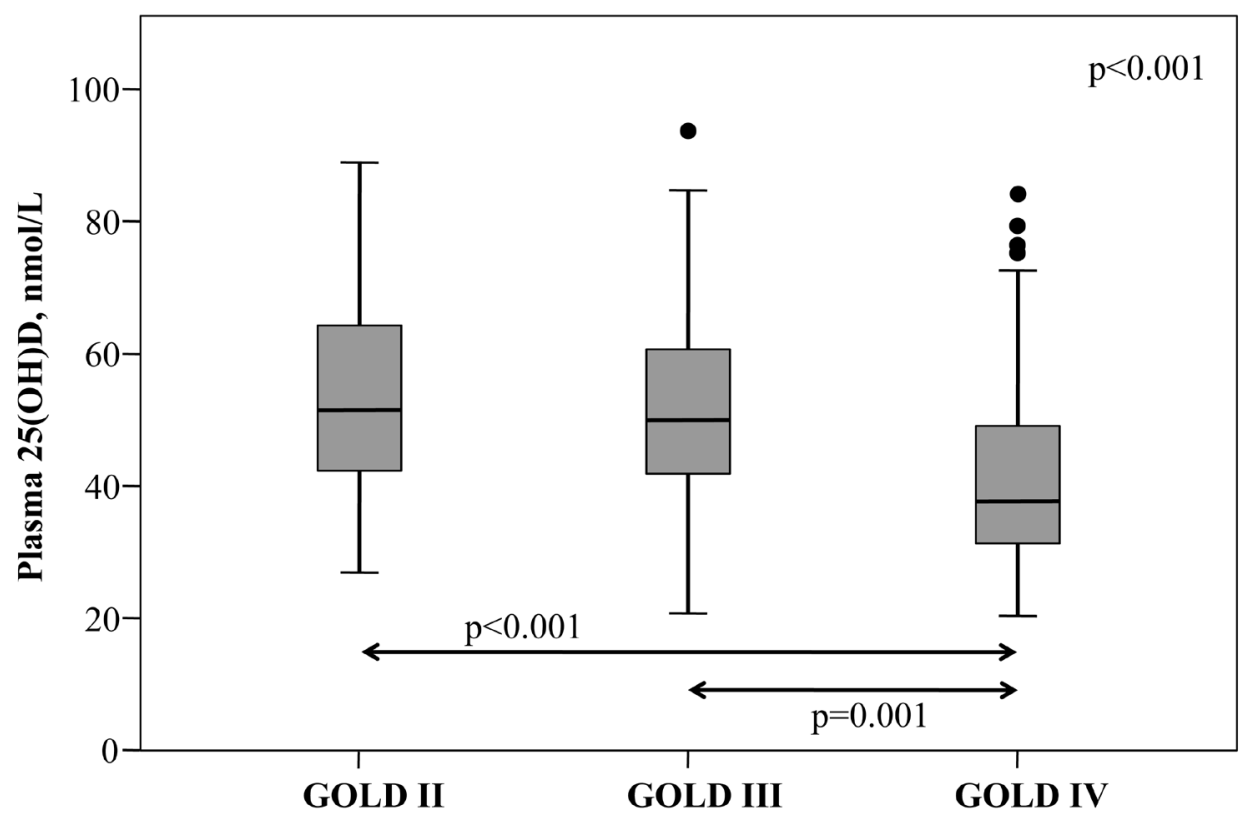

Figure 1. Plasma 25(OH)D concentrations among the GOLD stages

Table 2. Univariate regression analyses for bone mineral density (T-score)

\begin{tabular}{lccc}
\hline & B & 95\% $\mathbf{C l}$ & p-value \\
\hline Men & 0.188 & -0.177 to 0.553 & 0.311 \\
Age & -0.022 & -0.042 to -0.002 & 0.035 \\
BMI & 0.077 & 0.046 to 0.109 & $<0.001$ \\
FEV $_{1}$ & 0.011 & 0.000 to 0.022 & 0.044 \\
25(OH)D & 0.012 & 0.001 to 0.023 & 0.034 \\
6MWD & 0.001 & 0.000 to 0.003 & 0.109 \\
Oral corticosteroids & 0.032 & 0.000 to 0.000 & 0.697 \\
Inhaled corticosteroids & 0.032 & 0.000 to 0.000 & 0.696 \\
\hline
\end{tabular}

$\mathrm{BMI}=$ body mass index; $\mathrm{FEV}_{1}=$ forced expiratory volume in 1 second; $25(\mathrm{OH}) \mathrm{D}=$ 25-hydroxyvitamin $\mathrm{D}, 6 \mathrm{MWD}=6$-minute walking distance.

Table 3. Multivariate regression analyses for bone mineral density (T-score)

\begin{tabular}{lccc}
\hline & B & $95 \%$ Cl & p-value \\
\hline Age & -0.024 & -0.042 to -0.005 & 0.011 \\
BMI & 0.078 & 0.047 to 0.109 & $<0.001$ \\
FEV $_{1}$ & 0.005 & -0.005 to 0.015 & 0.360 \\
$25(\mathrm{OH}) D$ & 0.015 & 0.005 to 0.025 & 0.005 \\
\hline
\end{tabular}

$\mathrm{BMI}=$ body mass index; $\mathrm{FEV}_{1}=$ forced expiratory volume in 1 second; $25(\mathrm{OH}) \mathrm{D}=$ 25-hydroxyvitamin D. Adjusted R²: 0.22 


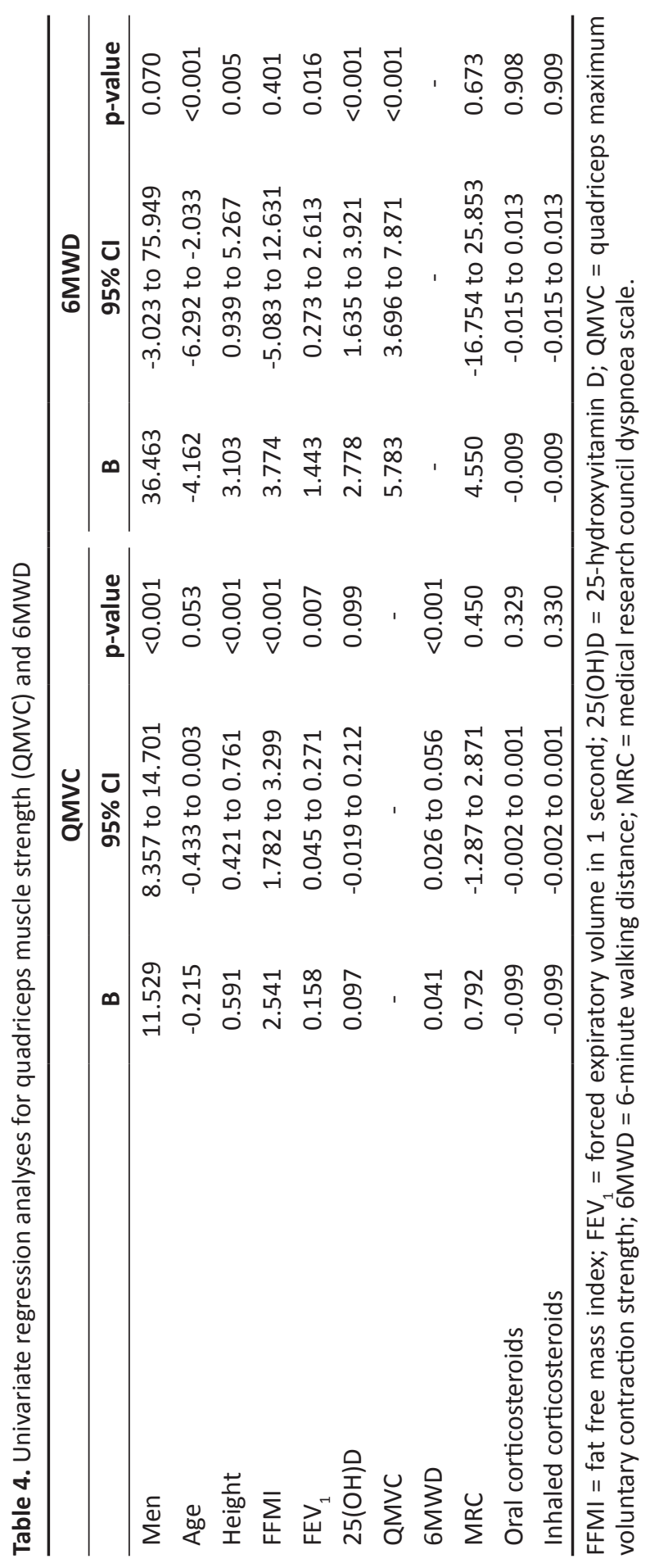




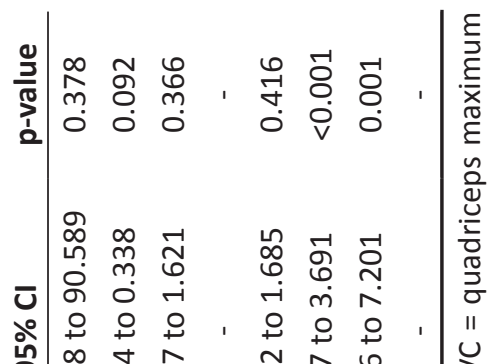

मूँ

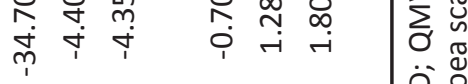

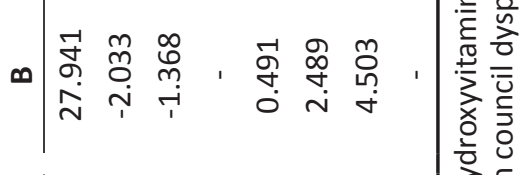

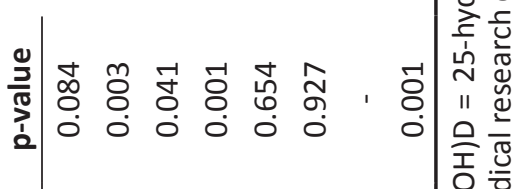

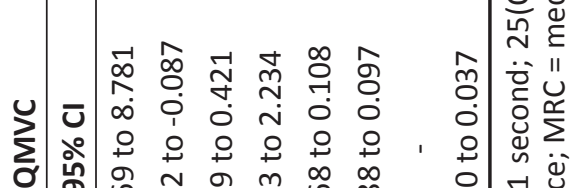

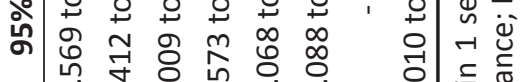

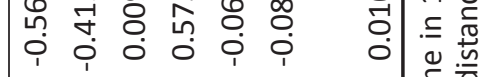

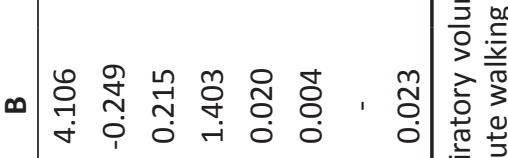

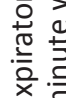

के

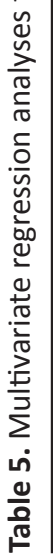

잉

일

$>-6$

岸

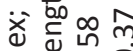

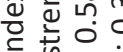

乞

है

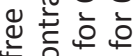

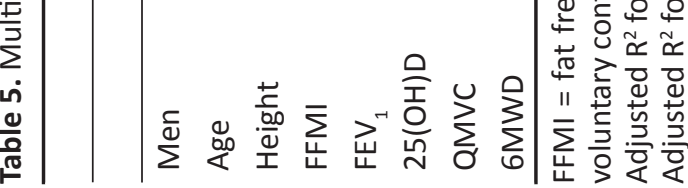




\section{DISCUSSION}

Our data demonstrated that vitamin $D$ deficiency was present in the majority of patients with COPD entering pulmonary rehabilitation. Additionally, after adjustment for potential confounders plasma $25(\mathrm{OH}) \mathrm{D}$ concentration was positively associated with bone mineral density and functional exercise capacity. However, plasma $25(\mathrm{OH}) \mathrm{D}$ concentration was not independently associated with quadriceps muscle strength. Based on these findings we suggest there might be a link between vitamin D and COPD-related osteoporosis and poor exercise capacity.

Although all blood samples were collected in summer, vitamin D deficiency was found in the majority of COPD patients (58\%). Vitamin D deficiency was found in $43 \%$ of GOLD stage II, $50 \%$ of GOLD stage III and $76 \%$ of GOLD stage IV COPD patients. These data are in line with data collected in Belgium during all seasons by Janssens and colleagues. ${ }^{16}$ They found vitamin D deficiency in $47 \%$ of GOLD stage II, $60 \%$ of GOLD stage III and $77 \%$ of GOLD stage IV COPD patients. Moreover, the prevalence of vitamin $D$ deficiency seems to be higher in our COPD cohort compared with the general Dutch population. In the Hoorn Study, a Dutch population-based cohort study, the prevalence of vitamin D deficiency ( $<50 \mathrm{nmol} / \mathrm{L}$ ) was $34 \%$ in summer and $51 \%$ in winter. ${ }^{25}$ In the Longitudinal Aging Study Amsterdam the prevalence of vitamin D deficiency (<50 nmol/L) was $48 \% .^{20}$

Our data showed that COPD patients with vitamin D deficiency had a significantly lower FEV and FVC than COPD patients with normal plasma 25(OH)D concentrations. Additionally, a large study of the general population demonstrated a strong relationship between plasma $25(\mathrm{OH}) \mathrm{D}$ concentration and pulmonary function. ${ }^{26}$ This relationship even remained after adjustment for the degree of leisure time physical activity and vitamin D intake. Moreover, in animal models vitamin D deficiency caused deficits in lung function ${ }^{27}$ and the rs7041 variant in the vitamin $\mathrm{D}$ binding gene was associated with the presence of COPD. ${ }^{16}$

Although it is suggested that vitamin D influences lung function, the mechanism is still unknown. However, some mechanisms have been suggested. First, vitamin D deficiency might be related to decreased pulmonary function due to thoracic vertebral fractures. Second, vitamin D deficiency has been suggested to result in altered host defense of the lung with subsequent growth of an abnormal flora that triggers inflammation. Hence, acute exacerbations of COPD are an important cause of hospitalisation and lead to a faster decline in lung function. Third, vitamin $D$ is suggested to have an effect on the extracellular matrix homeostasis within the lung resulting in the development of COPD. ${ }^{28}$

Furthermore, plasma 25(OH)D concentration was independently associated with bone mineral density. Førli and colleagues ${ }^{17}$ demonstrated that vitamin D deficiency was associated with reduced femur neck T-scores in underweight patients with end-stage pulmonary diseases waiting for lung transplantation. However, Franco and colleagues ${ }^{22}$ did not confirm this association in a small group $(n=49)$ of postmenopausal women and men with COPD. 
In healthy subjects it is well established that vitamin $\mathrm{D}$ is critical for bone health. A low plasma $25(\mathrm{OH}) \mathrm{D}$ concentration is associated with decreased intestinal calcium absorption causing compensatory increased parathyroid hormone concentrations. Additionally, parathyroid hormone, which has been identified as a determinant of osteoporosis in patients with COPD, ${ }^{29}$ activates osteoblasts which stimulate the transformation of pre-osteoclasts into mature osteoclasts. Mature osteoclasts dissolve the mineralised collagen matrix in bone causing osteopenia and osteoporosis. ${ }^{21}$

Besides low plasma 25(OH)D concentration, more patho-physiological mechanisms have been described to interact with pathways of bone remodelling in patients with COPD. Our data demonstrated that the prevalence of osteoporosis was still high (30\%) in patients with normal plasma $25(\mathrm{OH}) \mathrm{D}$ concentrations. This finding suggests that more factors besides plasma $25(\mathrm{OH}) \mathrm{D}$ concentration correlate with bone mineral density. Indeed, in line with previous data, ${ }^{3,23}$ we showed that older age, lower BMI and lower FEV ${ }_{1}$ were associated with reduced bone mineral density. However, many more factors, such as systemic inflammation, genetic background, smoking, physical inactivity, use of oral or inhaled corticosteroids and the presence of emphysema, have been associated with reduced bone mineral density. ${ }^{7}$

Nowadays, it is assumed that vitamin D has a role in skeletal muscle health. Recently, a review stated that vitamin $D$ affects muscle strength and function by several processes, including calcium homeostasis, cell proliferation, cell differentiation, fibre size, prevention of fatty degeneration, protection against insulin resistance and arachidonic acid mobilisation. ${ }^{12}$

In line with previous data in patients with end-stage pulmonary diseases, ${ }^{18}$ we showed that plasma $25(\mathrm{OH}) \mathrm{D}$ concentration was positively associated with walking distance after

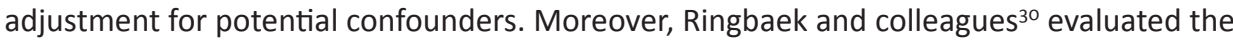
influence of vitamin D on the endurance shuttle walk test in 311 outpatients with COPD who participated in pulmonary rehabilitation. They demonstrated that lower plasma $25(\mathrm{OH}) \mathrm{D}$ concentrations were associated with smaller improvements in the endurance shuttle walk test.

Research on the relationship between plasma 25(OH)D concentration and skeletal muscle strength is scarce in patients with COPD. Our data showed no association between plasma $25(\mathrm{OH}) \mathrm{D}$ concentration and quadriceps muscle strength. In addition, Førli and colleagues ${ }^{18}$ demonstrated that plasma $25(\mathrm{OH}) \mathrm{D}$ concentration was not associated with hand grip strength after adjustment for potential confounders in patients with end-stage pulmonary diseases.

In healthy subjects, cross-sectional data on the relationship between vitamin D and muscle function are conflicting. ${ }^{31-34}$ This is partly due to variances in subjects studied and methods used. Recently, a meta-analysis demonstrated that vitamin D supplementation had a positive effect on muscle strength in subjects with plasma 25(OH)D concentrations below $25 \mathrm{nmol} / \mathrm{L}$ and no effect in subjects with plasma $25(\mathrm{OH}) \mathrm{D}$ concentrations above $25 \mathrm{nmol} / \mathrm{L} .{ }^{35}$ However, 
well-designed randomised controlled trials on the effect of vitamin D supplementation on muscle fibre composition, strength and exercise capacity are still lacking.

Some methodological considerations should be mentioned. Primarily, there could be a selection bias due to the inclusion of patients who were referred to pulmonary rehabilitation. However, the included COPD patients represented different stages of disease severity. In addition, a comparable prevalence of vitamin D deficiency was found in COPD patients recruited at a university hospital in Belgium. ${ }^{16}$ Secondly, no causal relationship could be established due to the cross-sectional design of the study. Thirdly, we did not include a healthy control group.

The strengths of our study are that all patients were included in summer, well-characterised and diagnosed with COPD according to the GOLD guidelines. By contrast, previous studies on the role of vitamin $D$ in osteoporosis and muscle dysfunction included patients with several different pulmonary diseases. ${ }^{17,18}$

Although randomised controlled trials on vitamin $\mathrm{D}$ supplementation in patients with COPD are lacking, we advise chest physicians to be alert for vitamin D deficiency in patients with COPD. It is already known that osteoporosis and muscle dysfunction influence morbidity and mortality in patients with COPD., ${ }^{710}$ Our data demonstrated that the prevalence of vitamin $D$ deficiency is high in COPD and that vitamin $D$ status is associated with bone mineral density and functional exercise capacity, suggesting a link between vitamin D and COPD-related osteoporosis and muscle dysfunction. Indeed, in healthy individuals randomised controlled trials have already demonstrated beneficial effects of vitamin D supplementation on bone health and skeletal muscle function. However, further research on the role of vitamin D in bone and muscle health in patients with COPD is warranted.

To conclude, the majority of patients with COPD entering pulmonary rehabilitation had vitamin D deficiency. Additionally, vitamin $\mathrm{D}$ status was positively associated with bone mineral density and functional exercise capacity as measured by 6MWD. In future, intervention studies will be necessary to determine whether vitamin D supplementation might be of benefit in the prevention or treatment of osteoporosis and poor exercise capacity in patients with COPD. 


\section{REFERENCES}

1. Rabe KF, Hurd S, Anzueto A et al. Global strategy for the diagnosis, management, and prevention of chronic obstructive pulmonary disease: GOLD executive summary. Am J Respir Crit Care Med 2007; 176: 532-55.

2. Barnes PJ, Celli BR. Systemic manifestations and comorbidities of COPD. Eur Respir J 2009; 33: 1165-85.

3. Graat-Verboom L, Wouters EF, Smeenk FW, van den Borne BE, Lunde R, Spruit MA. Current status of research on osteoporosis in COPD: a systematic review. Eur Respir J 2009; 34: 209-18.

4. Seymour JM, Spruit MA, Hopkinson NS et al. The prevalence of quadriceps weakness in COPD and the relationship with disease severity. Eur Respir J 2010; 36: 81-8.

5. Bossenbroek L, de Greef MH, Wempe JB, Krijnen WP, Ten Hacken NH. Daily physical activity in patients with chronic obstructive pulmonary disease: a systematic review. COPD 2011; 8: 306-19.

6. World Health Organization. Prevention and Management of Osteoporosis; report of a WHO scientific group [updated 2003; cited 2013 August]. Available from: http://whqlibdoc.who.int/trs/WHO_TRS_921. pdf.

7. Lehouck A, Boonen S, Decramer M, Janssens W. COPD, Bone Metabolism, and Osteoporosis. Chest 2011; 139: 648-57.

8. Vieth R. The role of vitamin D in the prevention of osteoporosis. Ann Med 2005; 37: 278-85.

9. Trivedi DP, Doll R, Khaw KT. Effect of four monthly oral vitamin D3 (cholecalciferol) supplementation on fractures and mortality in men and women living in the community: randomised double blind controlled trial. BMJ 2003; 326: 469.

10. Schols AM, Broekhuizen R, Weling-Scheepers CA, Wouters EF. Body composition and mortality in chronic obstructive pulmonary disease. Am J Clin Nutr 2005; 82: 53-9.

11. Rabinovich RA, Vilaro J. Structural and functional changes of peripheral muscles in chronic obstructive pulmonary disease patients. Curr Opin Pulm Med 2010; 16: 123-33.

12. Dirks-Naylor AJ, Lennon-Edwards $S$. The effects of vitamin D on skeletal muscle function and cellular signaling. J Steroid Biochem Mol Biol 2011; 125: 159-68.

13. Costa EM, Blau HM, Feldman D. 1,25-dihydroxyvitamin D3 receptors and hormonal responses in cloned human skeletal muscle cells. Endocrinology 1986; 119: 2214-20.

14. Bischoff-Ferrari HA, Dawson-Hughes B, Staehelin HB et al. Fall prevention with supplemental and active forms of vitamin D: a meta-analysis of randomised controlled trials. BMJ 2009; 339: b3692.

15. Janssens W, Lehouck A, Carremans C, Bouillon R, Mathieu C, Decramer M. Vitamin D beyond bones in chronic obstructive pulmonary disease: time to act. Am J Respir Crit Care Med 2009; 179: 630-6.

16. Janssens $\mathrm{W}$, Bouillon R, Claes B et al. Vitamin D deficiency is highly prevalent in COPD and correlates with variants in the vitamin D-binding gene. Thorax 2010; 65: 215-20.

17. Forli L, Halse J, Haug E, Bjortuft O, Vatn M, Kofstad J, Boe J. Vitamin D deficiency, bone mineral density and weight in patients with advanced pulmonary disease. J Intern Med 2004; 256: 56-62.

18. Forli L, Bjortuft O, Boe J. Vitamin D status in relation to nutritional depletion and muscle function in patients with advanced pulmonary disease. Exp Lung Res 2009; 35: 524-38.

19. Hopkinson NS, Li KW, Kehoe A et al. Vitamin D receptor genotypes influence quadriceps strength in chronic obstructive pulmonary disease. Am J Clin Nutr 2008; 87: 385-90.

20. Kuchuk NO, Pluijm SM, van Schoor NM, Looman CW, Smit JH, Lips P. Relationships of serum 25-hydroxyvitamin $D$ to bone mineral density and serum parathyroid hormone and markers of bone turnover in older persons. J Clin Endocrinol Metab 2009; 94: 1244-50.

21. Holick MF. Vitamin D deficiency. N Engl J Med 2007; 357: 266-81.

22. Franco CB, Paz-Filho G, Gomes PE, Nascimento VB, Kulak CA, Boguszewski CL, Borba VZ. Chronic obstructive pulmonary disease is associated with osteoporosis and low levels of vitamin D. Osteoporos Int 2009; 20: 1881-7. 
23. Graat-Verboom L, Spruit MA, van den Borne BE, Smeenk FW, Martens EJ, Lunde R, Wouters EF. Correlates of osteoporosis in chronic obstructive pulmonary disease: An underestimated systemic component. Respir Med 2009; 103: 1143-51.

24. Spruit MA, Watkins ML, Edwards LD et al. Determinants of poor 6-min walking distance in patients with COPD: the ECLIPSE cohort. Respir Med 2010; 104: 849-57.

25. van Dam RM, Snijder MB, Dekker JM, Stehouwer CD, Bouter LM, Heine RJ, Lips P. Potentially modifiable determinants of vitamin D status in an older population in the Netherlands: the Hoorn Study. Am J Clin Nutr 2007; 85: 755-61.

26. Black PN, Scragg R. Relationship between serum 25-hydroxyvitamin d and pulmonary function in the third national health and nutrition examination survey. Chest 2005; 128: 3792-8.

27. Zosky GR, Berry LJ, Elliot JG, James AL, Gorman S, Hart PH. Vitamin D deficiency causes deficits in lung function and alters lung structure. Am J Respir Crit Care Med 2011; 183: 1336-43.

28. Herr C, Greulich T, Koczulla RA et al. The role of vitamin D in pulmonary disease: COPD, asthma, infection, and cancer. Respir Res 2011; 12: 31.

29. Graat-Verboom L, van den Borne BE, Smeenk FW, Spruit MA, Wouters EF. Osteoporosis in COPD outpatients based on bone mineral density and vertebral fractures. J Bone Miner Res 2011; 26: 561-8.

30. Ringbaek T, Martinez G, Durakovic A, Thogersen J, Midjord AK, Jensen JE, Lange P. Vitamin d status in patients with chronic obstructive pulmonary disease who participate in pulmonary rehabilitation. $J$ Cardiopulm Rehabil Prev 2011; 31: 261-7.

31. Marantes I, Achenbach SJ, Atkinson EJ, Khosla S, Melton LJ, III, Amin S. Is vitamin D a determinant of muscle mass and strength? J Bone Miner Res 2011; 26: 2860-71.

32. Ceglia L, Chiu GR, Harris SS, Araujo AB. Serum 25-hydroxyvitamin D concentration and physical function in adult men. Clin Endocrinol (Oxf) 2011; 74: 370-6.

33. Houston DK, Cesari M, Ferrucci L et al. Association between vitamin D status and physical performance: the InCHIANTI study. J Gerontol A Biol Sci Med Sci 2007; 62: 440-6.

34. Gerdhem P, Ringsberg KA, Obrant KJ, Akesson K. Association between 25-hydroxy vitamin D levels, physical activity, muscle strength and fractures in the prospective population-based OPRA Study of Elderly Women. Osteoporos Int 2005; 16: 1425-31.

35. Stockton KA, Mengersen K, Paratz JD, Kandiah D, Bennell KL. Effect of vitamin D supplementation on muscle strength: a systematic review and meta-analysis. Osteoporos Int 2011; 22: 859-71. 



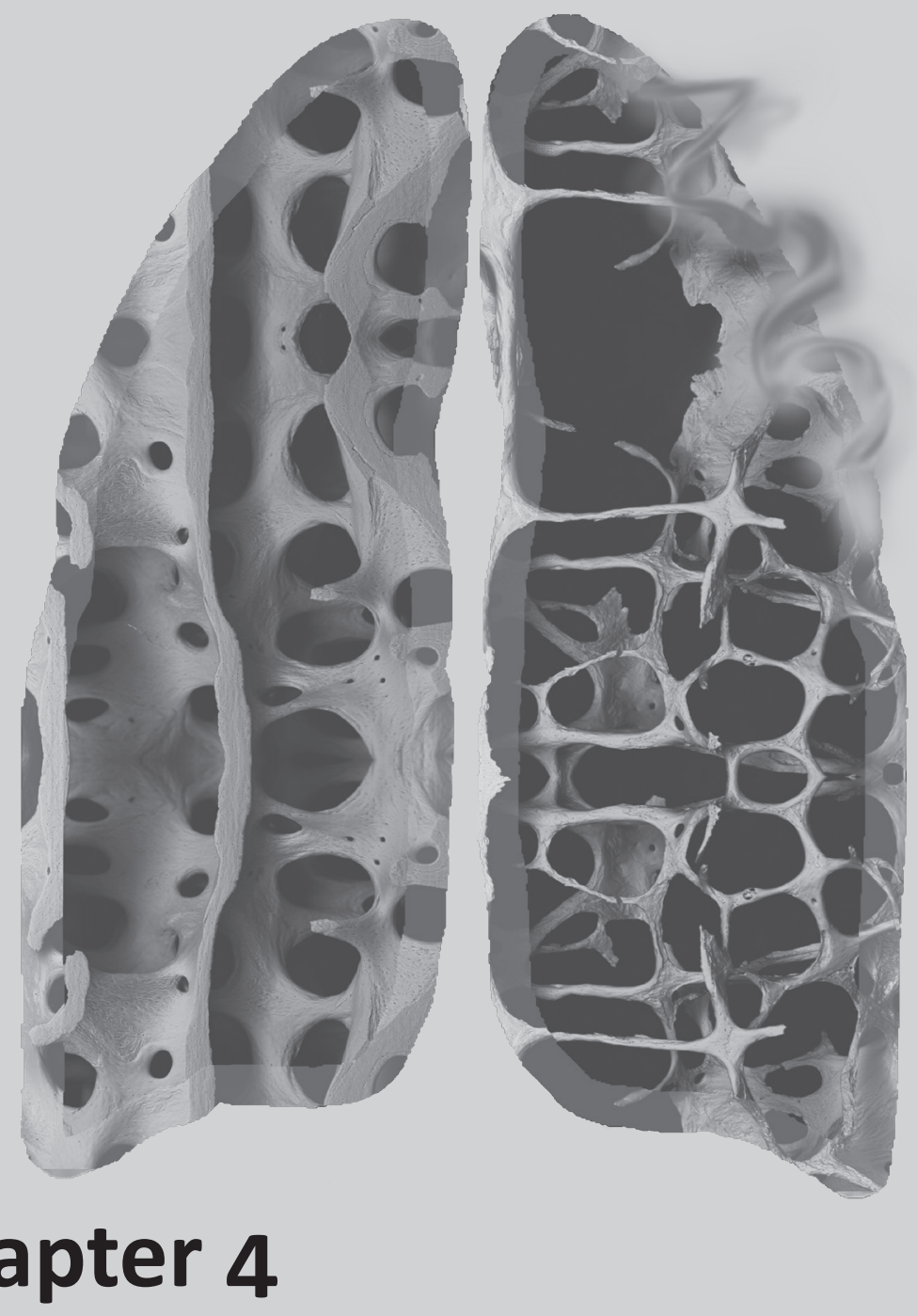

Bone attenuation on routine chest $\mathrm{CT}$ correlates with bone mineral density on DXA in patients with chronic obstructive pulmonary disease

Elisabeth A.P.M. Romme

John T. Murchinson

Kee F. Phang

Frits H. Jansen

Erica P.A. Rutten
Emiel F.M Wouters

Frank W.J.M. Smeenk

Edwin J.R. Van Beek

William MacNee

Journal of Bone and Mineral Research 2012; 27: 2338-43 


\begin{abstract}
COPD, although primarily a disease of the lungs, is associated with extra pulmonary effects such as muscle weakness and osteoporosis. Fractures due to osteoporosis cause significant morbidity and mortality, particularly in patients with COPD. To prevent osteoporotic fractures, it is important to diagnose osteoporosis in an early stage and to start anti-osteoporotic therapy in at risk patients. Because routine chest Computed Tomography (CT) is increasingly used to assess the extent of emphysema and airways disease in patients with COPD, we investigated whether simple attenuation measurement of the thoracic spine on routine chest CT may provide useful information on bone health in patients with COPD. Fifty-eight patients with moderate to very severe COPD were included in our study. The average attenuation of thoracic vertebrae 4, 7 and 10 on chest CT was correlated with the lowest bone mineral density (BMD) of the hip and lumbar spine (L1 to L4) on dual-energy X-ray absorptiometry (DXA) in patients with COPD. The inter and intra-observer variabilities of the attenuation measurements were low as shown by Bland Altman plots. Pearson's correlation coefficient between the average attenuation of the three thoracic vertebrae and the lowest BMD of the hip and lumbar spine was high $(r=0.827, p<0.001)$. A ROC analysis of the area under the curve for osteoporosis was 0.969 ( $p<0.001)$ corresponding to an attenuation threshold of $147 \mathrm{HU}$. In conclusion, our data demonstrated that bone attenuation measured on routine chest CT correlated strongly with BMD assessed on DXA in patients with COPD. Routine chest CT may provide useful information on bone health in patients with COPD.
\end{abstract}




\section{INTRODUCTION}

Chronic obstructive pulmonary disease (COPD), a condition that primarily affects the lungs, is characterized by airflow limitation that is not fully reversible. ${ }^{1}$ In addition to its pulmonary effects, COPD is characterized by extra pulmonary effects such as muscle weakness, ${ }^{2}$ arterial stiffness $^{3}$ and osteoporosis ${ }^{4}$ that contribute to the severity of the disease. ${ }^{5}$

Osteoporosis is a skeletal disease that is characterized by impaired bone strength due to low bone mineral density (BMD) or micro architectural deterioration. ${ }^{6}$ Patients with osteoporosis are at increased risk of fractures resulting in significant morbidity and mortality, particularly in patients with COPD where vertebral fractures further compromise pulmonary function. ${ }^{7,8}$ The current gold standard to diagnose osteoporosis is dual-energy X-ray absorptiometry (DXA). Indeed, the World Health Organization $(\mathrm{WHO})^{6}$ and International Society for Clinical Densitometry ${ }^{9}$ recommend a diagnosis of osteoporosis based on the lowest T-score of the hip or the lumbar spine on DXA. This method is also recommended in patients with COPD. ${ }^{10}$

More recently several other methods to measure BMD have been described. A wellestablished method is quantitative computed tomography (QCT). ${ }^{11}$ With standard QCT the lumbar vertebrae are scanned with a mineral reference phantom in the same field. Consequently, the attenuation of the lumbar vertebrae is measured in Hounsfield Units (HU) and transformed into bone mineral equivalents $\left(\mathrm{mg} / \mathrm{cm}^{3}\right)$ using standardized software. ${ }^{11}$

In addition to standard QCT, routine helical Computed Tomography (CT) has been suggested to be useful for BMD measurement. In vitro and in vivo data showed that BMD on routine CT correlated strongly with BMD on standard QCT. ${ }^{12}$ However, in this study a reference phantom was used in order to standardize measurements and to obtain a mineral reference while with routine CT a phantom is usually absent. More recently Miyabara and colleagues ${ }^{13}$ demonstrated a strong correlation between BMD measurements of the thoracic spine on coronary CT with or without a reference phantom in menopausal women. In addition, Pickhardt and colleagues ${ }^{14}$ compared simple attenuation measurement on CT colonography without a reference phantom with BMD measurement on DXA in adults aged 50 years and older. They demonstrated that simple attenuation measurement on CT colonography was effective for osteoporosis screening.

With this in mind we hypothesized that simple attenuation measurement of the thoracic spine on routine chest $\mathrm{CT}$, that are increasingly used to assess the extent of emphysema and airways disease in patients with COPD, may provide useful information on bone health in patients with COPD. Therefore, we measured the average attenuation of thoracic vertebrae 4, 7 and 10 on chest CT and correlated these measurements with the lowest BMD of the hip and lumbar spine (L1 to L4) on DXA in patients with COPD. 


\section{MATERIALS AND METHODS}

\section{Subjects}

Patients with moderate to very severe COPD who were enrolled in a clinical trial at the Catharina Hospital (Eindhoven, the Netherlands) between February 2010 and September 2011 were included in our study. The purpose of the clinical trial was to investigate the pathophysiologic mechanism of osteoporosis in COPD. Since patients with osteopenia were excluded in this clinical trial, no patients with osteopenia were included in our study. All patients underwent both CT and DXA in order to assess the extent of emphysema and to measure BMD.

The inclusion criteria for the clinical trial were: Caucasian race, men or postmenopausal women aged 50 years or older, moderate to very severe COPD diagnosed according to the Global Initiative for Chronic Obstructive Lung Disease (GOLD) guidelines. ${ }^{1}$ The exclusion criteria were: malignancy in the last 5 years, hypo- or hyperthyroidism, hypogonadism, inflammatory bowel disease, auto-immune diseases, alcohol abuse, non-vertebral fracture in the last 12 months and pulmonary diseases other than COPD such as pulmonary fibrosis or bronchiectasis. Use of oral corticosteroids or antibiotics 4 weeks before study enrollment and use of anti-osteoporotic medication such as bisphosphonates, calcium or vitamin D supplementation were prohibited.

The study was approved by the medical ethical committee of the Catharina Hospital and registered at www.clinicaltrials.gov (NCT01067248). All patients gave written informed consent.

\section{Measurements}

Forced expiratory volume in 1 second $\left(\mathrm{FEV}_{1}\right)$ and forced vital capacity (FVC) were measured using standardized equipment (MasterScreen ${ }^{\mathrm{TM}}$ Body, Carefusion, San Diego, California, USA) according to the American Thoracic Society (ATS)/European Respiratory Society (ERS) guidelines. ${ }^{15}$ Total body weight and height were measured to calculate body mass index (BMI).

BMD of the lumbar spine ( $L 1$ to L4) and hip were measured using a Delphi upgraded to a discovery W (S/N70991) DXA scanner (Tromp Medical Engineering BV, Castricum, the Netherlands). Diagnosis of osteoporosis was based on the lowest T-score of these locations and defined according to the WHO criteria (osteoporosis: T-score $\leq-2.5$; osteopenia: T-score $<-1.0$ and >-2.5; and normal bone tissue: T-score $\geq-1.0){ }^{6}$

Chest CT examinations were performed using a single-energy 256 multidetector row scanner (Philips Brilliance intelligent CT, Philips Healthcare, Eindhoven, the Netherlands) with technical parameters of $120 \mathrm{kVp}, 350-\mathrm{mm}$ field of view, $2.5 \mathrm{~mm}$ slice thickness and ECG gated. The scanner was calibrated daily to ensure accurate $\mathrm{CT}$ attenuation numbers. All patients were scanned in supine position during deep inspiration without the use of contrast 
media. CT images were stored by an electronic Picture Archiving and Communication System (PACS) and assessed using VOXAR 3D version 16.0 software. Attenuation of thoracic vertebrae 4, 7 and 10 ( $T_{4}, T_{7}$ and $\left.T_{10}\right)$ were measured using a modification of a method described previously. ${ }^{16}$ The most central section of the vertebra was selected by inspecting the sagittal and coronal reformats. In this section, the mean attenuation was determined by placing a circular region of interest (ROI) in the central part of the vertebral body avoiding the basivertebral venous plexus posteriorly and the cortical bone. All ROIs were placed manually by one of the authors (EAR) who was blinded to the patients' personal details, history and BMD. The average attenuation of T4, T7 and T10 was calculated and expressed as Hounsfield Units (HU).

In order to investigate whether the size of the ROI influences the mean attenuation, we used ROIs with different size areas (ROI 1: T4, T7 and T10 $50 \mathrm{~mm}^{2}$ area; ROI 2: T4, T7 and T1O $100 \mathrm{~mm}^{2}$ area; ROI 3: T4 $100 \mathrm{~mm}^{2}$ area and T7 and T10 $200 \mathrm{~mm}^{2}$ area). In addition, the CT images of a random sample of 20 patients were assessed by two observers (EAR and KF) and assessed by one observer (EAR) twice to calculate the inter and intra-observer variabilities of the attenuation measurements on chest CT.

\section{Statistical analysis}

Data were assessed for normal distribution. Discrete variables were presented as percentages and continuous variables were presented as mean \pm standard deviation (SD). Continuous variables were compared by the two-tailed Student $t$-test.

The correlations between attenuation measurements using ROls of different size areas were assessed by calculating intraclass correlation coefficients. Inter and intra-observer variabilities of the attenuation measurements were determined by using the method as described by Bland and Altman. ${ }^{17}$ The limits of agreement were determined by plotting the mean measurement difference \pm 2 standard deviations (SD). The correlation between CTmeasured bone attenuation and DXA scan BMD was calculated using Pearson's correlation coefficient. A regression equation was calculated using linear regression. The diagnostic ability of CT-measured bone attenuation for osteoporosis was assessed using receiver operating statistic curve (ROC) analysis.

All statistical analyses were performed using the Statistical Package for Social Sciences version 17.0 (SPSS Inc., Chicago, IL, USA). Two-sided p-values $<0.05$ were considered statistically significant.

\section{RESULTS}

Fifty-eight patients with moderate to very severe COPD were included. The mean time interval between chest CT and DXA was 40.6 days. Table 1 shows the patients' demographics and characteristics. Twenty-seven (47\%) COPD patients had osteoporosis according to DXA measurements. 
The intra class correlation coefficients between the ROIs using different size areas were high (see supplement, e-Figure 1, 2 and 3). The correlation coefficient between ROI 1 and ROI 2 was $0.996(p<0.001)$ and between ROI 1 and ROI 3 was $0.990(p<0.001)$ and between ROI 2 and ROI 3 was $0.998(p<0.001)$. Because of the heterogeneity of bone, we decided to use the ROI with the largest size area for the final analyses.

Table 1. Patients' characteristics

\begin{tabular}{lcc}
\hline & Normal BMD & Osteoporosis \\
\hline Number & 31 & 27 \\
Males, n (\%) & $22(71)$ & $14(52)$ \\
Age, yrs & $65.4 \pm 8.2$ & $66.5 \pm 7.8$ \\
FEV $_{1}, \%$ predicted & $64.9 \pm 11.3$ & $53.7 \pm 17.1$ \\
FEV $_{1} /$ FVC ratio & $55.0 \pm 9.3$ & $44.8 \pm 10.0$ \\
BMI, kg/m² $_{\text {BMD hip, g/cm }}^{2}$ & $29.2 \pm 5.5$ & $24.5 \pm 4.6$ \\
BMD L1-L4, g/cm & $1.147 \pm 0.145$ & $0.800 \pm 0.110$ \\
Lowest BMD, g/cm2 & $1.187 \pm 0.167$ & $0.809 \pm 0.155$ \\
\hline
\end{tabular}

Results are presented as mean \pm standard deviation unless otherwise indicated.

$\mathrm{BMD}=$ bone mineral density; $\mathrm{FEV}_{1}=$ forced expiratory volume in the first second; $\mathrm{FVC}=$ forced vital capacity; $\mathrm{BMI}=$ body mass index

Figure 1 shows the inter and intra-observer variabilities. The Bland-Altman $95 \%$ limits of agreement between the two observers ranged from -8.87 to $5.41 \mathrm{HU}$ (Figure $1 \mathrm{~A}$ ). In addition, the Bland-Altman $95 \%$ limits of agreement between the two observations by one observer ranged from -9.28 to $8.86 \mathrm{HU}$ (Figure $1 \mathrm{~B}$ ).

The mean bone attenuation on chest CT in the patients studied was $152.3 \pm 56.5 \mathrm{HU}$. The mean bone attenuation was nearly 50\% lower in COPD patients with osteoporosis compared with COPD patients with normal BMD (see supplement, e-Figure $4, \mathrm{p}<0.001$ ). The mean attenuation of $\mathrm{T} 4(175.1 \mathrm{HU})$ was higher compared with the mean attenuation of T7 (139.3 $\mathrm{HU}, \mathrm{p}<0.001)$ and T10 (141.0 HU, $p<0.001)$.

The correlation between CT-measured bone attenuation and the lowest BMD assessed on DXA was high ( $r=0.827, p<0.001$, Figure 2). The regression equation was: BMD assessed on DXA (in $\mathrm{g} / \mathrm{cm}^{2}$ ) $=0.003 *$ CT-measured attenuation (in $\mathrm{HU}$ ) +0.460 . In addition, the correlation coefficient between bone attenuation and BMD of the hip was $0.775(p<0.001)$ and between bone attenuation and BMD of the lumbar spine was $0.767(p<0.001)$. Figure 3 shows the ROC curve for predicting osteoporosis with simple attenuation measurement on chest CT. The area under the curve was 0.969 ( $p<0.001$ ). The attenuation threshold with the highest sensitivity and specificity for osteoporosis was $147 \mathrm{HU}$ (sensitivity $93 \%$ and specificity $97 \%$ ). 
A

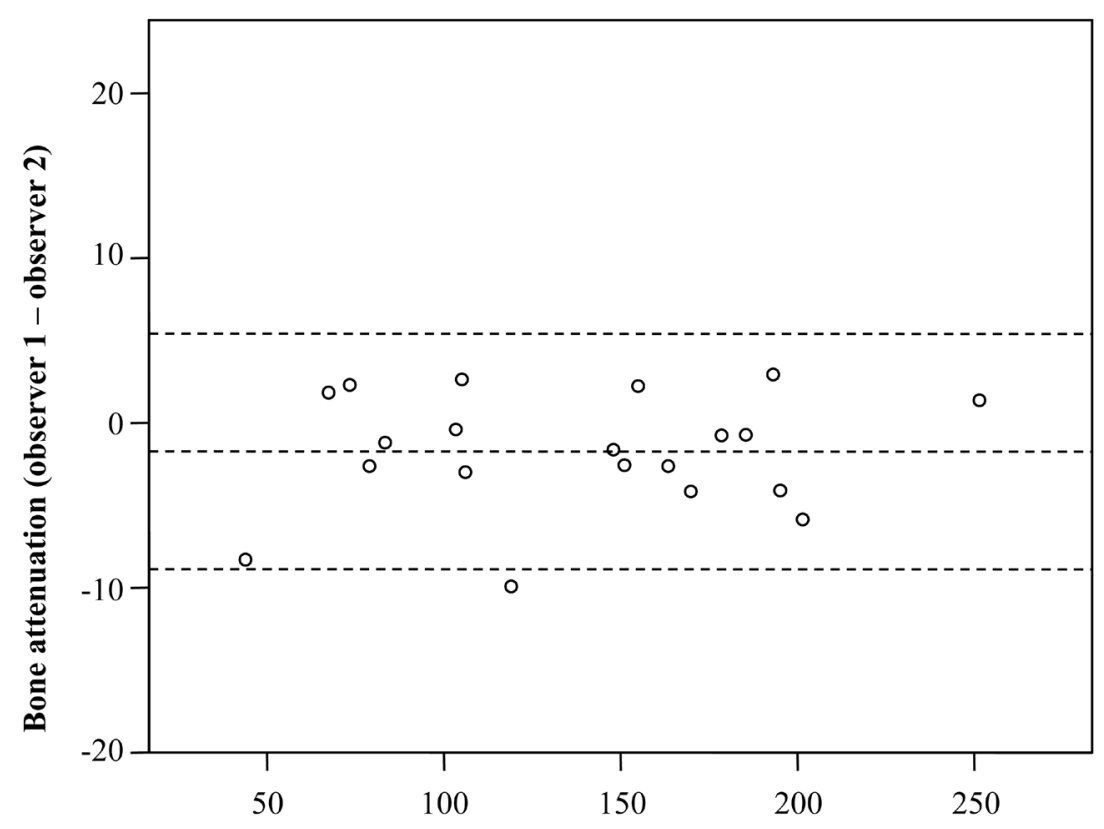

Mean bone attenuation

B

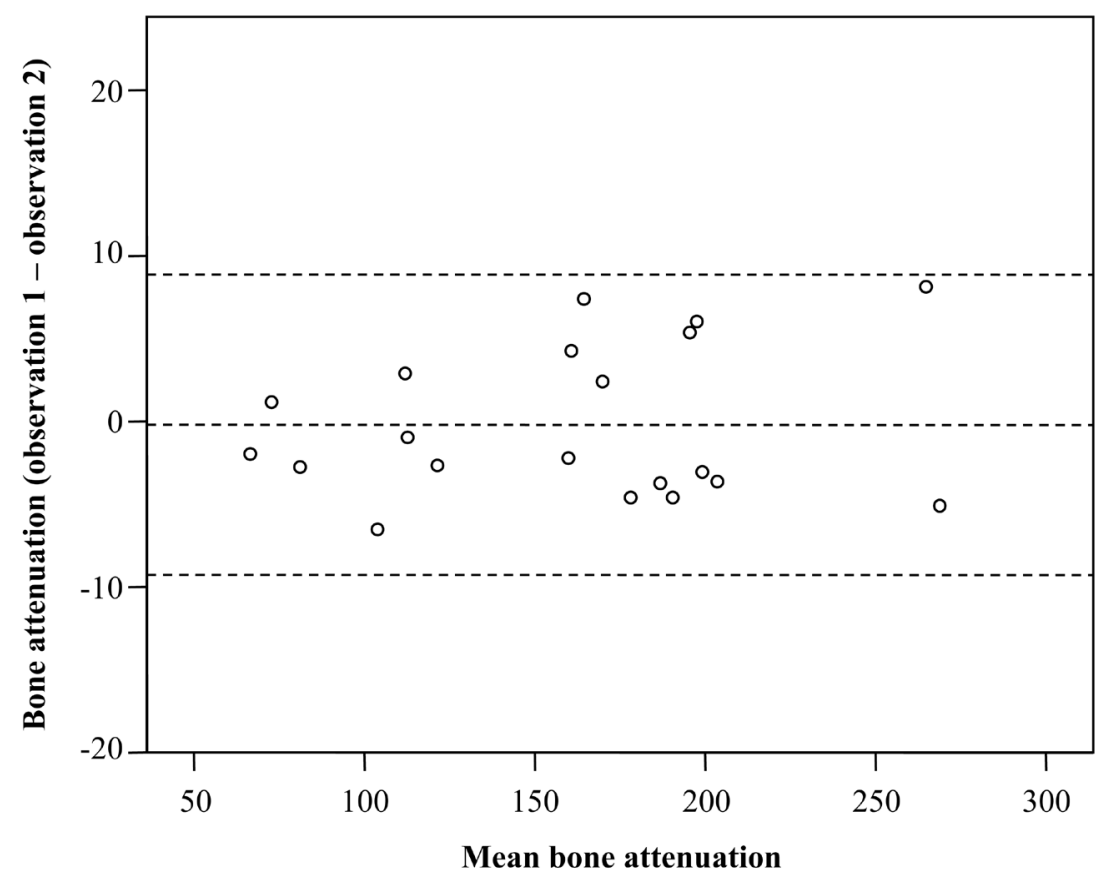

Figure 1. Bland Altman plots for the inter-observer (A) and intra-observer (B) variabilities of the bone attenuation measurements on chest CT 


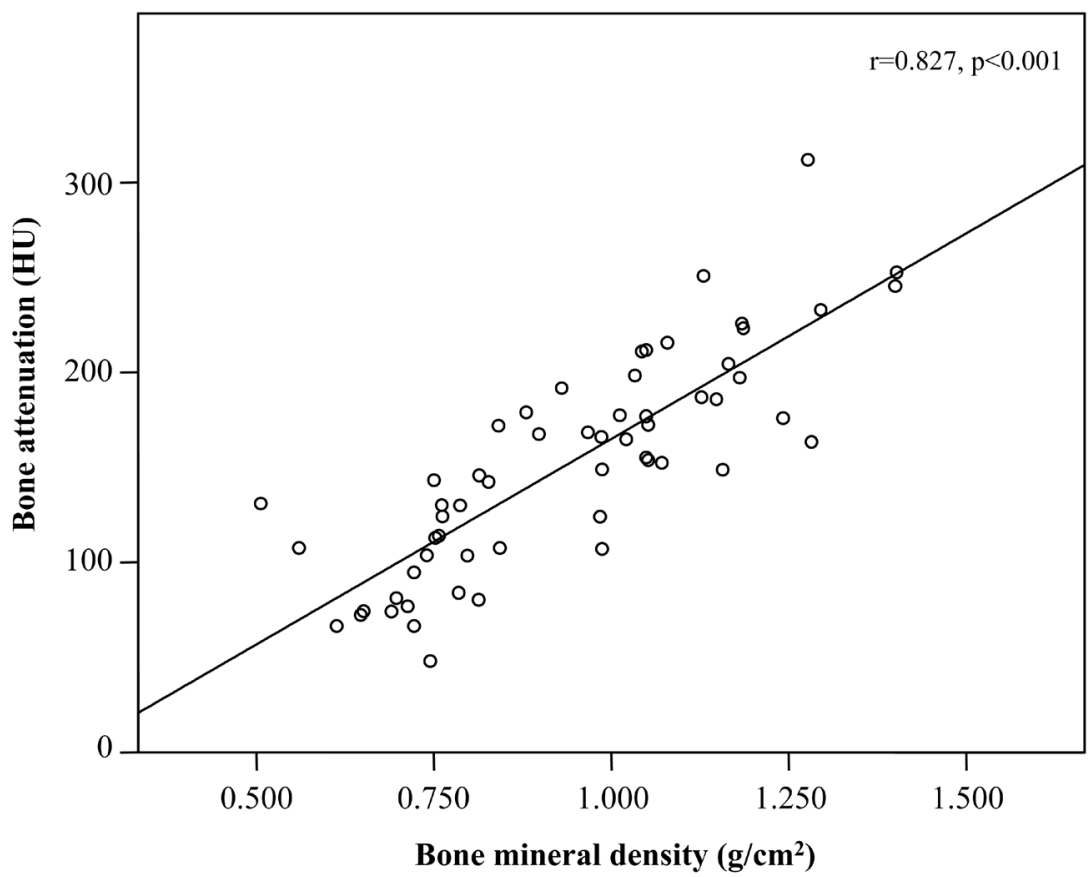

Figure 2. Correlation between CT-measured bone attenuation and DXA scan BMD

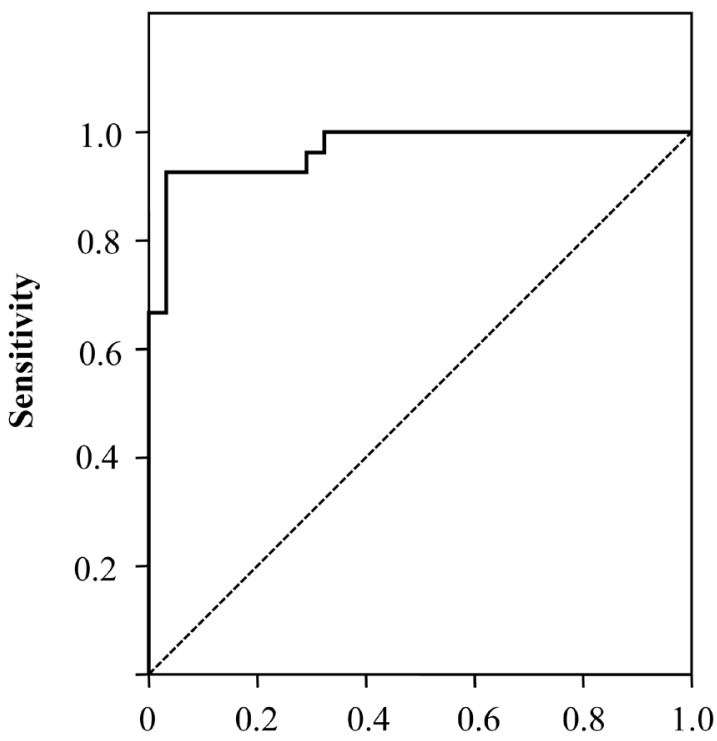

1-Specificity

Figure 3. ROC curve for predicting osteoporosis with simple attenuation measurement of the thoracic spine on chest CT 


\section{DISCUSSION}

This study showed that the average attenuation of thoracic vertebrae 4, 7 and 10 on routine chest CT was strongly correlated with the lowest BMD of the hip and lumbar spine on DXA in patients with COPD. Our data suggest that simple attenuation measurement of the thoracic spine on routine chest $\mathrm{CT}$ may provide useful information on bone health in patients with COPD.

Data on the feasibility of simple attenuation measurement on routine CT are scarce. Ohara and colleagues ${ }^{16}$ described a method to measure bone density on chest $\mathrm{CT}$. They assessed the average attenuation of thoracic vertebrae 4, 7 and 10 and lumbar vertebra 1 on chest CT. In order to express bone density as milligram per milliliter, they scanned a reference phantom with the same scanning parameters as the subjects. In our study a modification of their method was used. However, we demonstrated in addition to their study that CT-measured bone attenuation was strongly correlated with DXA scan BMD, which is considered the gold standard for diagnosing osteoporosis.

More recently Pickhardt and colleagues ${ }^{14}$ compared simple attenuation measurement on CT colonography with BMD measurement on DXA in adults aged 50 years and older. The ROC analysis of the area under the curve for osteoporosis was 0.825 . In line with their data, we demonstrated that the area under the curve for osteoporosis was high (0.969). However, Pickhardt and colleagues opted to use an attenuation threshold that would yield $100 \%$ sensitivity for osteoporosis (160 HU) resulting in modest specificity $(46.4 \%)$, whereas our study used a slightly lower threshold (147 HU) giving high sensitivity $(93 \%)$ and specificity (97\%).

Miyabara and colleagues ${ }^{13}$ demonstrated that calibrated and uncalibrated BMD measurements of thoracic vertebrae 8 and 9 on coronary CT scans in 111 menopausal women correlated with BMD measurements of the lumbar spine (L2 to L4) on DXA. However, the correlation in their study $(r=0.60, p<0.0001)$ was not as strong as in ours. This may have resulted from differences in the methods used since they used the attenuation of the individual vertebrae rather than the average attenuation of the thoracic vertebrae and correlated BMD of the lumbar spine rather than the lowest BMD of the lumbar spine and hip. The poorer correlation in the study by Miyabara and colleagues may also have resulted from differences in the study population since their study population did not include subjects with osteoporosis.

In line with previous data, ${ }^{16}$ we showed that attenuation of thoracic vertebra 4 was higher compared with attenuation of thoracic vertebrae 7 and 10. Several studies have shown that $\mathrm{BMD}$ is higher in cervical spine compared with lumbar spine $\mathrm{e}^{18}$ and higher in thoracic spine compared with lumbar spine. ${ }^{19,20}$ These data provide a reason why vertebral fractures are more common in the thoracolumbar spine since decreased BMD results in reduced bone strength. ${ }^{18,21,22}$ Wasnich ${ }^{23}$ concluded that most osteoporotic vertebral fractures were located in the thoracolumbar spine at thoracic vertebra 8 or between thoracic vertebra 11 and lumbar 
vertebra 1. In addition, Graat-Verboom and colleagues ${ }^{8}$ showed that in patients with COPD most vertebral fractures were located at thoracic vertebrae 8 and 12 .

Although no reference phantom or external references were used, our data showed a strong correlation between bone attenuation measured on CT and BMD measured on DXA. Mineral reference phantoms are used in order to standardize measurements and obtain a mineral reference. ${ }^{11,13,24}$ Besides reference phantoms, internal references such as muscle and subcutaneous fat can be used as calibration references..$^{25-27}$ However, the use of reference phantoms and internal references has some disadvantages. Reference phantoms may cause beam hardening and scatter effects and internal references have a heterogeneous HU distribution. ${ }^{27}$

Automated placement of ROIs has been suggested to limit random errors. ${ }^{24,28}$ However, in our study the reproducibility with manually placed ROIs was good. In addition, attenuation measurements using ROIs of different sized areas were strongly correlated and previous data demonstrated that BMD measurements using ROIs of different shaped areas also gave strong correlations. ${ }^{29}$ These data suggest that ROls of different size or shape have no significant effect on the CT bone density measurements.

Some limitations of our study should be mentioned. Primarily, the number of patients was relatively small and patients with osteopenia were excluded. Since BMD had a normal distribution we do not think inclusion of osteopenia would have changed our results. Secondly, for the purpose of the present study all patients were scanned with the same CT and DXA scanner while in clinical practice several types of CT and DXA scanners are used. Thus while it is likely that similar associations would be shown with other scanners the osteoporosis attenuation threshold value that we have calculated in our study cannot be extrapolated to those scanners. Thirdly, we compared simple bone attenuation measurement on CT that assesses trabecular bone with BMD on DXA that assesses trabecular and cortical bone. It would therefore be of interest to compare simple attenuation measurement with QCT since both methods assess trabecular bone. However, this would result in a higher radiation exposure for the patients. Finally, vertebral fractures were not assessed in our study. Previous research showed that COPD patients with a normal BMD on DXA can have vertebral fractures. ${ }^{8,30}$ Theoretically, CT-measured bone attenuation of the thoracic spine should be superior to DXA scanned BMD of the hip and lumbar spine for prediction of thoracic vertebral fractures. Therefore, it would be interesting to correlate CT-measured bone attenuation of the thoracic spine with thoracic vertebral fractures.

The strengths of our study are the good characterization of the study population and the good reproducibility with simple attenuation measurement. This finding is in line with previous data that showed a good reproducibility with simple attenuation measurement on CT colonography. ${ }^{14}$ The reproducibility was even better with simple attenuation measurement than with QCT. ${ }^{14}$ 
Based on our data we suggest that simple attenuation measurement on chest CT is useful to assess bone health in patients with COPD. However, more research is warranted in order to establish a reference range for thoracic spine attenuation and to confirm the attenuation threshold of $147 \mathrm{HU}$ for osteoporosis in larger COPD populations and using different scanners. In addition to more research in COPD patients, it would be interesting to study this method in other patient populations. Furthermore, although CT can provide useful information on bone health, CT will not replace DXA as the gold standard for osteoporosis because of the higher radiation dose and higher costs. We also acknowledge that besides BMD measurements several other factors such as gender, age and body mass index are important for fracture risk prediction. . $31,32^{2}$

In conclusion, this study shows that simple attenuation measurement on routine chest CT can be used to assess bone health in patients with COPD. In future, more research is warranted to validate simple attenuation measurement on chest $\mathrm{CT}$ in order to screen for osteoporosis in patients with COPD.

\section{DISCLOSURES}

Elisabeth A.P.M. Romme was the recipient of a European Respiratory Society Fellowship (STRTF 381-2011). The work described in this manuscript was performed at the University of Edinburgh as part of this Fellowship. 


\section{REFERENCES}

1. Rabe KF, Hurd S, Anzueto A et al. Global strategy for the diagnosis, management, and prevention of chronic obstructive pulmonary disease: GOLD executive summary. Am J Respir Crit Care Med 2007; 176: 532-55.

2. Seymour JM, Spruit MA, Hopkinson NS et al. The prevalence of quadriceps weakness in COPD and the relationship with disease severity. Eur Respir J 2010; 36: 81-8.

3. Sabit R, Bolton $\mathrm{CE}$, Edwards $\mathrm{PH}$ et al. Arterial stiffness and osteoporosis in chronic obstructive pulmonary disease. Am J Respir Crit Care Med 2007; 175: 1259-65.

4. Graat-Verboom L, Wouters EF, Smeenk FW, van den Borne BE, Lunde R, Spruit MA. Current status of research on osteoporosis in COPD: a systematic review. Eur Respir J 2009; 34: 209-18.

5. Barnes PJ, Celli BR. Systemic manifestations and comorbidities of COPD. Eur Respir J 2009; 33: 1165-85.

6. World Health Organization. Prevention and Management of Osteoporosis; report of a WHO scientific group [updated 2003; cited 2013 August]. Available from: http://whqlibdoc.who.int/trs/WHO_ TRS_921.pdf.

7. Harrison RA, Siminoski K, Vethanayagam D, Majumdar SR. Osteoporosis-related kyphosis and impairments in pulmonary function: a systematic review. J Bone Miner Res 2007; 22: 447-57.

8. Graat-Verboom L, van den Borne BE, Smeenk FW, Spruit MA, Wouters EF. Osteoporosis in COPD outpatients based on bone mineral density and vertebral fractures. J Bone Miner Res 2011; 26: 561-8.

9. Lewiecki EM, Gordon CM, Baim S et al. International Society for Clinical Densitometry 2007 Adult and Pediatric Official Positions. Bone 2008; 43: 1115-21.

10. Graat-Verboom L, Spruit MA, van den Borne BE, Smeenk FW, Wouters EF. Whole-Body versus Local DXA-Scan for the Diagnosis of Osteoporosis in COPD Patients. J Osteoporos 2010; 2010: 640878.

11. Adams JE. Quantitative computed tomography. Eur J Radiol 2009; 71: 415-24.

12. Link TM, Koppers BB, Licht T, Bauer J, Lu Y, Rummeny EJ. In vitro and in vivo spiral CT to determine bone mineral density: initial experience in patients at risk for osteoporosis. Radiology 2004; 231: 805-11.

13. Miyabara Y, Holmes D, Camp J, Miller VM, Kearns AE. Comparison of calibrated and uncalibrated bone mineral density by CT to DEXA in menopausal women. Climacteric 2011; 15: 374-81.

14. Pickhardt PJ, Lee $\amalg$, Munoz Del RA et al. Simultaneous screening for osteoporosis at CT colonography: Bone mineral density assessment using MDCT attenuation techniques compared with the DXA reference standard. J Bone Miner Res 2011; 26: 2194-203.

15. Miller MR, Hankinson J, Brusasco V et al. Standardisation of spirometry. Eur Respir J 2005; 26: 319-38.

16. Ohara T, Hirai T, Muro S et al. Relationship between pulmonary emphysema and osteoporosis assessed by CT in patients with COPD. Chest 2008; 134: 1244-9.

17. Bland JM, Altman DG. Statistical methods for assessing agreement between two methods of clinical measurement. Lancet 1986; 1: 307-10.

18. Weishaupt D, Schweitzer ME, DiCuccio MN, Whitley PE. Relationships of cervical, thoracic, and lumbar bone mineral density by quantitative CT. J Comput Assist Tomogr 2001; 25: 146-50.

19. Hayashi T, Chen $\mathrm{H}$, Miyamoto K et al. Analysis of bone mineral density distribution at trabecular bones in thoracic and lumbar vertebrae using X-ray CT images. J Bone Miner Metab 2011; 29: 174-85.

20. Singer K, Edmondston S, Day R, Breidahl P, Price R. Prediction of thoracic and lumbar vertebral body compressive strength: correlations with bone mineral density and vertebral region. Bone 1995; 17: 167-74.

21. Cody DD, Goldstein SA, Flynn MJ, Brown EB. Correlations between vertebral regional bone mineral density (rBMD) and whole bone fracture load. Spine (Phila Pa 1976 ) 1991; 16: 146-54.

22. McBroom RJ, Hayes WC, Edwards WT, Goldberg RP, White AA, III. Prediction of vertebral body compressive fracture using quantitative computed tomography. J Bone Joint Surg Am 1985; 67: 120614.

23. Wasnich RD. Vertebral fracture epidemiology. Bone 1996; 18: 179S-83S. 
24. Kalender WA, Klotz E, Suess C. Vertebral bone mineral analysis: an integrated approach with CT. Radiology 1987; 164: 419-23.

25. Gudmundsdottir H, Jonsdottir B, Kristinsson S, Johannesson A, Goodenough D, Sigurdsson G. Vertebral bone density in Icelandic women using quantitative computed tomography without an external reference phantom. Osteoporos Int 1993; 3: 84-9.

26. Boden SD, Goodenough DJ, Stockham CD, Jacobs E, Dina T, Allman RM. Precise measurement of vertebral bone density using computed tomography without the use of an external reference phantom. J Digit Imaging 1989; 2: 31-8.

27. Mueller DK, Kutscherenko A, Bartel H, Vlassenbroek A, Ourednicek P, Erckenbrecht J. Phantom-less QCT BMD system as screening tool for osteoporosis without additional radiation. Eur J Radiol 2011; 79: 375-81.

28. Laval-Jeantet AM, Genant HK, Wu CY, Gluer CC, Faulkner KG, Steiger P. Factors influencing long-term in vivo reproducibility of QCT overtebral densitometry). J Comput Assist Tomogr 1993; 17: 915-21.

29. Steiger $P$, Block JE, Steiger $S$ et al. Spinal bone mineral density measured with quantitative CT: effect of region of interest, vertebral level, and technique. Radiology 1990; 175: 537-43.

30. Graat-Verboom L, Smeenk FW, van den Borne BE, Spruit MA, Jansen FH, van Enschot JW, Wouters EF. Progression of osteoporosis in patients with COPD: A 3-year follow up study. Respir Med 2012; 106: 861-70

31. Kanis JA, Johnell O, Oden A, Johansson $H$, McCloskey E. FRAX and the assessment of fracture probability in men and women from the UK. Osteoporos Int 2008; 19: 385-97.

32. Graat-Verboom L, Spruit MA, van den Borne BE, Smeenk FW, Martens EJ, Lunde R, Wouters EF. Correlates of osteoporosis in chronic obstructive pulmonary disease: An underestimated systemic component. Respir Med 2009; 103: 1143-51. 


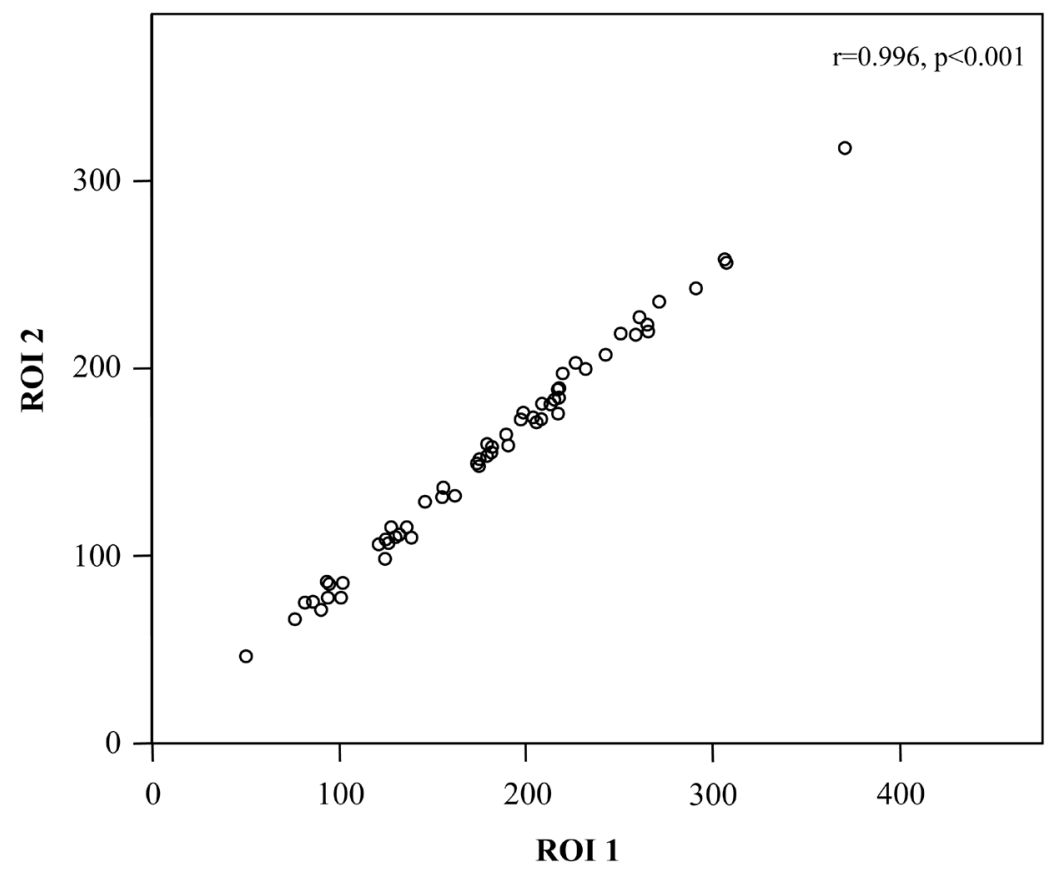

e-Figure 1. Correlation between attenuation measurements using ROI 1 and ROI 2

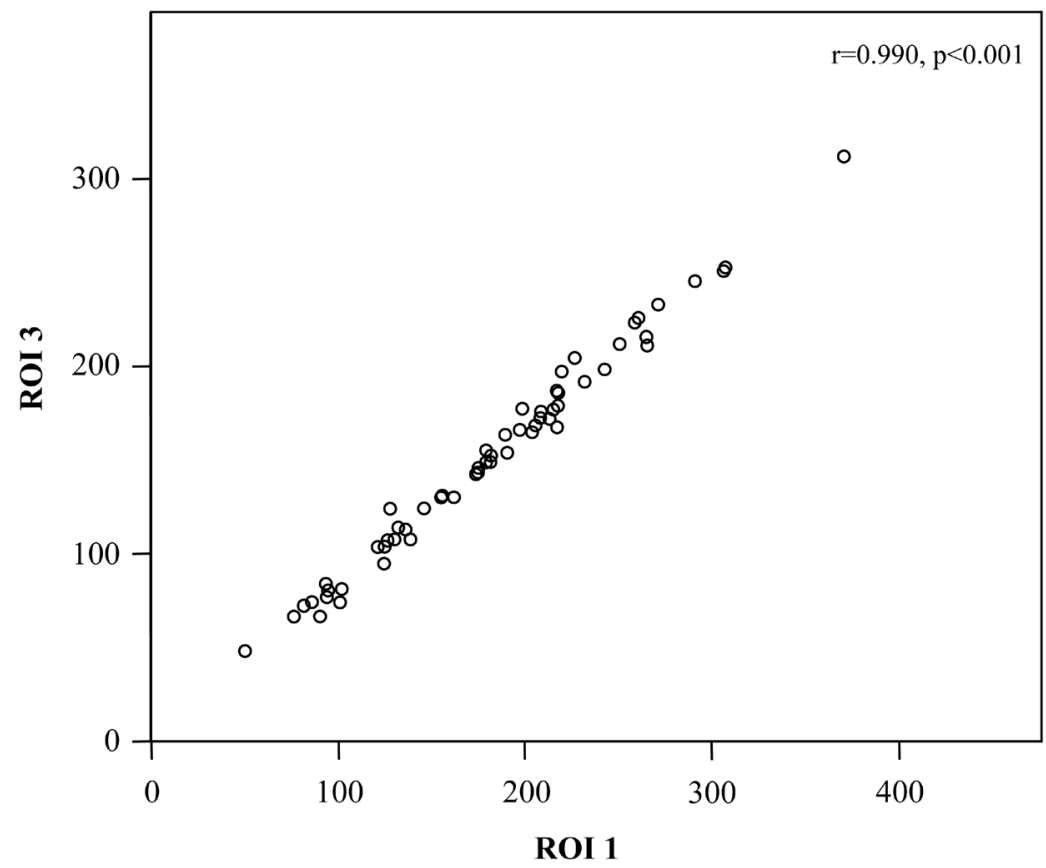

e-Figure 2. Correlation between attenuation measurements using ROI 1 and ROI 3 


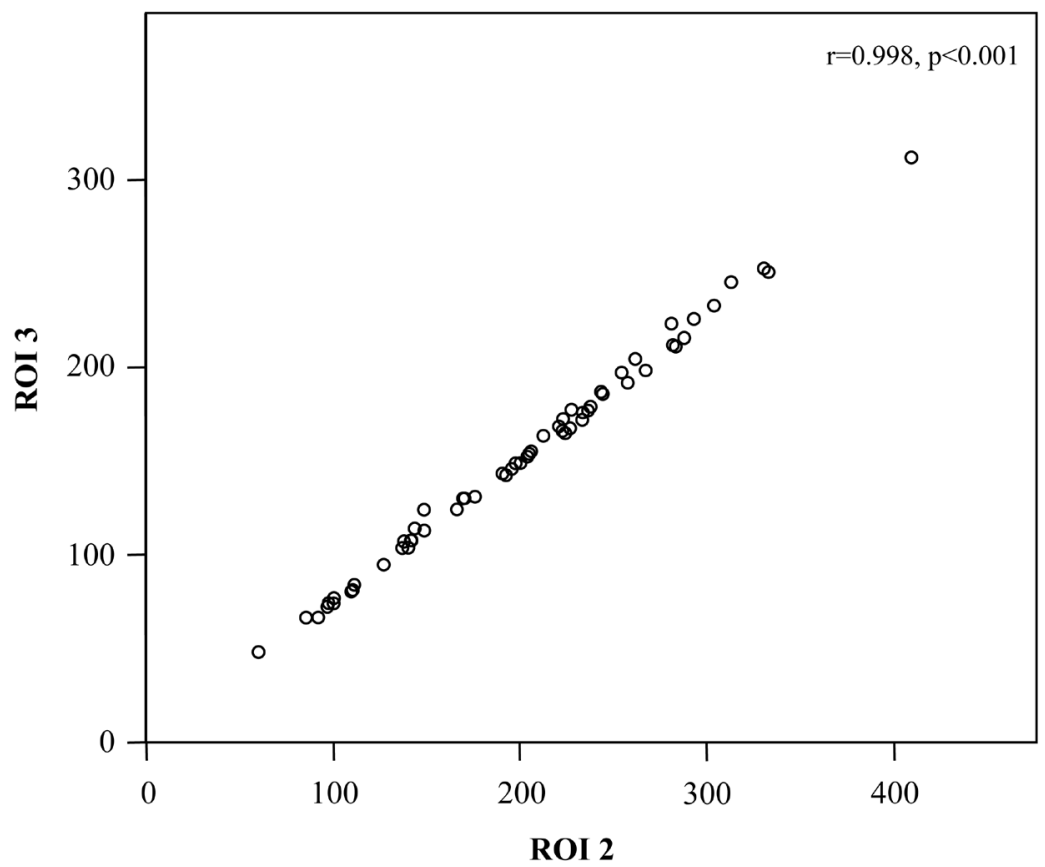

e-Figure 3. Correlation between attenuation measurements using ROI 2 and ROI 3

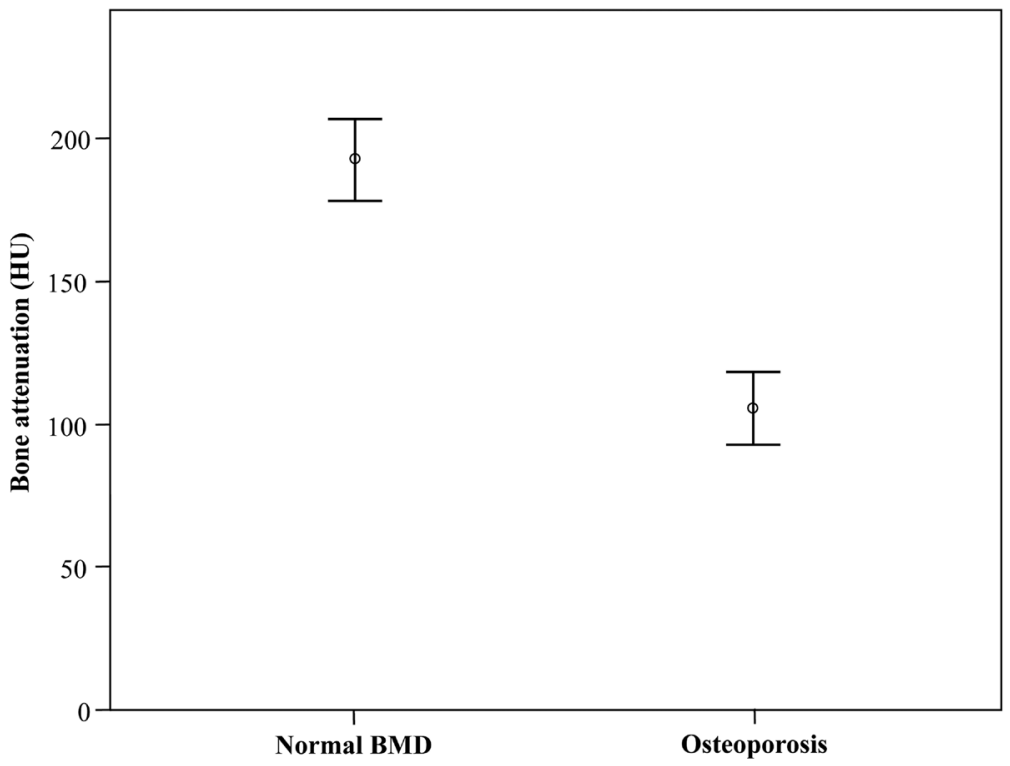

e-Figure 4. Mean bone attenuation between COPD patients with normal BMD and osteoporosis 



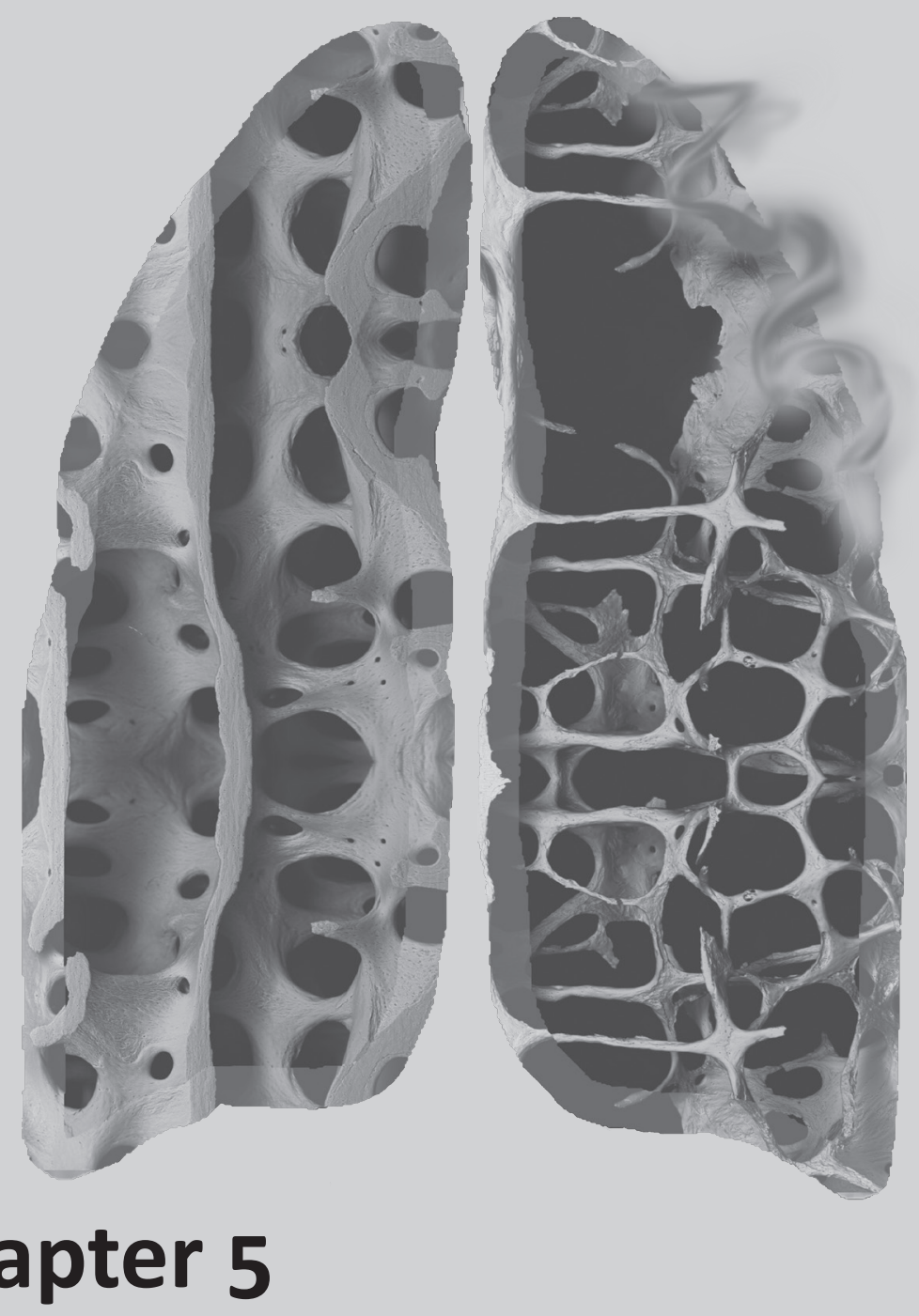

CT-measured bone attenuation in patients with chronic obstructive pulmonary disease: relation to clinical features and outcomes

Elisabeth A.P.M. Romme

John T. Murchinson

Lisa D. Edwards

Edwin J.R. Van Beek

David M. Murchison
Erica P.A. Rutten

Frank W.J.M. Smeenk

Michelle C. Williams

Emiel F.M. Wouters

William MacNee

and on behalf of the Evaluation of COPD Longitudinally to Identify Predictive Surrogate Endpoints (ECLIPSE) study investigators

Journal of Bone and Mineral Research 2013; 28: 1369-77 


\begin{abstract}
Osteoporosis is highly prevalent in COPD patients and has been related to several clinical features. However, most studies have been in relatively small COPD cohorts. Therefore, the objectives of this study were to compare bone attenuation measured on low-dose chest computed tomography (CT) between COPD subjects, smoker and non-smoker controls, and to relate bone attenuation to clinical parameters, inflammatory biomarkers and outcomes in a large, well-characterized COPD cohort. We studied 1634 COPD subjects, 259 smoker controls and 186 non-smoker controls who participated in a large longitudinal study (ECLIPSE). We measured bone attenuation, extent of emphysema and coronary artery calcification (Agatston score) on baseline CT scans, and clinical parameters, inflammatory biomarkers and outcomes. Bone attenuation was lower in COPD subjects compared with smoker and non-smoker controls (164.9 $\pm 49.5 \mathrm{HU}$ versus $183.8 \pm 46.1 \mathrm{HU}$ versus $212.1 \pm 54.4$ $\mathrm{HU}, \mathrm{p}<0.001)$. Bone attenuation was not significantly different between COPD subjects and smoker controls after adjustment for age, sex and pack years of smoking. In the COPD subjects, bone attenuation correlated positively with $\mathrm{FEV}_{1}(\mathrm{r}=0.062, \mathrm{p}=0.014), \mathrm{FEV}_{1} / \mathrm{FVC}$ ratio $(r=0.102, p<0.001)$, body mass index $(r=0.243, p<0.001)$, fat free mass index (FFMI, $r=0.265$, $p<0.001)$ and C-reactive protein $(r=0.104, p<0.001)$, and correlated negatively with extent of emphysema ( $r=-0.090, p<0.001)$, Agatston score $(r=-0.177, p<0.001)$ and interleukin-8 $(r=-$ $0.054, p=0.035)$. In a multiple regression model, older age, lower FFMI and higher Agatston score were associated with lower bone attenuation. Lower bone attenuation was associated with higher exacerbation $(r=-0.057, p=0.022)$ and hospitalization $(r=-0.078, p=0.002)$ rates, but was not associated with all-cause mortality. In conclusion, CT-measured bone attenuation was lower in COPD subjects compared with non-smoker controls but not compared with smoker controls, after adjustment for age, sex and pack years of smoking. In the COPD subjects, bone attenuation was associated with age, body composition and coronary artery calcification, but was not associated with all-cause mortality.
\end{abstract}




\section{INTRODUCTION}

Chronic obstructive pulmonary disease (COPD) has, in addition to its pulmonary effects, several extrapulmonary effects that may contribute to the severity of the disease. ${ }^{1-5}$ Osteoporosis, which is characterized by low bone mineral density and micro-architectural changes, ${ }^{6}$ is recognized as one such extrapulmonary effect. The prevalence of osteoporosis has been suggested to be higher in COPD patients than in control subjects matched for age and sex. ${ }^{7}$ However, as described in a meta-analysis, most of studies on osteoporosis have been performed in relatively small cohorts. ${ }^{8}$

In COPD patients, osteoporosis is associated with older age, lower body mass index (BMI), more severe airflow limitation and the use of oral and inhaled corticosteroids. ${ }^{8-11}$ More recently, low bone density has been associated with emphysema, ${ }^{12-14}$ and with cardiovascular disease in patients with chronic kidney disease..$^{15}$ Although both osteoporosis and cardiovascular disease are common in COPD patients, ${ }^{11,16}$ research on a relationship between bone health and cardiovascular disease in COPD is sparse. ${ }^{17}$

The mechanism linking osteoporosis with COPD is not entirely clear. Osteoporosis has been suggested to be either a comorbidity, due to shared risk factors (e.g. older age and smoking) or a systemic effect of COPD with a cause-and-effect relationship. ${ }^{18}$ Several pathophysiologic mechanisms linking osteoporosis with COPD have been suggested, including systemic inflammation, ${ }^{19}$ disturbance of the osteoprotegerin (OPG)/ receptor activator of NF-KB (RANK)/ RANK ligand (RANKL) pathway ${ }^{14}$ and vitamin D deficiency. ${ }^{20}$

The Evaluation of COPD Longitudinally to Identify Predictive Surrogate Endpoints (ECLIPSE; study identification number SCO104960; Clinicaltrials.gov identifier NCTO0292552) is a longitudinal study in a large cohort of COPD subjects, smoker and non-smoker controls. ${ }^{21}$ As part of this study, a low-dose chest computed tomography (CT) scan was performed from which measurements of bone density of the thoracic vertebrae can be made, ${ }^{22}$ in addition to the extent of emphysema and coronary artery calcification. The objectives of this study were 1) To compare CT-measured bone attenuation of the thoracic vertebrae between COPD subjects, smoker and non-smoker controls; and 2) To relate CT-measured bone attenuation to clinical parameters, inflammatory biomarkers and outcomes in a large, well-characterized COPD cohort.

\section{MATERIALS AND METHODS}

Our analysis was based on the data collected in the ECLIPSE study. The design and aims of the study have been published previously. ${ }^{21}$ The study was conducted in accordance with the Declaration of Helsinki and Good Clinical Practice guidelines. All subjects provided written informed consent and the study was approved by the relevant ethics and review boards. 


\section{Subjects}

COPD subjects who were between the ages of 40 and 75 years were enrolled in the study if they had a history of 10 or more pack years of smoking, a forced expiratory volume in 1 second $\left(\mathrm{FEV}_{1}\right.$ ) of less than $80 \%$ of the predicted value after bronchodilator use, and a ratio of $\mathrm{FEV}_{1}$ to forced vital capacity (FVC) of 0.7 or less after bronchodilator use. In addition, smoker and non-smoker control subjects who were between the ages of 40 and 75 years were enrolled if they had an $\mathrm{FEV}_{1}$ of more than $85 \%$ of the predicted value after bronchodilator use and an $\mathrm{FEV}_{1} / \mathrm{FVC}$ ratio of more than 0.7 after bronchodilator use. Smoker controls had a history of 10 or more pack years of smoking, and non-smoker controls had a history of less than 1 pack year of smoking. Subjects were excluded if they had a respiratory disease other than COPD, a significant inflammatory disease (e.g. rheumatoid arthritis and lupus), cancer in the 5 years prior to study entry, evidence of alcohol, drug or solvent abuse, had undergone lung surgery or used oral corticosteroids chronically.

\section{Measurements}

At baseline, subjects underwent standard spirometry after the administration of 400 $\mu \mathrm{g}$ of inhaled albuterol/ salbutamol. The subjects' self-reported respiratory symptoms, medications, smoking history, occupational exposure, and coexisting medical conditions were documented at study entry with the use of the American Thoracic Society-Division of Lung disease questionnaire. Nutritional status was assessed by the BMI and fat free mass index (FFMI), the latter was measured using bioelectrical impedance analysis (Bodystat 1500). In COPD subjects, the 6 minute walk was performed according to the American Thoracic Society guideline. ${ }^{23}$

Bone attenuation, extent of emphysema and coronary artery calcification were assessed on baseline low-dose CT scans of the chest acquired using multi-detector-row CT scanners (Siemens Healthcare, Erlangen, Germany or GE Healthcare, Milwaukee, WI) with a minimum of 4 rows which have been shown to produce comparable density values when using similar protocols. Imaging was performed in the supine position, at suspended full inspiration, without administration of intravenous contrast. Exposure settings were $120 \mathrm{kVp}$ and 40 $\mathrm{mAs}$, and images were reconstructed using $1.0 \mathrm{~mm}$ (Siemens) or $1.25 \mathrm{~mm}$ (GE) contiguous slices and a low spatial frequency reconstruction algorithm (GE: Standard; Siemens: b35f). CT scanners were calibrated regularly using industry and institutional standards.

Bone attenuation was measured on CT using the software VOXAR 3D version 16.0 (Toshiba Medical Visualisation Systems, Edinburgh, UK) as described previously, and has been shown to correlate with bone density measurements by DXA scanning. ${ }^{22}$ Briefly, the mean bone attenuation of thoracic vertebrae 4, 7 and 10 (T4, T7 and T10) were determined by placing circular regions of interest in the central parts of the vertebral bodies. The average bone attenuation of these three vertebrae $\mathrm{T} 4, \mathrm{~T} 7$ and $\mathrm{T} 10$ was calculated and expressed in Hounsfield Units (HU). 
Quantitative assessment of emphysema was performed by attenuation mask analysis (Pulmonary Workstation 2.0, VIDA Diagnostics, lowa City, IA, USA). The extent of emphysema was expressed as the percent of low attenuation areas (\%LAA) with an HU of less than $-950 .{ }^{24}$

Coronary artery calcification was measured as the Agatston score on a dedicated postprocessing workstation (Vitrea Fx, version 3.1.0, Vital Images, Minnetonka, USA) using calcium score analysis software (VScore, Vital Images, Minnetonka, USA). The Agatston score was calculated as previously described. ${ }^{25}$ The calcium score percentile based on age, gender and ethnicity was calculated using previously published distributions from a cohort of healthy, asymptomatic individuals from the Multi-Ethnic Study of Atherosclerosis (MESA). ${ }^{26}$

Serum and plasma samples for biomarker measurements were collected in the morning, after fasting overnight, at baseline. Blood samples were stored at $-80^{\circ} \mathrm{C}$ until they were analyzed centrally. Circulating white blood cell (WBC) count was measured in a central clinical laboratory. Interleukin-6 (IL-6), interleukin-8 (IL-8) and tumor necrosis factor- $\alpha$ (TNF- $\alpha$ ) were measured in serum samples using validated immunoassays on the SearchLight Protein Array Platform (Aushon Biosystems, Inc., Billerica, MA, USA). Fibrinogen (K-ASSAY fibrinogen test, Kamiya Biomedical Co., Seattle, WA, USA) and C-reactive protein (CRP) (Roche Diagnostics, Mannheim, Germany) were measured using immunoturbidometric assays validated for use with EDTA plasma. ${ }^{27}$ Biomarker values $>95^{\text {th }}$ percentile for healthy non-smokers were considered to be elevated..$^{28}$ Systemic inflammation was defined as 2 or more elevated biomarker levels (WBC, CRP, IL-6 and fibrinogen) at study entry as previously described. ${ }^{28}$

\section{Outcomes}

All subjects were contacted monthly by telephone to assess the frequency of exacerbations and hospitalizations using a structured interview scheme. ${ }^{21}$ Rate of decline in FEV was determined as previously described. ${ }^{27}$ Survival status was recorded for all subjects at the 3 year visit date. In the case subjects withdrew from the study early, their survival status was recorded at the next planned visit and again at the 3 year time-point. Date of death or last confirmed alive date were reported.

\section{Statistical analysis}

Results are shown as mean (SD or SE), median (interquartile range [IQR]), or frequency (percentage), as appropriate. Comparisons between subject groups were carried out using analysis of variance (ANOVA), Kruskal-Wallis tests, or Cochran-Mantel-Haenszel tests, and the characteristics of each COPD subpopulation were compared with the full ECLIPSE population. Univariate associations between bone attenuation and clinical factors were assessed by Spearman correlation coefficients. Multiple regression models to estimate bone attenuation were constructed based on predictors identified in the literature: ${ }^{6,8,11,29}$ age, sex, pack years of smoking, $\mathrm{FEV}_{1}, \mathrm{FEV}_{1} / \mathrm{FVC}$, FFMI, \%LAA, CRP, IL-8, and Agatston score. A Cox proportional hazards model was used to determine the effect of bone attenuation on all-cause mortality. Two-sided $p$ values $<0.05$ were considered significant with no adjustment for multiple testing. Analyses were conducted with SAS ${ }^{\circledR}$ Version 9.1 (SAS Institute, Cary, NC, USA). 


\section{RESULTS}

In total, 2164 COPD subjects, 337 smoker controls and 245 non-smoker controls were enrolled in the ECLIPSE study. Six hundred fifty subjects were excluded because their scans were either not available or the scans had not been adequately performed to assess bone attenuation. Seventeen subjects who used oral corticosteroids were also excluded since we did not wish to assess the bone density in these patients with this risk factor for osteoporosis. Thus, our cohort comprised 1634 COPD subjects, 259 smoker controls and 186 non-smoker controls (Table 1). Our study cohort was not significantly different compared to the ECLIPSE cohort as a whole (see supplement, e-Table 1). The Agatston score was measured in a subpopulation of 672 COPD subjects, representative of the total COPD cohort of the ECLIPSE study (see supplement, e-Table 1).

CT-measured bone attenuation was lower in COPD subjects compared with smoker and nonsmoker controls (164.9 $\pm 49.5 \mathrm{HU}$ versus $183.8 \pm 46.1 \mathrm{HU}$ versus 212.1 $\pm 54.4 \mathrm{HU}$ respectively, $\mathrm{p}<0.001)$. However, the difference in bone attenuation between COPD subjects and smoker controls was not statistically significant after adjustment for age, sex and pack years of smoking ( $p=0.206$, Figure 1$)$.

In the COPD subjects, CT-measured bone attenuation correlated positively with $\mathrm{FEV}_{1}, \mathrm{FEV}_{1} / \mathrm{FVC}$ ratio, BMI, FFMI and CRP, and correlated negatively with \%LAA, Agatston score and IL-8 after correction for age, sex and pack years of smoking (Table 2). Figure 2 shows the correlation between bone attenuation and Agatston score. The significantly positive correlation between bone attenuation and CRP disappeared after adjustment for BMI ( $r=0.015, p=0.558)$. In a multiple regression model, older age, lower FFMI and higher Agatston score were associated with lower CT-measured bone attenuation (Table 3).

Four hundred forty-eight COPD subjects (27\%) had 2 or more elevated biomarker levels and 707 COPD subjects (43\%) had no elevated biomarker levels at baseline. CT-measured bone attenuation was not significantly different between the patients with and without systemic inflammation (165.8 $\pm 49.4 \mathrm{HU}$ versus $163.8 \pm 49.1 \mathrm{HU}, \mathrm{p}=0.241$ ).

CT-measured bone attenuation correlated positively with the rate of decline in $\mathrm{FEV}_{1}$, and correlated negatively with exacerbation and hospitalization rates after adjustment for age, sex and pack years of smoking (Table 4). One hundred fifty-four ( $9 \%$ ) COPD subjects died during 3 years of follow up. The mean bone attenuation in the survivors was $165.9 \pm 48.8$ HU compared with $156.0 \pm 55.5 \mathrm{HU}$ in the non-survivors $(p=0.223)$. Cox proportional hazards modeling showed that bone attenuation was not associated with all-cause mortality in COPD subjects (Table 5). 


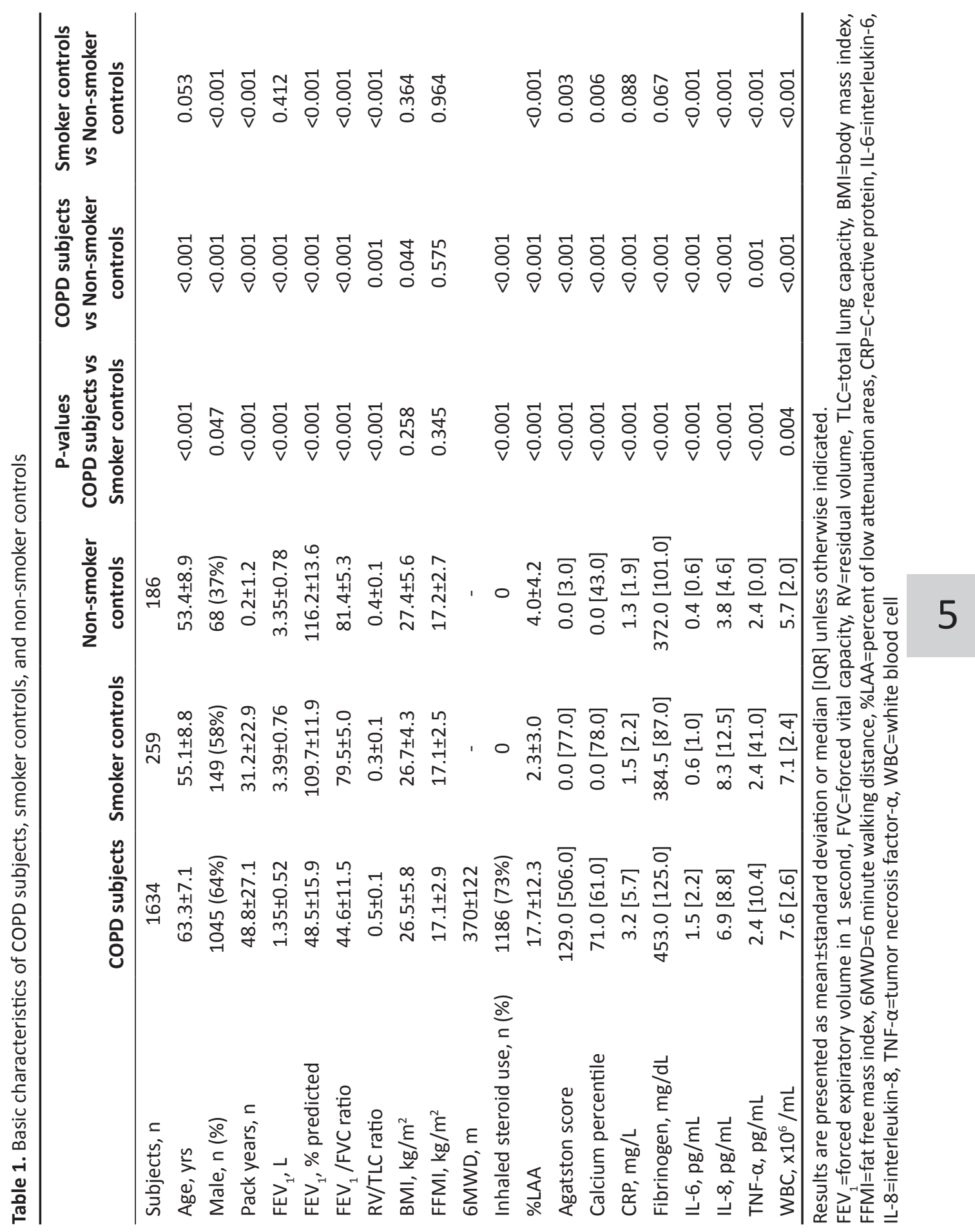




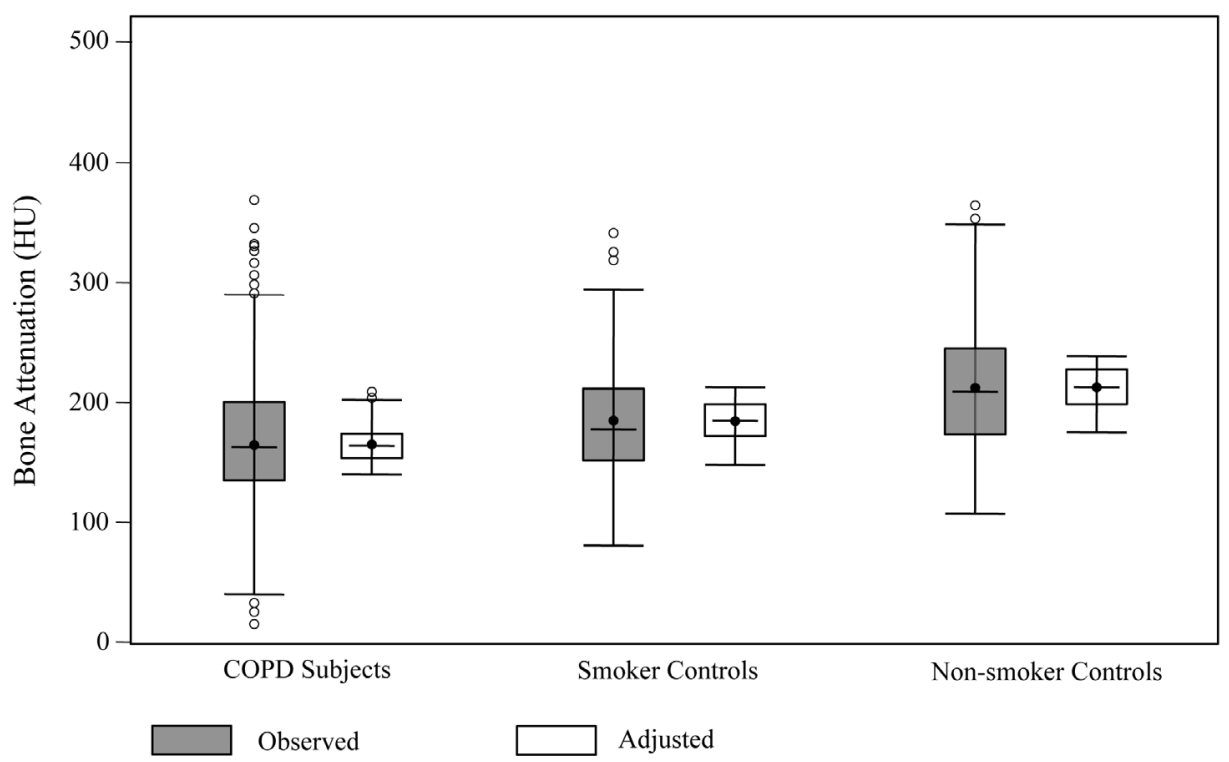

Figure 1. CT-measured bone attenuation in COPD subjects, smoker controls and non-smoker controls

Observed values: the average bone attenuation of thoracic vertebrae 4, 7 and 10 .

Adjusted values: the average bone attenuation of thoracic vertebrae 4, 7 and 10 after adjustment for age, sex en pack years of smoking.

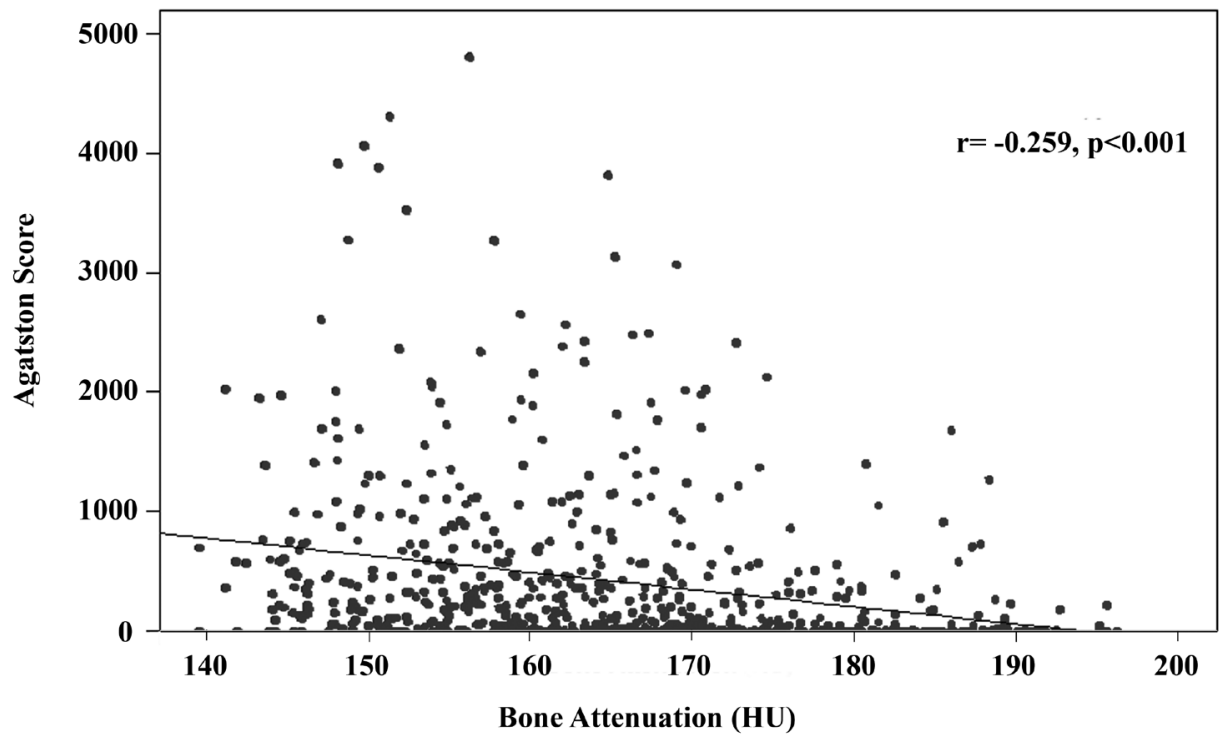

Figure 2. Correlation between CT-measured bone attenuation and Agatston score 
Table 2. Correlations between bone attenuation and clinical assessments in COPD subjects after adjustment for age, sex, and pack years of smoking

\begin{tabular}{lcc}
\hline & Spearman Correlation Coefficient & p-value \\
\hline $\mathrm{FEV}_{1}, \mathrm{~L}$ & 0.062 & 0.014 \\
$\mathrm{FEV}_{1}, \%$ predicted & 0.077 & 0.002 \\
$\mathrm{FEV}_{1} / \mathrm{FVC}$ ratio & 0.102 & $<0.001$ \\
$\mathrm{RV} / \mathrm{TLC}$ ratio & 0.010 & 0.824 \\
$\mathrm{BMI}, \mathrm{kg} / \mathrm{m}^{2}$ & 0.243 & $<0.001$ \\
$\mathrm{FFMI}, \mathrm{kg} / \mathrm{m}^{2}$ & 0.265 & $<0.001$ \\
$6 \mathrm{MWD}, \mathrm{m}$ & 0.001 & 0.957 \\
$\mathrm{mMRC}$ score & -0.040 & 0.112 \\
Inhaled steroid use & -0.004 & 0.874 \\
$\% \mathrm{LAA}$ & -0.090 & $<0.001$ \\
Agatston score & -0.177 & $<0.001$ \\
Calcium percentile & -0.172 & $<0.001$ \\
$\mathrm{CRP}, \mathrm{mg} / \mathrm{L}$ & 0.104 & $<0.001$ \\
Fibrinogen, mg/dL & 0.046 & 0.070 \\
IL-6, pg/mL & 0.036 & 0.175 \\
IL-8, pg/mL & -0.054 & 0.035 \\
TNF- $\alpha, \mathrm{pg} / \mathrm{mL}$ & -0.016 & 0.525 \\
WBC, $\mathrm{x} 10^{6} / \mathrm{mL}$ & 0.033 & 0.189 \\
\hline
\end{tabular}

$\mathrm{FEV}_{1}=$ forced expiratory volume in 1 second, $\mathrm{FVC}=$ forced vital capacity, $\mathrm{RV}=$ residual volume, $\mathrm{TLC}=$ total lung capacity, $\mathrm{BMI}=$ body mass index, $\mathrm{FFMl}=$ fat free mass index, $6 \mathrm{MWD}=6$ minute walking distance, $\mathrm{mMRC}=$ modified Medical Research Council dyspnoea scale, \%LAA=percent of low attenuation areas, CRP=C-reactive protein, IL-6=interleukin-6, IL-8=interleukin-8, TNF$\alpha=$ tumor necrosis factor $-\alpha, W B C=$ white blood cell 
Table 3. Multivariate regression for bone attenuation in COPD subjects

\begin{tabular}{lcccc}
\hline & \multicolumn{2}{c}{ Total COPD cohort } & \multicolumn{2}{c}{ Agatston cohort } \\
& Estimate(SE) & p value & Estimate(SE) & p-value \\
\hline Age & $-1.807(0.181)$ & $<0.001$ & $-1.780(0.283)$ & $<0.001$ \\
Female & $4.517(3.319)$ & 0.174 & $-5.901(5.034)$ & 0.242 \\
Pack years & $0.019(0.047)$ & 0.692 & $-0.043(0.076)$ & 0.569 \\
FEV $_{1}$ & $-2.972(3.554)$ & 0.403 & $-6.679(5.469)$ & 0.223 \\
FEV $_{1} /$ FVC & $0.244(0.173)$ & 0.159 & $0.553(0.268)$ & 0.039 \\
FFMI $_{\text {\%LAA }}$ & $4.506(0.475)$ & $<0.001$ & $4.528(0.682)$ & $<0.001$ \\
CRP $_{\text {IL-8 }}$ & $-0.043(0.131)$ & 0.740 & $0.075(0.200)$ & 0.706 \\
Agatston score & $0.024(0.104)$ & 0.819 & $0.098(0.145)$ & 0.498 \\
\hline
\end{tabular}

$\mathrm{FEV}_{1}=$ forced expiratory volume in 1 second, $\mathrm{FVC}=$ forced vital capacity, $\mathrm{FFMI}=$ fat free mass index, \%LAA=percent of low attenuation areas, CRP=C-reactive protein, IL-8=interleukin-8 R-square: 0.141

Table 4. Correlations between bone attenuation and clinical outcomes in COPD subjects after adjustment for age, sex, and pack years of smoking

\begin{tabular}{lcc}
\hline & Spearman Correlation Coefficient & p-value \\
\hline${\text { Decline in } \mathrm{FEV}_{1}, \mathrm{ml} / \mathrm{yr}}^{\text {Exacerbation rate }}$ & 0.064 & 0.010 \\
Hospitalization rate & -0.057 & 0.022 \\
\hline
\end{tabular}

$\mathrm{FEV}_{1}=$ forced expiratory volume in 1 second

Table 5. Cox proportional hazards for all-cause mortality in COPD subjects

\begin{tabular}{lcc}
\hline & Hazard Ratio Estimate $(95 \% \mathrm{Cl})$ & p-value \\
\hline Age, yrs & $1.063(1.036,1.091)$ & $<0.001$ \\
Male versus Female & $1.128(0.802,1.587)$ & 0.489 \\
Bone attenuation, HU & $0.998(0.995,1.002)$ & 0.282 \\
\hline
\end{tabular}




\section{DISCUSSION}

Our data showed that bone attenuation of thoracic vertebrae 4, 7 and 10 measured on lowdose chest CT was lower in COPD subjects compared with smoker and non-smoker controls. In the COPD subjects, older age, lower FFMI and higher Agatston score were independently associated with lower CT-measured bone attenuation. In addition, lower CT-measured bone attenuation was associated with lower rate of decline in $\mathrm{FEV}_{1}$ and higher exacerbation and hospitalization rates, but was not associated with all-cause mortality.

In line with previous data, 8,17,30 COPD subjects had lower bone attenuation compared with smoker and non-smoker controls. However, the difference in bone attenuation between COPD subjects and smoker controls was not statistically significant after adjustment for age, sex and pack years of smoking. Since older age, female gender and smoking are wellestablished risk factors of osteoporosis, ${ }^{6}$ these factors may contribute to the difference in bone density between COPD subjects and smoker controls. Our data suggest that osteoporosis is a comorbidity rather than a systemic effect of COPD.

In the COPD subjects, higher bone attenuation of thoracic vertebrae 4, 7 and 10 was associated with higher $\mathrm{FEV}_{1}$ and less severe emphysema. In line with these findings, Ohara and colleagues ${ }^{13}$ demonstrated that in 65 male COPD patients the average bone density of thoracic vertebrae 4, 7 and 10 correlated positively with $\mathrm{FEV}_{1}(\mathrm{r}=0.286)$ and correlated negatively with \%LAA ( $r=-0.522)$. The higher correlation coefficients reported in their study may be due to differences in the study populations (e.g. race and sex) or the methods used (such as different slice thickness, emphysema quantification in a part of the lung rather than the whole lung, and assessment of bone attenuation with phantom CT). Several other studies have demonstrated a relationship between bone health and lung function parameters. ${ }^{8,31}$ It has even been suggested that the skeletal and pulmonary systems share a common underlying mechanism such as impairment of Wingless tail/ $\beta$-catenin signalling ${ }^{32}$ or disturbance of the RANK/RANKL/OPG pathway due to systemic inflammation. ${ }^{33}$

In addition to its relation with lung function parameters, bone attenuation decreased with age in the COPD subjects. A previous study showed that bone density of the thoracic vertebrae correlated negatively with age in male COPD patients, ${ }^{13}$ and a cross-sectional study with 554 COPD patients showed that patients aged 55 years or older had an increased risk of osteoporosis compared with their younger peers. ${ }^{29}$ In the general population, older age is a well-established risk factor of osteoporosis. ${ }^{6,34}$ In a healthy young skeleton, the rate of bone formation and matrix mineralization equals the rate of bone resorption and matrix degradation. However, during the aging process significant amounts of bone are lost due to enhanced resorption coupled with decreased formation, resulting in osteoporosis. ${ }^{35}$

Bone attenuation correlated positively with BMI and FFMI. This finding is supported by a study in which overweight and obese COPD patients had a decreased risk of osteoporosis whereas cachectic COPD patients had an increased risk of osteoporosis compared with 
their normal weight peers. ${ }^{29}$ Low body weight, BMI and FFMI are well-known risk factors of osteoporosis in COPD patients ${ }^{8,36}$ and in the general population. ${ }^{6,34}$ Low body weight may lead to bone loss due to decreased mechanical loading or direct effects of loss of fat free mass or fat mass on bone metabolism. Loss of fat free mass may result in bone loss due to increased systemic inflammation and protein breakdown, ${ }^{30}$ and loss of fat mass may result in reduced bone formation due to decreased secretion of bone active hormones from the pancreatic beta cells (e.g. insulin and amylin) and from adipocytes (e.g. leptin). ${ }^{37}$

Moreover, bone attenuation correlated negatively with coronary artery calcification. Although the relationship between bone density and cardiovascular disease has been studied widely in non-COPD populations, ${ }^{15,38-40}$ only one previous study showed a relationship between low bone density and increased arterial stiffness in COPD patients. ${ }^{17}$ The relationship between the skeletal and cardiovascular systems may be due to common risk factors like older age and smoking, or a shared underlying mechanism such as systemic inflammation, ${ }^{17}$ disturbance of the RANK/RANKL/OPG system ${ }^{41}$ and reduced bone perfusion due to generalized atherosclerosis. ${ }^{15}$

In our study, bone attenuation was similar among the COPD subjects with and without systemic inflammation. Notably, bone attenuation was negatively correlated with IL-8, while positively correlated with CRP. The positive correlation between bone attenuation and CRP disappeared after adjustment for $\mathrm{BMI}$, suggesting an interaction with BMI. A previous study in COPD patients indeed showed that an obese BMI was associated with elevated CRP levels. ${ }^{42}$

Although a meta-analysis demonstrated that the use of inhaled corticosteroids was associated with increased risk of fractures in COPD patients, ${ }^{9}$ our data did not show a relationship between bone attenuation and the use of inhaled corticosteroids. However, the lack of a relationship may be due to the design of our study since we did not record cumulative doses of inhaled corticosteroids.

Furthermore, no relationship was found between bone attenuation and the 6 minute walking distance. In line with this finding, a cross-sectional study with 95 COPD patients found no relationship between the 6 minute walking distance or the International Physical Activity Questionnaire total activity score and the T-score of the femoral neck or the lumbar spine. ${ }^{43}$ Although research demonstrating a relationship between physical activity and bone density is sparse in COPD patients, ${ }^{44}$ reductions in ground reaction forces, weight-bearing activities and muscular contraction are suggested to result in disuse osteoporosis ${ }^{45}$ and physical exercise has shown to have a positive effect on bone density in postmenopausal women. ${ }^{46}$

Regarding clinical outcomes, CT-measured bone attenuation correlated positively with rate of decline in $\mathrm{FEV}_{1}$, and correlated negatively with exacerbation and hospitalization rates, but was not associated with all-cause mortality. The positive correlation between bone attenuation and rate of decline in $\mathrm{FEV}_{1}$ may be due to a higher rate of decline in $\mathrm{FEV}_{1}$ in the subjects with a higher FEV 1 at baseline. Previous data have indeed demonstrated that the rate 
of decline in $\mathrm{FEV}_{1}$ is higher in subjects with less severe COPD. ${ }^{27}$ Although bone attenuation was correlated with exacerbation and hospitalization rates, it was not associated with allcause mortality. In the general population, data on the relationship between bone mineral density and mortality are conflicting ${ }^{47,48}$.

This study has several limitations. First, bone health was assessed using bone attenuation on CT rather than bone density on DXA which is the gold standard to diagnose osteoporosis. However, CT-measured bone attenuation has been shown to be strongly correlated with DXA scanned bone mineral density in COPD patients. ${ }^{22}$ Second, vertebral fractures were not assessed although vertebral fractures can occur in COPD patients with normal bone density. ${ }^{49}$ Third, bone attenuation was only assessed on the baseline CT scans. Since rate of bone loss has been associated with mortality in elderly men and women, ${ }^{48}$ it would be interesting to correlate changes in bone attenuation to clinical parameters and outcomes in COPD patients. Acknowledging these limitations, this study is important for several reasons. First, we compared bone attenuation in a large cohort of COPD subjects, smoker and nonsmoker controls, while previous studies reported comparisons of bone density in relatively small numbers of COPD subjects and control subjects. ${ }^{17,30}$ Second, our analyses were adjusted for age, sex and pack years of smoking, whereas previous data were not adjusted for these confounders. ${ }^{17,30}$ Third, our study contributes to the insight in the systemic complexity of COPD since it showed, as far as we know, for the first time a relationship between bone attenuation and coronary artery calcification in COPD subjects. Fourth, our study demonstrated that CT-measured bone attenuation was associated with clinical parameters in COPD subjects. These data suggest, in addition to our previous data, ${ }^{22}$ that CT-measured bone attenuation can be used to assess bone health in COPD subjects.

Our data showed that bone density is lower in COPD subjects compared with control subjects. Chest physicians should be aware of the risk of poor bone health in their COPD patients. Since bone attenuation was independently associated with age, body composition and coronary artery calcification, these factors may contribute to or protect against poor bone health in COPD patients. However, longitudinal studies are needed to study the factors that contribute to osteoporosis or are protective against osteoporosis in COPD and to study their underlying mechanisms.

In conclusion, CT-measured bone attenuation of the thoracic vertebrae was lower in COPD subjects compared with smoker and non-smoker controls. However, bone attenuation was not significantly different between COPD subjects and smoker controls after adjustment for age, sex and pack years of smoking, suggesting osteoporosis may be a comorbidity rather than a systemic effect of COPD. In the COPD subjects, CT-measured bone attenuation was independently associated with age, body composition and coronary artery calcification, but not with all-cause mortality. 


\section{DISCLOSURES}

The ECLIPSE study was supported by GlaxoSmithKline. Lisa D. Edwards is an employee of GlaxoSmithKline and owns stock in GlaxoSmithKline. Elisabeth A.P.M. was the recipient of a European Respiratory Society Fellowship (STRTF 381-2011). The work described in this manuscript was performed at the University of Edinburgh as part of this Fellowship. 


\section{REFERENCES}

1. Andreassen $\mathrm{H}$, Vestbo J. Chronic obstructive pulmonary disease as a systemic disease: an epidemiological perspective. Eur Respir J Suppl 2003; 46: 2s-4s.

2. Fabbri LM, Luppi F, Beghe B, Rabe KF. Complex chronic comorbidities of COPD. Eur Respir J 2008; 31 : 204-12.

3. Barnes PJ, Celli BR. Systemic manifestations and comorbidities of COPD. Eur Respir J 2009; 33: 1165-85.

4. Chatila WM, Thomashow BM, Minai OA, Criner GJ, Make BJ. Comorbidities in chronic obstructive pulmonary disease. Proc Am Thorac Soc 2008; 5: 549-55.

5. Wouters EF, Creutzberg EC, Schols AM. Systemic effects in COPD. Chest 2002; 121: 127S-30S.

6. World Health Organization. Prevention and Management of Osteoporosis; report of a WHO scientific group [updated 2003; cited 2013 August]. Available from: http://whqlibdoc.who.int/trs/WHO_ TRS_921.pdf.

7. Duckers JM, Evans BA, Fraser WD, Stone MD, Bolton CE, Shale DJ. Low Bone Mineral Density in Men with Chronic Obstructive Pulmonary Disease. Respir Res 2011; 12: 101.

8. Graat-Verboom L, Wouters EF, Smeenk FW, van den Borne BE, Lunde R, Spruit MA. Current status of research on osteoporosis in COPD: a systematic review. Eur Respir J 2009; 34: 209-18.

9. Loke YK, Cavallazzi R, Singh S. Risk of fractures with inhaled corticosteroids in COPD: systematic review and meta-analysis of randomised controlled trials and observational studies. Thorax 2011; 66: 699-708.

10. Kjensli A, Mowinckel P, Ryg MS, Falch JA. Low bone mineral density is related to severity of chronic obstructive pulmonary disease. Bone 2007; 40: 493-7.

11. Lehouck A, Boonen S, Decramer M, Janssens W. COPD, Bone Metabolism, and Osteoporosis. Chest 2011; 139: 648-57.

12. Bon J, Fuhrman CR, Weissfeld JL et al. Radiographic emphysema predicts low bone mineral density in a tobacco-exposed cohort. Am J Respir Crit Care Med 2011; 183: 885-90.

13. Ohara T, Hirai T, Muro S et al. Relationship between pulmonary emphysema and osteoporosis assessed by CT in patients with COPD. Chest 2008; 134: 1244-9.

14. Bai $P$, Sun $Y$, Jin J, Hou J, Li R, Zhang $Q$, Wang Y. Disturbance of the OPG/RANK/RANKL pathway and systemic inflammation in COPD patients with emphysema and osteoporosis. Respir Res 2011; 12: 157.

15. London GM. Soft bone - hard arteries: a link? Kidney Blood Press Res 2011; 34: 203-8.

16. Feary JR, Rodrigues LC, Smith CJ, Hubbard RB, Gibson JE. Prevalence of major comorbidities in subjects with COPD and incidence of myocardial infarction and stroke: a comprehensive analysis using data from primary care. Thorax 2010; 65: 956-62.

17. Sabit R, Bolton $\mathrm{CE}$, Edwards $\mathrm{PH}$ et al. Arterial stiffness and osteoporosis in chronic obstructive pulmonary disease. Am J Respir Crit Care Med 2007; 175: 1259-65.

18. Decramer M, Rennard S, Troosters T et al. COPD as a lung disease with systemic consequences--clinical impact, mechanisms, and potential for early intervention. COPD 2008; 5: 235-56.

19. Sinden NJ, Stockley RA. Systemic inflammation and comorbidity in COPD: a result of 'overspill' of inflammatory mediators from the lungs? Review of the evidence. Thorax 2010; 65: 930-6.

20. Romme EA, Rutten EP, Smeenk FW, Spruit MA, Menheere PP, Wouters EF. Vitamin D status is associated with bone mineral density and functional exercise capacity in patients with chronic obstructive pulmonary disease. Ann Med 2013; 45: 91-6.

21. Vestbo J, Anderson W, Coxson $\mathrm{HO}$ et al. Evaluation of COPD Longitudinally to Identify Predictive Surrogate End-points (ECLIPSE). Eur Respir J 2008; 31: 869-73.

22. Romme EA, Murchison JT, Phang KF et al. Bone attenuation on routine chest CT correlates with bone mineral density on DXA in patients with COPD. J Bone Miner Res 2012; 27: 2338-43.

23. ATS statement: guidelines for the six-minute walk test. Am J Respir Crit Care Med 2002; 166: 111-7. 
24. Gietema HA, Muller NL, Fauerbach PV, Sharma S, Edwards LD, Camp PG, Coxson HO. Quantifying the extent of emphysema: factors associated with radiologists' estimations and quantitative indices of emphysema severity using the ECLIPSE cohort. Acad Radiol 2011; 18: 661-71.

25. Agatston AS, Janowitz WR, Hildner FJ, Zusmer NR, Viamonte M, Jr., Detrano R. Quantification of coronary artery calcium using ultrafast computed tomography. J Am Coll Cardiol 1990; 15: 827-32.

26. McClelland RL, Chung H, Detrano R, Post W, Kronmal RA. Distribution of coronary artery calcium by race, gender, and age: results from the Multi-Ethnic Study of Atherosclerosis (MESA). Circulation 2006; 113: 30-7.

27. Vestbo J, Edwards LD, Scanlon PD et al. Changes in forced expiratory volume in 1 second over time in COPD. N Engl J Med 2011; 365: 1184-92.

28. Agusti A, Edwards LD, Rennard SI et al. Persistent systemic inflammation is associated with poor clinical outcomes in COPD: a novel phenotype. PLoS One 2012; 7: e37483.

29. Graat-Verboom L, Spruit MA, van den Borne BE, Smeenk FW, Martens EJ, Lunde R, Wouters EF. Correlates of osteoporosis in chronic obstructive pulmonary disease: An underestimated systemic component. Respir Med 2009; 103: 1143-51.

30. Bolton $\mathrm{CE}$, lonescu AA, Shiels KM et al. Associated loss of fat-free mass and bone mineral density in chronic obstructive pulmonary disease. Am J Respir Crit Care Med 2004; 170: 1286-93.

31. Bon J. Does radiographic emphysema correlate with low bone mineral density? Curr Opin Pulm Med 2012; 18: 125-30.

32. Kneidinger N, Yildirim AO, Callegari J et al. Activation of the WNT/beta-catenin pathway attenuates experimental emphysema. Am J Respir Crit Care Med 2011; 183: 723-33.

33. Hardy R, Cooper MS. Bone loss in inflammatory disorders. J Endocrinol 2009; 201: 309-20.

34. Kanis JA, Johnell O, Oden A, Johansson $\mathrm{H}$, McCloskey E. FRAX and the assessment of fracture probability in men and women from the UK. Osteoporos Int 2008; 19: 385-97.

35. Syed FA, Ng AC. The pathophysiology of the aging skeleton. Curr Osteoporos Rep 2010; 8: 235-40.

36. Bolton CE, Cannings-John R, Edwards PH et al. What community measurements can be used to predict bone disease in patients with COPD? Respir Med 2008; 102: 651-7.

37. Reid IR. Fat and bone. Arch Biochem Biophys 2010; 503: 20-7.

38. Schulz E, Arfai K, Liu X, Sayre J, Gilsanz V. Aortic calcification and the risk of osteoporosis and fractures. J Clin Endocrinol Metab 2004; 89: 4246-53.

39. Tanko LB, Christiansen C, Cox DA, Geiger MJ, McNabb MA, Cummings SR. Relationship between osteoporosis and cardiovascular disease in postmenopausal women. J Bone Miner Res 2005; 20 1912-20.

40. Toussaint ND, Lau KK, Strauss BJ, Polkinghorne KR, Kerr PG. Associations between vascular calcification, arterial stiffness and bone mineral density in chronic kidney disease. Nephrol Dial Transplant 2008; 23: $586-93$

41. Vega D, Maalouf NM, Sakhaee K. CLINICAL Review \#: the role of receptor activator of nuclear factorkappaB (RANK)/RANK ligand/osteoprotegerin: clinical implications. J Clin Endocrinol Metab 2007; 92 : 4514-21.

42. Breyer MK, Spruit MA, Celis AP, Rutten EP, Janssen PP, Wouters EF. Highly elevated C-reactive protein levels in obese patients with COPD: a fat chance? Clin Nutr 2009; 28: 642-7.

43. Silva DR, Coelho AC, Dumke A et al. Osteoporosis prevalence and associated factors in patients with COPD: a cross-sectional study. Respir Care 2011; 56: 961-8.

44. Nishimura Y, Nakata H, Tsutsumi M, Maeda H, Yokoyama M. Relationship between changes of bone mineral content and twelve-minute walking distance in men with chronic obstructive pulmonary disease: a longitudinal study. Intern Med 1997; 36: 450-3.

45. Lau RY, Guo X. A review on current osteoporosis research: with special focus on disuse bone loss. J Osteoporos 2011; 2011: 293808.

46. Howe TE, Shea B, Dawson L et al. Exercise for preventing and treating osteoporosis in postmenopausal women. Cochrane Database Syst Rev 2011; CD000333. 
47. Mussolino ME, Madans JH, Gillum RF. Bone mineral density and mortality in women and men: the NHANES I epidemiologic follow-up study. Ann Epidemiol 2003; 13: 692-7.

48. Nguyen ND, Center JR, Eisman JA, Nguyen TV. Bone loss, weight loss, and weight fluctuation predict mortality risk in elderly men and women. J Bone Miner Res 2007; 22: 1147-54.

49. Graat-Verboom L, van den Borne BE, Smeenk FW, Spruit MA, Wouters EF. Osteoporosis in COPD outpatients based on bone mineral density and vertebral fractures. J Bone Miner Res 2011; 26: 561-8. 


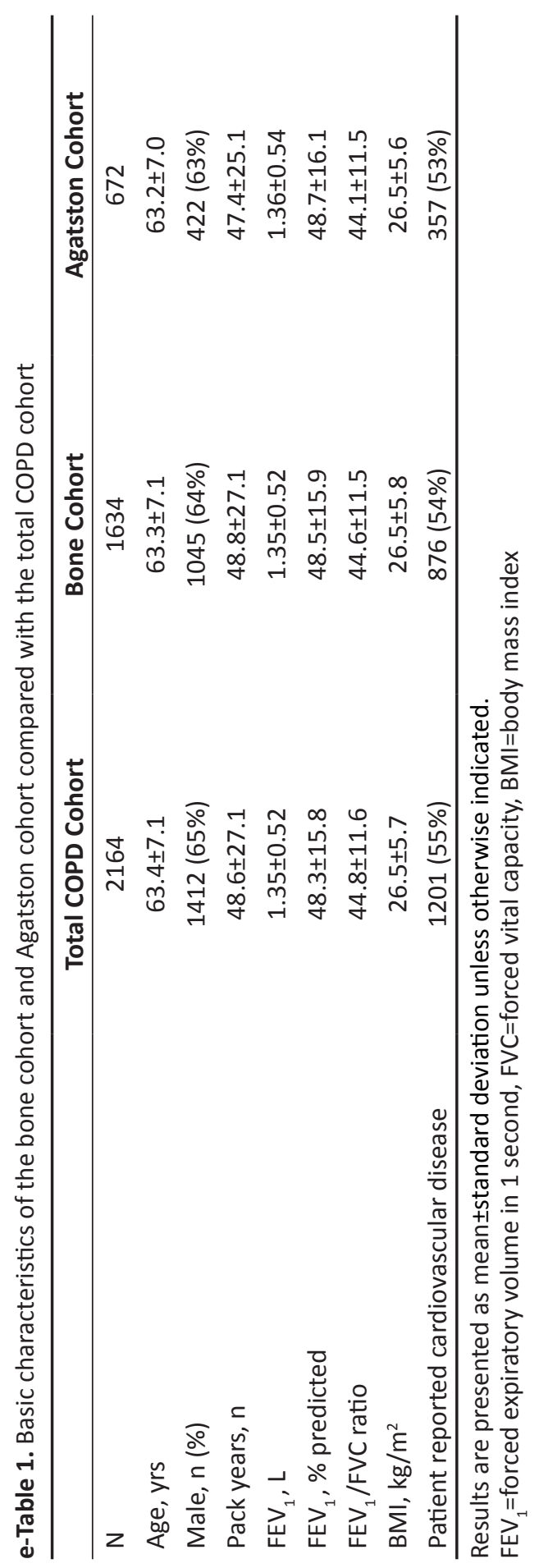






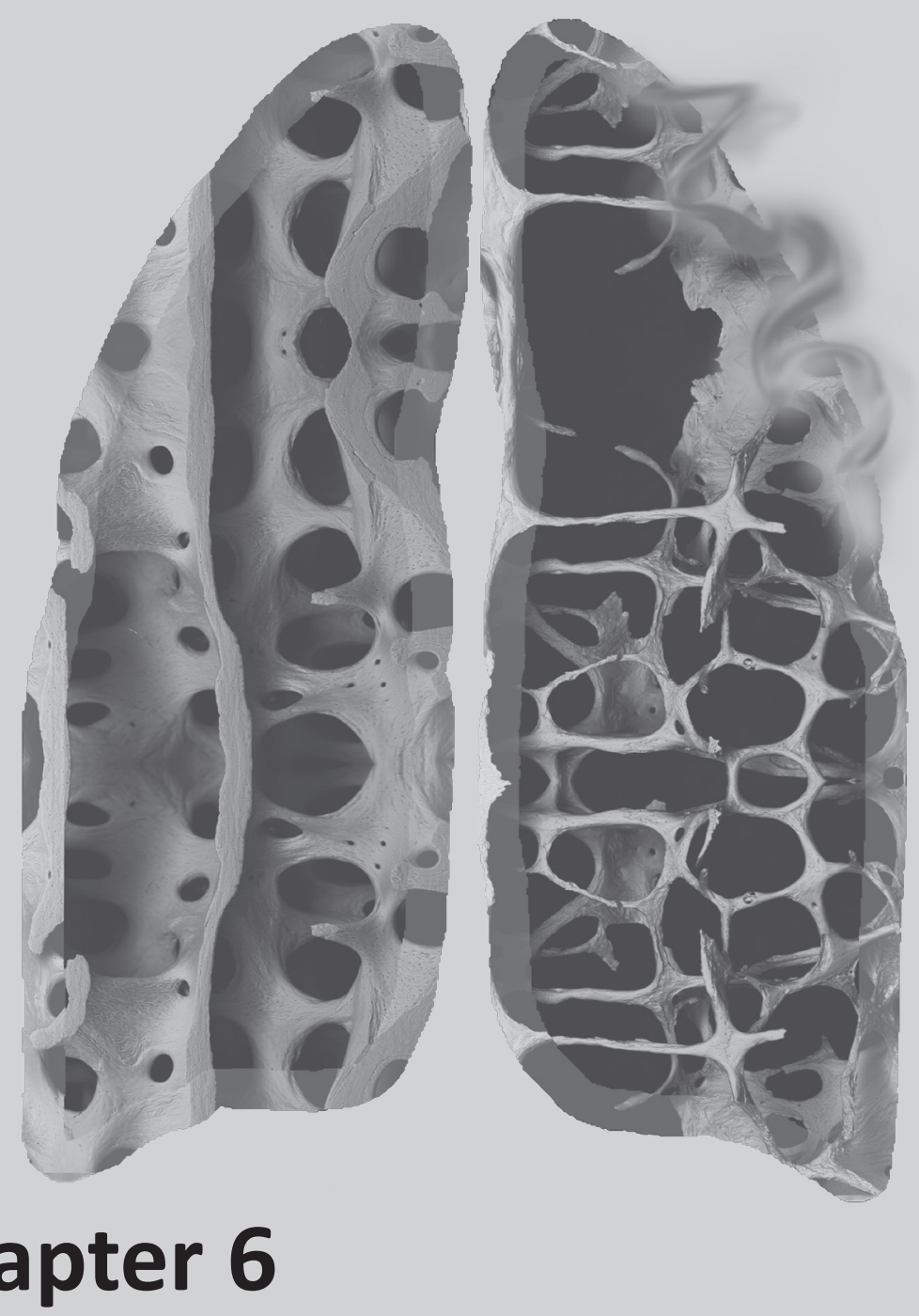

Associations between COPD-related manifestations: arterial calcification and stiffness, bone density, emphysema and all-cause mortality

Elisabeth A.P.M. Romme

David A. McAllister

John T. Murchison

Edwin J.R. Van Beek

George S. Petrides

Respiratory Research 2013; 14: 129
Cameron O. S. Price

Erica P.A. Rutten

Frank W.J.M. Smeenk

Emiel F.M. Wouters

William MacNee 


\section{ABSTRACT}

\section{Purpose}

To examine associations between arterial stiffness, coronary artery calcium (CAC), thoracic aortic calcium (TAC), bone attenuation of the thoracic vertebrae, extent of emphysema and all-cause mortality in a COPD cohort.

\section{Materials and Methods}

The institutional review board approved the study protocol. We studied 119 COPD subjects (mean age $67.8 \pm 7.3$ years, $66 \%$ males and mean $\mathrm{FEV}_{1} 46.0 \pm 17.5 \%$ predicted), who were recruited from a university hospital between April 2003 and December 2005. We measured arterial stiffness as carotid-radial pulse wave velocity (PWV), and we assessed CAC, TAC, bone attenuation of the thoracic vertebrae and extent of emphysema on computed tomography of the chest. We identified deaths from the national register.

\section{Results}

Subjects with higher CAC were more likely to be older $(p<0.001)$ and male $(p=0.03)$, and more likely to have higher systolic blood pressure $(p=0.001)$ and a history of hypertension $(p=0.002)$ or ischemic heart disease $(p=0.003)$. Higher CAC was associated with higher PWV (OR 1.62, $p=0.04$ ) and lower bone attenuation (OR 0.32, $p=0.02$ ), but not with the extent of emphysema after adjustment for age, sex and pack years of smoking. In a Cox proportionalhazards model, CAC, TAC and extent of emphysema predicted all-cause mortality (HR 2.01, 2.09 and 0.66 , respectively).

\section{Conclusion}

Increased CAC was associated with increased arterial stiffness and lower bone attenuation. In addition, CAC, TAC and extent of emphysema predicted all-cause mortality in a COPD cohort. Thus, quantitative assessment of CAC, TAC and emphysema on computed tomography of the chest might provide relevant prognostic information in COPD patients. 


\section{INTRODUCTION}

Chronic obstructive pulmonary disease (COPD), in addition to its pulmonary manifestations, is associated with significant extrapulmonary manifestations. Cardiovascular disease and osteoporosis are recognised extrapulmonary manifestations, whose prevalence is higher in COPD patients than in control subjects matched for age and sex. ${ }^{1,2}$

In general population studies, a relationship has been suggested between cardiovascular disease and osteoporosis. Postmenopausal women with osteoporosis had a 3.9-fold increased risk of cardiovascular events compared with postmenopausal women with osteopenia. ${ }^{3}$ In 2348 postmenopausal women, increased aortic calcification, a marker of cardiovascular disease, was associated with lower bone density and an increased number of vertebral and hip fractures, ${ }^{4}$ and in a subpopulation studied longitudinally, progression of aortic calcification was associated with bone loss. ${ }^{4}$

Although cardiovascular disease and osteoporosis are common in COPD patients, ${ }^{1,2}$ there are few studies on the relationship between cardiovascular disease and osteoporosis in COPD. Sabit and colleagues ${ }^{5}$ found that COPD subjects with osteoporosis had increased arterial stiffness, another marker of cardiovascular disease, compared with COPD subjects without osteoporosis. In addition, arterial stiffness and osteoporosis have been shown to relate to the extent of emphysema. ${ }^{6,7}$ These data suggest associations between cardiovascular disease, osteoporosis and emphysema. Furthermore, COPD-related extrapulmonary manifestations are thought to contribute to morbidity and mortality. ${ }^{8}$

The objectives of this study were: 1) To determine the associations between markers of cardiovascular disease (coronary artery calcium [CAC], thoracic aortic calcium [TAC] and arterial stiffness), bone attenuation of the thoracic vertebrae, and extent of emphysema; and 2) To identify whether these factors predict all-cause mortality in a COPD cohort.

\section{MATERIALS AND METHODS}

Our analysis was based on the data of a cohort study designed to identify prognostic markers in COPD. ${ }^{6}$ The study was conducted in accordance with the amended Declaration of Helsinki, the protocol was approved by the Lothian Research Ethics Committee (LREC/2003/8/28), and all subjects gave written informed consent.

\section{Subjects}

The inclusion and exclusion criteria have been described previously. ${ }^{6}$ In summary, all subjects were included between April 2003 and December 2005, had a clinical history compatible with COPD, a history of smoking for at least 10 pack years and evidence of chronic airflow limitation on spirometry. All subjects who had low-dose computed tomography (CT) of the chest were included in our analysis. 
Height, weight and post-bronchodilator spirometry were measured according to American Thoracic Society/ European Respiratory Society standards. The subjects' self-reported respiratory symptoms, medications, smoking history, occupational exposure, and coexisting medical conditions were documented at study entry using structured interviews.

\section{Arterial stiffness}

Peripheral blood pressure was measured in all subjects, and arterial stiffness was assessed in 104 subjects. Arterial stiffness was measured as carotid-radial pulse wave velocity (PWV) as described previously. ${ }^{6}$ Briefly, we used the Q-wave of a simultaneously recorded electrocardiograph to identify the onset of the pressure wave, and used applanation tonometry of the carotid and radial arteries to record the pressure waveform at the peripheral site. The difference in wave transit time between the carotid and radial arteries was used to calculate carotid-radial PWV.

\section{CT scanning}

Low-dose CT scanning of the chest was performed without contrast media at full inspiration using a 16-slice multi-detector-row CT scanner (135 kV, 20 mAS; Toshiba Aquilion, Toshiba, Japan). Images were reconstructed with a slice thickness of $1 \mathrm{~mm}$ increment using an FC-03 filter (Toshiba, Japan).

CAC and TAC were assessed on the standard images used for analysis of the lungs as previously described. ${ }^{9}$ Images were analysed on a dedicated post-processing workstation (VOXAR 3D) using calcium analysis software. CAC and TAC were quantified using the Agatston score. ${ }^{10}$ Calcification was defined as an area $\geq 1 \mathrm{~mm}^{2}$ in the axial plane of a coronary artery or the thoracic aorta with an attenuation threshold of $\geq 130$ Hounsfield units. Regions of interest were drawn, and CAC and TAC were calculated by multiplying by a weighting factor selected dependent on the peak signal within the region of interest. Total CAC was obtained by summing the weighted scores from each coronary artery, and total TAC was obtained by summing the weighted scores from the ascending aorta, aortic arch and descending aorta superiorly to the upper limit of the thoracic vertebrae 12 (T12). The CT images of a random sample of 25 patients were independently assessed by two observers and assessed by one observer twice. The intra-class correlation coefficients were high for inter-observer and intraobserver agreements for CAC (0.88 and 0.99 respectively) and TAC (both 0.99).

Emphysema was quantified by in-house software using the $15^{\text {th }}$ percentile point of the frequency distribution of lung attenuation, and pixel index for -950 (PI-950) Hounsfield units as previously described. ${ }^{6}$ Bone attenuation of the thoracic vertebrae was measured according to a method described in detail previously. ${ }^{11}$ The mean bone attenuation of thoracic vertebrae 4, 7 and 10 (T4, T7 and T10) were determined by placing circular regions of interest in the central parts of the vertebral bodies. The average bone attenuation of these three vertebrae T4, T7 and T10 was calculated and expressed in Hounsfield units. 


\section{Mortality}

Deaths occurring anywhere in the United Kingdom were identified by obtaining records from the General Registry Office for Scotland. Survival time was calculated in number of days from date of CT scan until date of death with a census cut-off date of 31 December 2011.

\section{Statistical analysis}

CAC and TAC were log transformed (normalising/ linearising transformations). For CAC, subjects were classified into three pre-specificed groups: $C A C=0,0<C A C \leq 400$ and $C A C>400$. Comparisons among the three groups were made using one way analysis of variance (ANOVA) or Kruskal-Wallis test. Univariate and multinominal logistic regression analyses were performed to estimate associations between CAC, TAC, PWV, bone attenuation and $15^{\text {th }}$ percentile. Time to death was compared using Kaplan Meier curves, and Cox proportionalhazards analysis was used to estimate associations between all-cause mortality and CAC, TAC, PWV, bone attenuation and $15^{\text {th }}$ percentile.

All statistical analyses were performed in SPSS version 17.0 (SPSS Inc., Chicago, IL, USA). Two-sided $p$-values $\leq 0.05$ were considered statistically significant.

\section{RESULTS}

One hundred nineteen COPD subjects (aged $67.8 \pm 7.3$, 66\% were males, mean forced expiratory volume in 1 second $\left[\mathrm{FEV}_{1}\right] \%$ predicted was $\left.46.0 \pm 17.5\right)$ were included in our analysis. Subjects with higher CAC were more likely to be older $(p<0.001)$, male $(p=0.03)$, and to have higher systolic blood pressure $(p=0.001)$, a history of hypertension $(p=0.002)$ or ischemic heart disease $(p=0.003)$, higher TAC $(p<0.001)$ and lower bone attenuation $(p=0.006)$ (Table 1). As expected there was a significant correlation between CAC and TAC (Spearman's $r=0.57$, $p<0.001)$. Higher CAC was associated with higher PWV (OR 1.62, $p=0.04)$ and lower bone attenuation (OR $0.32, \mathrm{p}=0.02$ ), but was not associated with $\mathrm{FEV}_{1}, 15^{\text {th }}$ percentile and $\mathrm{PI}-950$ after adjustment for age, sex and pack years of smoking (Table 2). As described previously, PWV correlated with $15^{\text {th }}$ percentile and PI-950 $(r=0.47, p<0.001) .{ }^{6}$ Bone attenuation was not associated with PWV, $15^{\text {th }}$ percentile or PI-950 (data not shown).

\section{Mortality}

The median follow-up was 65 (0-83) months. During the observation period, 30 subjects $(25 \%)$ died. A respiratory cause of death was the primary aetiology in 18 subjects $(60 \%)$, and cardiovascular cause of death was the primary aetiology in 7 subjects (23\%). In a Cox proportional-hazards model, CAC predicted all-cause mortality after adjustment for age, sex, $\mathrm{FEV}_{1}$ and pack years of smoking ( $\mathrm{HR} 2.01,95 \% \mathrm{Cl} 1.13-3.58, \mathrm{p}=0.02$, Table 3). Figure 1 and Table 4 show the Kaplan-Meier curves and numbers at risk. TAC predicted all-cause mortality similarly to CAC (see supplement, e-Table 1). Lower $15^{\text {th }}$ percentile (more emphysema) was associated with increased all-cause mortality after adjustment for age and sex (HR 0.65, Cl 0.45-0.95, $\mathrm{p}=0.03$ ), but not after adjustment for age, sex, $\mathrm{FEV}_{1}$ and pack years of smoking $(p=0.06)$ (see supplement, e-Table 2). PWV and bone attenuation were not associated with all-cause mortality (see supplement, e-Table 2 ). 


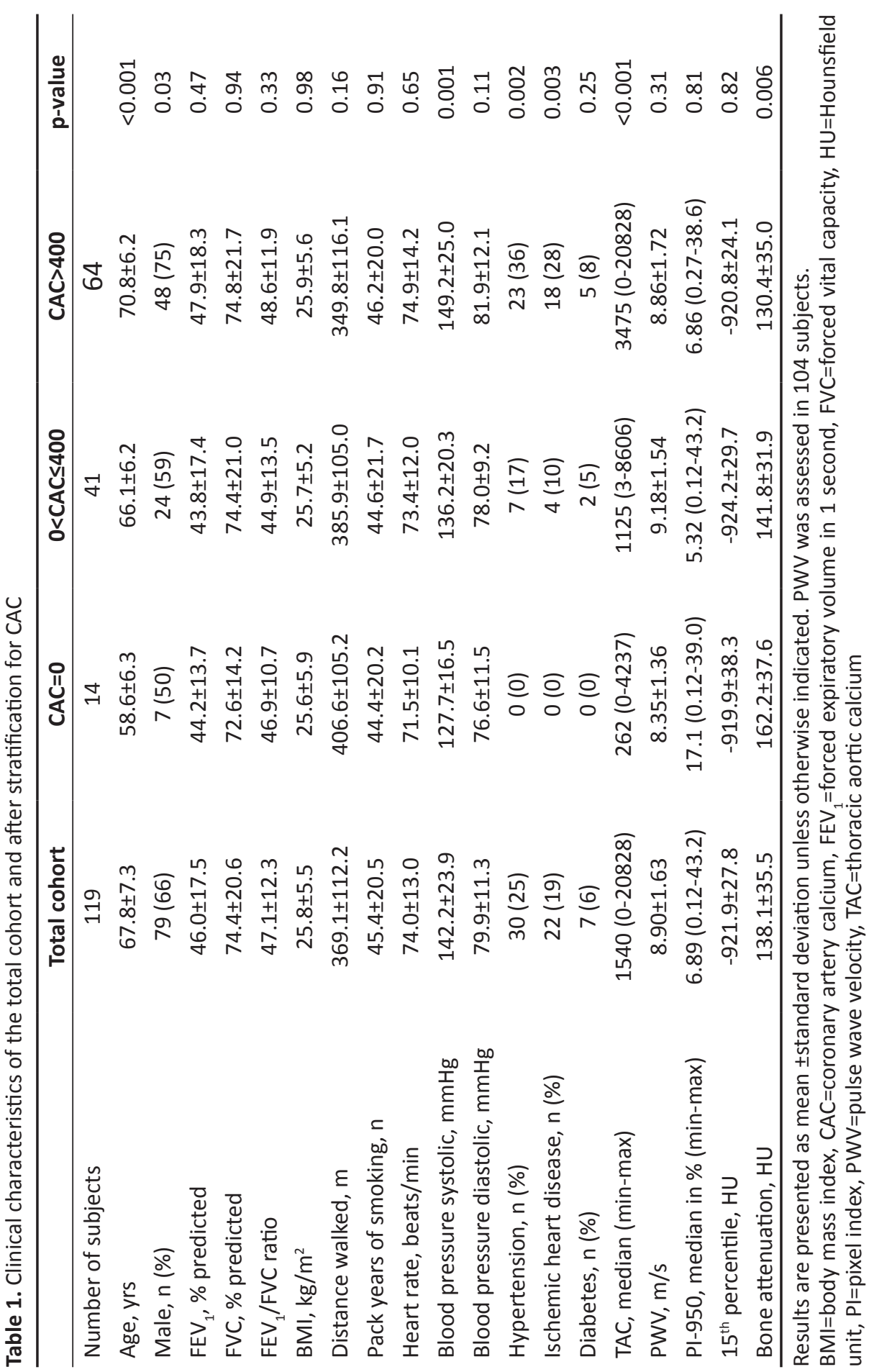


Table 2. Multinomial regression for CAC

\begin{tabular}{|c|c|c|c|c|c|}
\hline & \multicolumn{2}{|c|}{$0<C A C \leq 400$} & \multicolumn{2}{|c|}{ CAC $>400$} & \multirow[b]{2}{*}{ p-value } \\
\hline & Odds ratio & $95 \% \mathrm{Cl}$ & Odds ratio & $95 \% \mathrm{Cl}$ & \\
\hline$P W V^{a}$ & 1.92 & $1.08-3.44$ & 1.62 & $0.91-2.91$ & 0.05 \\
\hline$P W V^{b}$ & 2.03 & $1.10-3.74$ & 1.62 & $0.87-3.02$ & 0.04 \\
\hline Bone attenuation/ SD ${ }^{a}$ & 0.46 & $0.21-1.03$ & 0.33 & $0.14-0.77$ & 0.02 \\
\hline Bone attenuation/SD ${ }^{b}$ & 0.43 & $0.19-1.00$ & 0.32 & $0.13-0.76$ & 0.02 \\
\hline $\mathrm{FEV}_{1}{ }^{\mathrm{a}}$ & 0.82 & $0.22-3.09$ & 0.84 & $0.21-3.29$ & 0.96 \\
\hline $\mathrm{FEV}_{1}{ }^{\mathrm{b}}$ & 0.80 & $0.21-3.05$ & 0.82 & $0.21-3.25$ & 0.95 \\
\hline $15^{\text {th }}$ percentile/ SD a & 0.80 & $0.45-1.45$ & 0.64 & $0.45-1.63$ & 0.76 \\
\hline $15^{\text {th }}$ percentile $/ S^{b}$ & 0.80 & $0.43-1.48$ & 0.84 & $0.43-1.64$ & 0.77 \\
\hline
\end{tabular}

Reference category $\mathrm{CAC}=0$

a after adjustment for age and sex

${ }^{\mathrm{b}}$ after adjustment for age, sex and pack years of smoking

$\mathrm{Cl}=$ confidence interval, $\mathrm{FEV}_{1}=$ forced expiratory volume in 1 second, $\mathrm{PWV}=$ pulse wave velocity,

$\mathrm{SD}=$ standard deviation

Table 3. Cox proportional-hazards for all-cause mortality

\begin{tabular}{lccccc}
\hline & CAC $=\mathbf{0}$ & $\mathbf{0}<C A C \leq 400$ & CAC $>$ 400 & Per 10-fold increase in CAC & p-value \\
\hline $\begin{array}{l}\text { Number of } \\
\text { subjects }\end{array}$ & 14 & 41 & 64 & - & - \\
Mortality, n (\%) & $1(7)$ & $4(10)$ & $25(39)$ & - & - \\
CAC $^{\text {CAC }}{ }^{\text {a }}$ & - & 1.33 & 6.46 & $2.17(1.29-3.65)$ & 0.004 \\
CAC $^{\text {b }}$ & - & 1.18 & 5.15 & $2.02(1.13-3.59)$ & 0.02 \\
CAC $^{c}$ & - & 1.14 & 5.09 & $1.94(1.11-3.41)$ & 0.02 \\
\hline
\end{tabular}

${ }^{a}$ after adjustment for age and sex

${ }^{\mathrm{b}}$ after adjustment for age, sex and FEV

c after adjustment for age, sex, $\mathrm{FEV}_{1}$ and pack years of smoking

$\mathrm{CAC}=$ coronary artery calcium, $\mathrm{FEV}_{1}=$ forced expiratory volume in 1 second 


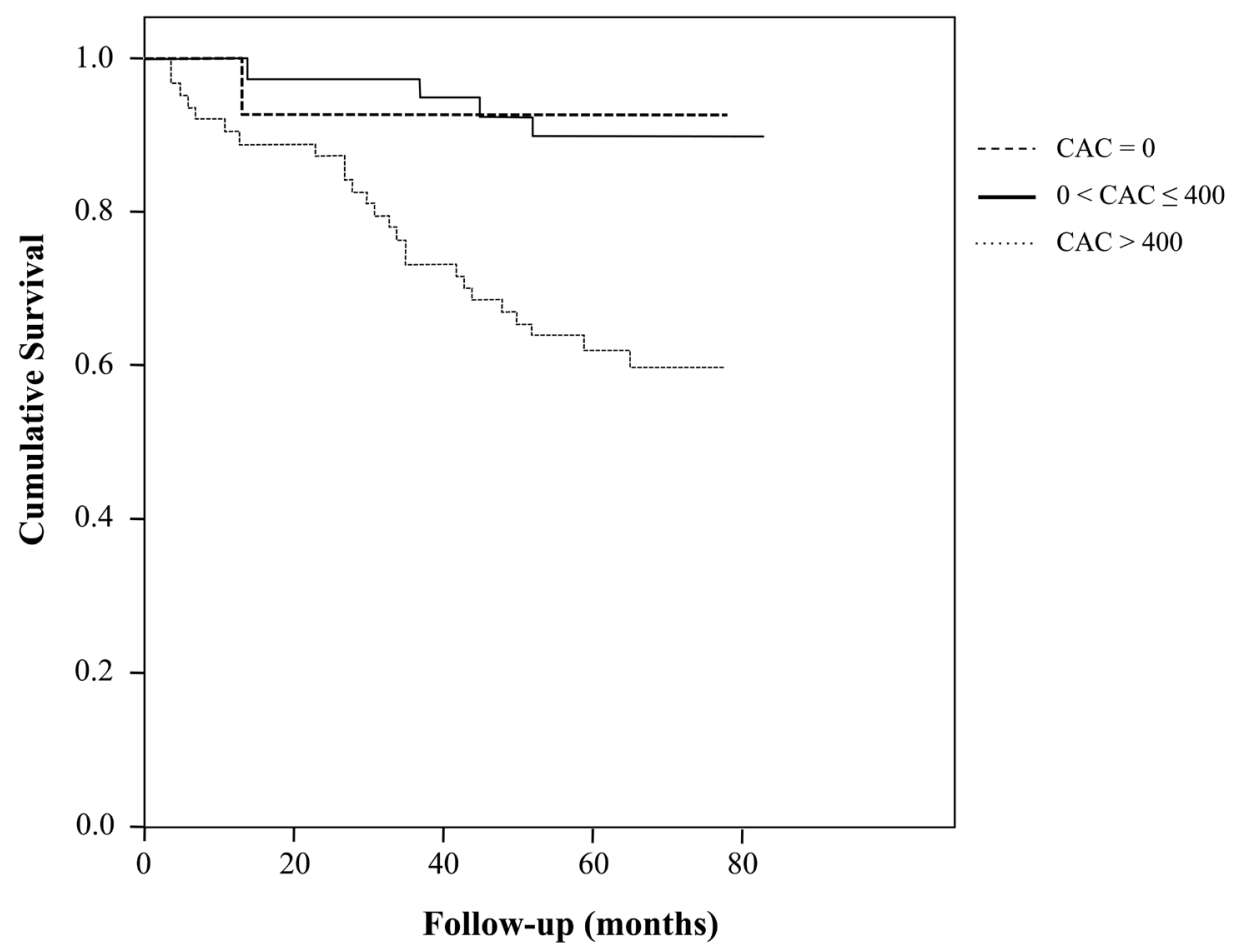

Figure 1. Kaplan-Meier

$\mathrm{CAC}=$ coronary artery calcium

Table 4. Numbers at risk

\begin{tabular}{lccc}
\hline & CAC $=\mathbf{0}$ & 0 $<$ CAC $\leq$ 400 & CAC $>$ 400 \\
\hline 0 months & 14 & 41 & 64 \\
30 months & 13 & 40 & 52 \\
60 months & 10 & 31 & 32 \\
\hline
\end{tabular}

$\mathrm{CAC}=$ coronary artery calcium 


\section{DISCUSSION}

We found that increased CAC was associated with increased arterial stiffness and lower bone attenuation in COPD subjects, but was not associated with extent of emphysema. CAC, TAC and extent of emphysema predicted all-cause mortality in our COPD cohort, while arterial stiffness and bone attenuation were not associated with all-cause mortality.

In line with previous studies, ${ }^{4,5}$ our data suggest a relationship between cardiovascular disease and osteoporosis in COPD patients. In our study, the association between CAC and bone attenuation was independent of age, sex and pack years of smoking. In a prospective study in 2442 postmenopausal women, the association between osteoporosis and cardiovascular events was independent of traditional cardiovascular risk factors such as age, cigarette smoking, hypertension and hyperlipidemia. ${ }^{3}$ These data suggest that, in addition to common risk factors, other factors might be involved in the vascular-bone relationship, including systemic inflammation, ${ }^{5}$ disturbance of the receptor activator of NF-kB/ receptor activator of NF-KB ligand/ osteoprotegerin system or reduced bone perfusion due to generalised atherosclerosis.

Our data showed a weak association between CAC and arterial stiffness in a COPD cohort after adjustment for age, sex and pack years of smoking. Previous studies in older populations have found associations between CAC and arterial stiffness after adjustment for confounders. ${ }^{12}$ Thus, in addition to common risk factors, atherosclerosis may cause arterial stiffening, ${ }^{13}$ while increased arterial stiffness in turn may promote atherosclerotic changes due to greater shear and intraluminal stresses. ${ }^{14}$

In line with previous research, ${ }^{15,16}$ CAC was not associated with the degree of airflow obstruction or the extent of emphysema. CAC was not associated with the severity of airflow obstruction or the extent of emphysema in 1159 smokers of the Multicentre Italian Lung Detection (MILD) study, ${ }^{16}$ and CAC and proximal aortic calcification were not associated with the severity of airflow obstruction in subjects without clinical cardiovascular disease of the Multi-Ethnic Study of Atherosclerosis (MESA) study. ${ }^{15,17}$ Notably, as reported previously in this cohort, arterial stiffness did correlate with the extent of emphysema in COPD subjects. ${ }^{6}$ The relationship between arterial stiffness and emphysema might be due to connective tissue degradation ${ }^{6}$ or elastin degradation. ${ }^{18}$

Bone attenuation was not associated with the extent of emphysema. In contrast, a recent review stated that more severe emphysema is associated with reduced bone mineral density. ${ }^{19}$ Bon and colleagues ${ }^{7}$ showed that the extent of emphysema was independently associated with bone mineral density in 190 current and former smokers, and Ohara and colleagues $^{20}$ demonstrated that the extent of emphysema was independently associated with CT-measured bone density of the thoracic and lumbar vertebrae in 65 male COPD subjects. The discrepancy between our data and their data might be due to differences in the study population (e.g. smokers versus COPD patients) and methods used (e.g. attenuation threshold of low attenuation areas). 
CAC and TAC predicted all-cause mortality after adjustment for age, sex, FEV and $_{1}$ pack years of smoking. Several studies have shown that CAC is a predictor of cardiovascular events and mortality in smokers. ${ }^{21,22}$ Here we show that CAC was a strong predictor of all-cause mortality in a COPD cohort. The hazard ratios reported in our COPD subjects were comparable with those reported in smokers and subjects without known coronary artery diseases. In 1159 smokers, the hazard ratio of $\mathrm{CAC}>400$ was $4.00(\mathrm{Cl} 1.17-13.7)$ for all-cause mortality compared with $\mathrm{CAC} \leq 400$ after adjustment for age, sex, body mass index and history of diabetes or hypertension. ${ }^{16}$ In our study, the hazard ratio of CAC $>400$ was $4.6(\mathrm{Cl} 1.63-13.12, p=0.004$, data not shown) compared with $\mathrm{CAC} \leq 400$ after adjustment for age, sex, $\mathrm{FEV}_{1}$ and pack years of smoking. In 3966 subjects without known coronary artery diseases, the crude hazard ratio of CAC $\geq 400$ was HR 6.54 ( $\mathrm{Cl} 3.51-12.21)$ for all-cause mortality, ${ }^{23}$ and in our study the crude hazard ratio of $C A C>400$ was 6.46 .

Although CAC and TAC were associated with all-cause mortality, arterial stiffness was not associated with all-cause mortality in our COPD cohort. This finding is in contrast to previous studies that have demonstrated a relationship between increased arterial stiffness and allcause mortality in subjects with chronic kidney disease. ${ }^{24,25}$ The lack of a relationship between increased arterial stiffness and mortality in our study might be explained by the fact that we measured carotid-radial PWV rather than carotid-femoral PWV which is the gold standard. ${ }^{26}$ A study in 305 end-stage renal disease patients showed indeed that carotid-femoral PWV was an independent predictor of cardiovascular mortality, whereas carotid-radial and femoralposterior tibial PWV were not associated with mortality. ${ }^{27}$

In addition, the extent of emphysema was associated with all-cause mortality after adjustment for age and sex, but not after adjustment for age, sex and FEV. As such, it may be that emphysema causes increased mortality indirectly through reducing lung function. Our findings are in line with previous studies that have shown associations between the extent of emphysema and all-cause mortality in COPD subjects. ${ }^{28}$

Although lower bone attenuation was associated with increased CAC, bone attenuation was not associated with all-cause mortality in our COPD cohort. In contrast, previous studies have shown that bone density and rate of bone loss are related to mortality in elderly men and women. ${ }^{29,30}$ The Rotterdam Study demonstrated that in elderly men the risk of mortality increased when bone density was below average, and that the relationship between bone density and mortality was nonlinear. ${ }^{29}$ In addition, Szulc and colleagues ${ }^{30}$ showed in 781 elderly men that bone resorption markers predicted mortality more strongly than bone mineral density. The lack of a relationship between bone attenuation and mortality in our study might be due to the study population (e.g. COPD subjects rather than elderly subjects) and the methods used (e.g. bone attenuation of the thoracic vertebrae rather than bone mineral density of the hip, lumbar spine or whole body).

Our study has several limitations. First, bone attenuation was assessed on low-dose chest CT while dual energy X-ray absorptiometry is the gold standard. However, previous data 
have demonstrated that bone attenuation measured on CT is strongly correlated with bone mineral density assessed on dual energy X-ray absorptiometry. ${ }^{11}$ Second, CAC and TAC were measured on non-gated scans, however, it has been shown previously that measurements of CAC and TAC on non-gated chest CT scans show good agreement with measurements from electrocardiographically gated chest CT scans. ${ }^{9}$ Third, arterial stiffness was measured as carotid-radial PWV rather than carotid-femoral PWV which is the gold standard. ${ }^{26}$ Although our study has several limitations, we measured several COPD-related manifestations such as CAC, TAC, bone attenuation and extent of emphysema in a well-characterised COPD cohort.

Our data showed that CAC, TAC and emphysema which were measured on low-dose chest CT predicted all-cause mortality in COPD subjects. We suggest that low-dose chest CT might contribute to early diagnosis of COPD-related manifestations and improved risk stratification, although further evidence, ideally from randomised controlled trials, are required to determine the benefits of this screening approach in COPD patients.

In conclusion, our study showed that increased CAC was associated with increased arterial stiffness and lower bone attenuation in COPD subjects. CAC, TAC and emphysema predicted all-cause mortality in our COPD cohort, suggesting that quantitative assessment of CAC, TAC and emphysema provide relevant prognostic information in COPD subjects.

\section{DISCLOSURES}

Elisabeth A.P.M. Romme was the recipient of a European Respiratory Society Fellowship (STRTF 381-2011). The work described in this manuscript was performed the University of Edinburgh as part of this Fellowship. 


\section{REFERENCES}

1. Graat-Verboom L, Wouters EF, Smeenk FW, van den Borne BE, Lunde R, Spruit MA. Current status of research on osteoporosis in COPD: a systematic review. Eur Respir J 2009; 34: 209-18.

2. Mannino DM, Thorn D, Swensen A, Holguin F. Prevalence and outcomes of diabetes, hypertension and cardiovascular disease in COPD. Eur Respir J 2008; 32: 962-9.

3. Tanko LB, Christiansen C, Cox DA, Geiger MJ, McNabb MA, Cummings SR. Relationship between osteoporosis and cardiovascular disease in postmenopausal women. J Bone Miner Res 2005; 20: 1912-20.

4. Schulz E, Arfai K, Liu X, Sayre J, Gilsanz V. Aortic calcification and the risk of osteoporosis and fractures. J Clin Endocrinol Metab 2004; 89: 4246-53.

5. Sabit R, Bolton $\mathrm{CE}$, Edwards $\mathrm{PH}$ et al. Arterial stiffness and osteoporosis in chronic obstructive pulmonary disease. Am J Respir Crit Care Med 2007; 175: 1259-65.

6. McAllister DA, Maclay JD, Mills NL et al. Arterial stiffness is independently associated with emphysema severity in patients with chronic obstructive pulmonary disease. Am J Respir Crit Care Med 2007; 176: 1208-14.

7. Bon J, Fuhrman CR, Weissfeld JL et al. Radiographic emphysema predicts low bone mineral density in a tobacco-exposed cohort. Am J Respir Crit Care Med 2011; 183: 885-90.

8. Divo M, Cote C, de Torres JP et al. Comorbidities and Risk of Mortality in Patients with Chronic Obstructive Pulmonary Disease. Am J Respir Crit Care Med 2012; 186: 155-61.

9. Budoff MJ, Nasir K, Kinney GL et al. Coronary artery and thoracic calcium on noncontrast thoracic CT scans: comparison of ungated and gated examinations in patients from the COPD Gene cohort. J Cardiovasc Comput Tomogr 2011; 5: 113-8.

10. Agatston AS, Janowitz WR, Hildner FJ, Zusmer NR, Viamonte M, Jr., Detrano R. Quantification of coronary artery calcium using ultrafast computed tomography. J Am Coll Cardiol 1990; 15: 827-32.

11. Romme EA, Murchison JT, Phang KF et al. Bone attenuation on routine chest CT correlates with bone mineral density on DXA in patients with COPD. J Bone Miner Res 2012; 27: 2338-43.

12. van Popele NM, Mattace-Raso FU, Vliegenthart R et al. Aortic stiffness is associated with atherosclerosis of the coronary arteries in older adults: the Rotterdam Study. J Hypertens 2006; 24: 2371-6.

13. Farrar DJ, Bond MG, Riley WA, Sawyer JK. Anatomic correlates of aortic pulse wave velocity and carotid artery elasticity during atherosclerosis progression and regression in monkeys. Circulation 1991; 83 1754-63.

14. Demer LL. Effect of calcification on in vivo mechanical response of rabbit arteries to balloon dilation. Circulation 1991; 83: 2083-93.

15. Barr RG, Ahmed FS, Carr JJ, Hoffman EA, Jiang R, Kawut SM, Watson K. Subclinical atherosclerosis, airflow obstruction and emphysema: the MESA Lung Study. Eur Respir J 2012; 39: 846-54.

16. Sverzellati N, Cademartiri F, Bravi F et al. Relationship and prognostic value of modified coronary artery calcium score, FEV1, and emphysema in lung cancer screening population: the MILD trial. Radiology 2012; 262: 460-7.

17. McAllister DA, MacNee W, Duprez D et al. Pulmonary function is associated with distal aortic calcium, not proximal aortic distensibility. MESA lung study. COPD 2011; 8: 71-8.

18. MacNee W, Maclay J, McAllister D. Cardiovascular injury and repair in chronic obstructive pulmonary disease. Proc Am Thorac Soc 2008; 5: 824-33.

19. Bon J. Does radiographic emphysema correlate with low bone mineral density? Curr Opin Pulm Med 2012; 18: 125-30.

20. Ohara T, Hirai T, Muro S et al. Relationship between pulmonary emphysema and osteoporosis assessed by CT in patients with COPD. Chest 2008; 134: 1244-9.

21. Jacobs PC, Prokop $M$, van der Graaf $Y$ et al. Comparing coronary artery calcium and thoracic aorta calcium for prediction of all-cause mortality and cardiovascular events on low-dose non-gated computed tomography in a high-risk population of heavy smokers. Atherosclerosis 2010; 209: 455-62. 
22. Shaw L, Raggi P, Callister TQ, Berman DS. Prognostic value of coronary artery calcium screening in asymptomatic smokers and non-smokers. Eur Heart J 2006; 27: 968-75.

23. Mohlenkamp S, Lehmann N, Moebus S et al. Quantification of coronary atherosclerosis and inflammation to predict coronary events and all-cause mortality. J Am Coll Cardiol 2011; 57: 1455-64.

24. Karras A, Haymann JP, Bozec E et al. Large Artery Stiffening and Remodeling Are Independently Associated With All-Cause Mortality and Cardiovascular Events in Chronic Kidney Disease. Hypertension 2012; 60: 1451-7.

25. Blacher J, Guerin AP, Pannier B, Marchais SJ, Safar ME, London GM. Impact of aortic stiffness on survival in end-stage renal disease. Circulation 1999; 99: 2434-9.

26. Laurent S, Cockcroft J, Van BL et al. Expert consensus document on arterial stiffness: methodological issues and clinical applications. Eur Heart J 2006; 27: 2588-605.

27. Pannier B, Guerin AP, Marchais SJ, Safar ME, London GM. Stiffness of capacitive and conduit arteries: prognostic significance for end-stage renal disease patients. Hypertension 2005; 45: 592-6.

28. Celli BR, Locantore N, Yates J et al. Inflammatory biomarkers improve clinical prediction of mortality in chronic obstructive pulmonary disease. Am J Respir Crit Care Med 2012; 185: 1065-72.

29. Van Der Klift M, Pols HA, Geleijnse JM, van der Kuip DA, Hofman A, De Laet CE. Bone mineral density and mortality in elderly men and women: the Rotterdam Study. Bone 2002; 30: 643-8.

30. Szulc P, Maurice C, Marchand F, Delmas PD. Increased bone resorption is associated with higher mortality in community-dwelling men >or=50 years of age: the MINOS study. J Bone Miner Res 2009; 24: 1116-24. 
e-Table 1. Cox proportional-hazards for all-cause mortality

\begin{tabular}{lccc}
\hline & Per 10-fold increase in TAC & 95\% Cl & p-value \\
\hline TAC & 2.20 & $1.20-4.03$ & 0.01 \\
TAC $^{\text {a }}$ & 2.08 & $0.99-4.38$ & 0.06 \\
TAC $^{\text {b }}$ & 1.97 & $0.93-4.19$ & 0.08 \\
TAC $^{c}$ & 2.09 & $0.95-4.59$ & 0.07 \\
\hline
\end{tabular}

${ }^{a}$ after adjustment for age and sex

${ }^{\mathrm{b}}$ after adjustment for age, sex and FEV

c after adjustment for age, sex, $\mathrm{FEV}_{1}$ and pack years of smoking

$\mathrm{Cl}=$ confidence interval, $\mathrm{FEV}_{1}$ =forced expiratory volume in 1 second, $\mathrm{TAC}=$ thoracic aortic calcification

e-Table 2. Cox proportional-hazards for all-cause mortality

\begin{tabular}{|c|c|c|c|}
\hline & Hazard ratio & $95 \% \mathrm{Cl}$ & p-value \\
\hline PWV & 0.91 & $0.72-1.16$ & 0.44 \\
\hline PWV a & 0.86 & $0.67-1.10$ & 0.23 \\
\hline PWV b & 0.85 & $0.67-1.08$ & 0.18 \\
\hline PWV c & 0.81 & $0.62-1.06$ & 0.13 \\
\hline Bone attenuation/SD & 0.98 & $0.68-1.40$ & 0.90 \\
\hline Bone attenuation/SD ${ }^{a}$ & 1.04 & $0.72-1.50$ & 0.84 \\
\hline Bone attenuation/SD ${ }^{\mathrm{b}}$ & 1.10 & $0.76-1.57$ & 0.62 \\
\hline Bone attenuation/SD ${ }^{c}$ & 1.11 & $0.77-1.60$ & 0.58 \\
\hline $15^{\text {th }}$ percentile/ SD & 0.70 & $0.49-1.00$ & 0.05 \\
\hline $15^{\text {th }}$ percentile/ SD ${ }^{\text {a }}$ & 0.65 & $0.45-0.95$ & 0.03 \\
\hline $15^{\text {th }}$ percentile/ SD ${ }^{b}$ & 0.69 & $0.46-1.04$ & 0.07 \\
\hline $15^{\text {th }}$ percentile/ SD ${ }^{c}$ & 0.66 & $0.43-1.01$ & 0.06 \\
\hline
\end{tabular}

a after adjustment for age and sex

${ }^{\mathrm{b}}$ after adjustment for age, sex and FEV

c after adjustment for age, sex, FEV ${ }_{1}$ and pack years of smoking

$\mathrm{Cl}=$ confidence interval, $\mathrm{FEV}_{1}=$ forced expiratory volume in 1 second, $\mathrm{PWV}=$ pulse wave velocity, $\mathrm{SD}=$ standard deviation 




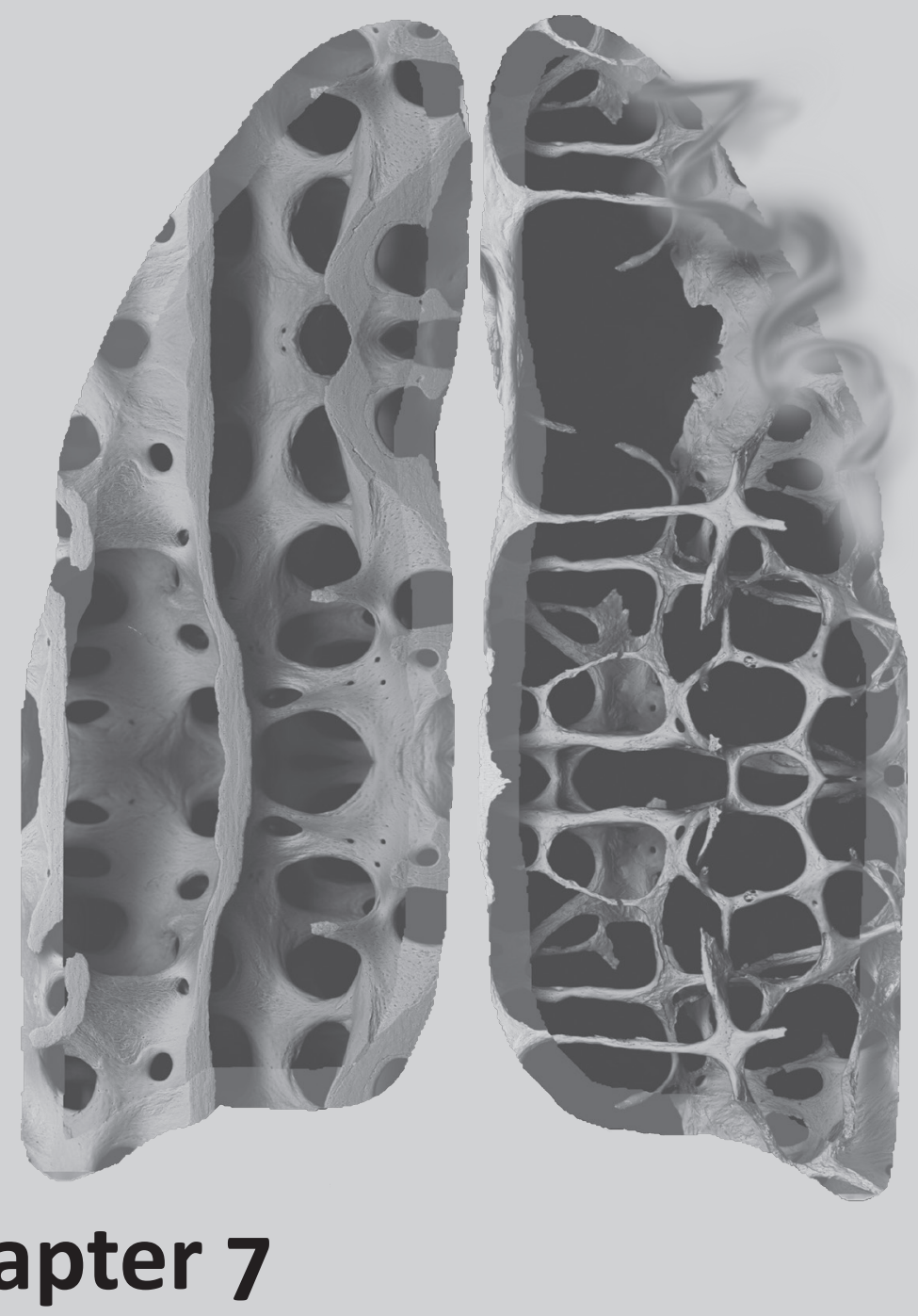

Bone stiffness and failure load are related with clinical parameters in men with chronic obstructive pulmonary disease

Elisabeth A.P.M. Romme

Erica P.A. Rutten

Piet Geusens

Joost J.A. de Jong

Bert van Rietbergen
Frank W.J.M. Smeenk

Emiel F.M. Wouters

Joop P.W. van den Bergh

Journal of Bone and Mineral Research 2013; 28: 2186-93 


\begin{abstract}
Osteoporosis is frequently seen in patients with chronic obstructive pulmonary disease (COPD). Since research on bone structure and bone strength in COPD patients is limited, the objectives of this pilot study were: 1) To compare bone structure, stiffness and failure load, measured at the peripheral skeleton, between men with and without COPD after stratification for areal bone mineral density (aBMD); and 2) To relate clinical parameters with bone stiffness and failure load in men with COPD. We included 30 men with COPD (normal aBMD $n=18$, osteoporosis $n=12$ ) and 17 men without COPD (normal aBMD $n=9$, osteoporosis $\mathrm{n}=8$ ). We assessed pack years of smoking, body mass index (BMI), fat free mass index (FFMI), pulmonary function $\left(\mathrm{FEV}_{1}, \mathrm{FEV}_{1} / \mathrm{FVC}, \mathrm{DLCO}\right.$ and $\mathrm{KCO}$ ) and extent of emphysema. Bone structure of the distal radius and tibia was assessed by high resolution peripheral quantitative computed tomography (HR-pQCT), and bone stiffness and failure load of the distal radius and tibia were estimated from micro-finite element analysis ( $\mu \mathrm{FEA})$. After stratification for aBMD and COPD, men with osteoporosis showed abnormal bone structure $(p<0.01)$, lower bone stiffness $(p<0.01)$ and lower failure load $(p<0.01)$ compared with men with normal aBMD, and men with COPD had comparable bone structure, stiffness and failure load compared with men without COPD. In men with COPD, lower FFMI was related with lower bone stiffness and failure load of the radius and tibia and lower DLCO and KCO were related with lower bone stiffness and failure load of the tibia after normalization with respect to femoral neck aBMD. Thus, this pilot study could not detect differences in bone structure, stiffness and failure load between men with and without COPD after stratification for aBMD. FFMI and gas transfer capacity of the lung were significantly related with bone stiffness and failure load in men with COPD after normalization with respect to femoral neck aBMD.
\end{abstract}




\section{INTRODUCTION}

Osteoporosis and vertebral fractures are frequently seen in patients with chronic obstructive pulmonary disease (COPD) and related with the severity of airflow obstruction. ${ }^{1-3}$ The relationship between COPD and osteoporosis is assumed to be due to common risk factors, such as older age and cigarette smoking, or to COPD-specific mechanisms, such as systemic inflammation, ${ }^{4}$ the use of corticosteroids ${ }^{5}$ and vitamin D deficiency. ${ }^{6}$

The current gold standard for diagnosing osteoporosis is areal bone mineral density (aBMD) on dual energy X-ray absorptiometry (DXA). ${ }^{7}$ Although low aBMD is a well-established risk factor of fragility fractures, ${ }^{8}$ COPD subjects with a normal aBMD can have vertebral fractures, ${ }^{9}$ suggesting that other factors are involved. Indeed, in addition to $\mathrm{aBMD}$, bone strength is influenced by several structural and material properties of bone. ${ }^{10}$

Recently, high resolution peripheral quantitative computed tomography (HR-pQCT) has been introduced to assess structural parameters of bone. ${ }^{11}$ In addition, HR-pQCT images can be used to estimate mechanical parameters of bone, such as bone stiffness and failure load, from micro-finite element analysis ( $\mu \mathrm{FEA}$ ).12,13 Previous data have shown that structural parameters assessed on HR-pQCT and mechanical parameters estimated from $\mu$ FEA are related with fragility fractures. ${ }^{11}$ Vilayphiou and colleagues ${ }^{14}$ showed that bone structure, stiffness and failure load were associated with all types of fractures in postmenopausal women, and Graeff and colleagues ${ }^{15}$ demonstrated that structural and mechanical parameters of bone were superior to $\mathrm{aBMD}$ in discriminating men with and without vertebral fractures.

Although previous studies have shown that lung function parameters and radiographic emphysema are related with aBMD and vertebral fractures, ${ }^{16-18}$ research on structural and mechanical parameters of bone in COPD patients is sparse. A previous study using histomorphometry and micro computed tomography $(\mu \mathrm{CT})$ showed that structural parameters of bone in bone biopsies were different in postmenopausal women with COPD compared with control subjects. ${ }^{19}$ However, the COPD and control groups were not matched for aBMD.

Since research on structural and mechanical parameters of bone in COPD patients is limited, the objectives of this pilot study were: 1) To compare bone structure, stiffness and failure load, measured at the peripheral skeleton, between men with and without COPD after stratification for aBMD; and 2) To relate clinical parameters with bone stiffness and failure load in men with COPD.

\section{MATERIALS AND METHODS}

\section{Subjects}

This study included men with moderate to very severe COPD and men without COPD matched for age, who were enrolled in a clinical trial at the Catharina hospital (Eindhoven, the Netherlands) between February 2010 and September 2011. The inclusion and exclusion 
criteria of this clinical trial have been published previously..$^{20}$ Women were excluded from our analysis, because their number was relatively small and previous data showed differences in bone structure between men and women. ${ }^{21}$

The study was approved by the medical ethical committee of the Catharina hospital (Mo91971) and registered at www.clinicaltrials.gov (NCT01067248). All subjects gave written informed consent.

\section{Clinical parameters}

At study entry, structured interviews were used to document the subjects' self-reported smoking history, medications (e.g. use of oral or inhaled corticosteroids) and coexisting medical conditions. Total body weight and height were measured to calculate body mass index (BMI). Fat free mass (FFM) was assessed by bio-impedance analysis (Bodystat 1500, Bodystat Ltd., Onchan, Isle of Man) and FFM index (FFMI) was calculated as FFM divided by height ${ }^{2}$.

Pulmonary function was measured with standardized equipment (MasterScreen ${ }^{\mathrm{TM}}$ Body, Carefusion, San Diego, California, USA) according to the guidelines of the American Thoracic Society (ATS)/ European Respiratory Society (ERS). ${ }^{22}$ Measurements included forced expiratory volume in 1 second $\left(F_{1} V_{1}\right)$, forced vital capacity (FVC), vital capacity (VC), total lung capacity (TLC), residual volume (RV), inspiratory capacity (IC) and expiratory reserve volume (ERV). Following the ERS recommendations, the single-breath technique was used to determine the diffusion capacity for carbon monoxide (DLCO) and transfer coefficient for carbon monoxide (KCO). ${ }^{23}$

Chest CT examinations were performed using a single-energy 256 multidetector row scanner (Philips Brilliance intelligent CT, Philips Healthcare, Eindhoven, The Netherlands) with technical parameters of $120 \mathrm{kVp}, 350-\mathrm{mm}$ field of view, $2.5 \mathrm{~mm}$ slice thickness and ECG gated. The scanner was calibrated daily to ensure accurate $\mathrm{CT}$ attenuation numbers. All subjects were scanned in supine position, during deep inspiration and without administration of contrast. Emphysema was quantified by in-house software using the $15^{\text {th }}$ percentile point of the frequency distribution of lung density and pixel index for -950 (PI-950) Hounsfield units, as previously described. ${ }^{24-27}$

\section{Bone density, structure, stiffness and failure load}

Areal BMD (aBMD) of the lumbar spine ( $\mathrm{L} 1$ to $\mathrm{L} 4$ ), femoral neck and total hip were measured using a Delphi upgraded to a discovery W (S/N70991) DXA scanner (Tromp Medical Engineering BV, Castricum, The Netherlands). Diagnosis of osteoporosis was based on the lowest T-score of the lumbar spine, femoral neck and total hip, and defined according to the criteria of the World Health Organization (WHO) (osteoporosis: T-score $\leq-2.5$; osteopenia: T-score <-1.0 and >-2.5; and normal aBMD: T-score $\geq-1.0) .{ }^{7}$ 
High-resolution pQCT (HR-pQCT) images of the non-dominant (or non-fractured) distal radius and tibia were taken using a HR-pQCT device (XtremeCT, Scanco Medical AG, Brüttisellen, Switzerland) with standard in vivo parameters of $60 \mathrm{kVp}, 900 \mu \mathrm{A}$ and $100 \mathrm{~ms}$ integration time. Each measurement took approximately 3 minutes and resulted in a $9.02 \mathrm{~mm}$ thick stack of parallel images (110 slices, voxel size of $82 \mu \mathrm{m}$ ). Quality control was performed by daily scans of a phantom containing rods of hydroxyapatite (HA) embedded in a soft-tissue equivalent resin (QRM, Moehrendorf, Germany).

The HR-pQCT images were evaluated using standard software of the manufacturer to assess total bone density (Dtot), trabecular density (Dtrab), relative bone volume (BV/TV), trabecular number (Tb.N), trabecular thickness (Tb.Th), trabecular separation (Tb.Sp), cortical density (Dcort) and cortical thickness (Ct.Th), as described previously. ${ }^{28,29}$ In addition, $\mu$ FEA was performed to calculate bone stiffness in kiloNewton per millimeter $(\mathrm{kN} / \mathrm{mm})$ and failure load in kiloNewton ( $\mathrm{kN}$ ), as described previously. ${ }^{13,29}$ Bone stiffness is the resistance against deformation, and failure load is the estimated load at which bone failure will occur.

\section{Statistical analysis}

Subjects were classified into: COPD subjects with normal aBMD, COPD subjects with osteoporosis, control subjects with normal aBMD and control subjects with osteoporosis. Comparisons among groups were made using Mann-Whitney $U$ and Chi-square analyses. Bonferroni correction was used to adjust for multiple comparisons. Two-sided p-values $\leq 0.0125(0.05 / 4)$ were considered statistically significant.

Standard simple and multiple regression models were used to assess relationships between clinical parameters and bone stiffness and failure load. Preliminary analyses were conducted to ensure no violation of the assumptions of normality, linearity, multicollinearity and homoscedasticity. Since the study group is relatively small en femoral neck aBMD is a strong predictor of osteoporosis-related fractures, ${ }^{30}$ multiple regression models were adjusted for femoral neck aBMD only.

All statistical analyses were performed in SPSS version 17.0 (SPSS Inc., Chicago, IL, USA).

\section{RESULTS}

We included 30 men with COPD (normal $a B M D n=18$, osteoporosis $n=12$ ) and 17 men without COPD (normal aBMD $n=9$, osteoporosis $n=8$ ). Table 1 shows the clinical characteristics. COPD subjects with osteoporosis had lower BMI $(p=0.007)$, FFMI $(p=0.01), F_{1}(p=0.008), F_{1} /$ FVC $(p=0.005), D L C O(p=0.001)$ and KCO ( $p<0.001)$ compared with COPD subjects with normal aBMD, and control subjects with osteoporosis had similar clinical characteristics compared with control subjects with normal aBMD. No differences were found in the use of corticosteroids between COPD subjects with and without osteoporosis.

Table 2 shows the structural and mechanical parameters of bone after stratification for COPD and aBMD. COPD subjects and control subjects with osteoporosis had lower total bone 
density, lower trabecular density, lower relative bone volume, lower trabecular number, higher trabecular separation, lower cortical thickness, lower bone stiffness and lower failure load compared with COPD subjects and control subjects with normal aBMD, respectively. In addition, COPD subjects had comparable bone structure, stiffness and failure load compared with control subjects after stratification for aBMD.

In the total cohort, BMI, FFMI, FVC, VC, DLCO, KCO, PI-950, $15^{\text {th }}$ percentile and aBMD were significantly related with bone stiffness and failure load of the radius and tibia, and $\mathrm{FEV}_{1}$, TLC and IC were significantly related with bone stiffness and failure load of the radius or tibia (see supplement, e-Table 1 and e-Table 2). In the COPD subjects, BMI, FFMI, DLCO, $\mathrm{KCO}, \mathrm{PI}-950,15^{\text {th }}$ percentile and aBMD were significantly related with bone stiffness and failure load of the radius and tibia, and $\mathrm{FEV}_{1}$ and $\mathrm{FEV}_{1} / \mathrm{FVC}$ were significantly related with bone stiffness and failure load of the radius or tibia (see supplement, e-Table 3 and e-Table 4). In the COPD subjects, lower FFMI was significantly related with lower bone stiffness and failure load of the radius and tibia and DLCO and KCO were significantly related with lower bone stiffness and failure load of the tibia, after adjustment for femoral neck aBMD (Table 3). Figure 1 shows the relationship between DLCO and failure load of the tibia in the COPD subjects after adjustment for femoral neck aBMD. 


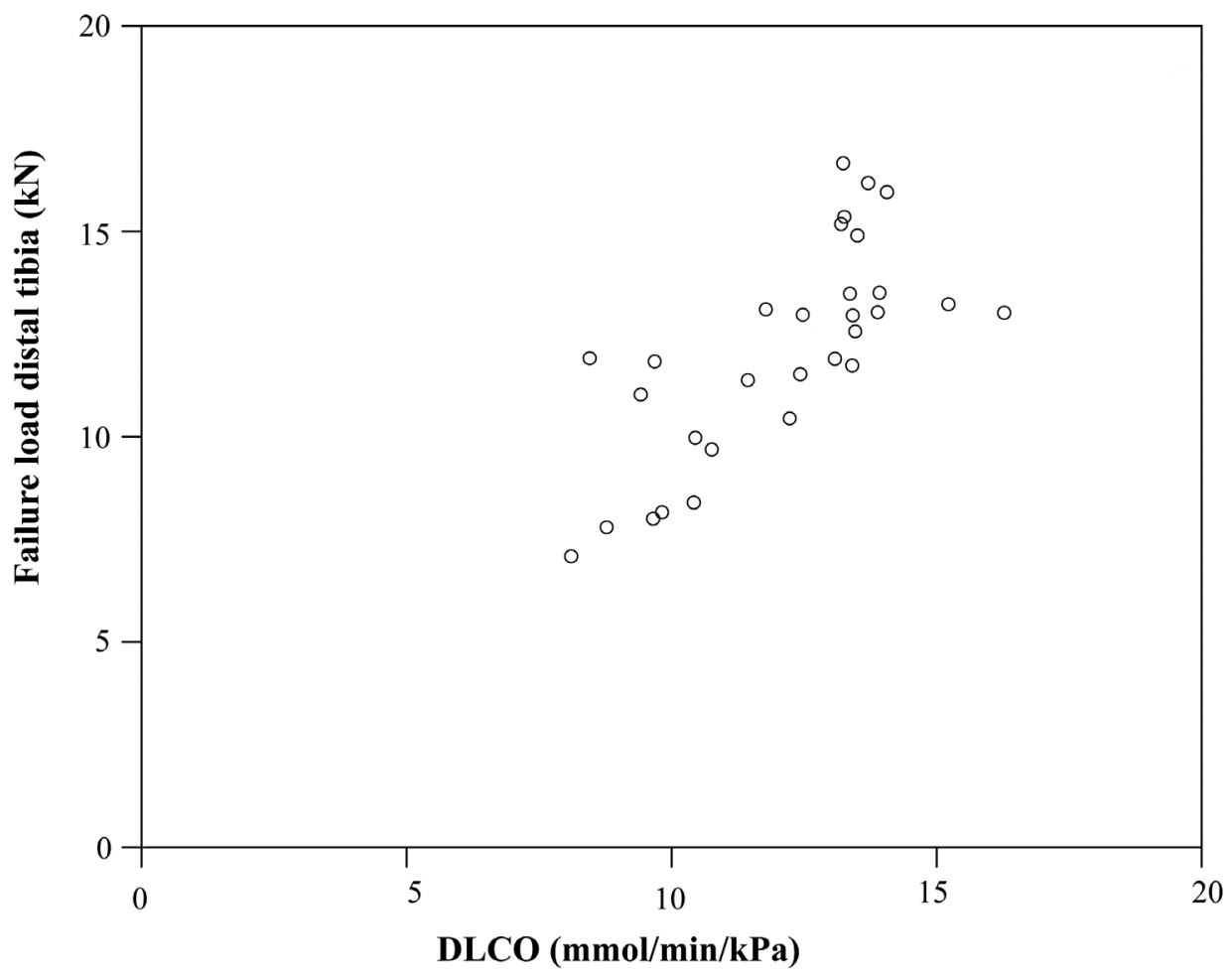

Figure 1. Diffusion capacity for carbon monoxide related with failure load of the distal tibia in COPD subjects after adjustment for femoral neck aBMD $\left(\mathrm{g} / \mathrm{cm}^{2}\right)$ $\mathrm{aBMD}=$ areal bone mineral density; $\mathrm{DLCO}=$ diffusion capacity for carbon monoxide. 


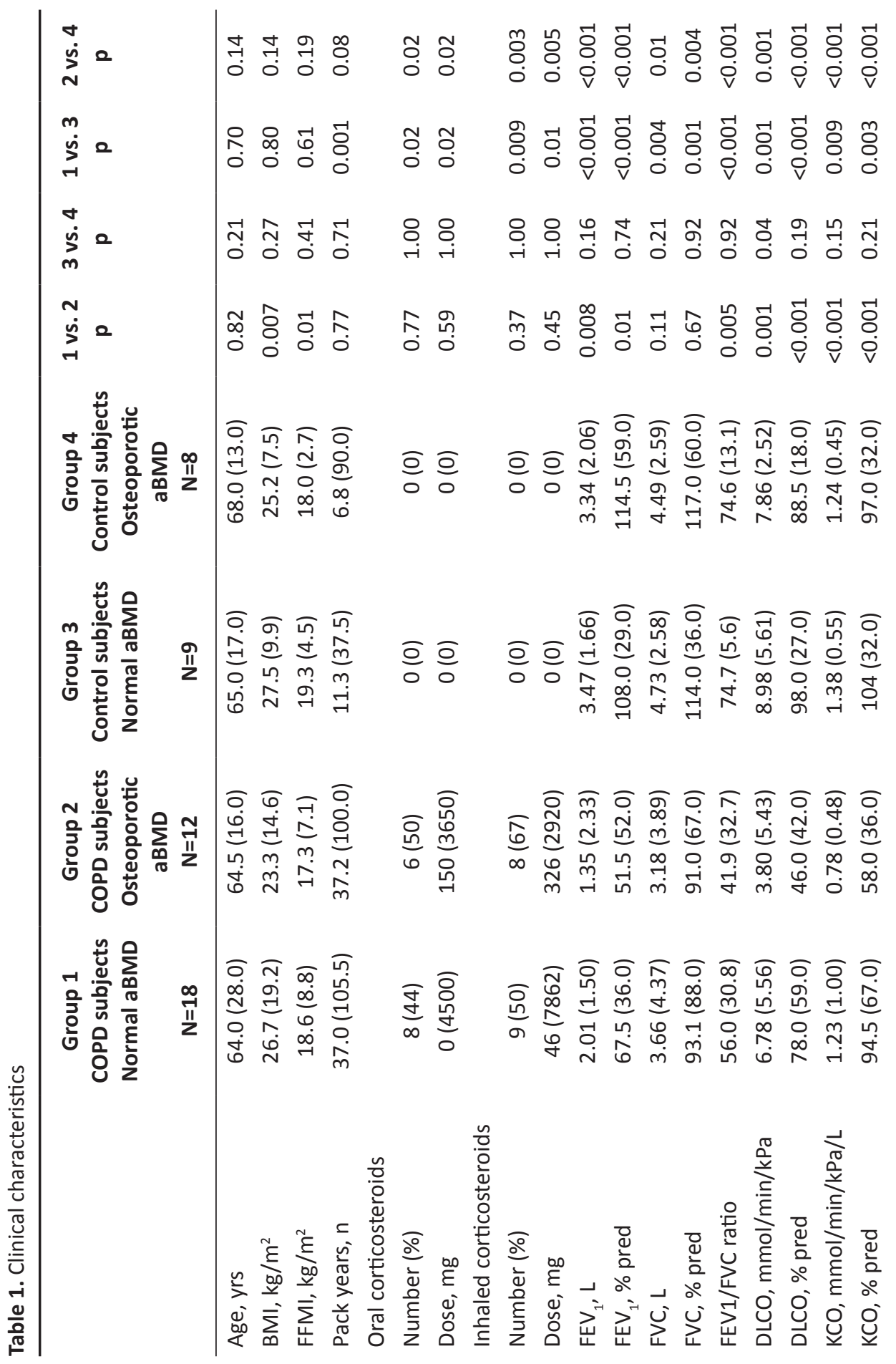




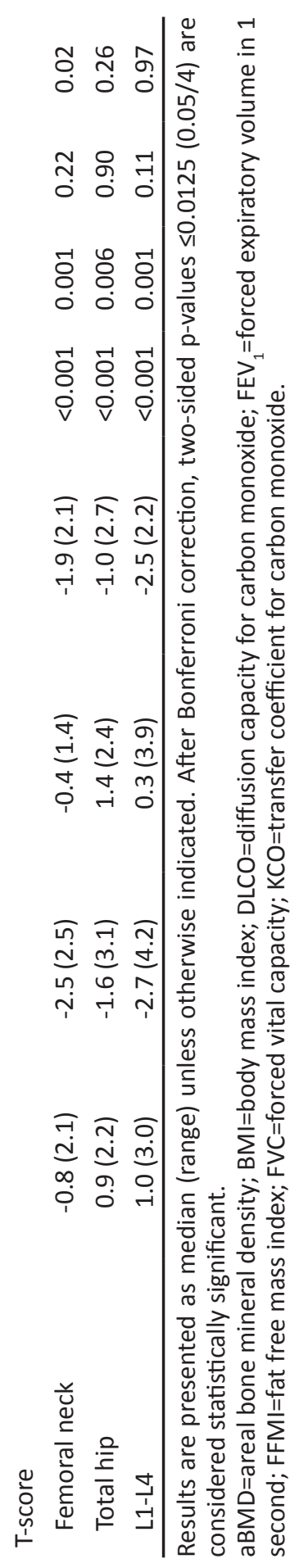




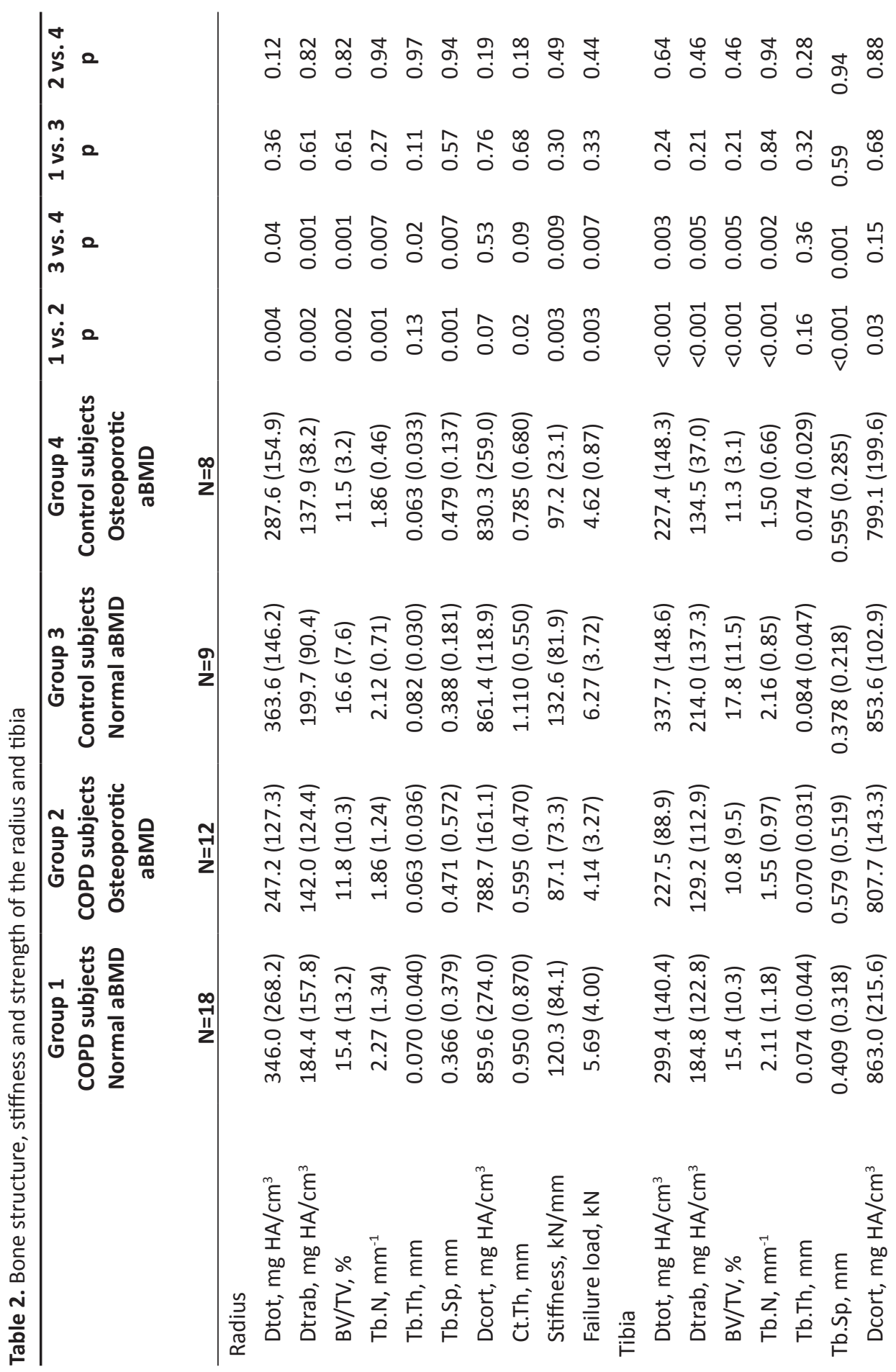




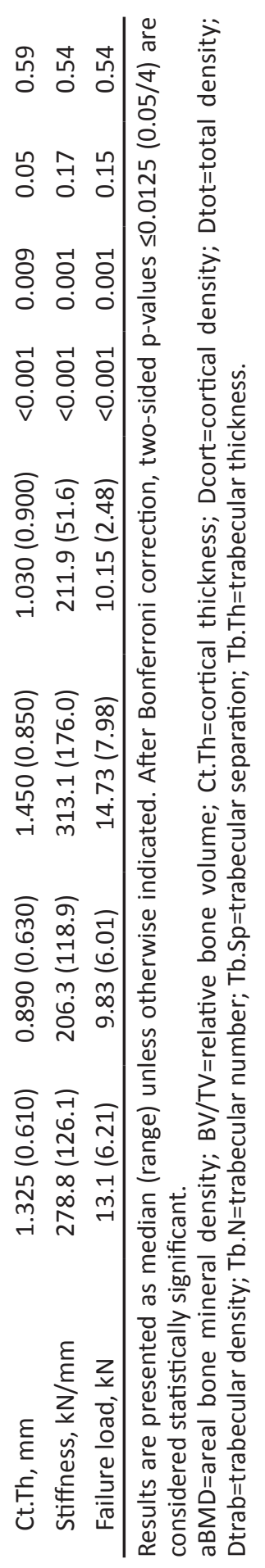




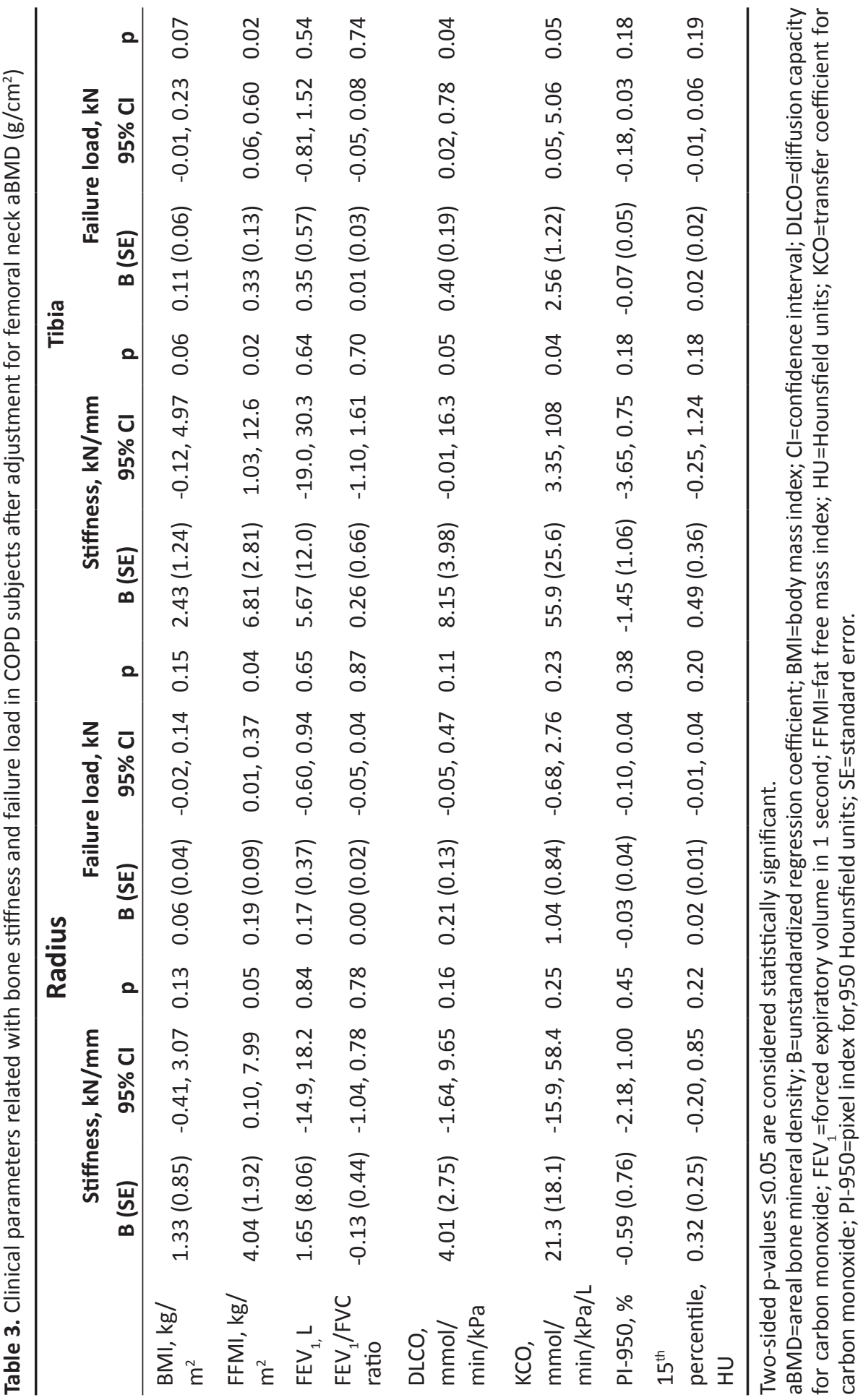




\section{DISCUSSION}

This study could not detect differences in bone structure, stiffness and failure load, measured at the peripheral skeleton, between men with and without COPD after stratification for aBMD. FFMI and gas transfer capacity of the lung were significantly related with bone stiffness and failure load in men with COPD after normalization with respect to femoral neck aBMD.

Our data showed that men with osteoporosis had impaired bone structure and lower bone stiffness and failure load compared with men with normal aBMD. These findings are in line with previous data demonstrating associations between $\mathrm{aBMD}$, bone structure, stiffness and failure load..$^{14,28,31}$ In addition, previous data have shown that structural and mechanical parameters of bone are even better predictors of vertebral fractures than $\mathrm{BBMD}^{15,28}$ suggesting that structural and mechanical parameters of bone might improve the prediction of vertebral fractures.

After stratification for COPD and aBMD, men with COPD had comparable bone structure, stiffness and failure load compared with men without COPD. To the best of our knowledge, only one previous study has investigated differences in bone structure between subjects with and without COPD. ${ }^{19}$ This study showed that postmenopausal women with COPD had abnormal bone structure compared with control subjects. ${ }^{19}$ However, the COPD and control groups were not matched for aBMD. These findings suggest that structural parameters of bone are more impaired in COPD patients than in control subjects, whereas structural and mechanical parameters of bone are similar in COPD patients and control subjects after matching for aBMD.

Several pulmonary parameters, including FEV ${ }_{1}$ FVC, VC, TLC, IC, DLCO, KCO, $15^{\text {th }}$ percentile and PI-950, were significantly related with bone stiffness and failure load. Although research on associations between pulmonary function and mechanical parameters of bone is lacking, previous studies have shown associations between pulmonary function and bone density or fragility fractures. ${ }^{18,32}$ In 85 subjects with moderate to very severe COPD, lower VC and DLCO and more severe emphysema were associated with osteoporosis defined as a T score $<-2.5$, whereas lower VC and FEV 1 were associated with vertebral fractures. ${ }^{17}$ In addition, a longitudinal study in 70 subjects with emphysema showed that lung volume reduction surgery improved pulmonary function and $\mathrm{aBMD}$, compared with respiratory rehabilitation therapy. ${ }^{33}$ These findings suggest associations between the pulmonary and skeletal system.

FFMI was significantly related with bone stiffness and failure load of the radius and tibia and DLCO and KCO were significantly related with bone stiffness and failure load of the tibia, after normalization with respect to femoral neck aBMD. These data suggest that FFMI and gas transfer capacity of the lung are related with properties of bone that are only partially related with $\mathrm{aBMD}$, such as bone structure, micro damage burden, collagen type and cross-linking. ${ }^{10}$ 
FFMI might interact with properties of bone via physical activity. Reduced physical activity has been related with bone loss and osteoporosis-related fractures, ${ }^{34,35}$ whereas, on the other hand, exercise interventions have been shown to increase $\mathrm{aBMD}^{36}$ and reduce the number of fractures. ${ }^{37}$ In addition to physical activity, decreased mechanical loading might influence bone strength.

In addition to FFMI, gas transfer capacity of the lung might interact with properties of bone. The gas transfer capacity of the lung is associated with several factors that have already been related with properties of bone. First, a lower gas transfer capacity of the lung is associated with emphysema, ${ }^{23}$ which has been related with osteoporosis. ${ }^{18}$ The relationship between emphysema and osteoporosis might be due to a common mechanism, such as impaired $W n t / \beta$-catenin signaling. ${ }^{38}$ Second, a lower gas transfer capacity of the lung is associated with anemia, ${ }^{23}$ which has been related with osteoporosis and vertebral fractures. ${ }^{39,40}$ Animal studies have demonstrated that anemia-induced hypoxia might be responsible for the effects on bone remodeling. ${ }^{41}$ However, additional research is needed to further elucidate the interaction between hypoxia and bone remodeling. Third, a lower gas transfer capacity of the lung is associated with thoracic deformity, ${ }^{23}$ which has been related with vertebral fractures. ${ }^{42}$ These data suggest a mechanical relationship between lung function and osteoporosis. Fourth, a higher gas transfer capacity of the lung is associated with obesity, ${ }^{23}$ which has been shown to be protective against osteoporosis. ${ }^{16}$ Previous research has indeed shown beneficial effects of adipose tissue on bone density. ${ }^{43,44}$ Although several potential mechanisms have been described, additional research is warranted to further investigate the relationship between gas transfer capacity of the lung and mechanical parameters of bone.

Some limitations should be mentioned. First, no causal relationship could be established due to the cross-sectional design of the study. Second, a relatively small number of men was included. Third, subjects with osteopenia were excluded, as described previously. ${ }^{20}$ Fourth, our bone analyses were limited to the peripheral skeleton, because high resolution computed tomography is only possible at peripheral sites. Acknowledging these limitations, our study is the first to show that disease-specific parameters, such as FFMI and gas transfer capacity of the lung, are related with structural and mechanical parameters of bone in COPD subjects.

Since FFMI and gas transfer capacity of the lung were related with bone stiffness and failure load independent of aBMD, we suggest that FFMI and gas transfer capacity of the lung can improve risk stratification of fragility fractures in COPD patients. A combination of clinical features and structural and mechanical parameters of bone is likely to be a better predictor of fragility fractures than aBMD alone. ${ }^{45}$ Longitudinal studies are needed to investigate which clinical features and structural and mechanical parameters of bone are related with future fractures.

This pilot study could not detect differences in bone structure, stiffness and failure load between men with and without COPD after stratification for aBMD. FFMI and gas transfer capacity of the lung were related with bone stiffness and failure load in men with COPD after 
normalization with respect to femoral neck aBMD. These data suggest that FFMI and gas transfer capacity of the lung might interact with structural and mechanical parameters of bone. Longitudinal studies are needed to further investigate associations between clinical features and structural and mechanical parameters of bone in COPD patients.

\section{DISCLOSURES}

This study was funded by the Weijerhorst Foundation. Bert van Rietbergen is a consultant for Scanco Medical AG. 


\section{REFERENCES}

1. Graat-Verboom L, Wouters EF, Smeenk FW, van den Borne BE, Lunde R, Spruit MA. Current status of research on osteoporosis in COPD: a systematic review. Eur Respir J 2009; 34: 209-18.

2. Nuti R, Siviero P, Maggi S, Guglielmi G, Caffarelli C, Crepaldi G, Gonnelli S. Vertebral fractures in patients with chronic obstructive pulmonary disease: the EOLO Study. Osteoporos Int 2009; 20: 989-98.

3. Kjensli A, Falch JA, Ryg M, Blenk T, Armbrecht G, Diep LM, Ellingsen I. High prevalence of vertebral deformities in COPD patients: relationship to disease severity. Eur Respir J 2009; 33: 1018-24.

4. Hardy R, Cooper MS. Bone loss in inflammatory disorders. J Endocrinol 2009; 201: 309-20.

5. Weinstein RS. Clinical practice. Glucocorticoid-induced bone disease. N Engl J Med 2011; 365: 62-70.

6. Romme EA, Rutten EP, Smeenk FW, Spruit MA, Menheere PP, Wouters EF. Vitamin D status is associated with bone mineral density and functional exercise capacity in patients with chronic obstructive pulmonary disease. Ann Med 2013; 45: 91-6.

7. World Health Organization. Prevention and Management of Osteoporosis; report of a WHO scientific group [updated 2003; cited 2013 August]. Available from: http://whqlibdoc.who.int/trs/WHO_ TRS_921.pdf.

8. Marshall D, Johnell O, Wedel H. Meta-analysis of how well measures of bone mineral density predict occurrence of osteoporotic fractures. BMJ 1996; 312: 1254-9.

9. Graat-Verboom L, van den Borne BE, Smeenk FW, Spruit MA, Wouters EF. Osteoporosis in COPD outpatients based on bone mineral density and vertebral fractures. J Bone Miner Res 2011; 26: 561-8.

10. Seeman E, Delmas PD. Bone quality--the material and structural basis of bone strength and fragility. N Engl J Med 2006; 354: 2250-61.

11. Link TM. Osteoporosis imaging: state of the art and advanced imaging. Radiology 2012; 263: 3-17.

12. Macneil JA, Boyd SK. Bone strength at the distal radius can be estimated from high-resolution peripheral quantitative computed tomography and the finite element method. Bone 2008; 42: 1203-13.

13. Pistoia W, van RB, Lochmuller EM, Lill CA, Eckstein F, Ruegsegger P. Estimation of distal radius failure load with micro-finite element analysis models based on three-dimensional peripheral quantitative computed tomography images. Bone 2002; 30: 842-8.

14. Vilayphiou N, Boutroy S, Sornay-Rendu E, van RB, Munoz F, Delmas PD, Chapurlat R. Finite element analysis performed on radius and tibia HR-pQCT images and fragility fractures at all sites in postmenopausal women. Bone 2010; 46: 1030-7.

15. Graeff C, Marin F, Petto H et al. High resolution quantitative computed tomography-based assessment of trabecular microstructure and strength estimates by finite-element analysis of the spine, but not DXA, reflects vertebral fracture status in men with glucocorticoid-induced osteoporosis. Bone 2012; 52: 568-77.

16. Graat-Verboom L, Smeenk FW, van den Borne BE, Spruit MA, Donkers-van Rossum AB, Aarts RP, Wouters EF. Risk factors for osteoporosis in Caucasian patients with moderate chronic obstructive pulmonary disease: A case control study. Bone 2012; 50: 1234-9.

17. Ogura-Tomomatsu H, Asano K, Tomomatsu K et al. Predictors of osteoporosis and vertebral fractures in patients presenting with moderate-to-severe chronic obstructive lung disease. COPD 2012; 9: 332-7.

18. Bon J. Does radiographic emphysema correlate with low bone mineral density? Curr Opin Pulm Med 2012; 18: 125-30.

19. Kulak CA, Borba VC, Jorgetti V et al. Skeletal microstructural abnormalities in postmenopausal women with chronic obstructive pulmonary disease. J Bone Miner Res 2010; 25: 1931-40.

20. Romme EA, Murchison JT, Phang KF et al. Bone attenuation on routine chest CT correlates with bone mineral density on DXA in patients with COPD. J Bone Miner Res 2012; 27: 2338-43.

21. Baker JF, Davis M, Alexander R et al. Associations between body composition and bone density and structure in men and women across the adult age spectrum. Bone 2013; 53: 34-41.

22. Miller MR, Hankinson J, Brusasco V et al. Standardisation of spirometry. Eur Respir J 2005; 26: 319-38. 
23. Macintyre N, Crapo RO, Viegi G et al. Standardisation of the single-breath determination of carbon monoxide uptake in the lung. Eur Respir J 2005; 26: 720-35.

24. McAllister DA, Maclay JD, Mills NL et al. Arterial stiffness is independently associated with emphysema severity in patients with chronic obstructive pulmonary disease. Am J Respir Crit Care Med 2007; 176: 1208-14.

25. Bergin C, Muller N, Nichols DM et al. The diagnosis of emphysema. A computed tomographic-pathologic correlation. Am Rev Respir Dis 1986; 133: 541-6.

26. Gevenois PA, de M, V, De VP, Zanen J, Yernault JC. Comparison of computed density and macroscopic morphometry in pulmonary emphysema. Am J Respir Crit Care Med 1995; 152: 653-7.

27. Gevenois PA, De VP, Sy M et al. Pulmonary emphysema: quantitative CT during expiration. Radiology 1996; 199: 825-9.

28. Boutroy S, Bouxsein ML, Munoz F, Delmas PD. In vivo assessment of trabecular bone microarchitecture by high-resolution peripheral quantitative computed tomography. J Clin Endocrinol Metab 2005; 90 : 6508-15.

29. Dalzell N, Kaptoge S, Morris N et al. Bone micro-architecture and determinants of strength in the radius and tibia: age-related changes in a population-based study of normal adults measured with high-resolution pQCT. Osteoporos Int 2009; 20: 1683-94.

30. Johnell O, Kanis JA, Oden A et al. Predictive value of BMD for hip and other fractures. J Bone Miner Res 2005; 20: 1185-94.

31. Mittra E, Rubin C, Gruber B, Qin YX. Evaluation of trabecular mechanical and microstructural properties in human calcaneal bone of advanced age using mechanical testing, microCT, and DXA. J Biomech 2008; 41: 368-75.

32. Lehouck A, Boonen S, Decramer M, Janssens W. COPD, Bone Metabolism, and Osteoporosis. Chest 2011; 139: 648-57.

33. Mineo TC, Ambrogi V, Mineo D, Fabbri A, Fabbrini E, Massoud R. Bone mineral density improvement after lung volume reduction surgery for severe emphysema. Chest 2005; 127: 1960-6.

34. Marie PJ, Kassem M. Extrinsic mechanisms involved in age-related defective bone formation. J Clin Endocrinol Metab 2011; 96: 600-9.

35. Pluijm SM, Koes B, De LC et al. A simple risk score for the assessment of absolute fracture risk in general practice based on two longitudinal studies. J Bone Miner Res 2009; 24: 768-74.

36. Howe TE, Shea B, Dawson $\mathrm{U}$ et al. Exercise for preventing and treating osteoporosis in postmenopausal women. Cochrane Database Syst Rev 2011; CD000333.

37. De KD, Smulders E, Weerdesteyn V, Smits-Engelsman BC. Exercise interventions to reduce fall-related fractures and their risk factors in individuals with low bone density: a systematic review of randomized controlled trials. Osteoporos Int 2009; 20: 2111-25.

38. Kneidinger N, Yildirim AO, Callegari J et al. Activation of the WNT/beta-catenin pathway attenuates experimental emphysema. Am J Respir Crit Care Med 2011; 183: 723-33.

39. Korkmaz $\mathrm{U}$, Korkmaz $\mathrm{N}$, Yazici $\mathrm{S}$ et al. Anemia as a risk factor for low bone mineral density in postmenopausal Turkish women. Eur J Intern Med 2012; 23: 154-8.

40. Chen Z, Thomson CA, Aickin M et al. The relationship between incidence of fractures and anemia in older multiethnic women. J Am Geriatr Soc 2010; 58: 2337-44.

41. Fujimoto $\mathrm{H}$, Fujimoto $\mathrm{K}$, Ueda A, Ohata M. Hypoxemia is a risk factor for bone mass loss. J Bone Miner Metab 1999; 17: 211-6.

42. Cortet B, Roches E, Logier R, Houvenagel E, Gaydier-Souquieres G, Puisieux F, Delcambre B. Evaluation of spinal curvatures after a recent osteoporotic vertebral fracture. Joint Bone Spine 2002; 69: 201-8.

43. Reid IR. Relationships between fat and bone. Osteoporos Int 2008; 19: 595-606.

44. Reid IR. Fat and bone. Arch Biochem Biophys 2010; 503: 20-7.

45. Kanis JA, Johnell O, Oden A, Johansson $H$, McCloskey E. FRAX and the assessment of fracture probability in men and women from the UK. Osteoporos Int 2008; 19: 385-97. 
e-Table 1. Predictors of bone stiffness and failure load of the distal radius in the total cohort

\section{Radius}

\begin{tabular}{|c|c|c|c|c|c|c|}
\hline & \multicolumn{3}{|c|}{ Stiffness, kN/mm } & \multicolumn{3}{|c|}{ Failure load, kN } \\
\hline & B (SE) & $95 \% \mathrm{Cl}$ & p & B (SE) & $95 \% \mathrm{Cl}$ & p \\
\hline Age, yrs & $-0.97(0.65)$ & $-2.29,0.35$ & 0.15 & $-0.05(0.03)$ & $-0.11,0.02$ & 0.15 \\
\hline $\mathrm{BMI}, \mathrm{kg} / \mathrm{m}^{2}$ & $2.52(0.77)$ & $0.97,4.07$ & 0.002 & $0.12(0.04)$ & $0.05,0.19$ & 0.002 \\
\hline $\mathrm{FFMI}, \mathrm{kg} / \mathrm{m}^{2}$ & 6.65 (1.68) & $3.26,10.0$ & $<0.001$ & $0.31(0.08)$ & $0.16,0.47$ & $<0.001$ \\
\hline Pack years, $n$ & $-0.17(0.15)$ & $-0.48,0.13$ & 0.25 & $-0.01(0.01)$ & $-0.02,0.01$ & 0.28 \\
\hline $\mathrm{FEV}_{1}, \mathrm{~L}$ & 7.49 (3.92) & $-0.41,15.4$ & 0.06 & $0.36(0.18)$ & $0.00,0.73$ & 0.05 \\
\hline FVC, L & $8.37(3.60)$ & $1.11,15.6$ & 0.03 & $0.40(0.17)$ & $0.07,0.74$ & 0.02 \\
\hline $\mathrm{FEV}_{1} / \mathrm{FVC}$ ratio & $0.25(0.27)$ & $-0.30,0.79$ & 0.37 & $0.01(0.01)$ & $-0.01,0.04$ & 0.33 \\
\hline VC, L & $8.97(3.75)$ & $1.42,16.5$ & 0.02 & $0.43(0.17)$ & $0.09,0.78$ & 0.02 \\
\hline TLC, L & 6.59 (3.29) & $-0.05,13.2$ & 0.05 & $0.33(0.15)$ & $0.03,0.63$ & 0.03 \\
\hline $\mathrm{RV}, \mathrm{L}$ & $0.72(4.36)$ & $-8.08,9.51$ & 0.87 & $0.05(0.20)$ & $-0.35,0.46$ & 0.80 \\
\hline RV/TLC ratio & $-0.42(0.41)$ & $-1.23,0.40$ & 0.31 & $-0.02(0.02)$ & $-0.06,0.02$ & 0.31 \\
\hline IC, L & $6.78(4.73)$ & $-2.76,16.3$ & 0.16 & $0.35(0.22)$ & $-0.09,0.79$ & 0.12 \\
\hline ERV, L & $9.11(6.15)$ & $-3.30,21.5$ & 0.15 & $0.41(0.28)$ & $-0.17,0.98$ & 0.16 \\
\hline $\begin{array}{l}\text { DLCO, mmol/ } \\
\mathrm{min} / \mathrm{kPa}\end{array}$ & $6.01(1.63)$ & $2.73,9.28$ & 0.001 & $0.29(0.07)$ & $0.14,0.44$ & $<0.001$ \\
\hline $\begin{array}{l}\mathrm{KCO}, \mathrm{mmol} / \\
\mathrm{min} / \mathrm{kPa} / \mathrm{L}\end{array}$ & 38.4 (12.8) & $12.6,64.3$ & 0.004 & $1.82(0.59)$ & $0.63,3.01$ & 0.004 \\
\hline PI-950, \% & $-1.51(0.68)$ & $-2.88,-0.14$ & 0.03 & $-0.07(0.03)$ & $-0.14,-0.01$ & 0.02 \\
\hline $\begin{array}{l}15^{\text {th }} \text { percentile, } \\
H U\end{array}$ & $0.46(0.18)$ & $0.10,0.81$ & 0.01 & $0.02(0.01)$ & $0.01,0.04$ & 0.01 \\
\hline \multicolumn{7}{|l|}{$\begin{array}{l}\text { Areal BMD, g/ } \\
\mathrm{cm}^{2}\end{array}$} \\
\hline Femoral neck & $120(22.7)$ & $74.5,166$ & $<0.001$ & 5.65 (1.04) & $3.56,7.75$ & $<0.001$ \\
\hline Total hip & 92.5 (15.7) & $60.9,124$ & $<0.001$ & $4.31(0.72)$ & $2.86,5.77$ & $<0.001$ \\
\hline L1-L4 & 79.6 (14.9) & $49.6,110$ & $<0.001$ & 3.69 (0.69) & $2.31,5.08$ & $<0.001$ \\
\hline
\end{tabular}

Two sided $p$-values $\leq 0.05$ are considered statistically significant.

$\mathrm{B}=\mathrm{unstandardized}$ regression coefficient; $\mathrm{BMD}=$ bone mineral density; $\mathrm{BMI}=$ body mass index; $\mathrm{Cl}=$ confidence interval; $\mathrm{DLCO}=$ diffusion capacity for carbon monoxide; $\mathrm{ERV}=$ expiratory reserve volume; $\mathrm{FEV}_{1}=$ forced expiratory volume in 1 second; $\mathrm{FFMI}=$ fat free mass index; $\mathrm{FVC}=$ forced vital capacity; $\mathrm{HU}=$ Hounsfield units; IC=inspiratory capacity; $\mathrm{KCO}=$ transfer coefficient for carbon monoxide; PI-950=pixel index for -950 Hounsfield units; $\mathrm{RV}=$ residual volume; $\mathrm{TLC}=$ total lung capacity; VC=vital capacity. 
e-Table 2. Predictors of bone stiffness and failure load of the distal tibia in the total cohort

\section{Tibia}

Stiffness, kN/mm

Failure load, kN

\begin{tabular}{|c|c|c|c|c|c|c|}
\hline & B (SE) & $95 \% \mathrm{Cl}$ & p & B (SE) & $95 \% \mathrm{Cl}$ & p \\
\hline Age, yrs & 0.06 (1.39) & $-2.75,2.86$ & 0.97 & $0.00(0.06)$ & $-0.13,0.13$ & 0.98 \\
\hline $\mathrm{BMI}, \mathrm{kg} / \mathrm{m}^{2}$ & $5.69(1.57)$ & $2.53,8.85$ & 0.001 & $0.27(0.07)$ & $0.12,0.41$ & 0.001 \\
\hline FFMI, $\mathrm{kg} / \mathrm{m}^{2}$ & $13.4(3.54)$ & $6.27,20.5$ & $<0.001$ & $0.63(0.16)$ & $0.31,0.96$ & $<0.001$ \\
\hline Pack years, $\mathrm{n}$ & $-0.56(0.31)$ & $-1.17,0.06$ & 0.08 & $-0.03(0.01)$ & $-0.05,0.00$ & 0.09 \\
\hline $\mathrm{FEV}_{1}, \mathrm{~L}$ & $17.5(8.07)$ & $1.27,33.8$ & 0.04 & $0.81(0.37)$ & $0.06,1.56$ & 0.04 \\
\hline FVC, L & $15.4(7.59)$ & $0.10,30.7$ & 0.05 & $0.74(0.35)$ & $0.04,1.45$ & 0.04 \\
\hline $\mathrm{FEV}_{1} / \mathrm{FVC}$ ratio & $0.83(0.55)$ & $-0.28,1.94$ & 0.14 & $0.04(0.03)$ & $-0.02,0.09$ & 0.16 \\
\hline VC, L & $16.3(7.91)$ & $0.34,32.2$ & 0.05 & $0.78(0.36)$ & $0.05,1.52$ & 0.04 \\
\hline TLC, L & $11.9(6.83)$ & $-1.89,25.7$ & 0.09 & $0.58(0.31)$ & $-0.05,1.22$ & 0.07 \\
\hline RV, L & $1.99(8.94)$ & $-16.0,20.0$ & 0.83 & $0.11(0.41)$ & $-0.72,0.94$ & 0.79 \\
\hline RV/TLC ratio & $-0.68(0.83)$ & $-2.36,1.01$ & 0.42 & $-0.03(0.04)$ & $-0.11,0.05$ & 0.42 \\
\hline IC, L & $19.8(9.47)$ & $0.70,38.9$ & 0.04 & $0.91(0.44)$ & $0.03,1.79$ & 0.04 \\
\hline ERV, L & 1.99 (12.9) & $-24.1,28.1$ & 0.88 & $0.17(0.60)$ & $-1.04,1.37$ & 0.78 \\
\hline $\begin{array}{l}\mathrm{DLCO}, \mathrm{mmol} / \\
\mathrm{min} / \mathrm{kPa}\end{array}$ & $3.2(3.32)$ & $6.53,19.9$ & $<0.001$ & $0.62(0.15)$ & $0.31,0.92$ & $<0.001$ \\
\hline $\begin{array}{l}\mathrm{KCO}, \mathrm{mmol} / \\
\mathrm{min} / \mathrm{kPa} / \mathrm{L}\end{array}$ & $92.2(25.8)$ & $40.2,144$ & 0.001 & $4.25(1.20)$ & $1.84,6.65$ & 0.001 \\
\hline PI-950, \% & $-3.53(1.43)$ & $-6.42,-0.63$ & 0.02 & $-0.16(0.07)$ & $-0.30,-0.03$ & 0.02 \\
\hline $\begin{array}{l}15^{\text {th }} \text { percentile, } \\
\mathrm{HU}\end{array}$ & $0.80(0.39)$ & $0.02,1.59$ & 0.05 & $0.04(0.02)$ & $0.00,0.07$ & 0.04 \\
\hline \multicolumn{7}{|l|}{$\begin{array}{l}\text { Areal BMD, g/ } \\
\mathrm{cm}^{2}\end{array}$} \\
\hline Femoral neck & 318 (37.0) & 243,392 & $<0.001$ & $14.7(1.71)$ & $11.3,18.1$ & $<0.001$ \\
\hline Total hip & $236(25.4)$ & 185,288 & $<0.001$ & 10.9 (1.17) & $8.57,13.3$ & $<0.001$ \\
\hline L1-L4 & $196(26.6)$ & 143,250 & $<0.001$ & $9.11(1.23)$ & $6.64,11.6$ & $<0.001$ \\
\hline
\end{tabular}

Two sided $p$-values $\leq 0.05$ are considered statistically significant.

$\mathrm{B}=$ unstandardized regression coefficient; $\mathrm{BMD}=$ bone mineral density; $\mathrm{BMI}=$ body mass index; $\mathrm{Cl}=$ confidence interval; $\mathrm{DLCO}=$ diffusion capacity for carbon monoxide; $\mathrm{ERV}=$ expiratory reserve volume; $F E V_{1}=$ forced expiratory volume in 1 second; $F F M I=$ fat free mass index; $F V C=$ forced vital capacity; $\mathrm{HU}=$ Hounsfield units; $\mathrm{IC}=$ inspiratory capacity; $\mathrm{KCO}=$ transfer coefficient for carbon monoxide; PI-950=pixel index for -950 Hounsfield units; RV=residual volume; TLC=total lung capacity; VC=vital capacity. 
e-Table 3. Predictors of bone stiffness and failure load of the distal radius in the COPD subjects

\section{Radius}

\begin{tabular}{|c|c|c|c|c|c|c|}
\hline & \multicolumn{3}{|c|}{ Stiffness, kN/mm } & \multicolumn{3}{|c|}{ Failureload, kN } \\
\hline & B (SE) & $95 \% \mathrm{Cl}$ & $\mathbf{p}$ & B (SE) & $95 \% \mathrm{Cl}$ & $\mathbf{p}$ \\
\hline Age, yrs & $-0.69(0.76)$ & $-2.25,0.86$ & 0.37 & $-0.03(0.04)$ & $-0.11,0.04$ & 0.37 \\
\hline $\mathrm{BMI}, \mathrm{kg} / \mathrm{m}^{2}$ & $2.33(0.83)$ & $0.62,4.03$ & 0.009 & $0.11(0.04)$ & $0.03,0.19$ & 0.01 \\
\hline FFMI, $\mathrm{kg} / \mathrm{m}^{2}$ & $6.13(1.83)$ & $2.38,9.89$ & 0.002 & $0.29(0.09)$ & $0.12,0.47$ & 0.002 \\
\hline Pack years, $\mathrm{n}$ & $0.05(0.21)$ & $-0.38,0.49$ & 0.81 & $0.00(0.01)$ & $-0.02,0.02$ & 0.86 \\
\hline $\mathrm{FEV}_{1}, \mathrm{~L}$ & $12.6(8.29)$ & $-4.38,29.6$ & 0.14 & $0.68(0.38)$ & $-0.11,1.47$ & 0.09 \\
\hline FVC, L & $6.60(5.11)$ & $-3.86,17.1$ & 0.21 & $0.35(0.24)$ & $-0.14,0.84$ & 0.16 \\
\hline $\mathrm{FEV}_{1} / \mathrm{FVC}$ ratio & $0.51(0.47)$ & $-0.44,1.46$ & 0.28 & $0.03(0.02)$ & $-0.02,0.07$ & 0.23 \\
\hline VC, L & 7.54 (5.08) & $-2.87,17.9$ & 0.15 & $0.39(0.24)$ & $-0.09,0.88$ & 0.11 \\
\hline TLC, L & 5.45 (3.98) & $-2.73,13.6$ & 0.18 & $0.29(0.18)$ & $-0.09,0.67$ & 0.13 \\
\hline $\mathrm{RV}, \mathrm{L}$ & 2.47 (5.94) & $-9.73,14.7$ & 0.68 & $0.13(0.28)$ & $-0.44,0.70$ & 0.64 \\
\hline RV/TLC ratio & $-0.37(0.62)$ & $-1.64,0.89$ & 0.55 & $-0.02(0.03)$ & $-0.08,0.04$ & 0.50 \\
\hline IC, L & 4.77 (6.13) & $-7.84,17.4$ & 0.44 & $0.29(0.29)$ & $-0.30,0.87$ & 0.33 \\
\hline ERV, L & 7.34 (7.44) & $-7.95,22.6$ & 0.33 & $0.33(0.35)$ & $-0.38,1.05$ & 0.35 \\
\hline $\begin{array}{l}\mathrm{DLCO}, \mathrm{mmol} / \\
\mathrm{min} / \mathrm{kPa}\end{array}$ & 7.45 (2.41) & $2.52,12.4$ & 0.004 & $0.37(0.11)$ & $0.14,0.60$ & 0.002 \\
\hline $\begin{array}{l}\mathrm{KCO}, \mathrm{mmol} / \\
\mathrm{min} / \mathrm{kPa} / \mathrm{L}\end{array}$ & $45.0(16.6)$ & $11.1,78.9$ & 0.01 & $2.18(0.77)$ & $0.60,3.76$ & 0.009 \\
\hline PI-950, \% & $-1.44(0.82)$ & $-3.14,0.25$ & 0.09 & $-0.07(0.04)$ & $-0.15,0.01$ & 0.07 \\
\hline $\begin{array}{l}15^{\text {th }} \text { percentile, } \\
\mathrm{HU}\end{array}$ & $0.57(0.27)$ & $0.01,1.14$ & 0.05 & $0.03(0.01)$ & $0.00,0.05$ & 0.04 \\
\hline \multicolumn{7}{|l|}{$\begin{array}{l}\text { Areal BMD, g/ } \\
\mathrm{cm}^{2}\end{array}$} \\
\hline Femoral neck & $106(29.2)$ & $45.7,166$ & 0.001 & $5.10(1.36)$ & $2.32,7.88$ & 0.001 \\
\hline Total hip & $88.2(20.3)$ & $46.5,130$ & $<0.001$ & 4.21 (0.95) & $2.27,6.15$ & $<0.001$ \\
\hline L1-L4 & $74.4(20.1)$ & $33.3,116$ & 0.001 & $3.51(0.94)$ & $1.57,5.44$ & 0.001 \\
\hline
\end{tabular}

Two sided $p$-values $\leq 0.05$ are considered statistically significant.

$\mathrm{B}=\mathrm{unstandardized}$ regression coefficient; $\mathrm{BMD}=$ bone mineral density; $\mathrm{BMI}=$ body mass index; $\mathrm{Cl}=$ confidence interval; $\mathrm{DLCO}=$ diffusion capacity for carbon monoxide; $\mathrm{ERV}=$ expiratory reserve volume; $\mathrm{FEV}_{1}=$ forced expiratory volume in 1 second; $\mathrm{FFMI}=$ fat free mass index; $\mathrm{FVC}=$ forced vital capacity; $\mathrm{HU}=$ Hounsfield units; IC=inspiratory capacity; $\mathrm{KCO}=$ transfer coefficient for carbon monoxide; PI-950=pixel index for -950 Hounsfield units; $\mathrm{RV}=$ residual volume; $\mathrm{TLC}=$ total lung capacity; VC=vital capacity. 
e-Table 4. Predictors of bone stiffness and failure load of the distal tibia in the COPD subjects

\section{Tibia}

Stiffness, $\mathrm{kN} / \mathrm{mm}$

Failureload, $\mathrm{kN}$

\begin{tabular}{|c|c|c|c|c|c|c|}
\hline & B (SE) & $95 \% \mathrm{Cl}$ & p & B (SE) & $95 \% \mathrm{Cl}$ & p \\
\hline Age, yrs & 0.35 (1.47) & $-2.65,3.36$ & 0.81 & $0.01(0.07)$ & $-0.13,0.15$ & 0.85 \\
\hline $\mathrm{BMI}, \mathrm{kg} / \mathrm{m}^{2}$ & $5.18(1.50)$ & $2.10,8.25$ & 0.002 & $0.24(0.07)$ & $0.10,0.39$ & 0.002 \\
\hline FFMI, $\mathrm{kg} / \mathrm{m}^{2}$ & $13.1(3.33)$ & $6.22,19.9$ & 0.001 & $0.62(0.16)$ & $0.30,0.94$ & $<0.001$ \\
\hline Pack years, $\mathrm{n}$ & $-0.23(0.40)$ & $-1.05,0.60$ & 0.58 & $-0.01(0.02)$ & $-0.05,0.03$ & 0.59 \\
\hline $\mathrm{FEV}_{1}, \mathrm{~L}$ & 33.5 (15.1) & $2.50,64.5$ & 0.04 & $1.63(0.71)$ & $0.19,3.07$ & 0.03 \\
\hline FVC, L & $9.70(9.84)$ & $-10.5,29.9$ & 0.33 & $0.52(0.46)$ & $-0.42,1.46$ & 0.27 \\
\hline $\mathrm{FEV}_{1} / \mathrm{FVC}$ ratio & $1.78(0.84)$ & $0.07,3.50$ & 0.04 & $0.08(0.04)$ & $0.00,0.16$ & 0.05 \\
\hline VC, L & $12.0(9.78)$ & $-8.05,32.0$ & 0.23 & $0.62(0.46)$ & $-0.32,1.55$ & 0.19 \\
\hline TLC, L & $8.93(7.33)$ & $-6.14,24.0$ & 0.23 & $0.47(0.34)$ & $-0.23,1.17$ & 0.18 \\
\hline $\mathrm{RV}, \mathrm{L}$ & $5.56(10.8)$ & $-16.7,27.9$ & 0.61 & $0.29(0.51)$ & $-0.75,1.33$ & 0.57 \\
\hline RV/TLC ratio & $-0.42(1.13)$ & $-2.75,1.90$ & 0.71 & $-0.02(0.05)$ & $-0.13,0.09$ & 0.68 \\
\hline IC, L & $20.2(10.6)$ & $-1.70,42.1$ & 0.07 & $0.96(0.50)$ & $-0.06,1.98$ & 0.06 \\
\hline ERV, L & $-8.98(13.8)$ & $-37.2,19.3$ & 0.52 & $-0.32(0.64)$ & $-1.64,1.00$ & 0.62 \\
\hline $\begin{array}{l}\text { DLCO, mmol/ } \\
\mathrm{min} / \mathrm{kPa}\end{array}$ & $17.7(4.12)$ & $9.25,26.2$ & $<0.001$ & $0.84(0.19)$ & $0.44,1.23$ & $<0.001$ \\
\hline $\begin{array}{l}\mathrm{KCO}, \mathrm{mmol} / \\
\mathrm{min} / \mathrm{kPa} / \mathrm{L}\end{array}$ & $116(27.8)$ & $59.6,173$ & $<0.001$ & $5.38(1.31)$ & $2.69,8.07$ & $<0.001$ \\
\hline PI-950, \% & $-3.82(1.54)$ & $-7.02,-0.62$ & 0.02 & $-0.18(0.07)$ & $-0.33,-0.03$ & 0.02 \\
\hline $\begin{array}{l}15^{\text {th }} \text { percentile, } \\
\mathrm{HU}\end{array}$ & $1.23(0.54)$ & $0.11,2.35$ & 0.03 & $0.06(0.03)$ & $0.01,0.11$ & 0.03 \\
\hline \multicolumn{7}{|l|}{$\begin{array}{l}\text { Areal BMD, g/ } \\
\mathrm{cm}^{2}\end{array}$} \\
\hline Femoral neck & $272(43.8)$ & 182,361 & $<0.001$ & $12.6(2.07)$ & $8.37,16.9$ & $<0.001$ \\
\hline Total hip & $215(29.4)$ & 154,275 & $<0.001$ & 9.95 (1.40) & $7.08,12.8$ & $<0.001$ \\
\hline L1-L4 & $178(32.5)$ & 111,244 & $<0.001$ & $8.29(1.53)$ & $5.17,11.4$ & $<0.001$ \\
\hline
\end{tabular}

Two sided $p$-values $\leq 0.05$ are considered statistically significant.

$\mathrm{B}=$ unstandardized regression coefficient; $\mathrm{BMD}=$ bone mineral density; $\mathrm{BMI}=$ body mass index; $\mathrm{Cl}=$ confidence interval; $\mathrm{DLCO}=$ diffusion capacity for carbon monoxide; $\mathrm{ERV}=$ expiratory reserve volume; $\mathrm{FEV}_{1}=$ forced expiratory volume in 1 second; $F F M I=$ fat free mass index; $F V C=$ forced vital capacity; $\mathrm{HU}=$ Hounsfield units; $\mathrm{IC}=$ inspiratory capacity; $\mathrm{KCO}=$ transfer coefficient for carbon monoxide; PI-950=pixel index for -950 Hounsfield units; RV=residual volume; TLC=total lung capacity; VC=vital capacity. 



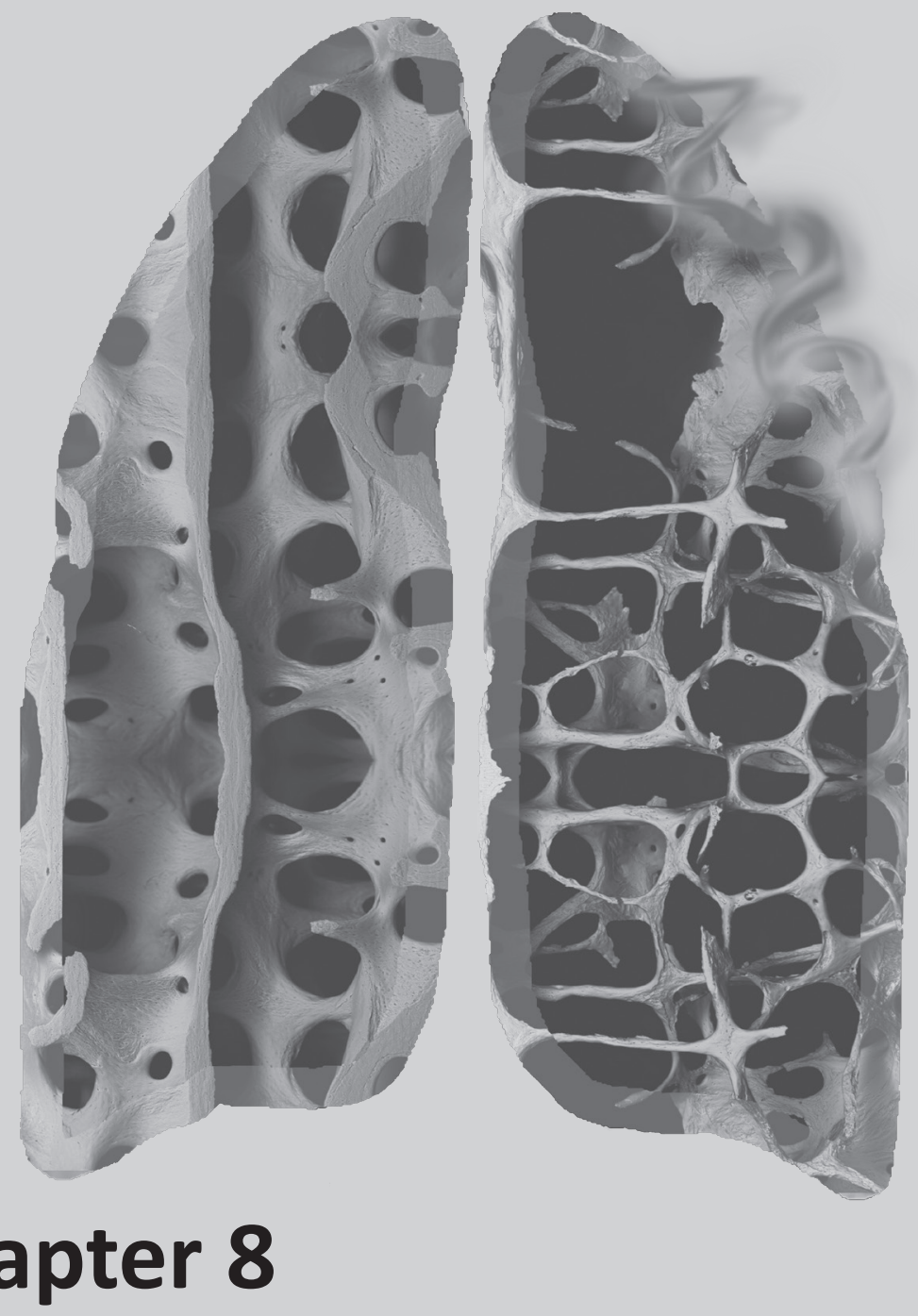

General discussion and future perspectives 


\section{GENERAL DISCUSSION AND FUTURE PERSPECTIVES}

Previous chapters of this thesis gave an overview of the current literature on osteoporosis in COPD, described an algorithm for measuring bone attenuation on chest $\mathrm{CT}$, associated CT-measured bone attenuation with clinical features of COPD, and compared structural and mechanical parameters of bone between men with and without COPD. In this chapter, we will discuss the main findings of this thesis and future perspectives.

\section{VITAMIN D AND COPD}

Vitamin D deficiency was found in the majority of COPD patients and related with airflow obstruction (chapter 3). Several factors might contribute to increased vitamin D deficiency in COPD patients, including poor diet, less exposure to sun light, renal dysfunction, accelerated skin aging or increased catabolism by corticosteroids. ' On the other hand, vitamin D deficiency might contribute to impaired lung function, due to osteoporosis-related vertebral fractures, an altered host defense of the lung resulting in COPD exacerbations, or direct effects on the extracellular matrix homeostasis within the lung. ${ }^{2-4}$ Recently, vitamin D supplementation was shown to reduce COPD exacerbations in subjects with vitamin $\mathrm{D}$ concentrations below $10 \mathrm{ng} / \mathrm{mL} .^{5}$

Lower plasma vitamin D concentrations were related with lower bone mineral density and poor functional exercise capacity in a COPD cohort (chapter 3). Although the role of vitamin $D$ in bone health is well-established, ${ }^{1}$ its role in skeletal muscle function is less clear. Previous cross-sectional and longitudinal data on the effects of vitamin D on skeletal muscle function have been conflicting, probably due to heterogeneity in vitamin D doses, duration of treatment, or methods used for assessing skeletal muscle function. ${ }^{6-10} \mathrm{~A}$ review of the literature indicated that vitamin D might affect skeletal muscle function through the binding of 1,25-hydroxyvitamin $D$ to vitamin $D$ receptor, resulting in muscle growth and other adaptations..$^{11,12}$

Since vitamin $D$ deficiency might influence lung function and several COPD-related comorbidities, ${ }^{4,10,13}$ additional research on the role of vitamin D in COPD is warranted. Future randomised controlled trials in COPD patients should be focussed on the effects of vitamin D supplementation on lung function, skeletal muscle function, bone strength, cardiovascular disease, COPD exacerbations and mortality. In addition, these trials should explore interactions between baseline plasma vitamin D concentrations, polymorphisms in the vitamin $D$ receptor and clinical outcomes. Trials investigating the effects of vitamin $D$ supplementation on skeletal muscle function, exacerbations, lung function and pneumonia are underway (clinicaltrials.gov).

\section{CT SCANNING OF THE CHEST}

CT scans of the chest are frequently performed in COPD patients. In addition to information on pulmonary diseases, chest CT might provide useful information on markers of cardiovascular 
disease (e.g. coronary artery calcium and thoracic aortic calcium) and osteoporosis. ${ }^{14}$ Chapter 4 described an algorithm for measuring bone attenuation of the thoracic vertebrae on routine chest CT in a COPD cohort. This study showed that simple attenuation measurement of the thoracic vertebrae on chest CT had a good reproducibility and correlated strongly with bone mineral density measurement on DXA.

In chapters 5 and 6 , routine chest CT was used to assess extent of emphysema, markers of cardiovascular disease and bone attenuation of the thoracic vertebrae in two large cohorts. In the ECLIPSE cohort, older age, lower fat free mass index and higher coronary artery calcium were independently associated with lower CT-measured bone attenuation (chapter 5). In a Scottish cohort, higher coronary artery calcium was independently associated with lower CT-measured bone attenuation, and, additionally, all-cause mortality was predicted by coronary artery calcium, thoracic aortic calcium and extent of emphysema (chapter 6).

Since chest CT provides useful information on several COPD-related comorbidities, chest CT might contribute to identification of various CT phenotypes. ${ }^{14,15}$ Previous studies have already demonstrated that chest CT provides useful information on extent of emphysema, airway wall dimensions, pulmonary nodules, markers of cardiovascular disease, bone density of the thoracic vertebrae, vertebral fractures and kyphotic angle. ${ }^{14,16-19}$ This information might lead to a more accurate phenotyping of individuals with COPD and, hence, to better personalised treatment.

Although information on COPD-related comorbidities seems to be readily available on chest CT without additional patient time or radiation exposure, radiological evaluation will be extended, which will add a modest amount of costs. In addition, variation across scanners, scanning protocols, evaluation techniques and software is likely to lead to a high variability in outcome measures. Therefore, additional research is needed to develop automated computer-aided evaluation tools and to standardise assessment methods before integrated imaging on chest CT can be implemented in clinical practice.

\section{BONE IMAGING AND STRENGTH}

A strong predictor of non-traumatic fractures is bone mineral density, which nowadays is considered the gold standard for diagnosing osteoporosis. ${ }^{20,21}$ However, other properties of bone might contribute to non-traumatic fractures, since vertebral fractures can also occur in COPD patients with normal bone density or osteopenia. ${ }^{22}$ Indeed, bone strength is influenced by several material and structural properties of bone, including bone mineral density, composition and number of collagen cross-links, micro- and macrostructure of bone and burden of micro damages. ${ }^{23}$

Several other methods have been developed to assess bone strength and predict nontraumatic fractures. ${ }^{24}$ Vertebral fracture assessment on X-rays of the spine was shown to reflect microarchitectural deterioration ${ }^{25}$ and predict incidental vertebral fractures, ${ }^{26}$ and can therefore be used to predict future fractures. One of the most promising techniques is 
High-Resolution peripheral Quantitative Computed Tomography (HR-pQCT). With HR-pQCT, structural parameters of bone can be assessed and mechanical parameters of bone can be estimated using micro-finite element analysis ( $\mu \mathrm{FEA}) .^{24}$ These structural and mechanical parameters have been shown to be superior to bone mineral density in discriminating between subjects with and without fractures. ${ }^{27}$

Previous studies on osteoporosis in COPD patients have mainly used bone mineral density measurement and vertebral fracture assessment for diagnosing osteoporosis and predicting future fractures. ${ }^{28}$ In chapter 7 , structural and mechanical parameters of bone were assessed on HR-pQCT images in men with and without COPD. Since this pilot study could not detect any differences in structural or mechanical parameters of bone between men with and without COPD after adjustment for bone mineral density, bone structure and strength appear to be comparable between subjects with and without COPD. However, after adjustment for bone mineral density, mechanical parameters of bone were related with fat free mass index and gas transfer capacity of the lung. These findings might suggest that disease-specific factors contribute to loss of bone strength in COPD patients.

Since bone strength is influenced by several properties of bone, future research on osteoporosis in COPD should not be focussed on bone mineral density alone. Structural and mechanical parameters assessed on HR-pQCT have already shown promising results in nonCOPD patients. ${ }^{29}$ Therefore, future research on osteoporosis in COPD should be focussed on structural and mechanical parameters of bone. Hopefully, this will lead to more insight into the pathophysiologic mechanisms of osteoporosis in COPD and, consequently, to improved treatment of osteoporosis in COPD.

\section{FINAL CONCLUSIONS AND RECOMMENDATIONS}

This thesis has resulted in the following conclusions and recommendations:

1. Osteoporosis is highly prevalent and largely under-diagnosed in COPD patients. COPD patients at risk for osteoporosis include older patients, patients with low body or muscle mass, patients who are less physically active, patients who use corticosteroids, patients with vitamin D deficiency, patients with a high number of pack years smoked and patients with high alcohol consumption.

2. Vitamin D deficiency is found in the majority of COPD patients and is related with impaired lung function, osteoporosis and poor physical activity. Future research on COPD should be focussed on vitamin $\mathrm{D}$ as the target of treatment for both pulmonary and extrapulmonary manifestations of COPD.

3. A new algorithm was introduced to assess bone attenuation of the thoracic vertebrae on routine chest $\mathrm{CT}$. This algorithm had a good reproducibility and was strongly correlated with bone mineral density measurement on DXA.

4. Chest CT provides useful information on COPD and several related comorbidities, such as markers of cardiovascular disease, emphysema, pulmonary nodules and bone health. Therefore, chest CT might be useful for integrated imaging in COPD patients. 
5. Future research on osteoporosis in COPD should be focussed on structural and mechanical parameters of bone. Although in our pilot study structural and mechanical parameters of bone were similar in men with and without COPD, mechanical parameters of bone were related with disease-specific features, including fat free mass index and gas transfer capacity of the lung. 


\section{REFERENCES}

1. Holick MF. Vitamin D deficiency. N Engl J Med 2007; 357: 266-81.

2. Hanson C, Rutten EP, Wouters EF, Rennard S. Diet and vitamin D as risk factors for lung impairment and COPD. Transl Res 2013; doi: 10.1016/j.trsl.2013.04.004 [Epub ahead of print].

3. Wood AM, Bassford C, Webster D, Newby P, Rajesh P, Stockley RA, Thickett DR. Vitamin D-binding protein contributes to COPD by activation of alveolar macrophages. Thorax 2011; 66: 205-10.

4. Herr C, Greulich T, Koczulla RA et al. The role of vitamin D in pulmonary disease: COPD, asthma, infection, and cancer. Respir Res 2011; 12: 31.

5. Lehouck A, Mathieu C, Carremans $C$ et al. High doses of vitamin d to reduce exacerbations in chronic obstructive pulmonary disease: a randomized trial. Ann Intern Med 2012; 156: 105-14.

6. Marantes I, Achenbach SJ, Atkinson EJ, Khosla S, Melton LJ, III, Amin S. Is vitamin D a determinant of muscle mass and strength? J Bone Miner Res 2011; 26: 2860-71.

7. Ceglia L, Chiu GR, Harris SS, Araujo AB. Serum 25-hydroxyvitamin D concentration and physical function in adult men. Clin Endocrinol (Oxf) 2011; 74: 370-6.

8. Houston DK, Cesari M, Ferrucci L et al. Association between vitamin D status and physical performance: the InCHIANTI study. J Gerontol A Biol Sci Med Sci 2007; 62: 440-6.

9. Gerdhem P, Ringsberg KA, Obrant KJ, Akesson K. Association between 25-hydroxy vitamin D levels, physical activity, muscle strength and fractures in the prospective population-based OPRA Study of Elderly Women. Osteoporos Int 2005; 16: 1425-31.

10. Pludowski P, Holick MF, Pilz S et al. Vitamin D effects on musculoskeletal health, immunity, autoimmunity, cardiovascular disease, cancer, fertility, pregnancy, dementia and mortality-A review of recent evidence. Autoimmun Rev 2013; 12: 976-89.

11. Dirks-Naylor AJ, Lennon-Edwards S. The effects of vitamin D on skeletal muscle function and cellular signaling. J Steroid Biochem Mol Biol 2011; 125: 159-68.

12. Ceglia L. Vitamin D and skeletal muscle tissue and function. Mol Aspects Med 2008; 29: 407-14.

13. Janssens W, Lehouck A, Carremans C, Bouillon R, Mathieu C, Decramer M. Vitamin D beyond bones in chronic obstructive pulmonary disease: time to act. Am J Respir Crit Care Med 2009; 179: 630-6.

14. Mets OM, de Jong PA, Prokop M. Computed tomographic screening for lung cancer: an opportunity to evaluate other diseases. JAMA 2012; 308: 1433-4.

15. Mets OM, de Jong PA, van GB, Gietema HA, Lammers JW. Quantitative computed tomography in COPD: possibilities and limitations. Lung 2012; 190: 133-45.

16. Coxson HO, Rogers RM. Quantitative computed tomography of chronic obstructive pulmonary disease. Acad Radiol 2005; 12: 1457-63.

17. Woo EK, Mansoubi H, Alyas F. Incidental vertebral fractures on multidetector CT images of the chest: prevalence and recognition. Clin Radiol 2008; 63: 160-4.

18. Jiang SD, Wu QZ, Lan SH, Dai LY. Reliability of the measurement of thoracolumbar burst fracture kyphosis with Cobb angle, Gardner angle, and sagittal index. Arch Orthop Trauma Surg 2012; 132: 221-5.

19. Jacobs PC, Gondrie MJ, Mali WP, Oen AL, Prokop M, Grobbee DE, van der Graaf Y. Unrequested information from routine diagnostic chest CT predicts future cardiovascular events. Eur Radiol 2011; 21: $1577-85$.

20. World Health Organization. Prevention and Management of Osteoporosis; report of a WHO scientific group [updated 2003; cited 2013 August]. Available from: http://whqlibdoc.who.int/trs/WHO_TRS_921. pdf.

21. Lewiecki EM, Gordon CM, Baim S et al. International Society for Clinical Densitometry 2007 Adult and Pediatric Official Positions. Bone 2008; 43: 1115-21.

22. Graat-Verboom L, van den Borne BE, Smeenk FW, Spruit MA, Wouters EF. Osteoporosis in COPD outpatients based on bone mineral density and vertebral fractures. J Bone Miner Res 2011; 26: 561-8.

23. Seeman E, Delmas PD. Bone quality--the material and structural basis of bone strength and fragility. $\mathrm{N}$ Engl J Med 2006; 354: 2250-61. 
24. Link TM. Osteoporosis imaging: state of the art and advanced imaging. Radiology 2012; 263: 3-17.

25. Genant HK, Delmas PD, Chen P et al. Severity of vertebral fracture reflects deterioration of bone microarchitecture. Osteoporos Int 2007; 18: 69-76.

26. Lindsay R, Silverman SL, Cooper $C$ et al. Risk of new vertebral fracture in the year following a fracture. JAMA 2001; 285: 320-3.

27. Cheung AM, Adachi JD, Hanley DA et al. High-resolution peripheral quantitative computed tomography for the assessment of bone strength and structure: a review by the canadian bone strength working group. Curr Osteoporos Rep 2013; 11: 136-46.

28. Graat-Verboom L, Wouters EF, Smeenk FW, van den Borne BE, Lunde R, Spruit MA. Current status of research on osteoporosis in COPD: a systematic review. Eur Respir J 2009; 34: 209-18.

29. Engelke K, Libanati C, Fuerst T, Zysset P, Genant HK. Advanced CT based In Vivo Methods for the Assessment of Bone Density, Structure, and Strength. Curr Osteoporos Rep 2013; doi: 10.1007/s11914013-0147-2 [Epub ahead of print]. 



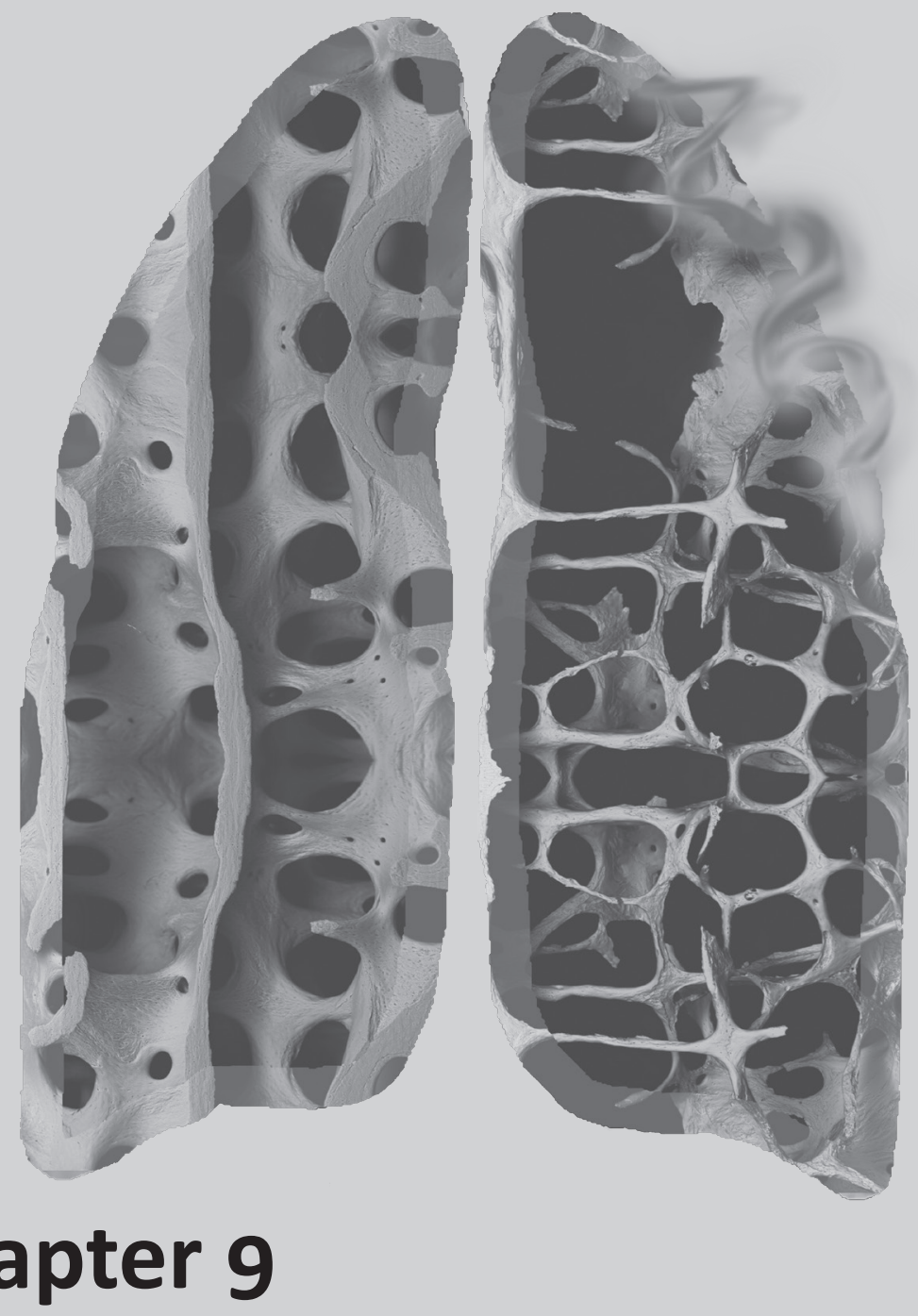

Summary of this thesis / Samenvatting van dit proefschrift 


\section{SUMMARY OF THIS THESIS}

This thesis primarily focused on diagnostic imaging and risk factors of osteoporosis in COPD. The main objectives of this thesis were 1) to give an overview of the current literature on osteoporosis in COPD; 2) to develop a new algorithm for measuring bone density on routine chest $\mathrm{CT}$; 3 ) to study associations between $\mathrm{CT}$-measured bone attenuation and clinical features of COPD; and 4) to study structural and mechanical parameters of bone in subjects with and without COPD. In this chapter, we will provide an overview of the main findings of this thesis.

Chapter $\mathbf{2}$ gives an overview of the current literature on osteoporosis in COPD. Osteoporosis is frequently seen in COPD patients. The prevalence of osteoporosis is around $33 \%$ in COPD patients, compared with $11 \%$ in controls matched for age. Risk factors of osteoporosis in COPD patients include older age, low body or muscle mass, physical inactivity, tobacco smoking, alcohol use and vitamin D deficiency. In addition to these risk factors, COPD-specific factors, such as the use of corticosteroids and systemic inflammation, might contribute to the development of osteoporosis in COPD patients.

The gold standard for diagnosing osteoporosis is dual energy X-ray absorptiometry (DXA). In addition to DXA, vertebral fracture assessment might be helpful to identify COPD patients at risk of fracture. Vertebral fractures reflect the severity of microarchitectural deterioration and are related with a high annual number of incidental vertebral fractures. The clinical technique of choice for diagnosing vertebral fractures is the Genant visual semi-quantitative method.

Management of osteoporosis is primarily focused on preventing osteoporosis-related fractures. Since osteoporosis is frequently seen in COPD patients, (chest) physicians should inform all COPD patients about the benefits of a healthy diet, physical activity and smoking cessation. In addition, COPD patients at risk of osteoporosis, but preferably all COPD patients, should be screened for osteoporosis using DXA and vertebral fracture assessment, and, if necessary, treatment of osteoporosis should be initiated (e.g. calcium and vitamin $D$ supplementation, bisphosphonates). Moreover, all COPD patients who use corticosteroids should be treated according to the guidelines for management of corticosteroid-induced osteoporosis.

Chapter 3 describes associations between vitamin D, bone mineral density, skeletal muscle strength and functional exercise capacity in patients with moderate to very severe COPD entering pulmonary rehabilitation. Vitamin $D$ deficiency was found in the majority of COPD patients and increased with more severe airflow obstruction. In addition, plasma vitamin D concentrations were related with bone mineral density and functional exercise capacity.

Chapter 4 describes an algorithm for measuring bone attenuation of the thoracic vertebrae on routine chest CT in COPD patients. This algorithm had a good reproducibility. In addition, 
bone attenuation of the thoracic vertebrae on chest CT was strongly correlated with bone mineral density of the hip and lumbar spine on DXA. Therefore, bone attenuation measurement on routine chest CT might be useful for assessing bone density.

In chapters 5 and 6, routine chest CT was used to assess bone attenuation of the thoracic vertebrae in two large cohorts. In the ECLIPSE cohort (chapter 5), CT-measured bone attenuation was lower in COPD subjects than in smoker and non-smoker controls. In the COPD subjects, older age, lower fat free mass index and higher coronary artery calcium were independently associated with lower CT-measured bone attenuation. In addition, lower CTmeasured bone attenuation was associated with a lower rate of decline in $\mathrm{FEV}_{1}$ and higher exacerbation and hospitalisation rates, but was not associated with all-cause mortality. In a Scottish cohort (chapter 6 ), increased coronary artery calcium was associated with increased arterial stiffness and lower CT-measured bone attenuation. In addition, coronary artery calcium, thoracic aortic calcium and extent of emphysema were associated with all-cause mortality, while arterial stiffness and bone attenuation were not associated with all-cause mortality.

Chapter $\mathbf{7}$ describes a pilot study on structural and mechanical parameters of bone in men with and without COPD. This study could not detect any differences in bone structure, stiffness and failure load between men with and without COPD after stratification for bone mineral density. In men with COPD, fat free mass index and gas transfer capacity of the lung were related with bone stiffness and failure load after adjustment for bone mineral density.

Chapter 8 discusses the main findings of this thesis and future perspectives. The main conclusions of this thesis can be summarised as follows:

1. Osteoporosis is highly prevalent and remains largely under-diagnosed in COPD patients.

2. Vitamin D deficiency is found in the majority of COPD patients and is associated with several COPD-related features.

3. Routine chest CT provides opportunities for measuring bone density in COPD patients.

4. Although structural and mechanical parameters of bone appear to be similar in men with and without COPD, mechanical parameters of bone might be related with disease specific features such as fat free mass index and gas transfer capacity of the lung. 


\section{SAMENVATTING VAN DIT PROEFSCHRIFT}

Dit proefschrift is gericht op de diagnostiek van en risicofactoren voor osteoporose bij COPD patiënten. De doelstellingen van het proefschrift zijn: 1) het samenvatten van de huidige literatuur over osteoporose bij COPD patiënten; 2) het ontwikkelen van een algoritme voor het meten van de botdichtheid op een CT scan van de thorax; 3) het bestuderen van verbanden tussen de botdichtheid, gemeten op een CT scan van de thorax, en klinische uitkomstmaten van COPD; en 4) het bestuderen van de structurele en mechanische botparameters in deelnemers met en zonder COPD. In dit hoofdstuk worden de belangrijkste bevindingen van het proefschrift beschreven.

Hoofdstuk 2 geeft een overzicht van de huidige literatuur over osteoporose bij COPD. Osteoporose komt frequent voor bij patiënten met COPD. De prevalentie van osteoporose is ongeveer $33 \%$ bij COPD patiënten en ongeveer $11 \%$ bij gezonde leeftijdgenoten. $\mathrm{Er}$ zijn bij COPD patiënten verschillende risicofactoren voor osteoporose beschreven, zoals oudere leeftijd, laag lichaamsgewicht, weinig lichaamsbeweging, roken, alcoholgebruik en vitamine $D$ deficiëntie. Behalve deze algemene risicofactoren, zijn er ook verschillende COPD gerelateerde risicofactoren beschreven, zoals het gebruik van corticosteroïden en systemische inflammatie.

De gouden standaard voor het diagnosticeren van osteoporose is dual energy X-ray absorptiometry (DXA). Het beoordelen van wervelfracturen op beeldvorming van de wervelkolom kan als aanvulling op DXA worden gebruikt. Wervelfracturen geven de ernst van de microarchitecturele beschadiging weer en zijn gerelateerd aan een hoog aantal nieuwe wervelfracturen in het eerste jaar na het ontstaan van een wervelfractuur. De gouden standaard voor het beoordelen van wervelfracturen is de visuele semikwantitatieve methode van Genant.

De behandeling van osteoporose is hoofdzakelijk gericht op het voorkómen van fracturen. Omdat osteoporose frequent voorkomt bij COPD patiënten, zouden alle COPD patiënten moeten worden voorgelicht over de positieve effecten van een gezond dieet rijk aan eiwitten en vitamine $D$, voldoende lichaamsbeweging en stoppen met roken. Bovendien zouden alle COPD patiënten met risicofactoren voor osteoporose, maar bij voorkeur alle COPD patiënten, moeten worden gescreend op osteoporose door gebruik te maken van DXA scans en beeldvorming van de wervelkolom. Indien nodig moet gestart worden met een behandeling tegen osteoporose. De medicamenteuze behandeling van osteoporose kan bestaan uit calcium en vitamine $D$ suppletie en een bisfosfonaat. Bovendien zouden alle COPD patiënten die corticosteroïden gebruiken, behandeld moeten worden volgens de richtlijn voor de preventie en behandeling van corticosterö̈den geïnduceerde osteoporose.

Hoofdstuk 3 beschrijft de verbanden tussen vitamine D, botdichtheid, spierkracht en inspanningsvermogen bij patiënten met een matig tot zeer ernstig COPD die deelnemen aan een longrevalidatieprogramma. Vitamine $D$ deficiëntie werd gevonden in het merendeel van de COPD patiënten. Het aantal patiënten met een vitamine $D$ deficiëntie nam toe met de 
ernst van de COPD. De plasma vitamine $\mathrm{D}$ concentratie was gerelateerd aan de botdichtheid en het inspanningsvermogen.

Hoofdstuk 4 beschrijft een algoritme voor het meten van de botdichtheid van de thoracale wervels op een CT scan van de thorax bij patiënten met COPD. Het algoritme had een goede reproduceerbaarheid. Daarnaast was de botdichtheid van de thoracale wervels op een CT scan sterk gecorreleerd met de botdichtheid van de heup en lumbale wervels op een DXA scan. Deze resultaten tonen dat een botdichtheidsmeting op een CT scan van de thorax kan worden gebruikt voor het bestuderen van botweefsel.

In hoofdstuk 5 en 6 werden botdichtheidsmetingen verricht op CT scans van de thorax in twee verschillende onderzoeksgroepen. De data van de ECLIPSE studie (hoofdstuk 5) toonden dat COPD patiënten een lagere botdichtheid hadden dan gezonde rokers of niet-rokers. Bij de COPD patiënten waren een hogere leeftijd, lagere vet vrije massa index en hogere calciumscore van de coronairen geassocieerd met een lagere botdichtheid. Vervolgens was een lagere botdichtheid geassocieerd met een verminderde afname van de $\mathrm{FEV}_{1}$, meer exacerbaties en meer ziekenhuisopnames. Een lagere botdichtheid was echter niet gerelateerd aan een hogere mortaliteit. Een studie in Schotland (hoofdstuk 6) toonde dat een verhoogde calciumscore van de coronairen geassocieerd was met een verhoogde stijfheid van de vaten en een lagere botdichtheid. Vervolgens waren de mate van emfyseem en de calciumscores van de coronairen en thoracale aorta gerelateerd aan de mortaliteit, terwijl de stijfheid van de vaten en de botdichtheid niet waren gerelateerd aan de mortaliteit.

Hoofdstuk 7 beschrijft een studie naar de verschillen in structurele en mechanische botparameters tussen mannen met en zonder COPD. In deze studie werden geen verschillen gevonden in de structuur, stijfheid en draagkracht van bot tussen mannen met en zonder COPD na stratificatie voor botdichtheid. Bij de mannen met COPD was de vet vrije massa index en diffusie capaciteit van de longen gerelateerd met de stijfheid en draagkracht van bot na correctie voor botdichtheid.

In hoofdstuk 8 worden de belangrijkste bevindingen van dit proefschrift beschreven en bediscussieerd. De belangrijkste conclusies die op basis van dit proefschrift kunnen worden getrokken zijn:

1. Osteoporose komt frequent voor bij patiënten met COPD en wordt vaak niet, of pas laat, gediagnosticeerd.

2. Vitamine $D$ deficiëntie wordt gevonden bij een groot deel van de COPD patiënten en is geassocieerd met verschillende COPD gerelateerde comorbiditeiten.

3. Een CT scan van de thorax kan gebruikt worden voor het meten van de botdichtheid bij COPD patiënten.

4. Ondanks dat de structurele en mechanische botparameters bij mannen met en zonder COPD vergelijkbaar zijn, blijken de mechanische botparameters toch gerelateerd te zijn aan ziekte specifieke factoren, zoals vet vrije massa index en diffusie capaciteit van de longen. 



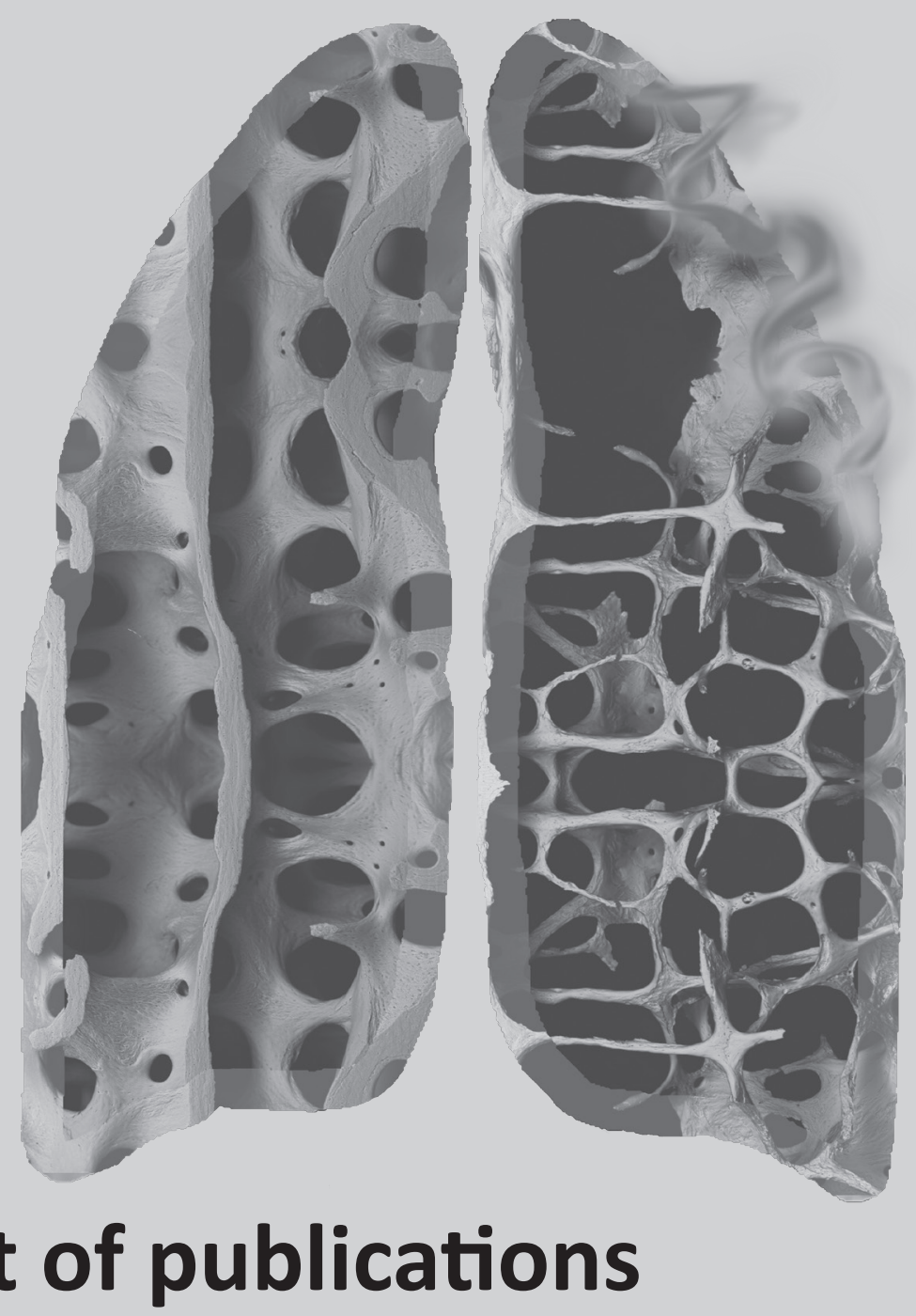





\section{List of publications}

1. van de Schoot L, Romme EA, van der Sangen MJ, Creemers GJ, van Lijnschoten G, van Driel OJ, Rutten HJ, Nieuwenhuijzen GA. A highly active and tolerable neoadjuvant regimen combining paclitaxel, carboplatin, 5 - $\mathrm{FU}$, and radiation therapy in patients with stage II and III esophageal cancer. Ann Surg Oncol 2008; 15: 88-95.

2. Romme EA, Murchison JT, Phang KF, Jansen FH, Rutten EP, Wouters EF, Smeenk FW, Van Beek EJ, Macnee W. Bone attenuation on routine chest CT correlates with bone mineral density on DXA in patients with COPD. J Bone Miner Res 2012; 27: 2338-43.

3. Romme EA, Rutten EP, Smeenk FW, Spruit MA, Menheere PP, Wouters EF. Vitamin $D$ status is associated with bone mineral density and functional exercise capacity in patients with chronic obstructive pulmonary disease. Ann Med 2013; 45: 91-6.

4. Romme EA, Murchison JT, Edwards LD, van Beek EJ, Murchison DM, Rutten EP, Smeenk FW, Williams MC, Wouters EF, Macnee W; on behalf of the Evaluation of COPD Longitudinally to Identify Predictive Surrogate Endpoints (ECLIPSE) study investigators. CT-measured bone attenuation in patients with chronic obstructive pulmonary disease: relation to clinical features and outcomes. J Bone Miner Res 2013; 28: 1369-77.

5. Romme EA, Murchison JT, van Beek EJ, Rutten EP, Smeenk FW, Wouters EF, MacNee W. Computed tomography: bone attenuation of the thoracic vertebrae as an indicator of bone health in COPD. Diagnostic Imaging Europe [updated 2013; cited 2013 August]. Available from: http://content.yudu.com/Library/A21dxl/DiagnosticlmagingEur/ resources/20.htm.

6. Romme EA, Smeenk FW, Wouters EF, Rutten EP. Osteoporosis in COPD. In: Rabe KF, Wedzicha JA, Wouters EF, editors. European Respiratory Monograph; number 59: COPD and comorbidity. Norwich (UK): Page Bros Ltd; 2013.

7. Romme EA, Rutten EP, Wouters EF, Smeenk FW. Review on osteoporosis in chronic obstructive pulmonary disease (COPD). Expert Rev Respir Med 2013; 7: 397-410.

8. Romme EA, Rutten EP, Geusens P, de Jong JJ, van Rietbergen B, Smeenk FW, Wouters EF, van den Bergh JP. Bone stiffness and failure load are related with clinical parameters in men with chronic obstructive pulmonary disease. J Bone Miner Res 2013; 28: 2186-93.

9. Berg I, Hanson C, Sayles H, Romberger D, Nelson A, Meza J, Miller B, Wouters E, MacNee W, Rutten E, Romme E, Vestbo J, Edwards L, Rennard S. Vitamin D, Vitamin D Binding Protein, Lung Function and Structure in COPD. Respir Med 2013; 107: 1578-88.

10. Romme EA, McAllister DA, Murchison JT, van Beek EJ, Petrides GS, Price CO, Rutten EP, Smeenk FW, Wouters EF, MacNee W. Associations between COPD-related manifestations: arterial calcification and stiffness, bone density, emphysema and allcause mortality. Respir Res 2013; 14: 129. 



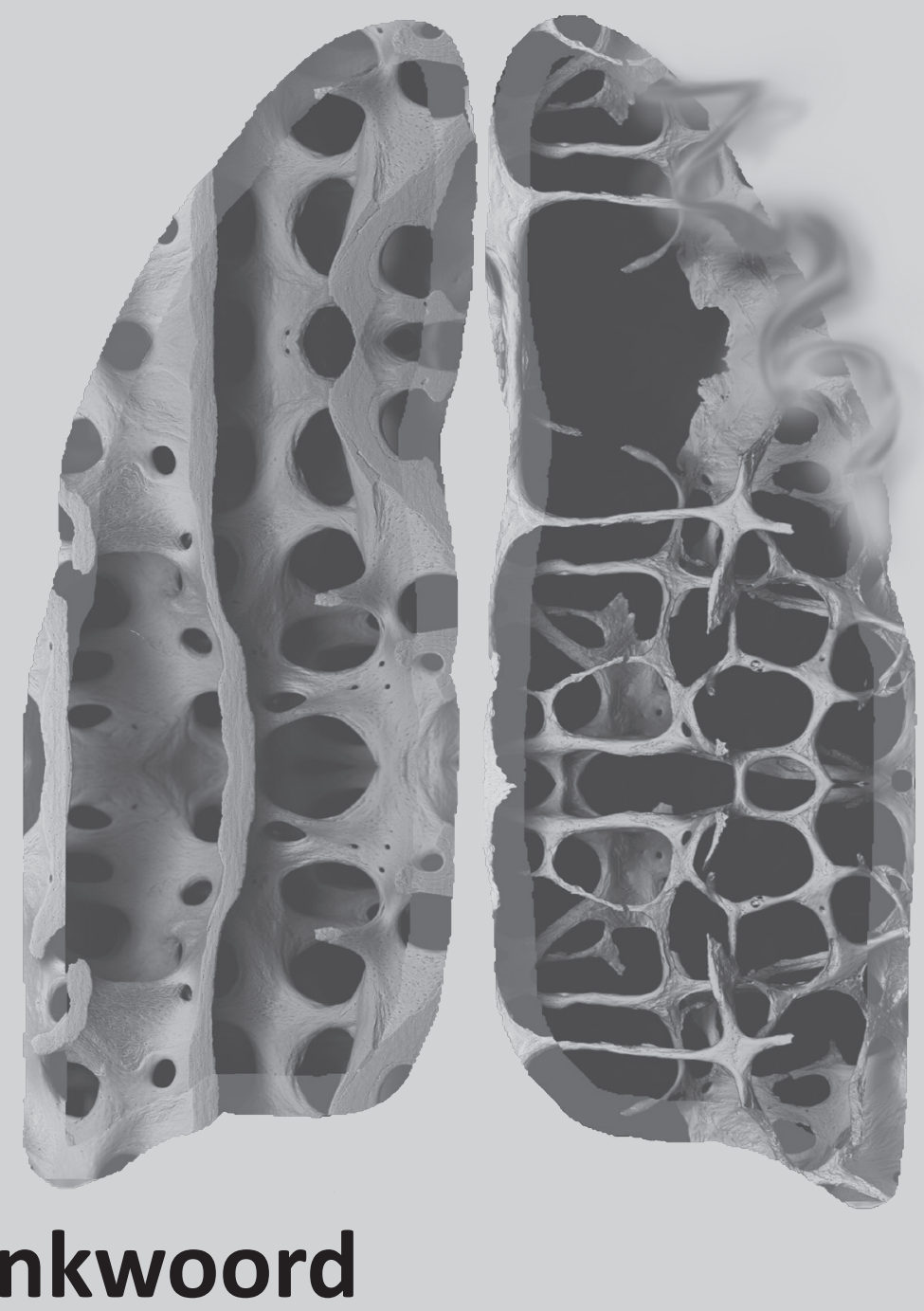




\section{DANKWOORD}

Het is zover! Mijn proefschrift is klaar. Ondanks dat ik er met veel plezier aan heb gewerkt, ben ik blij dat het eindresultaat voor $u$ ligt. Op deze plaats wil ik graag een aantal personen in het bijzonder bedanken.

Allereerst wil ik mijn promotoren en copromotor bedanken.

Prof. dr. E.F.M. Wouters. Beste professor Wouters, u stelde voor om een vervolgonderzoek te beginnen naar osteoporose bij COPD patiënten. Tijdens onze eerste kennismaking legde u uit waarom dit onderwerp zo interessant is en formuleerden wij samen enkele vraagstellingen. Echter, 3 jaar geleden kreeg het onderzoek plots een geheel andere wending. $U$ regelde dat ik naar Edinburgh kon voor het analyseren van de ECLIPSE data. Dit is een prachtige kans gebleken. Bedankt voor uw vertrouwen en voortreffelijke begeleiding.

Prof. dr. F.W.J.M. Smeenk. Beste Frank, ik bewonder jouw enthousiasme en inzet voor onderzoek en opleiding. Jij was altijd bereikbaar voor overleg en keek met een zeer kritische blik naar mijn data en teksten. Daarnaast gaf je mij het gevoel dat alles mogelijk was. De titel professor heb je absoluut verdiend. Onthoud echter één ding; autorijden en het instellen van de routeplanner gaan niet goed samen.

Dr. E.P.A. Rutten. Beste Erica, wij hebben heel wat uurtjes aan de telefoon doorgebracht voor het bespreken van statistische analyses, het interpreteren van data, het voorbereiden van congressen en, af en toe, het uiten van emoties. Ik heb met veel plezier met jou samengewerkt en ik hoop dat wij nog een paar mooie artikelen gaan schrijven. Daarnaast zal ik de dagen met jou in Edinburgh niet snel vergeten (Glasgow, busrit, porridge, ...).

I would also like to thank my supervisors in Edinburgh.

Prof. dr. W. MacNee. Dear Bill, many thanks for having me at your research institute. I am still impressed by all the things you do; travelling around the world, doing research, supervising PhD students, working in the clinics and ... playing in a band. Many thanks for your kind hospitality and all your help in my research project.

Prof. dr. J.T. Murchison. Dear John, thank you for your help with all the analyses and your great sense of humour. I will never forget the story about Burke and Hare... I hope we will stay in touch.

Prof. dr. E.J.R. van Beek. Beste Edwin, bedankt voor jouw kritische blik en radiologische hulp. Leuk dat ik met jou een toost kon uitbrengen op mijn gewonnen prijs in Chicago.

M. Connell. Dear Martin, many thanks for your great help and the lovely porridge meal you served me. 
In de loop van het onderzoek werd de onderzoeksgroep uitgebreid met de volgende personen: prof. dr. J.P.W. van den Bergh, prof. dr. P. Geusens en dr. ir. B. van Rietbergen. Beste heren, bedankt voor jullie enthousiasme en kritische blik. Onze samenwerking heeft tot een mooie publicatie in Journal of Bone and Mineral Research geleid. Ik hoop dat er nog een paar mooie publicaties mogen volgen.

Het onderzoek is uitgevoerd met grote steun van de maatschap longgeneeskunde in het Catharina ziekenhuis.

Dr. R.H.H. van Balkom. Beste Roland, bedankt voor de fijne supervisie tijdens mijn zaalstage op 13 west en de voortreffelijke manier waarop jij wekelijks het longfunctie onderwijs verzorgt. Jij hebt mij geleerd om kritisch naar diagnoses en behandelplannen te kijken en efficiënt te werken. Tevens bedankt voor jouw handige ski tips.

Dr. B.E.E.M. van den Borne. Beste Ben, bedankt voor het organiseren en geven van onderwijs over de longoncologie en jouw inzet voor wetenschappelijk onderzoek. Ik bewonder jouw brede interesses. Jij hebt mij ooit verteld dat jij, behalve het werk als longarts, het heerlijk vindt om een dagje op het land te werken. Ik hoor graag wanneer je de aardappels komt rooien...

Drs. J.P.H.M. Creemers. Beste Jacques, bedankt voor jouw vertrouwen in mij. Jij hebt mij gesteund bij het maken van een paar belangrijke beslissingen, zoals het kiezen voor de longgeneeskunde en het beginnen met een promotieonderzoek. Ik bewonder de manier waarop jij met patiënten en collega's omgaat. Jij hebt altijd, ook al heb je eigenlijk geen tijd, tijd voor overleg of een gezellig praatje.

Drs. P.L.M.L. Wielders. Beste Pascal, ongeveer 6 jaar geleden had ik een sollicitatiegesprek met jou en Frank. Ik mocht uiteindelijk toch bij jullie beginnen. Bedankt voor deze prachtige kans. Daarnaast heb jij mij geleerd om bepaalde dingen op een zakelijke manier te bekijken en te verwoorden. Bedankt voor jouw wijze raad.

Behalve de leden van de maatschap, wil ik ook drs. H.G.J. de Beer en drs. M. RietdijkSmulders bedanken. Beste Hans, het is klaar! En ja, je mag naar de verdediging van mijn proefschrift komen. Bedankt voor jouw interesse en grappige anekdotes. Beste Margriet, het was gezellig om met jou naar de ERS in Barcelona te gaan. Bedankt voor jouw kritische vragen en opmerkingen.

Een aantal data, die tijdens mijn onderzoeksperiode zijn verzameld, zijn nog niet geanalyseerd of gepubliceerd. Via deze weg wil ik de personen die hebben geholpen bij het includeren van proefpersonen en verzamelen van gegevens bedanken. De volgende personen wil ik graag in het bijzonder noemen. 
Longartsen Sint Anna ziekenhuis Geldrop. Bedankt dat ik ook een paar patiënten uit jullie kliniek mocht includeren. Beste Nelly Klerx, bedankt voor jouw hulp, enthousiasme en interesse in mijn onderzoek.

Diagnostisch Centrum Eindhoven. Beste Marlies, bedankt dat jouw afdeling wilde helpen bij het includeren van de gezonde deelnemers. Dames, bedankt voor jullie enorme inzet, gastvrijheid en interesse in mijn onderzoek.

Longpoli. Beste dames, bedankt voor jullie hulp en het attenderen van de longartsen op mijn onderzoek. Bedankt voor de heerlijke koffiemomentjes en jullie grappige verhalen.

Longfunctie. Beste allemaal, jullie hebben keihard gewerkt om bij zowel de 'gewone' reguliere patiënten als bij de studiedeelnemers 'bimmetjes' en longfuncties af te nemen. Bedankt voor jullie inzet, flexibiliteit en interesse in mijn onderzoek.

Radiologie. Beste Astrid Donkers, Frits Jansen, Rianne Verhees, Elly Hendriks en Elly van Hugte, bedankt voor jullie enthousiasme en inzet voor mijn onderzoek. Ondanks de drukte in de kliniek, was er altijd wel een gaatje in jullie agenda te vinden voor een kort overleg. Bedankt voor het maken van alle röntgenfoto's, CT en DXA scans.

Laboratorium. Beste medewerkers van het laboratorium, bedankt voor jullie hulp bij het verzamelen en verwerken van alle bloedmonsters. Beste Arjen-Kars, Joyce en Anton, bedankt voor jullie enthousiasme en inzet. Hopelijk komt er snel een vervolg op mijn onderzoek.

Beste Joost, bedankt voor het maken van de XtremeCT scans. Heel veel succes met je eigen promotie onderzoek.

Statistiek. Beste Wobbe, Saskia en Miriam, bedankt voor jullie hulp bij de statistiek. Jullie kritische blik heeft mij geholpen bij het juist interpreteren van de data.

Scientific writing. Beste Lisette, bedankt voor de geweldige cursus 'scientific writing'. Jij hebt mij geleerd hoe je een Engelse zin, alinea en tekst moet opbouwen. Bedankt voor het kritisch lezen van de Engelse teksten.

En dan nu, de collega's!

Longresearch. Beste dames, bedankt voor jullie gezelligheid en heerlijke theemomentjes. Bedankt voor jullie hulp bij het includeren en gastvrij ontvangen van de deelnemers. Beste Anne, bedankt voor jouw interesse in mijn onderzoek. Ondanks dat jij de indeling van mijn kast niet begrijpt, zit er echt een logische structuur in.

ELEGI. Dear Anja, Ellen, Jennifer (small), Jennifer (tall), Ken, Path, Roberto, Sheila, Spike and Susan, many thanks for the wonderful time in Edinburgh. Dear Spike, thank you for your 
funny stories and driving me to work. Dear Ellen and Leanne, thank you for the lovely stay at your place. Tot ziens in Nederland?

Ciro Horn. Beste Anouk, Daisy, Frits, Lowie, Martijn, Maurice en Sarah, bedankt dat ik bij jullie aan mocht sluiten tijdens congressen. Anouk, Lowie, Maurice en Sarah, heel veel succes met jullie promotieonderzoek. Ik kom te zijner tijd graag naar jullie verdediging kijken.

Arts-assistenten. Beste collega's, het is fijn om weer fulltime in de kliniek te werken. Bedankt voor jullie gezelligheid en collegialiteit. Bedankt voor het overnemen van de diensten in de periodes dat ik in Schotland was. Beste Lidwien, bedankt voor jouw hulp en praktische tips voor het succesvol afronden van een promotieonderzoek.

Fata Morgana. Lieve fata's, wat hebben wij ondertussen al veel meegemaakt. Ondanks dat iedereen zijn eigen weg gaat, blijft onze vriendschap. Bedankt voor jullie lieve en opbeurende woorden en dat jullie begrijpen dat het af en toe toch een beetje te druk is.

Familie en schoonfamilie. Lieve familie en schoonfamilie, het is eindelijk klaar! Bedankt voor jullie steun en warme belangstelling.

Paranimfen. Lieve Marielle, fijn dat jij mij wilt bijstaan tijdens deze speciale gebeurtenis. Jij laat mij zien wat echt belangrijk is in het leven. Vriendschap! Hopelijk blijft onze vriendschap voor eeuwig. Lieve Kiki, ja het is klaar! Alhoewel, longarts moet ik nog steeds worden. Dus er zullen zeker nog een aantal koffie-, thee- en wijnmomentjes op jullie bank volgen. Bedankt voor je steun en oprechte interesse in mijn onderzoek en klinische werk.

Last but not least. Lieve Marc, wat heb jij het zwaar gehad de afgelopen periode. Eerst de twijfel van wel of niet promoveren, daarna de periode in Schotland en dan nu de stress voor het goed afronden van het promotieonderzoek. Toch weet jij mij iedere keer weer te steunen. Bedankt voor jouw vertrouwen en liefde voor mij. 



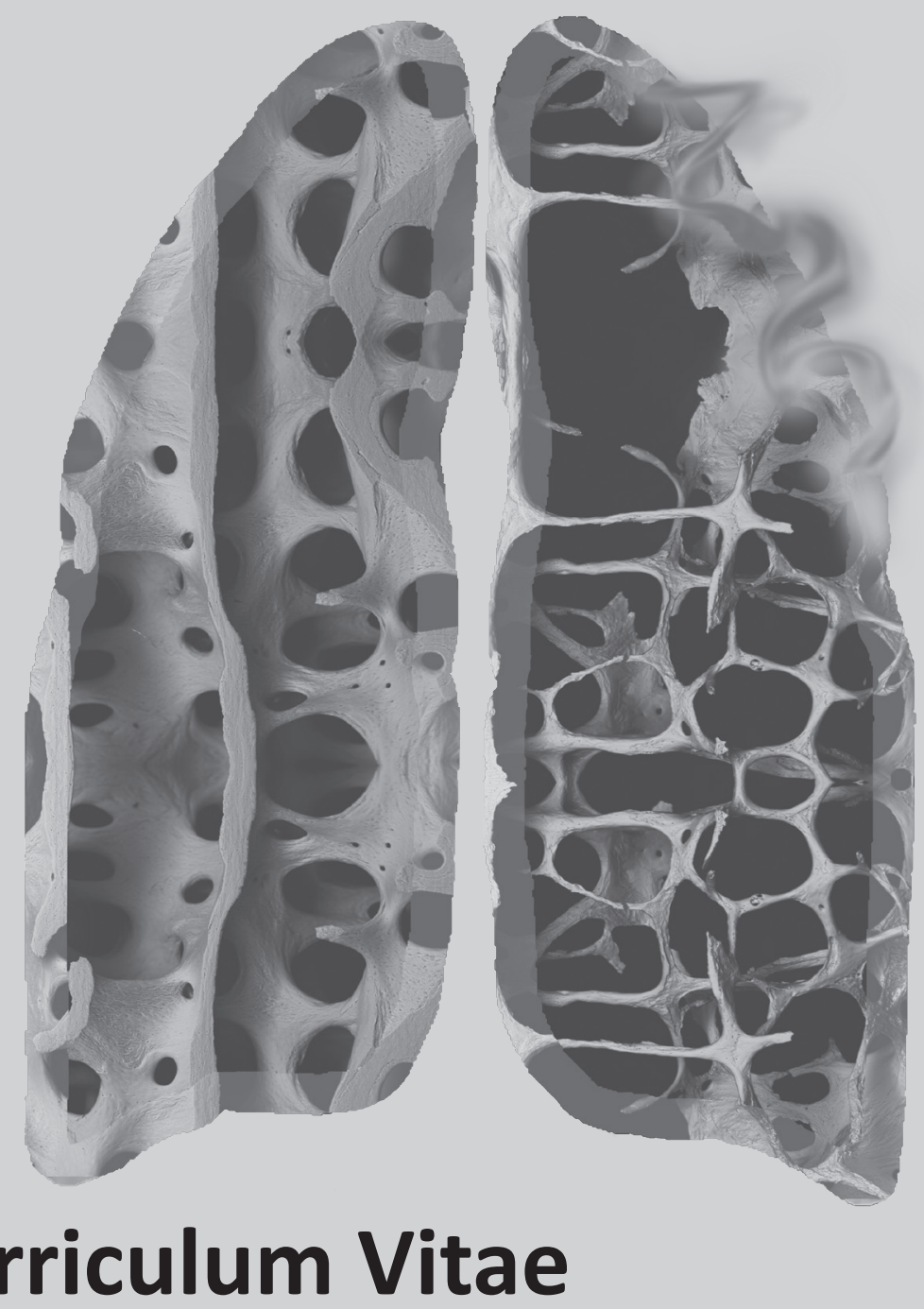


De auteur van dit proefschrift werd geboren op 27 januari 1983 in Hooge Zwaluwe. In 2001 behaalde zij haar eindexamen Atheneum aan het Newmancollege in Breda en ging zij geneeskunde studeren aan de Universiteit Maastricht.

Tijdens haar opleiding geneeskunde was zij actief lid van de Maastrichtse Studenten Roeivereniging Saurus en werkte zij als student-assistent bij de capaciteitsgroep onderwijsontwikkeling en -research van de Universiteit Maastricht onder leiding van prof. dr. Lambert Schuwirth. In het laatste jaar van haar opleiding deed zij een wetenschappelijke stage op de afdeling chirurgie van het Catharina ziekenhuis onder leiding van prof. dr. Harm J.T. Rutten en publiceerde zij haar eerste artikel. In oktober 2007 behaalde zij haar artsdiploma en werkte zij achtereenvolgens als arts-assistent niet in opleiding tot specialist op de afdelingen intensive care, inwendige geneeskunde en longgeneeskunde van het Catharina ziekenhuis.

In mei 2009 begon zij met haar promotieonderzoek op de afdeling longgeneeskunde van het Catharina ziekenhuis. Zij werd begeleid door prof. dr. Emiel F.M. Wouters (Maastricht University Medical Centre ${ }^{+}$), prof. dr. Frank W.J.M. Smeenk (Catharina ziekenhuis) en dr. Erica P.A. Rutten (CIRO+ Horn). Tijdens haar promotieonderzoek ontving zij een ERS ShortTerm Research Training Fellowship. Hiermee ging zij gedurende 3 maanden naar Edinburgh en werkte zij onder leiding van prof. dr. William MacNee (University of Edinburgh). De resultaten van haar promotie onderzoek werden gepresenteerd op verschillende nationale en internationale congressen en resulteerden in het winnen van verschillende prijzen (travel grant for best abstract on COPD tijdens ERS 2012, trainee research prize tijdens RSNA 2012 en de "Dr. Henk C. van Paassen prijs" tijdens de IWO bijeenkomst 2013) en dit proefschrift.

In december 2012 begon zij met haar opleiding tot longarts in het Catharina ziekenhuis onder leiding van prof. dr. Frank W.J.M. Smeenk. 